\title{
Effects of environmental factors on the paternal brood pouch and sound production in two sympatric pipefish species from the Chincoteague Bay, Virginia
}

Jennifer L. Ripley

West Virginia University

Follow this and additional works at: https://researchrepository.wvu.edu/etd

\section{Recommended Citation}

Ripley, Jennifer L., "Effects of environmental factors on the paternal brood pouch and sound production in two sympatric pipefish species from the Chincoteague Bay, Virginia" (2006). Graduate Theses,

Dissertations, and Problem Reports. 2403.

https://researchrepository.wvu.edu/etd/2403

This Dissertation is protected by copyright and/or related rights. It has been brought to you by the The Research Repository @ WVU with permission from the rights-holder(s). You are free to use this Dissertation in any way that is permitted by the copyright and related rights legislation that applies to your use. For other uses you must obtain permission from the rights-holder(s) directly, unless additional rights are indicated by a Creative Commons license in the record and/ or on the work itself. This Dissertation has been accepted for inclusion in WVU Graduate Theses, Dissertations, and Problem Reports collection by an authorized administrator of The Research Repository @ WVU.

For more information, please contact researchrepository@mail.wvu.edu. 
Effects of Environmental Factors on the Paternal Brood Pouch and Sound Production in Two Sympatric Pipefish Species from the Chincoteague Bay, Virginia

Jennifer L. Ripley, M.A.

\author{
Dissertation submitted to the \\ Eberly College of Arts and Sciences \\ at West Virginia University \\ in partial fulfillment of the requirements \\ for the degree of
}

Doctor of Philosophy in Biology

\author{
Christy M. Foran, Ph.D., Chair \\ Joseph A. Marshall, Ph.D. \\ Patricia M. Mazik, Ph.D. \\ David A. Ray, Ph.D. \\ Matthew E. Wilson, Ph.D. \\ Department of Biology \\ Morgantown, West Virginia \\ 2006
}

Keywords: Syngnathidae, polychlorinated biphenyls, hypoxia, development, paternal-fetal transfer, feeding behavior

Copyright 2006 Jennifer L. Ripley 


\begin{abstract}
Effects of environmental factors on the paternal brood pouch and sound production in two sympatric pipefish species from the Chincoteague Bay, Virginia
\end{abstract}

Jennifer L. Ripley

Pipefishes and seahorses of the family Syngnathidae are important inhabitants of diminishing grass beds threatened by excessive nutrient loads, sedimentation, and chemical contaminants. This research examined the influence of these environmental factors on two sympatric pipefishes from the Chincoteague Bay, Virginia. Syngnathids are characterized by a unique mode of reproduction in which the male carries developing embryos in a placenta-like ventral brood pouch until the fry are free-swimming. Interspecific comparisons revealed differences in parental nutrient allocation to embryos. In Syngnathus fuscus, females produce nutritionally poor eggs and males implant developing embryos adjacent to blood vessels. The loose connection between eggs and brood pouch tissues and the appearance of lipid droplets in the pouch of Syngnathus floridae suggest this species utilizes nutrient-rich eggs as nurse eggs to supplement embryonic development. A balanced sex ratio and similar size distributions between the sexes support the physiological evidence of equal parental contribution in S. floridae. In contrast, female-biased breeding populations indicate higher costs of $S$. fuscus paternity. Because of the potential for lipophilic contaminants to be transferred to developing pipefish through the paternal brood pouch, pipefish are likely to be exposed to contaminants during critical stages of development analogous to in utero human exposure. Following exposure to the PCB mixture Aroclor 1254 over the brood period, we found increased plasma protein and lipid levels in gravid females of both species and S. fuscus males, suggesting altered metabolic demands. Pouch fluid protein and lipid concentrations declined with Aroclor 1254 treatment in $S$. fuscus but not $S$. floridae. The first samples from $S$. fuscus indicate this species is more sensitive to PCB exposure during embryonic development and egg production. Seasonal declines in the concentration of dissolved oxygen, hypoxia, in estuarine waters present a problem of rapidly increasing severity. We investigated pipefish tolerance to hypoxic conditions by monitoring acoustic behavior during feeding. Both species produced high frequency, short duration clicks that positively correlated with food intake. Under hypoxia, reduced feeding activity corresponded with decreased sound production. Overall, these projects compare species responses to environmental stressors to determine how reproductive and feeding behavior relates to species sensitivity. 


\section{Table of Contents}

Abstract

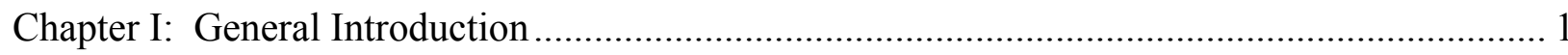

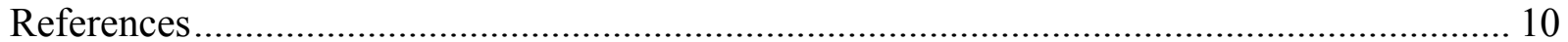

Chapter II: Population Structure, Growth Rates, and Seasonal Abundance of the Northern, Syngnathus fuscus, and Dusky Pipefishes, Syngnathus floridae, in the Chincoteague Bay,

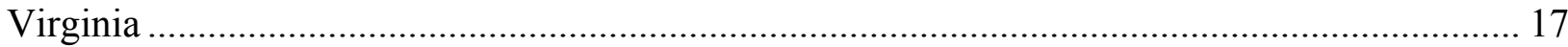

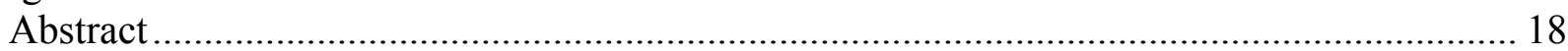

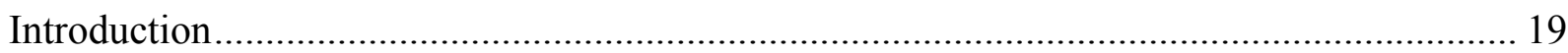

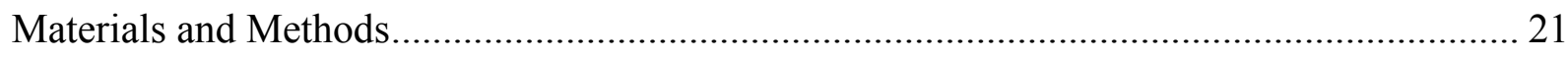

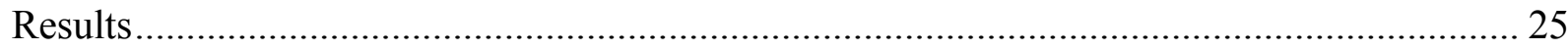

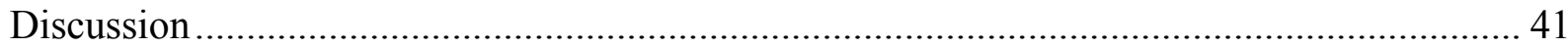

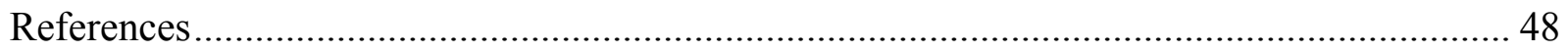

Chapter III: Differential Parental Nutrient Allocation in Two Congeneric Pipefish Species

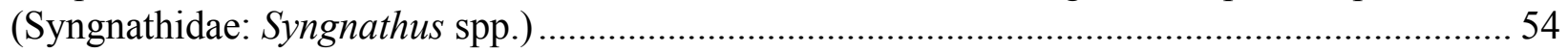

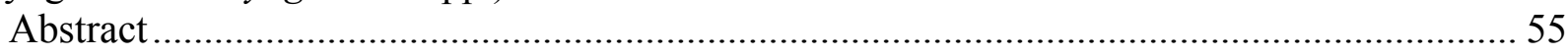

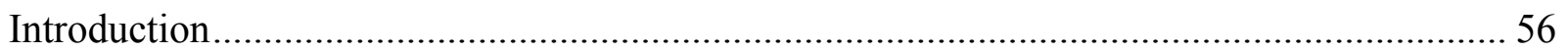

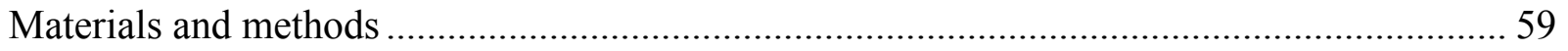

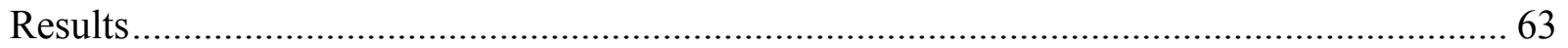

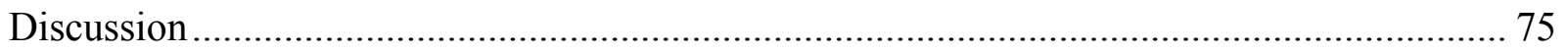

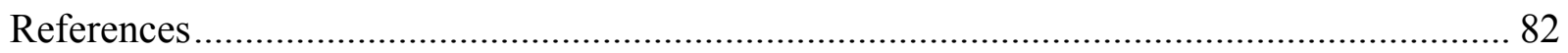

Chapter IV: Comparison of Parental PCB Exposure on Nutrient Allocation to Egg Production and Developing Embryos in the Placenta-like Paternal Brood Pouch of Two Pipefishes............ 90

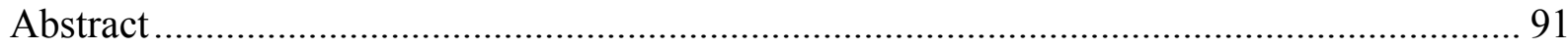

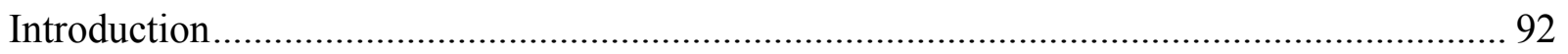

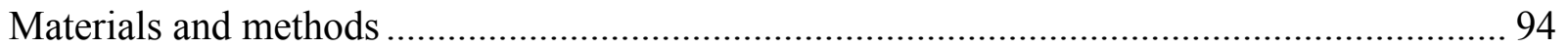

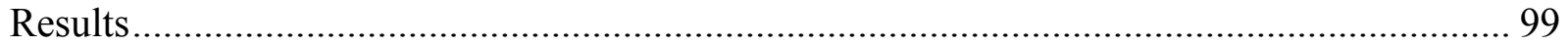

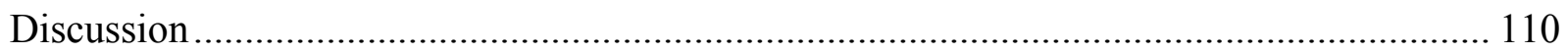

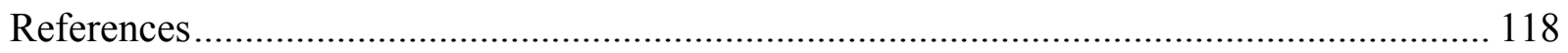


Chapter V: Influence of Estuarine Hypoxia on Feeding and Sound Production by Two

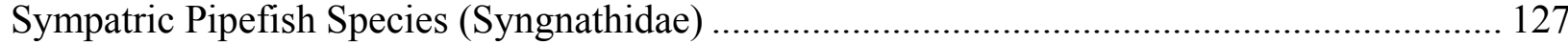

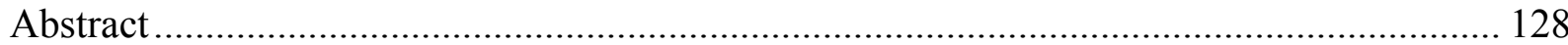

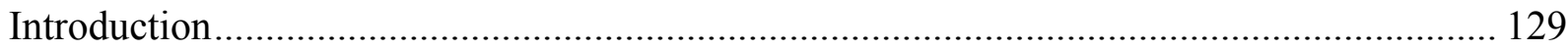

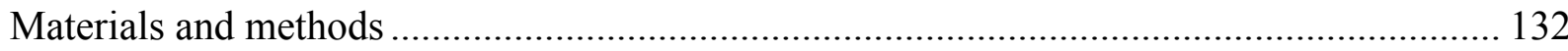

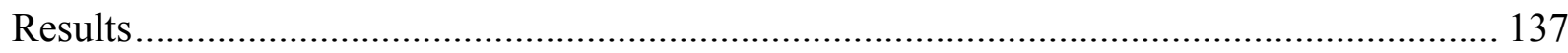

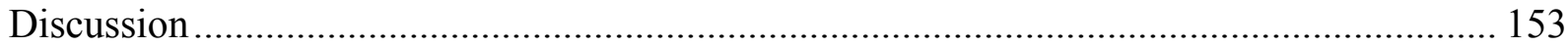

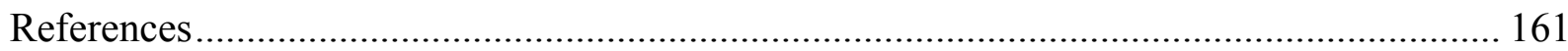

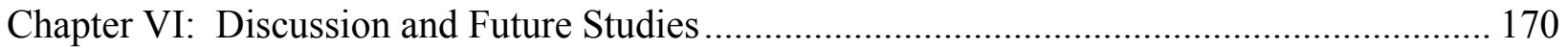

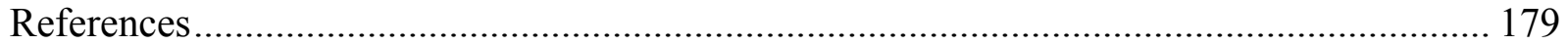

Appendix I: Paternal-Fetal Transfer of ${ }^{13} \mathrm{C}$-Palmitic Acid and ${ }^{15} \mathrm{~N}-\mathrm{L}$-Lysine in Two Congeneric

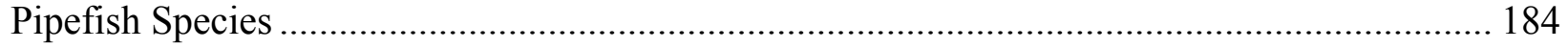

Appendix II: Capillary Electrophoresis Method for Characterization of Steroid Hormone Profiles

Appendix III: Histological Examination of the Paternal Brood Pouch and Central Nervous System of Aroclor 1254 Developmentally Exposed Pipefish Fry ....................................... 215

Appendix IV: Ethoxyresorufin- $O$-Deethylase (EROD) Activity in Pipefish Fry Developmentally

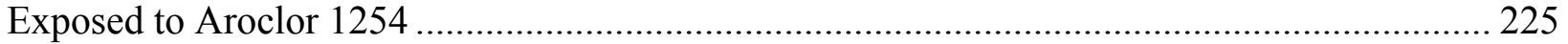

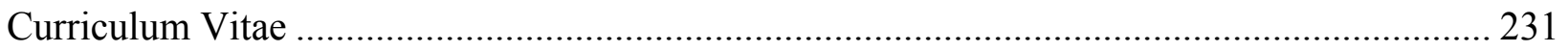




\section{List of Abbreviations}

ASR - Aquatic Surface Respiration

BSA - Bovine Serum Albumin

CE - Capillary Electrophoresis

CHES - 2-[N-Cyclohexylamino]Ethane-Sulfonic Acid

CPUE - Catch Per Unit Effort

CYP1A - Cytochrome P450 1A

DEC - n-Decanophenone

DI - Deionized Water

DO - Dissolved Oxygen

DMF - N,N-Dimethyl-Formamide

EDTA - (Ethylenedinitrilo)-Tetraacetic Acid

ER - Ethoxyresorufin

EROD - Ethosyresorufin- $O$-Deethylase

FIA - Flow Injection Analysis

HEPES - 4-(2-Hydroxyethyl)-1-Piperazineethane-Sulfonic Acid

NADH - Nicotinamide Adenine Dinucleotide

NADPH - Nicotinamide Adenine Dinucleotide Phosphate

$\mathrm{NaOH}$ - Sodium Hydroxide

ND - Not Determined

MEKC - Micellar Electrokinetic Chromatography

MS222 - 3-Aminobenzoic Acid Ethyl Ester

PCB - Polychlorinated Biphenyl

PMSF - Phenylmethylsulfonyl Fluoride

ppb - Parts Per Billion

ppm - Parts Per Million

ppt - Parts Per Thousand

psi - Pounds Per Square Inch

PTFE - Polytetrafluoroethylene

SAV - Submerged Aquatic Vegetation

SDS - Sodium Dodecyl Sulfate

SE - Standard Error

SL - Standard Length

TL - Total Length

UV - Ultra Violet

VEGF - Vascular Endothelial Growth Factor

WVU NRCCE - West Virginia University National Research Center for Coal and Energy YOY - Young of the Year 


\section{List of Figures}

\section{Chapter II: Population Structure, Growth Rates, and Seasonal Abundance of the Northern, Syngnathus fuscus, and Dusky Pipefishes, Syngnathus floridae, in the Chincoteague Bay, Virginia}

Fig. 1. Study area in the Chincoteague Bay, Virginia across the Delmarva Peninsula from the Chesapeake Bay. The star marks the sampling area which is detailed in Figures 2 and 3. . 33

Fig. 2. Collections of Syngnathus fuscus in the Chincoteague Bay, Virginia from May to September 2003-2005. The color of the circles indicates the sampling date with lighter shades denoting later dates. The size of the circles specify catch per unit effort (CPUE; fish seine $^{-1}$ ). Isocline shows $1 \mathrm{~m}$ depth line in each map......

Fig. 3. Collections of Syngnathus floridae in the Chincoteague Bay, Virginia from May to September 2003-2005. The color of the circles indicates the sampling date with lighter shades denoting later dates. The size of the circles specify catch per unit effort (CPUE; fish seine $^{-1}$ ). Isocline shows $1 \mathrm{~m}$ depth line in each map. 35

Fig. 4. Relationships between temperature (A) and collection date (B) with catch per unit effort (CPUE; fish seine $^{-1}$ ) of Syngnathus fuscus and Syngnathus floridae. (A) Catches of $S$. fuscus $(\mathrm{r}=0.8294, \mathrm{p}=0.0017)$ and $S$. floridae $(\mathrm{r}=0.6328, \mathrm{p}=0.0014)$ increased with higher water temperatures. (B) CPUE increased linearly with the passing of each month over the reproductive season for $S$. floridae $\left(\mathrm{r}^{2}=0.4766, \mathrm{p}=0.0031\right)$. Syngnathus fuscus abundance increased to a peak catch in August and then dropped in September $\left(\mathrm{r}^{2}=0.5831\right.$, $\mathrm{p}=0.0034)$

Fig. 5. Population sex ratios (number of males/number of females) for Syngnathus fuscus and Syngnathus floridae collected in the Chincoteague, Virginia during the 2005 reproductive season. Sex ratio data indicate a heavily female-biased population for $S$. fuscus with ratios significantly different from 1:1 male:female $\left(\chi^{2}=221.97, \mathrm{p}<0.001\right)$. Syngnathus floridae displayed a sex ratio following that of $1: 1$ male:female $\left(\chi^{2}=2.84, p=0.242\right) \ldots \ldots \ldots \ldots \ldots . . . .37$

Fig. 6. Abundance of Syngnathus fuscus (A) and Syngnathus floridae (B) brooding males and juveniles over the summer spawning seasons of 2003-05.

Fig. 7. Monthly length-frequency distributions of field-collected Syngnathus fuscus and Syngnathus floridae from the Chincoteague Bay from May to September 2004. Note changes in y-axis for some months.

Fig. 8. Drops in growth rate with progression of the spawning season for Syngnathus fuscus and Syngnathus floridae. Syngnathus fuscus growth rates declined linearly $\left(\mathrm{r}^{2}=0.5259\right.$, $\mathrm{p}=0.0076$ ). This relationship was not detected for $S$. floridae (Linear regression, $r^{2}=0.4001, p=0.0497 ; 2$-Degree polynomial, $\left.r^{2}=0.4619, p=0.1143\right)$ 


\section{Chapter III: Differential Parental Nutrient Allocation in Two Congeneric Pipefish Species (Syngnathidae: Syngnathus spp.)}

Fig. 1. Population sex ratios (number of males/number of females) for Syngnathus fuscus (black) and Syngnathus floridae (white) collected in the Chincoteague Bay, VA, USA during the 2003 (broken line) and 2004 (solid line) reproductive seasons. Sample sizes ranged from a minimum of 88 Syngnathus fuscus collected in September 2004 to 859 individuals of the same species counted in June 2004.

Fig. 2. (A) Protein, (B) lipid and (C) carbohydrate content of mature eggs (white) and released fry (black) from Syngnathus floridae (eggs, N=26; fry, N=6) and Syngnathus fuscus (eggs, $\mathrm{N}=16$, fry, $\mathrm{N}=7$ ). Values are mean $\pm \mathrm{SE}$. For all comparisons, interspecific differences (asterisks) exist between eggs but not fry $(\mathrm{P}<0.0001)$.......

Fig. 3. Illustrations and photomicrographs depict morphological differences in the Syngnathus fuscus (A and B) and Syngnathus floridae (C and D) male brood pouch. (A) Syngnathus fuscus are distinguished by their shorter snout length (I) and enclosure of developing embryos underneath a pouch-derived epithelium (II). Males form an enclosed brood pouch by the attachment of each flap to the ventral surface of the animal (III). (B) Blood vessels (asterisk) transverse the pouch flaps in close proximity to embedded developing embryos (arrow). (C) Syngnathus floridae, with the longer snout (I), attach embryos on only one face (II) to the pouch flap. The two flaps that form the pouch seal at the midline (III). (D) Lipid droplets (double-sided arrow) are distinguishable in the pouch secretions, while blood vessels (asterisk) pass below the embryo connection to the pouch flap (arrow).................. 72

Fig. 4. Changes in (A) protein, (B) lipid, and (C) carbohydrate concentrations in the pouch fluid of Syngnathus fuscus (gray squares; solid line) and Syngnathus floridae (white diamonds; broken line) across the progression of embryonic development. For both species, nutrient levels significantly decline in pouch fluid over the seven stages of development $(\mathrm{P}<0.05)$. The decrease in protein occurs at a steeper rate for Syngnathus floridae, while lipid concentrations drop more quickly in Syngnathus fuscus (both $\mathrm{P}<0.05$ ).

Fig. 5. Circulating carbohydrate levels in blood plasma of gravid females (black bars), brooding males (white bars) and non-brooding males (grey bars). Values are means $\pm \mathrm{SE}$. An asterisk indicates a significant difference between groups $(\mathrm{P}<0.05)$.

\section{Chpater IV: Comparison of Parental PCB Exposure on Nutrient Allocation to Egg Production and Developing Embryos in the Placenta-Like Paternal Brood Pouch of Two Pipefishes}

Fig. 1. Circulating protein, lipid, and carbohydrate concentrations in the blood plasma of Syngnathus fuscus and Syngnathus floridae gravid females and males which released fry from true control (white bars), acetone control (gray bars), and Aroclor 1254 treatments (53 $\mathrm{ppb}$; black bars). Bars are mean $\pm \mathrm{SE}$. Bars not connected by the same letter are significantly different (two-way ANOVA, $\mathrm{p}<0.05$ ). 
Fig. 2. Pouch fluid protein, lipid, and carbohydrate concentrations in true control (white bars), acetone control (gray bars), and Aroclor 1254 exposed (53 ppb; black bars) Syngnathus fuscus and Syngnathus floridae released fry males. Bars are mean $\pm \mathrm{SE}$.

Fig. 3. Protein, lipid, and carbohydrate content of Syngnathus fuscus and Syngnathus floridae mature, unfertilized eggs and released fry from true control (white bars), acetone control (gray bars), and Aroclor 1254 (53 ppb; black bars) treated adults. Bars are mean \pm SE. Bars not connected by the same letter are significantly different (two-way ANOVA, $\mathrm{p}<$ $0.05)$. True control fry were not considered in the statistical analyses due to the absence of data for $S$. fuscus.

\section{Chapter V: Influence of Estuarine Hypoxia on Feeding and Sound Production by Two Sympatric Pipefish Species (Syngnathidae)}

Fig. 1. Correlation of sound production with (a) feeding strikes and (b) wet weight (mg) of food in the gut of Syngnathus fuscus (black diamonds) and Syngnathus floridae (white squares).

Fig. 2. Spectrograms (top) and waveforms (bottom) of clicks produced during food intake by (a) Syngnathus fuscus and (b) Syngnathus floridae. Peak frequency is denoted by the darker shading in the spectrogram ....

Fig. 3. Effects of five days of $2 \mathrm{mg} / \mathrm{L}$ hypoxia on (a) food intake and (b) sound production by Syngnathus fuscus (black diamonds) and Syngnathus floridae (white squares). Means $\pm \mathrm{SE}$ are plotted....

Fig. 4. Behaviors associated with click production when food is not ingested by (a, c) Syngnathus fuscus and (b, d) Syngnathus floridae at (a, b) $2 \mathrm{mg} / \mathrm{L}$ and (c, d) $1 \mathrm{mg} / \mathrm{L}$ hypoxia. The accompaniment of sound production by food intake comprises the remaining behavioral coupling. Note the differences in the ranges of the behavior frequencies (y-axis).

Fig. 5. Effects of five days of $1 \mathrm{mg} / \mathrm{L}$ hypoxia on (a) food intake and (b) sound production by Syngnathus fuscus (black diamonds) and Syngnathus floridae (white squares). Means $\pm \mathrm{SE}$

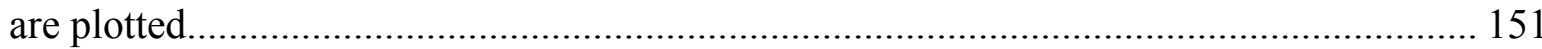

Fig. 6. Effects of $2 \mathrm{mg} / \mathrm{L}$ (black) and $1 \mathrm{mg} / \mathrm{L}$ (white) hypoxia exposure on sound production by Syngnathus fuscus (diamonds) and Syngnathus floridae (squares). Means $\pm \mathrm{SE}$ are plotted. 


\section{Appendix II: Capillary Electrophoresis Method for Characterization of Steroid Hormone Profiles}

Fig. 1. Schematic of custom built capillary electrophoresis instrument. Directions for fabrication can be found at http://www.as.wvu.edu/ /holland/. The colored lines represent plastic pressure tubing (blue), copper pressure tubing (green), positive and negative wires (red and black), and the capillary (orange) 208

Fig. 2. Capillary electrophoresis separation of seven steroids on the lab built instrument: (1) DMF (i.e. neutral marker), (2) estriol, (3) 17ß-estradiol, (4) estrone, (5) testosterone, (6) 11ketotestosterone, (7) 17 $2,20 \beta$-dihydroxyprogresterone, (8) progesterone, and (9) ndecanophenone (i.e. micelle marker).

Fig. 3. Linear response ranges of the micelle marker $n$-decanophenone. (A) Relative peak height is significantly correlated with concentration $\left(r^{2}=0.8047, p<0.0001\right)$. (B) Conversely, relative area does not show a correlation $\left(\mathrm{r}^{2}=0.2214, \mathrm{p}=0.0767\right)$. 210

\section{Appendix III: Histological Examination of the Paternal Brood Pouch and the Central Nervous System of Aroclor 1254 Developmental Exposed Pipefish Fry}

Fig. 1. Preliminary histological sections of the paternal brood pouch with developing embryos. Note the interspecific differences in the connection of the two pouch flaps. Syngnathus floridae pouch folds meet midline while those of Syngnathus fuscus join at the ventral body surface. Magnification 40x.

Fig. 2. Preliminary histological sections of the anterior portion of newly released fry. These fry were developmentally exposed to acetone over the brooding period as a control for the Aroclor 1254 exposure. Magnification 40x. 


\section{List of Tables}

Chapter II: Population Structure, Growth Rates, and Seasonal Abundance of the Northern, Syngnathus fuscus, and Dusky Pipefishes, Syngnathus floridae, in the Chincoteague Bay, Virginia

Table 1. Abiotic measurements and pipefish catches from the Chincoteague Bay, Virginia, USA from May to September 2003-05.

Table 2. Standard length (SL) measurements and size differences between male brooding states and sexes

Table 3. Growth rates $\left(\mathrm{mm} \mathrm{day}^{-1}\right)$ of field collected pipefish from the Chincoteague Bay, Virginia

Chapter III: Differential Parental Nutrient Allocation in Two Congeneric Pipefish Species (Syngnathidae: Syngnathus spp.)

Table 1. Species comparisons of nutrient content of unfertilized eggs and newly released fry ... 66

Table 2. Relative nutrient content of the pouch fluid of brooding and non-brooding males

Table 3. Regressions of nutrient concentrations in brood pouch fluid over the stages of embryonic development

Table 4. Blood plasma concentrations of nutrients from adults collected in the Chincoteague Bay, VA, USA

Chapter IV: Comparison of Parental PCB Exposure on Nutrient Allocation to Egg Production and Developing Embryos in the Placenta-Like Paternal Brood Pouch of Two Pipefishes

Table 1. Interspecific comparisons of blood plasma nutrient concentrations from controls and adult pipefish exposed to Aroclor 1254 over the brooding period

Table 2. Effect of Aroclor 1254 exposure on nutrient levels in paternal pouch fluid following fry release

Table 3. Species comparisons of nutrient content and length of mature, unfertilized eggs and newly released fry from control and Aroclor 1254 exposed parents 
Chapter V: Influences of Estuarine Hypoxia on Feeding and Sound Production by Two Sympatric Pipefish Species (Syngnathidae)

Table 1. Behavioral pairings for Syngnathus fuscus (bold text) and Syngnathus floridae 144

Table 2. Ranges of individual sizes and sound parameters of feeding clicks for the baseline and hypoxia studies 145

Table 3. Summary of p-values investigating individual differences in sound parameters over the course of hypoxia exposure and between clicks produced during food intake versus a series leading to food expulsion.....

\section{Appendix I: Paternal-Fetal Transfer of ${ }^{13} \mathrm{C}$-Palmitic Acid and ${ }^{15} \mathrm{~N}-\mathrm{L}-\mathrm{L}$ sine in Two Congeneric Pipefish Species}

Table 1. Transfer of L-lysine- ${ }^{15} \mathrm{~N}_{2}$ and ${ }^{13} \mathrm{C}$-palmitic acid across the Syngnathus fuscus paternal brood pouch to developing young.......................................................................... 189

Table 2. Transfer of L-lysine- ${ }^{15} \mathrm{~N}_{2}$ and ${ }^{13} \mathrm{C}$-palmitic acid across the Syngnathus floridae paternal brood pouch to developing young. 190

\section{Appendix II: Capillary Electrophoresis Method for Characterization of Steroid Hormone Profiles}

Table 1. Migration times for elution of seven steroids relative to the neutral marker DMF ...... 207 


\section{Acknowledgements}

"What a long, strange trip it's been." - The Grateful Dead

The past four years have been an amazing, delightful, unforgettable adventure. Foremost, I wish to extend my deepest appreciation to my advisor and friend, Christy M. Foran. Christy's relentless determination (i.e. the NSF CAREER grant) and enthusiasm for science (i.e. 101 studies designed annually during and after SETAC) are unparallel and were the driving force behind my research and success. I was blessed with a rare opportunity to study under a bright, young scientist who is going to make significant contributions to many fields (including surfing and quantum physics) in the immediate future. My favorite moments involved Christy's humor and passion which transformed laborious field collections and devastating experimental failures into memorable comedy routines. After my master's degree, I had "lost my love" for science and research, as well as my trust in advisors and graduate education. I can never thank Christy enough for her exceptional guidance, unyielding encouragement, and friendship.

I am most grateful to Dr. Joseph Marshall. Dr. J is the reason I am writing these acknowledgements to my doctoral dissertation. Dr. J "adopted" me as an undergraduate student and introduced me to the field of fish bioacoustics. At that time, I had no clue that eight years later I would still be immersed in the field. Again, after my master's degree, I had almost given up on fulfilling my dreams of becoming a marine biologist. Dr. J "hunted me down" by scheduling appointments for me with new faculty at WVU to finish my graduate studies. I acknowledge my studies and contributions to fish bioacoustics can never approach those of Dr. J, but I do believe he passed onto me his most important attributes -- his enduring passion and intrigue for the oceans and all life within them. I am truly honored to even been considered "little Dr. J." 
I sincerely thank Tim Judd, Pat Mazik, David Ray, and Matt Wilson for their guidance and critique throughout this process. I also acknowledge the Wallops Island Marine Science Consortium for their assistance in gaining access to boats and equipment for collections. This research could not have been completed without the aid of numerous field and laboratory assistants. Evelyn Anderson, Brad Blaine, Debbie Hardee, Adam Martin, Rebecca Merritt, Wendy Sites, Desirae Templeton, Rachel Torres, and Holly Wilson deserve an extra visit to the Island Creamery for their exceptional animal care skills and enduring persistence in seining in all types of weather.

I am most appreciative to the Ripley support network. Mom, Dad, Jocie, Jeck, Charlie, Nana, Gpa, Skippy, Gracie, Penny, Killer, K2, and Al have supported both me and Todd financially and emotionally for the last seven years. There is no doubt that I would have never accomplished this dream without their love and encouragement and of course, Ripley vacations always help in recharging my tired mind. Also, it was nice to be warm, well fed, and clothed while I was studying and I definitely have all of the Ripley's to thank for these necessities. My immediate family - Todd, Haley, and Rocky - were my saviors. Rocky always shared his foil ball on a bad day and Haley showed me that things could be worse - I could have utters. I am most fortunate to be married to my best friend and research partner. Our relationship is truly unique that we complement one another perfectly in research and life. Our graduate studies will always be a special time for the Ripstueckles.

"You can only enjoy it to a certain point, then it becomes a mission."

Stated in the backseat of the Pathfinder by Jennifer Ripley while eating a whafflecone sundae from the Island Creamery on August 22, 2002. 


\section{Forward}

Each of the following chapters and appendices adhere to different formatting guidelines representing various scientific journals. Chapter I, IV and VI and Appendices I through IV follow the formatting style of Aquatic Toxicology. Chapter II adheres to the guidelines of Estuaries. Chapter III had been formatted for The Journal of Experimental Biology. Chapter V follows the style of Marine Environmental Research. 
Chapter I: General Introduction 
The Chesapeake Bay is one of the largest and most productive estuaries in the world (Sellner, 1987; Tong, 2001). The Bay watershed occupies an area of 103,000 km², encompassing parts of Delaware, Maryland, New York, Pennsylvania, Virginia, West Virginia and Washington D.C. "Chesapeake" is derived from the Native American "Tschiswapeki" which loosely translates into "great shellfish bay" (Chesapeake Bay Foundation, 2003). Every year more than 225 million kilograms of seafood are harvested. Commercial fisheries data for 2000 reported this harvest totaled more than $\$ 172$ million (Wood et al., 2002). In terms of shellfish, the Chesapeake Bay provides 70\% of the Nation's total blue crab crop and in 1993 , the crab collection was worth $\$ 126.6$ million (USGS, 1997; Wang et al., 2001). Before the mid 1960's, the Bay produced over half of the soft-shelled clams and one quarter of the oysters in the country (Tong, 2001). Although these figures are significant, they understate the value of the Chesapeake Bay ecosystem because they do not account for the ecological services the Bay provides to coastal Atlantic fisheries. That is, the Chesapeake Bay serves as an important seasonal feeding ground and nursery area for ecologically and economically important coastal species that range from Florida to the Canadian Maritime Provinces including menhaden, striped bass, spot, American shad, and summer flounder (Sherman et al., 1996; Wood et al., 2002). Most of the Chesapeake Bay is extremely shallow, averaging 9 meters in depth (Prichard, 1952). In these shallow waters, submerged aquatic vegetation (SAV), or bay grass, is prevalent. Grass beds play numerous important ecological roles providing food and habitat to blue crabs, oysters, and other invertebrates, serving as nursery habitat and feeding grounds to many commercial fish species, producing oxygen in the water column, filtering and trapping sediment, protecting shorelines from erosion by slowing down wave action, and removing excess nutrients (Thayer et al., 1975; Orth and Moore, 1984). Eelgrass, Zostera marina, forms the most 
important seagrass system in the north temperate latitudes, including the Chesapeake Bay (Orth, 1973, 1976; Orth and Moore, 1988). Macrofaunal density is higher in Zostera communities than any other benthic habitat in the Chesapeake Bay. Collections have yielded more than 115 macroinvertebrate taxa inhabiting the York River estuary and Chincoteague Bay (Orth, 1973). The presence of eelgrass and its ability to increase the habitat complexity of an area is also associated with fish communities that are more abundant and diverse than those found on adjacent, unvegetated areas. Specifically, otter trawls of the lower Bay have yielded 48 species of fish (Orth and Heck, 1980).

Since the time of the Industrial Revolution, water quality in the Chesapeake Bay has been noticeably deteriorating. This decline has accelerated over the past four decades (Kemp et al., 1983; Tong, 2001; Wood et al., 2002). Degrading influences, related to increasing fossil fuel consumption and relentless population growth include (1) overharvesting of shellfish and fish species, (2) nitrogen emissions from sewage treatment plants, agriculture, power plants, and motor vehicles, (3) phosphorus emissions from sewage and agriculture, (4) debris, sewage, fuel spills, and exhaust from over 400,000 registered watercraft, (5) storm water runoff, (6) sedimentation from land use changes, (7) industrial discharges, (8) construction of dams and other barriers to anadromous fish migration, and (9) disposal of dredged material (Anderson, 1989; Ulanowicz and Tuttle, 1992; McConnell, 1995; Boesch, 2000; Hauxwell et al., 2001; Tong, 2001). Historically over 81,000 hectares of grass beds filled the Chesapeake Bay. By 1984 only 15,000 hectares of SAV remained (Orth and Moore, 1984; Blankenship, 2003). Today, SAV is estimated to cover only $10 \%$ of its pre-1950 distribution (McConnell, 1995; Harwell and Orth, 2002). Consequently, significant declines in blue crab populations have been documented (Anderson, 1989). Six fish species that used to be commonly found in the area are 
now listed as rare, threatened, or endangered. For instance, the present population of brook trout is at least one-tenth of what it was historically. The federally endangered Maryland darter, a bottom dwelling fish, has become extinct just in the last decade (Tong, 2001). In Virginia, oyster harvests have dropped 98\% since the 1950s (McConnell, 1995; Chesapeake Bay Foundation, 2003). Much attention recently has been directed toward improving water quality and transplanting grasses to ultimately reestablish this critical habitat (Orth, 1976; Moore et al., 1996, 1997; Blankenship, 2003). Regardless of remediation efforts, species diversity has reduced 5090\% (McConnell, 1995; Williams, 2001).

Seahorses, sea dragons, and pipefishes of the teleost family Syngnathidae (meaning "jawfused") have captivated researchers (Huot, 1902) and the public (Milius, 2000) for over 100 years. Some early natural history texts classified seahorses as insects or shellfish. Even Linnaeus, the father of modern taxonomy, listed them with amphibians (Lourie et al., 1999). With a head resembling a horse, a grasping tail like a monkey, a pouch for the young similar to a kangaroo (Azzarello, 1991), armadillo-like bony armor, and independently moving eyes akin to a chameleon (Fritshes and Marshall, 2002), the confusion of early natural historians is justified. Even after decades of study, scientists, as well as the general population, are continuously intrigued with details of this family's unique mode of reproduction. Most fishes exhibit simple external fertilization and all the required nutrients for development are supplied in the eggs. In this group, however, females produce mature, hydrated eggs in a specialized ovary and males fertilize and incubate the eggs in a vascularized placenta-like brood pouch until the fry are released as free-swimming young (Lockwood, 1867; Duncker, 1915; Herald, 1959). This distinctive form of parental care is practiced by more than 320 species in 55 genera within the family Syngnathidae (Kuiter, 2000; Murdy et al., 2002). Four subfamilies group Syngnathids 
based on this paternal brood pouch. Syngnathinae, the pipefishes, encompasses the largest group. Members are described as stick-like with their head in line with the body. Males incubate eggs in a pouch that is formed by simple or overlapping skin folds under the trunk or tail. The Hippocampinae comprises the seahorses which possess a fully enclosed pouch with a small opening. Solegnathinae includes the seadragons in which the brood is mostly exposed under the tail or trunk. The Doryrhamphinae are a group of pipefishes that have a mostly exposed brood (Lourie et al., 1999; Kuiter, 2000; Murdy et al., 2002).

Seahorses and pipefishes range in size from tiny pygmy species just a few centimeters long to the largest pipefish over $65 \mathrm{~cm}$ in total length (Kuiter, 2000). All species appear to be diurnal and carnivorous, preying primarily on small crustaceans that are sucked up whole (Bergert and Wainwright, 1997; Colson et al., 1998; Kuiter, 2000). The long tubular snout with a small mouth at the tip lacks teeth. Considering the absence of a stomach, prey pass rapidly through the digestive system (Ryer and Orth, 1987; Teixeira and Musick, 1995). Syngnathids are essentially benthic fishes. Many species are continuously in touch with the substrate by simply lying on the bottom or clinging on to things with their tail. Overall, fin placement and mechanical properties of the muscles make them better suited for maneuverability than speed (Blake, 1976, 1980; Ashley-Ross, 2002). Apart from a few conspicuous coral reef dwellers, Syngnathids are highly camouflaged, mimicking leaves, sticks, and blades of eelgrass.

Seahorses can grow extra skin filaments to imitate algal fronds attached to seagrass stems or the seaweed of their habitats (Ginsburg, 1937). Encrusting organisms such as bryozoans, algae, and hydroids may also settle on their bony armor, camouflaging them further (Lourie et al., 1999). Despite this extraordinary camouflage, Syngnathids are targeted prey for crabs and many fishes. The occurrence of seahorses and pipefishes with damaged tails suggests escape from a crab or 
similar predator (Lourie et al., 1999). Some Syngnathids have been retrieved from the stomachs of red snapper, dolphin fish, tuna, flatheads, and anglerfish (Jordan and Gilbert, 1882; Herald, 1949).

Syngnathids have been documented to produce sound. Sound production extends across many taxonomic groups of fishes, suggesting it is important as a means of communication in the aquatic medium. In marine and freshwater species, sound production has been recorded during courtship, spawning, aggression, defense, and feeding events. Due to the speed and distance of sound travel in water, sound production is an effective mechanism to attract mates, coordinate spawning activities, and warn off predators and/or competitors (Fish et al., 1952; Tavolga, 1964; Myrberg, 1981; Lobel, 1998). Seahorse sounds have been described as loud clicks resembling the snapping of a finger against the thumb (Gill, 1905; Fish, 1953, 1954; Fish and Mowbray, 1970). Seahorse recordings document sound production during the introduction to new surroundings, courtship and spawning, and feeding (Gill, 1905; Tarasov, 1963; Fish and Mowbray, 1970; Bergert and Wainwright, 1997; Colson et al., 1998). Among these contexts, feeding clicks are the most widely noted. Color change serves as another method of communication. Some seahorses brighten quickly when involved in social interactions, signaling interest, recognition, or fitness (Vincent and Sadler, 1995).

Many Syngnathids, particularly seahorses, are threatened by overexploitation for medicinal, aquarium, and souvenirs uses. Early references to the therapeutic properties of seahorses date to Greek and Roman herbalists. In Europe, medicinal use continued until at least the eighteenth century (Lourie et al., 1999). Seahorses serve no purpose in Western medicine today. However, Chinese practices have been using seahorses extensively for 600 years (Vincent, 1996; Hu and Li, 2002). At least 20 million dried seahorses were traded worldwide in 
1995 for use in traditional Chinese medicine (Vincent, 1996). Economic change in China has lead to a high percentage of seahorses being incorporated into pre-packaged treatments. If given a choice, consumers prefer larger, pale, smooth seahorses, but these pre-packaged medicines remove choice from the consumer. As such, these remedies can utilize smaller, darker seahorses without patients being aware of the change. The consequence is that juveniles and previously less desirable species are now increasingly subject to exploitation (Vincent, 1996; Lourie et al., 1999). Several hundred thousand more seahorses and pipefishes are exported live each year for display in home and public aquaria (Vincent, 1996). While establishing favorable mating conditions is not a problem, rearing young is extremely difficult in captivity. Accordingly, successful husbandry protocols have not been developed (Herald and Rakowicz, 1951; Holliman, 1963; Prein, 1995; Berzins and Greenwell, 2001; Partridge et al., 2004). Thus, most captive seahorses are wild caught. Finally, a large number of seahorses are sold dried as souvenirs and decorations (Lourie et al., 1999). Their extraordinary shape and the ease with which they dry favor their incorporation into beach souvenirs.

Pipefishes and seahorses are distributed worldwide mostly in shallow, coastal tropical and temperate waters. Members of the family Syngnathidae are among the most abundant and ubiquitous fish inhabiting grass beds. In the Chesapeake Bay, two sympatric species of pipefish reside in the seasonal eelgrass beds. The Northern pipefish, Syngnathus fuscus, is a common resident of Atlantic coastal grass beds from North Carolina to Halifax. The Dusky pipefish, Syngnathus floridae, occupies a more southerly distribution from the Chesapeake Bay to Panama (Dawson, 1982). Compared to other fish populations occupying the grass beds of the Chesapeake Bay, S. fuscus ranked second in abundance, while S. floridae, placed sixth (Orth and Heck, 1980). This research examines pipefish populations collected from the Chincoteague Bay, 
Virginia. The Chincoteague Bay is located across the Delmarva Peninsula from the Chesapeake Bay on the Atlantic side of the Eastern shore. We selected this site because it is considered a relatively pristine Bay which was essential to our baseline studies (Kiddon et al., 2003). Further, West Virginia University is affiliated with the Wallops Island Marine Science Consortium and this relationship provided access to equipment and field sites. Ultimately this location also affords opportunities for comparative studies as the Chesapeake Bay is a short drive across the peninsula.

This research proposes to examine the effects of environmental factors on two behaviors integral to pipefish population success. As is common across the family Syngnathidae, few baseline data exist against which to measure population declines or shifts in size distributions. For this reason, the first study documents population measures and life history aspects for both species. The subsequent two investigations explore how parental physiology and exposure to an environmental toxicant impact reproduction and development. Even though the significance of the brood pouch is highly debated in the literature, it was hypothesized that the male contributes nutrients through either pouch fluid or blood excretions. Differential parental nutrient allocation was expected between the two species given conflicting accounts of fry survival when removed from the paternal brood pouch of closely related species (Azzarello, 1991; Drozdov et al., 1997). Following the characterization of parental nutrient contribution to offspring, laboratory exposure to polychlorinated biphenyls (PCBs), one of the most abundant, persistent contaminants found in the Chesapeake Bay (Ashley and Baker, 1999; Damstra et al., 2002; Toschik et al., 2005; Smith, 2006), examined the potential for parental exposure of this developmental toxicant to impact pipefish eggs and fry. Differential dependence on parental contributions during development was expected to alter the susceptibility of these species to environmental insult. Overall, parental 
nutrient allocation should decrease following sublethal exposure. For species with substantial paternal contribution via the brood pouch, male exposure may result in grave impacts on pipefish offspring. Species with nutrient-rich eggs and hence restricted paternal contribution are expected to be more susceptible to events of female exposure. In either case, fry success and ultimately reproductive success are impacted as nutrient reserves at release are decreased. The last study investigates pipefish sustainability by monitoring acoustic behavior during feeding in hypoxic, or low dissolved oxygen, conditions. Clicks are hypothesized to be highly correlated with feeding strikes and thus when dissolved oxygen levels drop, feeding and sound production frequency are expected to decrease. A reduction in feeding would impact the health of the organism and eventually its reproductive output as resources would be devoted to survival instead of gamete production. Overall, these projects investigate changes in nutrient uptake following toxicant exposure either from a decrease in parental contribution during embryonic development or a decrease in the feeding activity of the individual itself. Individual health and ultimately population success are the endpoints impacted by exposure to these environmental factors. 


\section{References}

Anderson, E.E., 1989. Economic benefits of habitat restoration: seagrass and the Virginia hardshell blue crab fishery. N. Am. J. Fish. Manage. 9, 140-149.

Ashley, J.T.F., Baker, J.E., 1999. Hydrophobic organic contaminants in surficial sediments of Baltimore harbor: inventories and sources. Environ. Toxicol. Chem. 18, 838-849.

Ashley-Ross, M.A., 2002. Mechanical properties of the dorsal fin muscle of seahorse (Hippocampus) and pipefish (Syngnathus). J. Exper. Zool. 293, 561-577.

Azzarello, M.Y., 1991. Some questions concerning the Syngnathidae brood pouch. Bull. Mar. Sci. $49,741-747$.

Bergert, B.A., Wainwright, P.C., 1997. Morphology and kinematics of prey capture in the Syngnathid fishes Hippocampus erectus and Syngnathus floridae. Mar. Biol. 127, 563570.

Berzins, I.K., Greenwell, M., 2001. An overview of common Syngnathid health problems. In: Program and Abstracts of Marine Ornamentals: Collection, Culture and Conservation, Lake Buena Vista, Florida.

Blake, R.W., 1976. On seahorse locomotion. J. Mar. Biol. Assoc. UK 56, 939-949.

Blake, R.W., 1980. Undulatory median fin propulsion of two teleosts with different modes of life. Can. J. Zool. 58, 2116-2119.

Blankenship, K., 2003. Submerged aquatic vegetation: a sunnier future. Bay J. 12, 1 \& 14.

Boesch, D.F., 2000. Measuring the health of the Chesapeake Bay: toward integration and prediction. Environ. Res. 82, 134-142.

Chesapeake Bay Foundation, 2003. General bay facts. Chesapeake Bay Foundation, Annapolis, Maryland. 
Colson, D.J., Patek, S.N., Brainerd, E.L., Lewis, S.M., 1998. Sound production during feeding in Hippocampus seahorses (Syngnathidae). Environ. Biol. Fishes 51, 221-229.

Damstra, T., Barlow, S., Bergman, A., Kavlock, R., Van der Kraak, G., 2002. Global assessment of the state-of-the-science of endocrine disruptors. World Health Organization, Geneva, Switzerland (WHO/PCS/EDC/02.2).

Dawson, C.E., 1982. Family Syngnathide. In: Bölke, J.E. (Ed.), Fishes of the Western North Atlantic, Part Eight, Order Gasterosteiformes, Suborder Syngnathoidei. Yale University, New Haven, Connecticut, USA, pp. 1-172.

Drozdov, A.L., Kornienko, E.S., Krasnolutsky, A.V., 1997. Reproduction and development of Syngnathus ascusimils. Russ. J. Mar. Biol. 23, 265-268.

Duncker, G., 1915. Revision der Syngnathidae. Jahrbuch der Hamburgischen Wissenschaftlichen Antalten 32, 9-120.

Fish, M.P., 1953. The production of underwater sound by the Northern seahorse, Hippocampus hudsonius. Copeia 2, 93-94.

Fish, M.P., 1954. The character and significance of sound production among fishes of the Western North Atlantic. Bull. Bingham Ocean. Coll. 14, 1-109.

Fish, M.P., Mowbray, W.H., 1970. Sounds of Western North Atlantic Fishes. Johns Hopkins Press, Baltimore, Maryland, USA.

Fish, M.P., Kelsey, A.S., Mowbray, W.H., 1952. Studies on the production of underwater sound by North Atlantic coastal fishes. J. Mar. Res. 11, 180-193.

Fritsches, K.A., Marshall, N.J., 2002. Independent and conjugate eye movements during optokinesis in teleost fish. J. Exper. Biol. 205, 1241-1252. 
Gill, T., 1905. The life history of the sea horses (Hippocampids). Proc. U.S. Nat. Mus. 1408, 805-814.

Ginsburg, I., 1937. Review of the seahorses (Hippocampus) found on the coasts of the American continents and of Europe. Proc. U.S. Nat. Mus. 83, 497-594.

Harwell, M.C., Orth, R.J., 2002. Seed bank patterns in Chesapeake Bay eelgrass (Zostera marina L.): a Bay-wide perspective. Estuaries 25, 1196-1204.

Hauxwell, J., Cebrian, J., Furlong, C., Valiela, I., 2001. Macroalgal canopies contribute to eelgrass (Zostera marina) decline in temperate estuarine ecosystems. Ecology 82, 10071022.

Herald, E.S., 1949. Piepfishes and seahorses as food for tuna. Calif. Fish Game 35, 329.

Herald, E.S., 1959. From pipefish to seahorse - a study of phylogenetic relationships. Proc. Calif. Acad. Sci. 29, 465-473.

Herald, E.S., Rakowicz, M., 1951. Stable requirements for raising sea horses. Aquar. J. 22, 234242.

Holliman, R.B., 1963. Gyrodactylus shorti, a new species of monogenetic trematode from the brood pouch of the Southern pipefish, Syngnathus scovelli (Evermann and Kendall). Tulane Studies Zool. 10, 83-86.

Hu, J.-Y., Li, B.-F., 2002. Research on the anti-fatigue effect of Syngnathus acus L. Chin. J. Mar. Drugs 21, 48-53.

Huot, A., 1902. Recherches sue les poisons lophobranches. Annals des Sciences Natural (Zool) $14,197-288$.

Jordan, D.S., Gilbert, C.H., 1882. Notes on fishes observed about Pensacola, Florida and Galveston, Texas with description of new species. Proc. U.S. Nat. Mus. 56, 265-266. 
Kemp, W.M., Twilley, R.R., Stevenson, J.C., Boynton, W.R., Means, J.C., 1983. The decline of submerged vascular plants in upper Chesapeake Bay: summary of results concerning possible causes. Mar. Tech. Soc. J. 17, 78-89.

Kiddon, J.A., Paul, J.F., Buffum, H.W., Strobel, C.S., Hale, S.S., Cobb, D., Brown, B.S., 2003. Ecological condition of US Mid-Atlantic estuaries, 1997-1998. Mar. Poll. Bull. 46, 12241244.

Kuiter, R.H., 2000. Seahorses, Pipefishes and Their Relatives. TMC Publishing, Chorleywood, UK.

Lobel, P.S., 1998. Possible species specific courtship sounds by two sympatric cichlid fishes in Lake Malawi, Africa. Environ. Biol. Fishes 52, 443-452.

Lockwood, S., 1867. The seahorse (Hippocampous hudsonius) and its young. Amer. Nat. 1, 225-234.

Lourie, S.A., Vincent, A.J.C., Hall, H.J., 1999. Seahorses: An Identification Guide to the World's Species. Project Seahorse, London.

McConnell, R.L., 1995. The human population carrying capacity of the Chesapeake Bay watershed: a preliminary analysis. Popul. Environ. 16, 335-351.

Milius, S., 2000. Pregnant—and still macho. Science News 157, 168.

Moore, K.A., Neckles, H.A., Orth, R.J., 1996. Zostera marina (eelgrass) growth and survival along a gradient of nutrients and turbidity in the lower Chesapeake Bay. Mar. Ecol. Prog. Ser. 142, 247-259.

Moore, K.A., Wetzel, R.L., Orth, R.J., 1997. Seasonal pulses of turbidity and their relations to eelgrass (Zostera marina L.) survival in an estuary. J. Exp. Mar. Biol. Ecol. 215, 115134. 
Murdy, E.O., Birdsong, R.S., Musick, J.A., 2002. Fishes of the Chesapeake Bay. Smithsonian Institution Press, Washington, D.C., USA.

Myrberg, A.A., 1981. Sound communication and interception in fishes. In: Tavolga, W.N., Popper, A.N., Fay, R.R. (Eds.), Hearing and Sound Communication in Fishes. SpringerVerlag, New York, USA, pp. 395-426.

Orth, R.J., 1973. Benthic infauna of eelgrass, Zostera marina, beds. Chesapeake Sci. 14, 258269.

Orth, R.J., 1976. The demise and recovery of eelgrass, Zostera marina, in the Chesapeake Bay, Virginia. Aquat. Bot. 2, 141-159.

Orth, R.J., Heck, K.L., 1980. Structural components of eelgrass (Zostera marina) meadows in the lower Chesapeake Bay - fishes. Estuaries 3, 278-288.

Orth, R.J., Moore, K.A., 1984. Distribution and abundance of submerged aquatic vegetation in the Chesapeake Bay: an historical perspective. Estuaries 7, 531-540.

Orth, R.J., Moore, K.A., 1988. Distribution of Zostera marina L. and Ruppia maritime L. sensu lato along depth gradients in the lower Chesapeake Bay. Aquat. Bot. 32, 291-305.

Partridge, C., Cazalas, C., Rozelle, J., Hemming, J., Boettcher, A., 2004. Small-scale captive breeding of a euryhaline pipefish. World Aqua., 51-54.

Prein, M., 1995. Aquaculture potential of seahorses and pipefishes. Naga, 20-21.

Prichard, D.W., 1952. Salinity distribution and circulation in the Chesapeake Bay. J. Mar. Res. $11,106-123$.

Ryer, C.H., Orth, R.J., 1987. Feeding ecology of the Northern pipefish, Syngnathus fuscus, in a seagrass community of the lower Chesapeake Bay. Estuaries 10, 330-336. 
Sellner, K.G., 1987. Phytoplankton in Chesapeake Bay: role in carbon, oxygen and nutrient dynamics. In: Majumdar, S.K., Hall, L.W., Austin, H.M. (Eds.), Contaminant Problems and Management of Living Chesapeake Bay Resources. The Pennsylvania Academy of Science, pp. 134-157.

Sherman, K., Jaworski, N.A., Smayda, T.J., 1996. The Northeast Shelf Ecosystem: Assessment, Sustainability, and Management. Blackwell Scientific Publicatins, Cambridge, Massachusetts, USA.

Smith, D.H, 2006. The Reduction of Toxics in State Waters: Monitoring Year 2005. Department of Environmental Quality, Commonwealth of Virginia, Richmond, Virginia, USA.

Tarasov, N.I., 1963. Zhivyye Zvuki Morya (The Live Sounds of the Sea). U.S. Naval Oceanographic Office, Washington, D.C., USA.

Tavolga, W.N., 1964. Sonic characteristics and mechanisms in marine fishes. In: Tavolga, W.N. (Ed.), Marine Bio-Acoustics, Pergamon Press, Oxford, UK, pp. 195-211.

Teixeira, R.L., Musick, J.A., 1995. Trophic ecology of two congeneric pipefishes (Syngnathidae) of the lower York River, Virginia. Environ. Biol. Fishes 43, 295-309.

Thayer, G.W., Wolfe, D.A., Williams, R.B., 1975. The impact of man on seagrass systems. Am. Sci. 63, 288-296.

Tong, S.T.Y., 2001. An integrated exploratory approach to examining the relationships of environmental stressors and fish responses. J. Aquat. Ecosyst. Stress Recovery 9, 1-19.

Toschik, P.C., Rattner, B.A., McGowan, P.C., Christman, M.C., Carter, D.B., Hale, R.C., Matson, C.W., Ottinger, M.A., 2005. Effects of contaminant exposure on reproductive success of ospreys (Pandion haliaetus) nesting in Delaware River and Bay, USA. Environ. Toxicol. Chem. 24, 617-628. 
Ulanowicz, R.E., Tuttle, J.H., 1992. The trophic consequences of oyster stock rehabilitation in Chesapeake Bay. Estuaries 15, 298-306.

United States Geological Survey (USGS), 1997. Ecosystem Trends and Response: Chesapeake Bay. U.S. Department of the Interior, U.S. Geological Survey, Washington, D.C., USA (Fact Sheet FS-213-96).

Vincent, A.C.J., 1996. The International Trade in Seahorses. TRAFFIC Internation, Cambridge, UK.

Vincent, A.C.J., Sadler, L.M., 1995. Faithful pair bonds in wild seahorses, Hippocampus whitei. Anim. Behav. 50, 1557-1569.

Wang, P., Batiuk, R., Linker, L., Shenk, G., 2001. Assessment of best management practices for improvement of dissolved oxygen in Chesapeake Bay estuary. Water Sci. Tech. 7, $173-180$.

Williams, S.L., 2001. Reduced genetic diversity in eelgrass transplantations affects both population growth and individual fitness. Ecol. Appl. 11, 1472-1488.

Wood, R.J., Boesch, D.F., Kennedy, V.S., 2002. Future consequences of climate change for the Chesapeake Bay ecosystem and its fisheries. Amer. Fish. Soc. Symp. 32, 171-184. 
Chapter II: Population Structure, Growth Rates, and Seasonal Abundance of the Northern, Syngnathus fuscus, and Dusky Pipefishes, Syngnathus floridae, in the Chincoteague Bay, Virginia 


\begin{abstract}
The northern pipefish, Syngnathus fuscus, and dusky pipefish, Syngnathus floridae, are among the most abundant ichthyofauna components of the Chesapeake Bay grass beds, but population structure and many life history traits remain uncharacterized. We conducted monthly collections from May through September 2003-2005 in a relatively pristine bay neighboring the Chesapeake to investigate seasonal migration and spawning, sex ratios, size at maturity, sexual dimorphism in length, and growth rate. Both S. fuscus and the less abundant S. floridae reproduced in the Chincoteague Bay, Virginia from May through September. Water temperature was significantly correlated with $S$. fuscus catches, while the presence of $S$. floridae spanned a longer period with a peak in abundance after maximum temperatures. Sex ratio data indicated $S$. floridae populations are balanced, while $S$. fuscus populations are strongly female-biased. Both species can quickly reach reproductive maturity, potentially within one season, because $S$. fuscus and $S$. floridae growth rates average $1.0 \mathrm{~mm}$ day $^{-1}$ and $0.97 \mathrm{~mm} \mathrm{day}^{-1}$ respectively. For $S$. fuscus, females were significantly longer than conspecific males for those samples measured when juveniles were not rapidly maturing. Size sexual dimorphism in this species coincides with reports of extensive paternal care, and supports the hypothesis that the strength of sexual selection differs in these species. Description of these life history traits provides a valuable database for Syngnathid conservation and a monitoring tool to assess degradation of this important habitat also essential to the growth and spawning of many commercial species.
\end{abstract}




\section{Introduction}

The Eastern Shore boarders the nation's largest estuary and one of the most productive systems in the world (Sellner 1987; Tong 2001). Many of the shallow coastal areas of the Chesapeake and Chincoteague Bays are covered by dense beds of submerged aquatic vegetation (SAV). These beds provide significant natural resources as they serve as a food source for waterfowl, a habitat and nursery area for many commercial fish and shellfish species, a shoreline erosion control mechanism, and a nutrient buffer (Orth 1973; Thayer et al. 1975; Orth and Heck 1980). Pipefishes and seahorses of the family Syngnathidae are among the most abundant and ubiquitous fish inhabiting seagrass beds. Compared to other fish populations occupying the grass beds of the Chesapeake Bay, the Northern pipefish, Syngnathus fuscus, ranked second in abundance behind spot, Leiostomus xanthurus, while the Dusky pipefish, Syngnathus floridae, placed sixth (Orth and Heck 1980). The neighboring Chincoteague Bay presents an appropriate study location for investigations of these pipefishes as it mirrors the habitat, and thus fauna, of the Chesapeake without the extensive water quality problems (Kiddon et al. 2003).

Members of the family Syngnathidae are characterized by a unique mode of ovoviviparous reproduction in which the male carries the developing embryos in a special organ referred to as the brood pouch (Lockwood 1867). A female oviposits her eggs directly onto the brooding skin where they are fertilized. The male then broods the developing embryos for a lengthy incubation period before releasing free-swimming fry. Despite the hypothesized roles of the brood pouch in protecting, aerating, osmotically buffering, and nourishing the embryos, much uncertainty remains in the extent of these functional roles for each species (for review see Azzarello 1991; Carcupino et al. 1997, 2002; Drozdov et al. 1997). The incomplete understanding of this paternal care mechanism has spawned recent interest in Syngnathid 
biology. For the two abundant species of the Chesapeake Bay region, trophic ecology and seasonal migration to deeper, warmer waters over winter are documented (Ryer and Boehlert 1983; Ryer and Orth 1987; Lazzari and Able 1990; Teixeira and Musick 1995). However, many other life history traits are only superficially known based on one season of data or a compilation of studies employing different methods at various locations (Able and Fahay 1998; Campbell and Able 1998). Considering S. fuscus and S. floridae abundance on eelgrass beds overlaps periods of growth and spawning for numerous commercial species as well as seasonal episodes of deteriorated water quality, assessment of pipefish catches, growth rates, and population dynamics could serve as monitoring tools indicating the health of the ecosystem (Officer et al. 1984; Lazzari and Able 1990; Breitburg 1992; Tong 2001). Further, concerns of extensive SAV lost and exploitation in the ornamental fish trade and Chinese medicine necessitates documentation of life history characteristics for Syngnathid conservation (Orth 1976; Orth and Moore 1984; Vincent 1996; Wood et al. 2002).

The aim of this study was to provide life history descriptions of S. fuscus and S. floridae. Specifically, we wished to expand upon our knowledge of sex ratios, size at maturity, and growth rates and explore the potential for sexual dimorphism in length measures. We also examined interspecific variations in seasonal abundance in relation to environmental parameters. By spanning several seasons and collecting from a relatively pristine site, this study provides robust baseline data for future comparisons to monitor the state of these Syngnathid populations and the Chesapeake Bay ecosystem. 


\section{STUDY LOCATION}

We collected $S$. fuscus and $S$. floridae from the seasonally abundant shallow eelgrass (Zostera marina) beds of the Chincoteague Bay, Virginia. The Chincoteague Bay is situated on the Eastern side of the Delmarva Peninsula opposite the Chesapeake Bay. Assateague and Chincoteague Islands form the eastern shoreline with outlets to the Atlantic Ocean north at Ocean City, Maryland $\left(37^{\circ} 52^{\prime} \mathrm{N}, 75^{\circ} 24^{\prime} \mathrm{W}\right)$ and south between Wallops and Chincoteague Islands (Fig. 1; $38^{\circ} 19^{\prime} \mathrm{N}, 75^{\circ} 05^{\prime} \mathrm{W}$ ). The grass bed we sampled was located $3.2 \mathrm{~km}$ southeast of Greenbackville, Virginia (Fig. 2 and $3 ; 37^{\circ} 59^{\prime} \mathrm{N}, 75^{\circ} 22^{\prime} \mathrm{W}$ to $37^{\circ} 59^{\prime} \mathrm{N}, 75^{\circ} 20^{\prime} \mathrm{W}$ ). The bottom substrate was comprised of thick mud with sparse patches of sand interspersed throughout the bed. Water depth ranged between approximately 0.7 and $1.3 \mathrm{~m}$.

\section{Materials and Methods}

\section{FIELD COLLECTIONS}

We sampled eelgrass fauna May through September 2003 to 2005. Sampling generally occurred monthly with the following exceptions. An additional collection was conducted midseason in June 2004. We were unable to sample during June 2005, and therefore performed two sets of measurements in both May and July 2005. Collection periods spanned 1-3 d with at least 3 sites visited each day. Trip dates and collection locations were selected to minimize eelgrass bed disturbance and maximize time and distance for recovery from our intrusion.

Sampling was performed over the tidal period, but most collections were conducted within $2 \mathrm{~h}$ of low tide. We selected collection locations based on visual confirmation of eelgrass and assessment of water depth. Site coordinates were marked with a Magellan ${ }^{\circledR}$ Meridian Marine global positioning unit and mapped with the software Magellan ${ }^{\circledR}$ MapSend BlueNav (version 
1.01b). In original sampling visits, temperature was recorded with a Lifegard ${ }^{\circledR}$ digital thermometer (Doctors Foster \& Smith) and salinity was measured by a temperature-compensated hand refractometer (Aquatic Ecosystems). Beginning in July 2004, an YSI 85 handheld meter was used to measure temperature, salinity, and dissolved oxygen (DO).

Seining events covered a distance of $\sim 25 \mathrm{~m}$ in approximately one minute using a $3.7 \mathrm{~m}$ by $1.2 \mathrm{~m}$ net with a $1.5 \mathrm{~m}^{2}$ bag and $0.4 \mathrm{~cm}^{2}$ mesh (Fish Net Company). Seining tracts followed a horseshoe shape which prevented sampling the same area more than once and allowed collection around the centrally located boat (17' Boston Whaler). Organisms were immediately sorted on a submerged platform. For every pipefish caught, sex and species were noted and standard length (SL; tip of the snout to the caudal peduncle) was measured with a ruler $( \pm 1 \mathrm{~mm})$. We morphologically distinguished males by the presence of a ventral brood pouch and distension of the anterior portion of the trunk identified females (Herald 1942). Juveniles were classified based on their small size and absence of the abovementioned determinate sexual characteristics. Larger juveniles were distinguished from newly matured females based on our early determination of minimum SL measures coinciding with sexual maturation (see Female sexual maturation determination). Snout length in relation to head length was utilized to separate the two species. Long snouts characterized S. floridae, while accordingly shorter snout-to-head lengths differentiated S. fuscus (Breder 1929; Herald 1965; Teixeira and Musick 1995; Murdy et al. 2002). Initially, all collected pipefish were retained for concurrent laboratory studies. Beginning in July 2004, only adult males and females exceeding the minimum length measure for sexual maturity by at least $3 \mathrm{~cm}$ were kept. Juveniles were held briefly $(<1 \mathrm{~h})$ in aerated tanks onboard the boat and returned before leaving the site. Pipefish were held for a maximum 
of $3 \mathrm{~d}$ at the field station in aerated tanks with daily water changes. Adults were transported in Kordon ${ }^{\circledR}$ breathing bags (Novalek Inc.) chilled with ice to the laboratory.

\section{ABUNDANCE, GROWTH RATE, AND SEX RATIO CALCULATIONS}

Pipefish abundance was determined by calculating catch per unit of effort (CPUE), or the number of individuals collected per seine. For every collection trip, we also plotted relative length-frequency distributions at SL increments of $5 \mathrm{~mm}$. The modal length was identified from the graphs, allowing the use of modal progression to estimate growth rate between sampling events. We calculated CPUE and growth rates for each species as well as individually for males, females, and juveniles. Sex ratios were computed for monthly collections yielding over 50 individuals by dividing the total number of males caught by the number of females. Sex ratios for the 2003 and 2004 field seasons are reported elsewhere (Ripley and Foran 2006). Operational sex ratios were not determined because these calculations would have required dissections of all the females to note gravidity.

\section{FEMALE SEXUAL MATURATION DETERMINATION}

For preliminary observations conducted in 2003, all collected pipefishes were held in the laboratory in same sex groups of 10-12 fish in filtered 37.81 tanks maintained at $24 \pm 1^{0} \mathrm{C}$ on a $14 \mathrm{~h}: 10 \mathrm{~h}$ light:dark cycle (on 06:00: off 20:00). Tissues were collected within $2 \mathrm{~d}$ of laboratory arrival for a concurrent study. We anaesthsized pipefish with 3-aminobenzoic acid ethyl ester (MS222; Sigma Aldrich) in saltwater. Fish were immediately measured with a ruler ( $\pm 1 \mathrm{~mm})$ and SL recorded. During dissection, the presence or absence of ovaries with mature oocytes was noted for females of both species. 


\section{STATISTICAL ANALYSIS}

Environmental data from the 3 years were considered together to investigate changes in salinity over the pipefish spawning season by linear regression. Fluctuations in temperature and DO were examined with 2-degree polynomial regressions. Temperature was related to collection month by a 2-degree polynomial regression. Interspecific differences in pipefish abundance, or CPUE, were considered for each collection year, as well as for every month of the season, by Wilcoxon Rank Sum tests. CPUE data for both species from August 2004 were omitted from all abundance analyses as these values were considered unexplained outliers. We employed a linear regression to investigate changes in CPUE with collection month for S. floridae and a 2-degree polynomial regression to examine the same relationship in S. fuscus. To explore the relationships between S. fuscus and S. floridae abundance and environmental variables, CPUE was correlated to temperature, salinity, and DO by the nonparametric Spearman's rho. Size differences between conspecific brooding and non-brooding males were tested for every collection trip by Wilcoxon Rank Sum analyses. Only collections with sample sizes greater than 8 were analyzed by the Wilcoxon Rank Sum so that a normal approximation for W could be assumed and the $\mathrm{Z}$ test statistic calculated. Males and females were similarly compared by Wilcoxon Rank Sum unless sample sizes exceeded 30 and normality was confirmed in which cases t-tests were performed. These comparisons were performed for every collection trip rather than the season to account for variability introduced by environmental parameters and collection effort. Chi-square analyses tested sex ratios observed in 2005 against a balanced population with a sex ratio of 1 . To explore factors influencing growth rate, we examined the relationship between collection date and S. fuscus growth rate with a linear regression. A relationship between the same variables was explored in S. floridae by both a linear and 2-degree polynomial 
regression. We investigated the effect of water temperature on the growth rate of each species by nonparametric correlations (Spearman's rho). Finally interspecific and sex/maturity differences in growth rate were explored with a 2-way ANOVA. All statistical analyses were performed with JMP 5.1 and an alpha value of 0.05 remained constant for the various tests.

\section{Results}

Environmental measurements confirmed expected DO, salinity, and temperature parameters for our location and condition (Kiddon et al. 2003). The Chincoteague Bay was not hampered by DO problems from 2003 to 2005. Most of our recorded DO concentrations exceeded state water quality standards of $5 \mathrm{mg} \mathrm{L}^{-1}$ and all of our data fell above hypoxia concentrations of $<2 \mathrm{mg} \mathrm{L}^{-1}$ (Table 1; Diaz and Rosenberg 1995; Kiddon et al. 2003). DO levels did significantly drop from high readings in May to minimum concentrations in July and August, recovering in September $\left(r^{2}=0.4149, p<0.0001\right.$; Table 1$)$. Bay salinity averaged $29.6 \pm 0.19$ ppt (mean \pm SE; Table 1). Salinity exhibited fluctuations ranging from 24.3 to $35.0 \mathrm{ppt}$ over the 3 year period, but no significant change in salinity characterized the passing of the summer

season $\left(r^{2}=0.0427, p=0.0140\right.$; Table 1$)$. Temperature in the Chincoteague Bay increased to maximum recordings in July and August and then declined in September $\left(r^{2}=0.7372, p<\right.$ 0.0001; Table 1).

\section{SEASONAL ABUNDANCE}

Syngnathus fuscus and S. floridae inhabited the Chincoteague Bay concurrently from May through September. These two sympatric species were distributed throughout the seasonal eelgrass beds, showing no evidence of site preference or species segregation (Fig. $2 \& 3$ ). 
Syngnathus fuscus abundance exceeded that of S. floridae. In early September 2005, we collected a peak catch of 944 S. fuscus pipefish and overall, $53 \%$ of our collections yielded over 200 individuals of this species. Out of 524 seines conducted during the 3 spawning seasons, $98 \%$ contained $S$. fuscus. The greatest number of S. floridae collected during a single trip occurred in August 2004 with 400 fish. Only 18\% of our catches captured more than 200 S. floridae and $65 \%$ of our seining attempts contained this species (Table 1). Pipefish abundance fluctuated yearly. In 2003 and 2004, interspecific differences in CPUE were not significant even though catches tended to contain more $S$. fuscus $(2003, \mathrm{~W}=33, \mathrm{p}=0.2903 ; 2004, \mathrm{~W}=50, \mathrm{p}=$ 0.0921). In 2005, S. fuscus abundance significantly exceeded that of $S$. floridae (W $=52, \mathrm{p}=$ 0.0370; Fig. 2 \& 3; Table 1). Interspecific differences in CPUE also varied monthly. During the middle of the reproductive season in June and July, catches contained more S. fuscus (June, W = $15, \mathrm{p}=0.0409 ;$ July, $\mathrm{W}=25, \mathrm{p}=0.0433$ ). Early and late in the season during May, August, and September, significant differences did not exist (May, $\mathrm{W}=23, \mathrm{p}=0.1832$; August, $\mathrm{W}=13, \mathrm{p}=$ 0.3827; September, $\mathrm{W}=14, \mathrm{p}=0.1904$; Fig. $2 \&$ 3; Table 1).

The species differed in their seasonal recruitment to the Bay. Syngnathus fuscus became abundant in May when water temperatures rose above $22^{\circ} \mathrm{C}$. For $S$. floridae, June temperatures had to reach $24^{\circ} \mathrm{C}$ before we captured substantial numbers of these pipefish on the grass beds (Fig. 4). Catches of both species increased with higher water temperatures (Fig. 4A; Table 1). CPUE also increased linearly with the passing of each month over the reproductive season for $S$. floridae (Fig. 3 \& 4B; Table 1). Syngnathus fuscus abundance increased to a peak catch in August and then dropped in September (Fig. 2 \& 4B; Table 1). Most pipefish, specifically 78\% for S. fuscus and $73 \%$ for S. floridae, were caught from June to August during the middle of the sampled season (Table 1). No relationship between CPUE and salinity emerged for either 
species ( $S$. fuscus, $\mathrm{r}=0.1143, \mathrm{p}=0.5800 ;$ S. floridae, $\mathrm{r}=-0.1255, \mathrm{p}=0.7950 ;$ Table 1$)$.

Likewise, no significant correlation existed with DO (S. fuscus, $\mathrm{r}=-0.6406, \mathrm{p}=0.4346 ; S$. floridae, $\mathrm{r}=-0.4621, \mathrm{p}=0.2070 ;$ Table 1$)$.

\section{MEASURES OF REPRODUCTIVES AND SEX RATIOS}

Females as small as $125 \mathrm{~mm}$ SL for S. fuscus and $103 \mathrm{~mm}$ for S. floridae were sexually mature as noted by the presence of distinct ovaries with orange-colored follicles or eggs. Maximum S. fuscus and S. floridae female size measured $228 \mathrm{~mm}$ and $212 \mathrm{~mm}$ respectively. Syngnathus fuscus males $99 \mathrm{~mm}$ brooded fertilized eggs in a fully formed brood pouch. For $S$. floridae males, while a pouch was observed on a male $87 \mathrm{~mm}$, the smallest brooding male was $91 \mathrm{~mm}$. Syngnathus fuscus males reached a size of $209 \mathrm{~mm}$. The largest $S$. floridae male measured $191 \mathrm{~mm}$. Sex ratio data indicate a heavily female-biased population for S. fuscus with ratios of males to females below 0.2 (Fig. 5). Sex ratios differed significantly from 1:1 male:female (Fig. 5). On the other hand, S. floridae displayed a sex ratio not significantly different from that of 1:1 male:female (Fig. 5).

No significant length difference was detected between brooding and non-brooding $S$. fuscus males early and late in the spawning season during May, August, and September (all p > 0.05; Table 2). However, non-brooding males were significantly shorter than brooding males in June and July (Table 2). Sexual dimorphism in length between S. fuscus males and females was detected at both ends of the season with female size surpassing that of males in May, August and September. Size differences between the sexes were not detected in June and July (all p >0.05; Table 2). For S. fuscus, comparisons of brooding versus non-brooding males showed an opposite length relationship over the breeding season when judged against males versus females. That is, 
during the part of the season when mature females were significantly larger than males, brooding and non-brooding males were the same size. In the middle of the breeding season when juveniles were becoming sexually mature, brooding males were larger than non-brooding males and no significant size differences were detected between the sexes. For S. floridae, sexual dimorphism in size was not detected. Brooding males were longer than non-brooding males in June, July, and August (Table 2).

Brooding males of both species were caught between May and September, coinciding with their seasonal abundance in the Bay (Fig. 6). Appearance of S. fuscus juveniles in the sampled areas occurred between June and August with a small amount in September. Collection of juveniles for S. floridae spanned June to September (Fig. 6). Peak abundance of brooding $S$. fuscus males was followed the next month by a maximum CPUE of juveniles. No such peaks in either brooding male or juvenile abundance were observed for S. floridae (Fig. 6).

\section{GROWTH RATES}

Length frequency data from 2004 indicated two age groups existed for both species. In May, adults dominated the population, but in early June, the population shifted to the young-ofthe-year (YOY) and two size classes emerged. Meanwhile, larger individuals who migrated into the grass beds and most likely spawned the previous year were few in number. Over June, accelerated growth diminished the separation between age classes so that in July and August most individuals fell in the size range of those capable of reproducing. By September the two age groups began to reform and few small individuals remained (Fig. 7). Monthly length frequency data from 2003 and 2005 followed the same pattern. 
Growth rates from May to September averaged $1.04 \pm 0.19 \mathrm{~mm} \mathrm{day}^{-1}(\mathrm{mean} \pm \mathrm{SE}$ ) for $S$. fuscus and $0.97 \pm 0.05 \mathrm{~mm} \mathrm{day}^{-1}$ for $S$. floridae (Table 3). Assuming the summer spawning season spanned 120 days, the potential size increase for both species was approximately 120 mm. For S. fuscus, growth rates significantly declined with the passing of the season (Fig. 8; Table 3). A May growth rate of $2.04 \pm 0.04 \mathrm{~mm} \mathrm{day}^{-1}$ decreased to $0.98 \pm 0.16 \mathrm{~mm} \mathrm{day}^{-1}$ in August. This relationship was not detected for S. floridae (Fig. 8; Table 3) but may be limited by reduced abundance of this species at the ends of the breeding season (Table 1). Neither species showed a correlation between growth rate and water temperature $(S$. fuscus, $\mathrm{r}=-0.4019, \mathrm{p}=$ 0.9141; S. floridae, $\mathrm{r}=0.2037, \mathrm{p}=0.7770)$.

Growth rates for juveniles, females, and males showed a trend of faster growth for $S$. fuscus juveniles when compared to reproductive adults. Data also indicated that females tended to grow faster than males in both species (Table 3). There was no statistical difference between species in the growth rate of males, females and juveniles over the course of the breeding season $(\mathrm{F}=1.2555, \mathrm{p}=0.2981)$. 
Table 1. Abiotic measurements and pipefish catches from the Chincoteague Bay, Virginia, USA from May to September 2003-05

\begin{tabular}{|c|c|c|c|c|c|c|c|c|}
\hline $\begin{array}{l}\text { Collection } \\
\text { Date }\end{array}$ & Temperature & $\begin{array}{l}\text { Dissolved } \\
\text { Oxygen }\end{array}$ & Salinity & $\begin{array}{l}\text { Total Catch } \\
\text { S. fuscus }\end{array}$ & $\begin{array}{l}\text { Total Catch } \\
\text { S. floridae }\end{array}$ & $\begin{array}{l}\text { Number } \\
\text { of Seines }\end{array}$ & $\begin{array}{l}\text { CPUE } \\
\text { S. fuscus }\end{array}$ & $\begin{array}{l}\text { CPUE } \\
\text { S. floridae }\end{array}$ \\
\hline \multicolumn{9}{|l|}{2003} \\
\hline 28 May & $18.22 \pm 0$ & ND & ND & 0 & 0 & 9 & 0 & 0 \\
\hline 17 June & $22.25 \pm 0.08$ & ND & $32.71 \pm 0.44$ & 46 & 0 & 14 & 3.3 & 0 \\
\hline 15 July & $28.63 \pm 0.46$ & ND & $29.00 \pm 0$ & 97 & 23 & 9 & 6.9 & 1.6 \\
\hline 6 August & $25.96 \pm 0.17$ & ND & $30.38 \pm 0.58$ & 230 & 53 & 12 & 15.3 & 3.5 \\
\hline $\begin{array}{l}6 \text { September } \\
\mathbf{2 0 0 4}\end{array}$ & $28.85 \pm 0.13$ & ND & $28.26 \pm 0.35$ & 176 & 92 & 11 & 17.1 & 8.7 \\
\hline 21-22 May & $22.20 \pm 0.82$ & ND & $32.25 \pm 1.11$ & 116 & 9 & 47 & 2.5 & 0.2 \\
\hline 9-10 June & $26.08 \pm 0.65$ & ND & $29.67 \pm 0.49$ & 470 & 9 & 44 & 10.7 & 0.2 \\
\hline 27-29 June & $26.74 \pm 0.59$ & ND & $31.30 \pm 0.62$ & 859 & 121 & 47 & 18.3 & 2.6 \\
\hline 19-21 July & $27.74 \pm 0.32$ & $6.74 \pm 0.38$ & $28.65 \pm 0.28$ & 466 & 227 & 31 & 14.6 & 7.1 \\
\hline 14-16 August & $23.68 \pm 0.41$ & $5.30 \pm 0.54$ & $26.60 \pm 0.95$ & 678 & 400 & 24 & 28.3 & 16.7 \\
\hline $\begin{array}{l}17 \text { September } \\
\mathbf{2 0 0 5}\end{array}$ & $24.14 \pm 0.13$ & $5.36 \pm 0.38$ & $27.72 \pm 0.13$ & 88 & 35 & 16 & 5.5 & 2.2 \\
\hline 11 May & $16.20 \pm 0.04$ & $9.34 \pm 0.15$ & $26.93 \pm 0.17$ & 25 & 0 & 15 & 1.7 & 0 \\
\hline 22-23 May & $17.66 \pm 0.21$ & $8.14 \pm 0.14$ & $26.79 \pm 0.08$ & 87 & 2 & 31 & 2.7 & 0.1 \\
\hline 6-7 July & $27.63 \pm 0.39$ & $6.48 \pm 0.37$ & $28.53 \pm 0.09$ & 614 & 47 & 38 & 16.2 & 1.2 \\
\hline 26-28 July & $28.41 \pm 0.40$ & $4.59 \pm 0.29$ & $30.10 \pm 0$ & 605 & 158 & 42 & 14.3 & 3.7 \\
\hline 8-10 August & $27.98 \pm 0.34$ & $5.32 \pm 0.42$ & $30.06 \pm 0.16$ & 933 & 169 & 72 & 12.9 & 2.4 \\
\hline 2-4 September & $26.03 \pm 0.23$ & $6.38 \pm 0.16$ & $30.26 \pm 0.04$ & 944 & 299 & 71 & 14.3 & 4.2 \\
\hline
\end{tabular}


Table 2. Standard length (SL) measurements and size differences between male brooding states and sexes

\begin{tabular}{|c|c|c|c|c|c|}
\hline $\begin{array}{l}\text { Collection } \\
\text { Date }\end{array}$ & $\begin{array}{l}\text { Brooding } \\
\text { Male SL }\end{array}$ & $\begin{array}{l}\text { Non-brooding } \\
\text { Male SL } \\
\end{array}$ & Female SL & $\begin{array}{l}\text { Brooding vs. } \\
\text { Non-brooding }\end{array}$ & $\begin{array}{l}\text { Male vs. } \\
\text { Female }\end{array}$ \\
\hline \multicolumn{6}{|c|}{ Syngnathus fuscus } \\
\hline \multicolumn{6}{|c|}{2003} \\
\hline \multicolumn{6}{|l|}{28 May } \\
\hline 17 June & $16.91 \pm 0.71$ & $16.68 \pm 0.27$ & $19.50 \pm 0.32$ & - & $* *$ \\
\hline 15 July & & & $14.07 \pm 0.45$ & & \\
\hline 5-6 Aug & $14.98 \pm 0.37$ & $15.15 \pm 0.34$ & $14.83 \pm 0.17$ & - & - \\
\hline $6 \mathrm{Sept}$ & $14.25 \pm 0.39$ & & $14.62 \pm 0.15$ & & - \\
\hline \multicolumn{6}{|l|}{2004} \\
\hline 21-22 May & $14.25 \pm 0.16$ & $14.23 \pm 0.35$ & $17.16 \pm 0.35$ & - & $* *$ \\
\hline 9-10 June & $16.80 \pm 0.22$ & & $19.07 \pm 0.24$ & & $* *$ \\
\hline 27-29 June & $16.43 \pm 0.41$ & $13.58 \pm 0.61$ & $14.64 \pm 0.25$ & $* *$ & - \\
\hline 19-21 July & $14.84 \pm 0.11$ & $13.69 \pm 0.46$ & $14.75 \pm 0.11$ & $*$ & - \\
\hline 14-16 Aug & $14.33 \pm 0.15$ & $13.71 \pm 0.38$ & $15.37 \pm 0.08$ & - & $* *$ \\
\hline 17 Sept & $14.54 \pm 0.41$ & & $15.61 \pm 0.22$ & & $*$ \\
\hline \multicolumn{6}{|l|}{2005} \\
\hline 11 May & $12.08 \pm 0.51$ & $11.85 \pm 0.28$ & & - & \\
\hline 22-23 May & $13.65 \pm 0.14$ & $13.84 \pm 0.17$ & $15.54 \pm 0.40$ & - & $* *$ \\
\hline 6-7 July & $14.95 \pm 0.58$ & $11.91 \pm 0.26$ & $13.85 \pm 0.20$ & $* *$ & - \\
\hline 26-28 July & & $13.83 \pm 0.34$ & $14.13 \pm 0.09$ & & - \\
\hline 8-10 Aug & $13.76 \pm 0.32$ & $13.66 \pm 0.25$ & $14.17 \pm 0.06$ & - & $*$ \\
\hline 2-4 Sept & $14.29 \pm 0.11$ & $14.66 \pm 0.39$ & $14.74 \pm 0.05$ & - & $*$ \\
\hline \multicolumn{6}{|c|}{ Syngnathus floridae } \\
\hline \multicolumn{6}{|c|}{2003} \\
\hline \multicolumn{6}{|l|}{28 May } \\
\hline \multicolumn{6}{|l|}{17 June } \\
\hline 15 July & & & $13.57 \pm 0.66$ & & \\
\hline 5-6 Aug & $13.74 \pm 0.44$ & & $13.29 \pm 0.54$ & & - \\
\hline $6 \mathrm{Sept}$ & $13.33 \pm 0.36$ & & $13.25 \pm 0.38$ & & - \\
\hline \multicolumn{6}{|l|}{2004} \\
\hline 21-22 May & & & $15.52 \pm 0.66$ & & \\
\hline \multicolumn{6}{|l|}{ 9-10 June } \\
\hline 27-29 June & $14.39 \pm 0.54$ & $10.87 \pm 0.54$ & $14.65 \pm 0.67$ & $* *$ & - \\
\hline 19-21 July & $12.70 \pm 0.24$ & $10.19 \pm 0.37$ & $13.08 \pm 0.26$ & $* *$ & - \\
\hline 14-16 Aug & $12.96 \pm 0.17$ & $10.33 \pm 1.06$ & $13.31 \pm 0.24$ & $* *$ & - \\
\hline 17 Sept & $13.50 \pm 0.55$ & & $13.71 \pm 0.62$ & & - \\
\hline \multicolumn{6}{|l|}{2005} \\
\hline \multicolumn{6}{|l|}{11 May } \\
\hline \multicolumn{6}{|l|}{ 22-23 May } \\
\hline 6-7 July & $13.06 \pm 1.14$ & & $14.00 \pm 0.70$ & & - \\
\hline 26-28 July & $13.83 \pm 0.27$ & $11.28 \pm 0.36$ & $14.20 \pm 0.30$ & $* *$ & - \\
\hline 8-10 Aug & $13.94 \pm 0.26$ & & $14.51 \pm 0.37$ & & - \\
\hline 2-4 Sept & $13.06 \pm 0.20$ & $13.30 \pm 1.11$ & $13.66 \pm 0.22$ & - & - \\
\hline
\end{tabular}


Table 3. Growth rates $\left(\mathrm{mm} \mathrm{day}^{-1}\right)$ of field collected pipefish from the Chincoteague Bay, Virginia

\begin{tabular}{|c|c|c|c|c|}
\hline Month & All Pipefish & Juvenile & Female & Male \\
\hline \multicolumn{5}{|c|}{ Syngnathus fuscus } \\
\hline \multicolumn{5}{|c|}{2003} \\
\hline June & 0.18 & 0.71 & 1.61 & \\
\hline July & 1.25 & 1.25 & 0.80 & 0.11 \\
\hline August & 1.21 & 0.57 & 0.57 & 0.16 \\
\hline Average & 0.88 & 0.84 & 0.99 & 0.14 \\
\hline \multicolumn{5}{|l|}{2004} \\
\hline May & 2.00 & & 2.00 & 1.38 \\
\hline June & 1.58 & 1.58 & 2.37 & 0.92 \\
\hline July & 1.02 & 1.82 & 1.14 & 0.91 \\
\hline August & 0.67 & 1.15 & 0.96 & 0.77 \\
\hline September & 0.08 & & 0.31 & \\
\hline Average & 1.07 & 1.52 & 1.36 & 1.00 \\
\hline \multicolumn{5}{|l|}{2005} \\
\hline May & 2.08 & & & 1.88 \\
\hline \multicolumn{5}{|l|}{ June } \\
\hline July & 1.19 & 1.19 & 1.19 & 1.07 \\
\hline July/August & 0.77 & 1.54 & 0.77 & 0.19 \\
\hline August & 0.39 & 0.39 & 0.39 & 0 \\
\hline Average & 1.11 & 1.04 & 0.78 & 0.79 \\
\hline \multicolumn{5}{|c|}{ Syngnathus floridae } \\
\hline \multicolumn{5}{|c|}{2003} \\
\hline \multicolumn{5}{|l|}{ June } \\
\hline July & 0.68 & 0.91 & 0.68 & 0.46 \\
\hline August & 1.05 & 0.97 & 0.65 & 0.32 \\
\hline Average & 0.87 & 0.94 & 0.67 & 0.39 \\
\hline \multicolumn{5}{|l|}{$2004^{\circ}$} \\
\hline May & 1.15 & & & \\
\hline June & 1.32 & 1.32 & 0.92 & \\
\hline July & 1.14 & 0.91 & 1.59 & 0.68 \\
\hline August & 1.15 & 0.29 & 0.58 & 0.67 \\
\hline September & 0.47 & 0.16 & 0.31 & \\
\hline Average & 1.05 & 0.67 & 0.85 & 0.68 \\
\hline \multicolumn{5}{|l|}{2005} \\
\hline \multicolumn{5}{|l|}{ May } \\
\hline June & & & & \\
\hline July & 1.43 & 1.19 & 1.91 & 1.19 \\
\hline July/August & 0.96 & 0.39 & 0.96 & 1.15 \\
\hline August & 0.58 & 0.58 & 0.19 & 0 \\
\hline Average & 0.99 & 0.72 & 1.02 & 0.78 \\
\hline
\end{tabular}




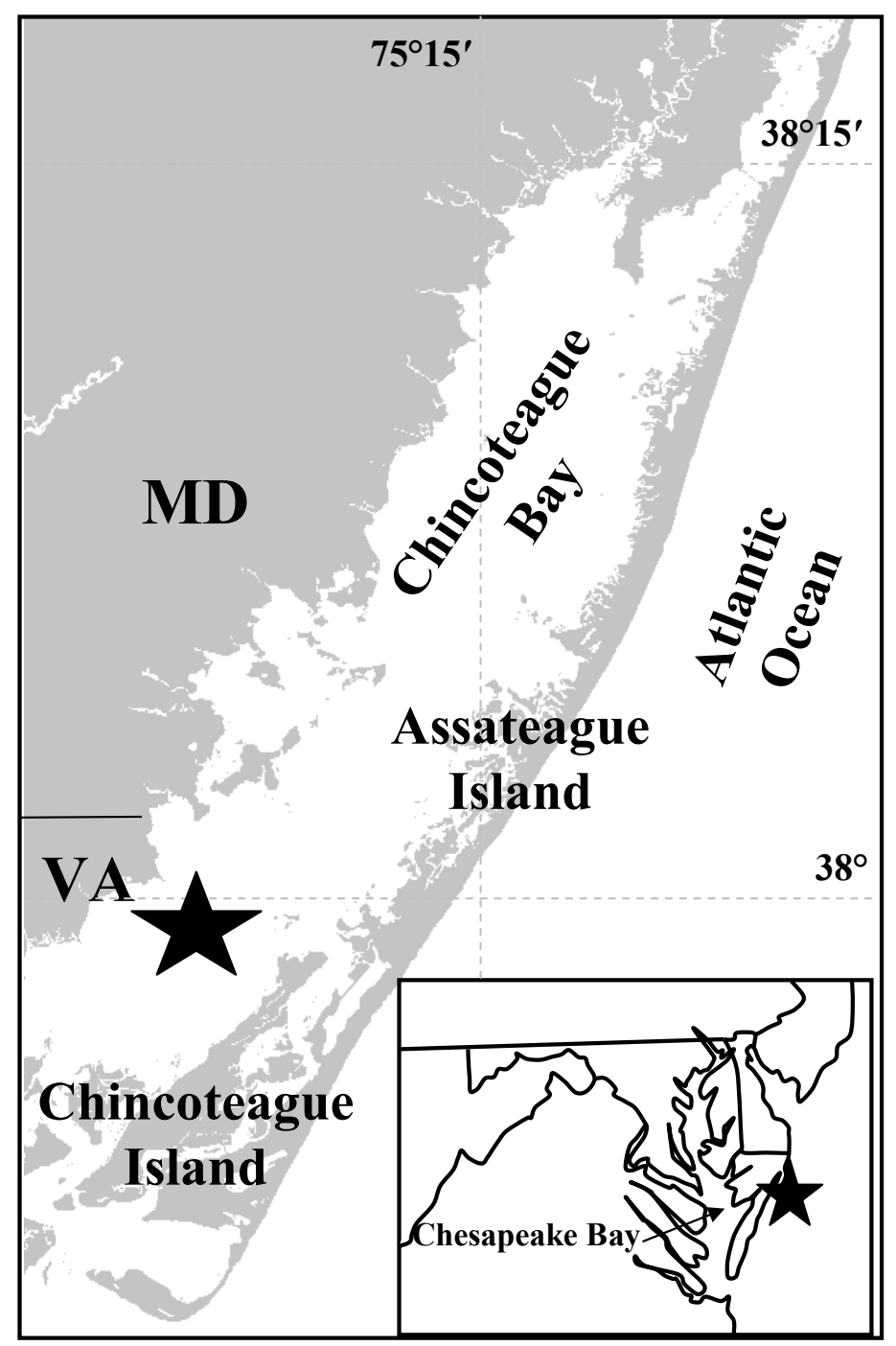

Fig. 1. Study area in the Chincoteague Bay, Virginia across the Delmarva Peninsula from the Chesapeake Bay. The star marks the sampling area which is detailed in Figures 2 and 3. 

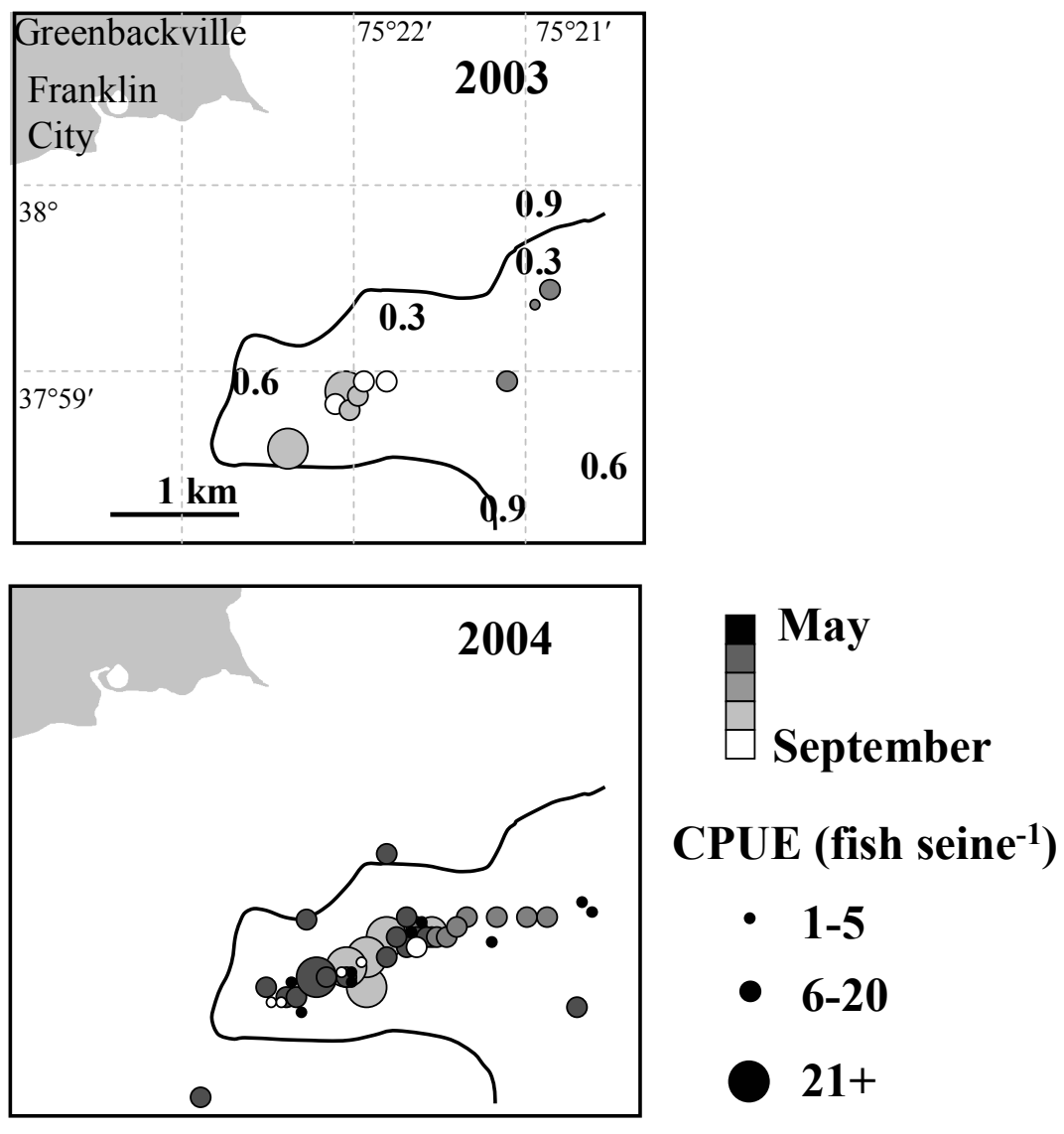

- 1-5

- 6-20

$21+$

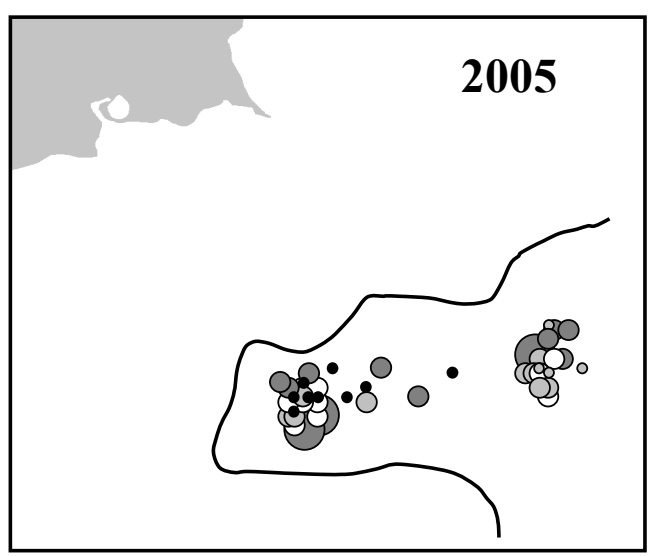

Fig. 2. Collections of Syngnathus fuscus in the Chincoteague Bay, Virginia from May to September 2003-2005. The color of the circles indicates the sampling date with lighter shades denoting later dates. The size of the circles specify catch per unit effort (CPUE; fish seine $^{-1}$ ). Isocline shows $1 \mathrm{~m}$ depth line in each map. 

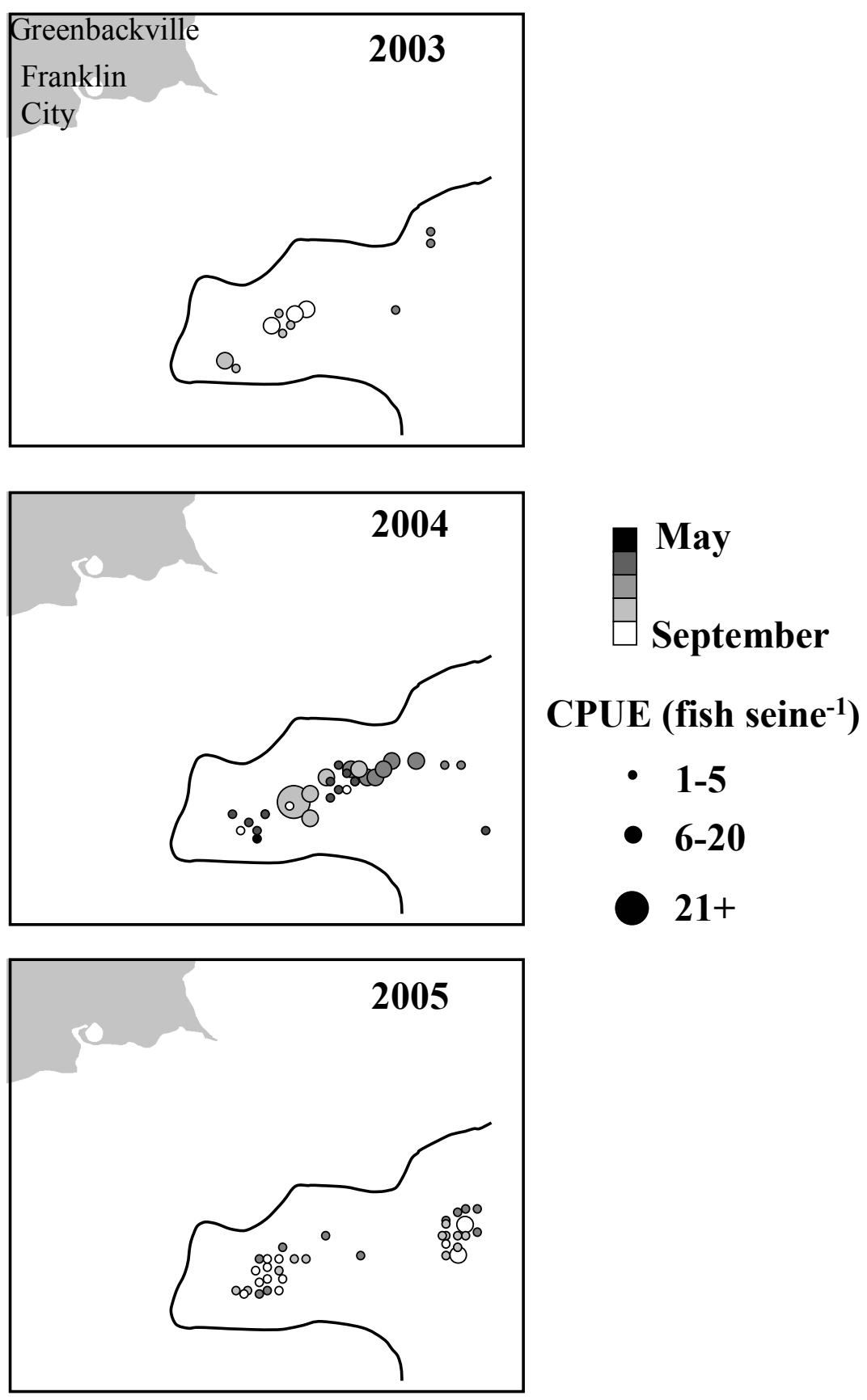

Fig. 3. Collections of Syngnathus floridae in the Chincoteague Bay, Virginia from May to September 2003-2005. The color of the circles indicates the sampling date with lighter shades denoting later dates. The size of the circles specify catch per unit effort (CPUE; fish seine $^{-1}$ ). Isocline shows $1 \mathrm{~m}$ depth line in each map. 

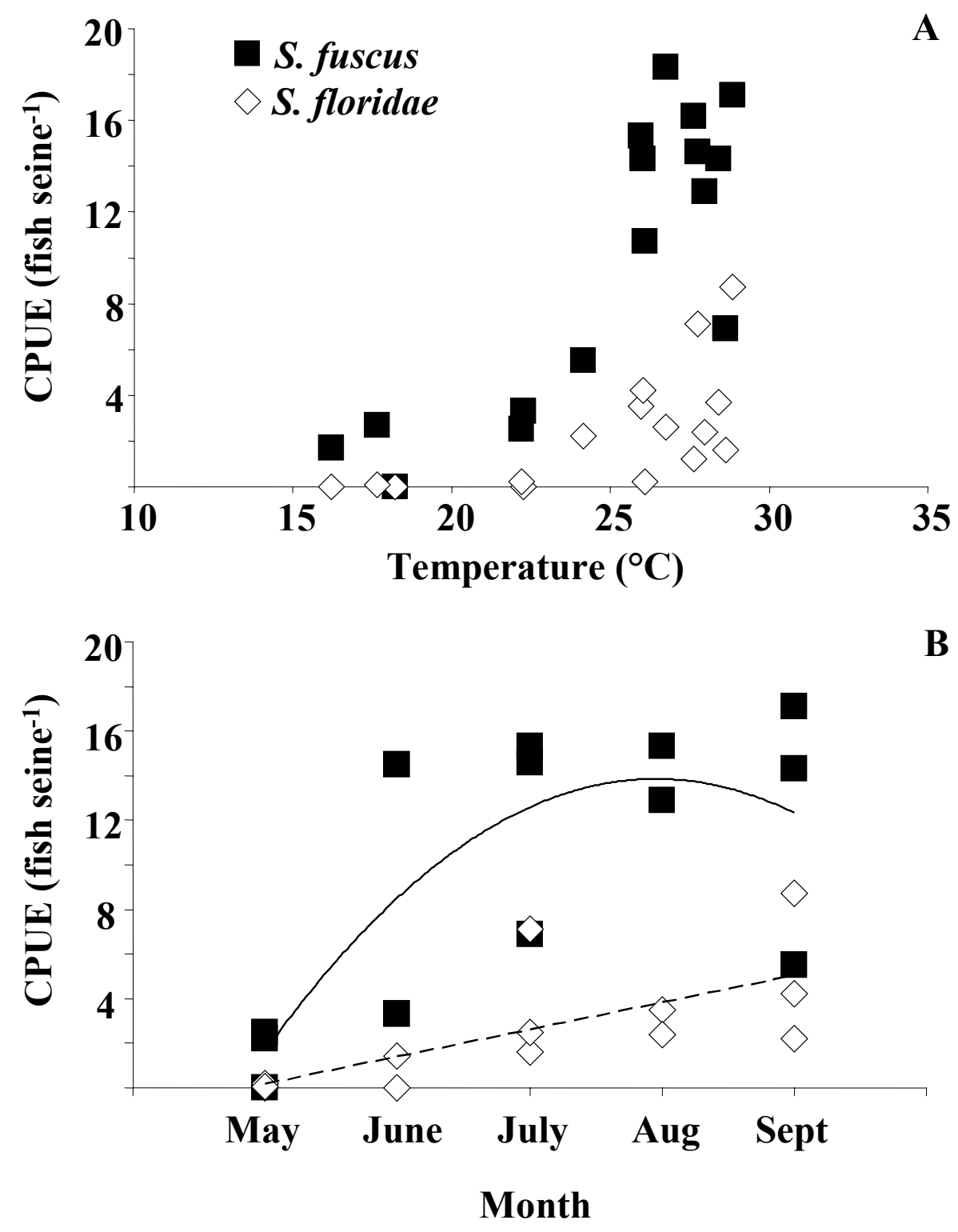

Fig. 4. Relationships between temperature (A) and collection date (B) with catch per unit effort (CPUE; fish seine ${ }^{-1}$ ) of Syngnathus fuscus and Syngnathus floridae. (A) Catches of $S$. fuscus $(\mathrm{r}=0.8294, \mathrm{p}=0.0017)$ and S. floridae $(\mathrm{r}=0.6328, \mathrm{p}=0.0014)$ increased with higher water temperatures. (B) CPUE increased linearly with the passing of each month over the reproductive season for $S$. floridae $\left(\mathrm{r}^{2}=0.4766, \mathrm{p}=0.0031\right)$. Syngnathus fuscus abundance increased to a peak catch in August and then dropped in September $\left(r^{2}=0.5831, p=0.0034\right)$. 


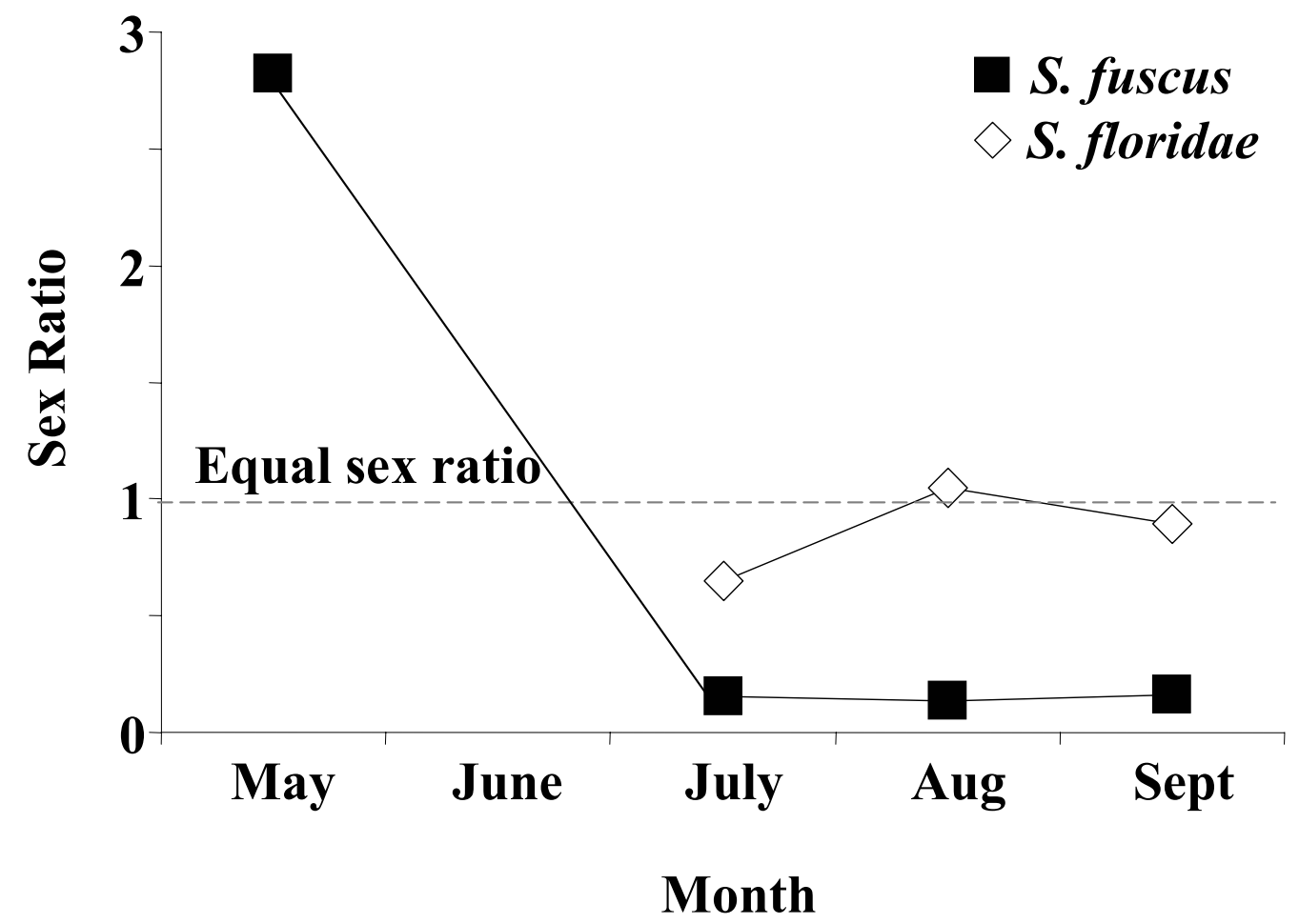

Fig. 5. Population sex ratios (number of males/number of females) for Syngnathus fuscus and Syngnathus floridae collected in the Chincoteague, Virginia during the 2005 reproductive season. Sex ratio data indicate a heavily female-biased population for $S$. fuscus with ratios significantly different from 1:1 male:female $\left(\chi^{2}=221.97, \mathrm{p}<0.001\right)$. Syngnathus floridae displayed a sex ratio following that of 1:1 male:female $\left(\chi^{2}=2.84, \mathrm{p}=0.242\right)$. 


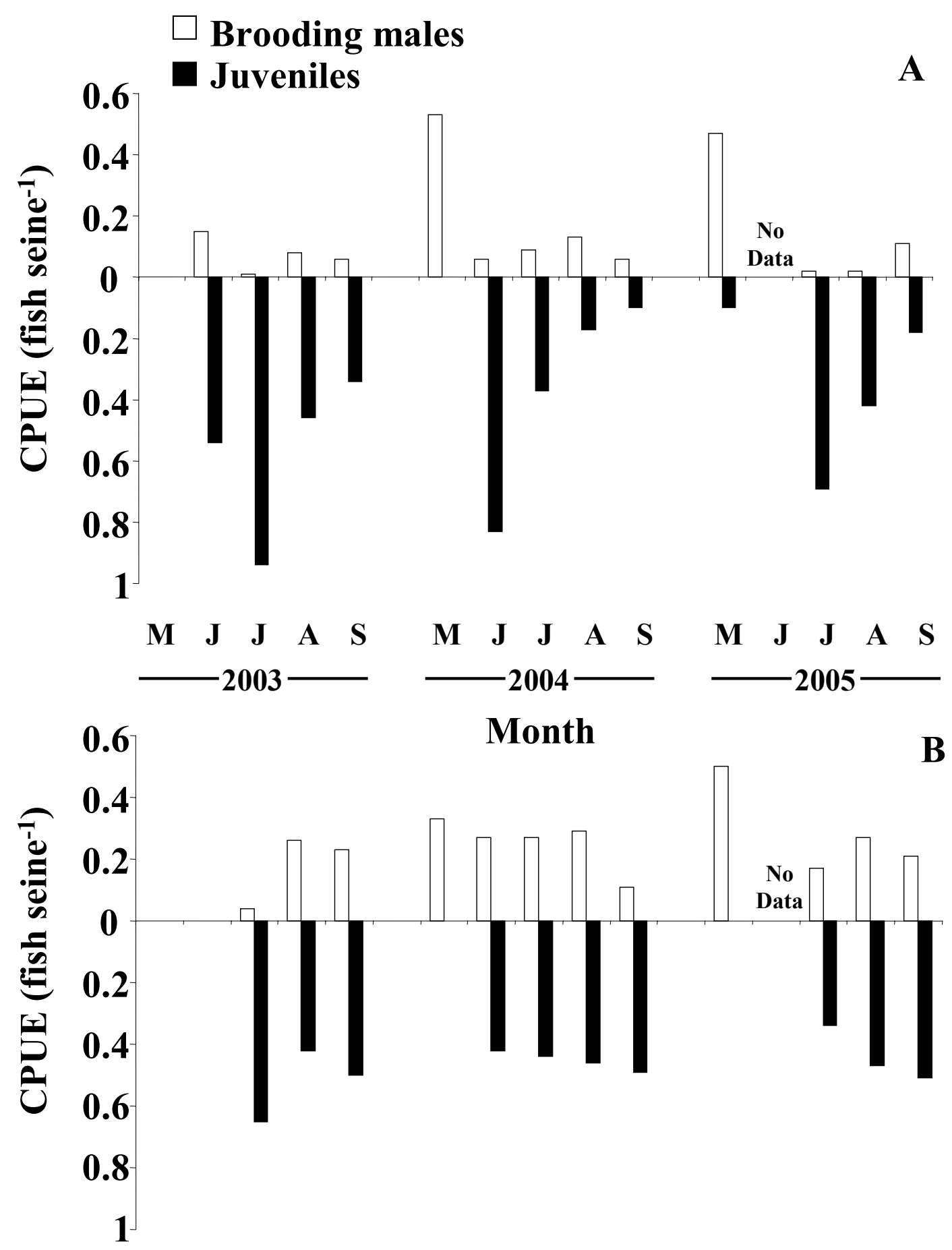

Fig. 6. Abundance of Syngnathus fuscus (A) and Syngnathus floridae (B) brooding males and juveniles over the summer spawning seasons of 2003-05. 


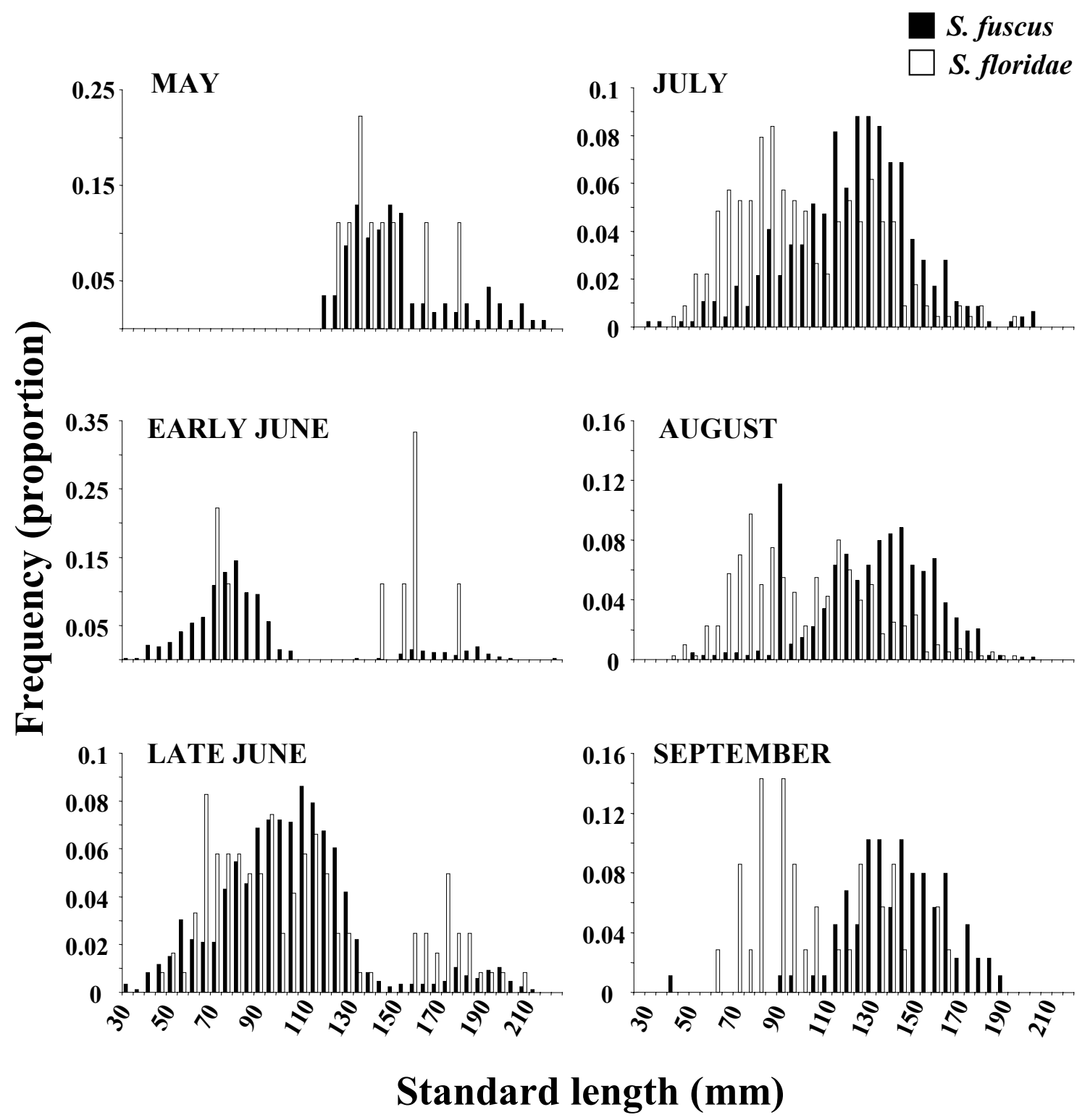

Fig. 7. Monthly length-frequency distributions of field-collected Syngnathus fuscus and Syngnathus floridae from the Chincoteague Bay from May to September 2004. Note changes in y-axis for some months. 


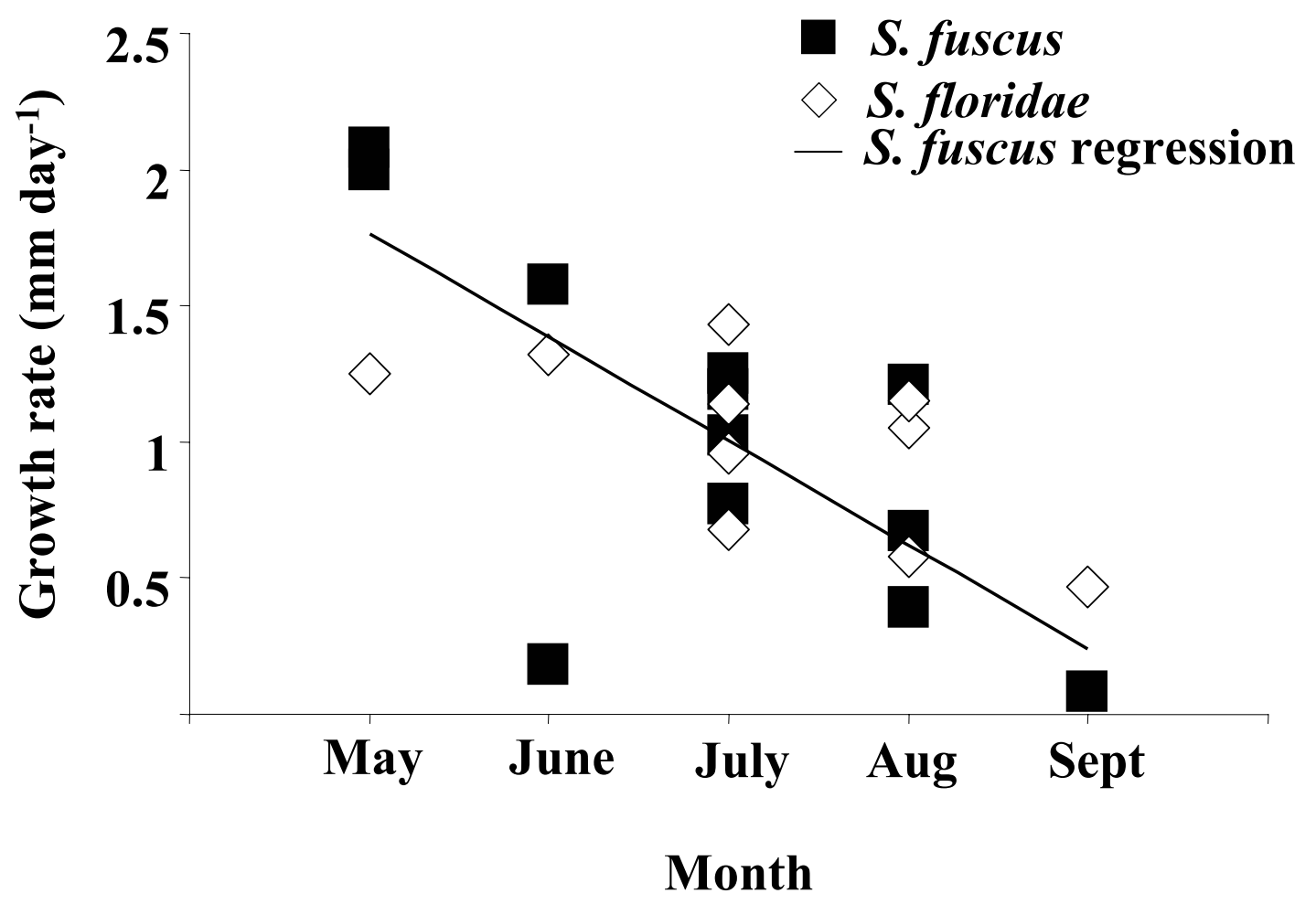

Fig. 8. Drops in growth rate with progression of the spawning season for Syngnathus fuscus and Syngnathus floridae. Syngnathus fuscus growth rates declined linearly $\left(\mathrm{r}^{2}=0.5259\right.$, $\mathrm{p}=0.0076$ ). This relationship was not detected for $S$. floridae (Linear regression, $\mathrm{r}^{2}=0.4001, \mathrm{p}=0.0497 ; 2$-Degree polynomial, $\left.\mathrm{r}^{2}=0.4619, \mathrm{p}=0.1143\right)$. 


\section{Discussion}

Syngnathus fuscus and Syngnathus floridae are sympatric inhabitants of the seasonal Zostera marina beds of the Chincoteague Bay from at least May through September. In other estuaries where two pipefishes cohabitate, spatial and temporal patterns divide the species (Diaz-Ruiz et al. 2000). Even though S. fuscus and S. floridae were not physically separated, seasonal migration differed. Previous investigations documented a peak in $S$. fuscus and $S$. floridae abundance in June and late July or early August respectively (Mercer 1973; Campbell and Able 1998). Our data showed extended time periods of copious pipefish occupation and shifts in abundance peaks to August for S. fuscus and September for $S$. floridae; however, interspecific differences in migration with S. fuscus returning to deeper water approximately one month before $S$. floridae holds constant for both descriptions. Interspecific divergence in seasonal migration patterns may be attributed to home ranges. Syngnathus fuscus occupies a more northerly distribution from Nova Scotia to Florida with few individuals found south of North Carolina and S. floridae inhabits southern waters from the Chesapeake Bay to Panama (Dawson 1982).

Water temperature is the dominant abiotic factor related to abundance for several Syngnathid species (Lazzari and Able 1990; Monteiro et al. 2001; Power and Attrill 2003; Bolland and Boettcher 2005). Correspondingly, S. fuscus displayed sensitivity to temperature with identical relationships presented by CPUE and water temperature when compared to collection month. Conversely, in this northern edge of the home range, $S$. floridae delayed appearance until water temperatures exceeded those triggering $S$. fuscus. Migration off the bed also did not coincide closely with water temperature changes for although temperatures decreased in September, $S$. floridae remained abundant in these relatively warm waters. Overall, temperature differences may explain the disparity in seasonal migration patterns between this study and that of Mercer (1973). The influence of temperature should be further 
investigated as this environmental factor is expected to change significantly in shallow, coastal grass beds as a result of climate change (Wood et al. 2002). Altered pipefish migrations could have a substantial bearing on this important ecosystem since pipefish serve as a prominent agent in the transfer of carbon from planktonic to benthic food webs (Ryer and Boehlert 1983).

The time frame of the summer spawning season mirrored the presence of S. fuscus and S. floridae in the Chincoteague Bay. Brooding S. fuscus and S. floridae males were collected May through September indicating the breeding period spanned at least 5 months which falls within the range of 4-9 months observed for other Syngnathids (Power and Attrill 2003; for summary see Takahashi et al. 2003). The proportion of reproductively active males peaked early in the summer season for $S$. fuscus trailed by a climax in juvenile abundance the subsequent month. Over winter, $S$. fuscus are reported to lie on the bottom of the continental shelf in a state of torpor (Wicklund et al. 1968). Thus these early peaks allowed S. fuscus to extend the growth period for juveniles before winter and to maximize reproductive output as males can spawn several times over the season (Lazzari and Able 1990; Able and Fahay 1998; Campbell and Able 1998). The absence of discrete crests in S. floridae brooding male and juvenile abundance may relate to the home range distribution and corresponding environmental conditions. Higher temperatures lead to faster gastric evacuation of food and increased energy gain, while water temperatures below $15^{\circ} \mathrm{C}$ severely restrict energy intake in Syngnathids (Ryer and Boehlert 1983). Warmer southern waters eliminate the necessity to maximize $S$. floridae growth over a limited summer season, removing the need to spawn early and creating a more gradual decline in the proportion of spawning males. For both species, the existence of brooding males over the entire season was concordant with the presence of juveniles. 
The minimum size at which $S$. floridae reproduced was less than that for $S$. fuscus and the overall maximum length was smaller for $S$. floridae males and females as well. Our observations agreed with previous reports that $S$. fuscus males less than $100 \mathrm{~mm}$ SL rarely brood (Dawson 1982; Campbell and Able 1998). On the contrary, our S. floridae collections contradicted earlier studies, revealing smaller brooding males than previously reported and greater maximum sizes both for males and females (Herald 1965). Males of the two species matured at a smaller size than conspecific females. Regardless, both male and female $S$. fuscus and S. floridae reproductively matured at approximately $50 \%$ of the maximum length. The minimum size at maturity was $47 \%$ for $S$. fuscus males and $55 \%$ for females of the maximum length. The same measures for $S$. floridae were $46 \%$ and $49 \%$ for males and females respectively. For the sympatric seahorse Hippocampus erectus, size at maturity also falls at 50\% the maximum size (Lourie et al. 1999). More substantial size increases characterize the Australian pipefish Syngnathoides biaculeatus and seahorse Hippocampus bargibanti at $71 \%$ and $58 \%$ of maximum length respectively (Lourie et al. 1999; Takahashi et al. 2003). More data is needed to investigate location and/or climatic-based trends in these measures, but this limited information does highlight the considerable size increase that is required for Syngnathid sexual maturation.

Standard length measures at midseason indicated non-brooding males were significantly smaller than brooding males. The presence of a brood pouch in these smaller males most likely represented recent sexual maturation and the development of this structure. Thus even though a brood pouch was present, our data indicated a period of maturation and growth was still needed before a male could incubate or compete for a brood. At the tails of the summer season, brooding and non-brooding males did not exhibit a size distinction. Here, the non-brooding state may be attributed to the recent release of a brood or the lack of an opportunity to mate. Differences in the SL measures of $S$. floridae males and females 
were not seen, but $S$. fuscus did display sexual dimorphism in size early and late in the summer. Again, growth and recent sexual maturation skewed the size ranges for both sexes at the middle of the season, diminishing sexual dimorphism.

The use of modal progression from length-frequency distributions to calculate growth rates assumes sampling gear is not size-biased, size-specific emigration does not occur, and mortality is constant across age and size classes (Campbell and Able 1998; Takahashi et al. 2003). The mesh size of our seine may not have been ideal to maximize catch of very small juveniles but we consistently collected individuals as small as $32 \mathrm{~mm}$ which parallels, and in some case rivals, other studies (Targett 1984; Campbell and Able 1998; Diaz-Ruiz et al. 2000; Takahashi et al. 2003; Bolland and Boettcher 2005). Further, the collection of grass, algae, and organisms in the seine bag created an interwoven matrix which aided in the prevention of escape. A seine net with any smaller mesh may be difficult to pull through the dense beds, may destroy habitat, and would dramatically reduce the area we could sample. In terms of size-specific migration, juveniles and adults of Syngnathus louisianae and Syngnathus scovelli spatially segregate and only S. biaculeatus juveniles larger than $80 \mathrm{~mm}$ migrate into seagrass beds (Diaz-Ruiz et al. 2000; Takahashi et al. 2003). Considering our collections contained fish of all size classes, size-selective migration was not likely. Very slow swimming speeds also limited size-specific migration (Blake 1980; Ashley-Ross 2002; Vincent et al. 2005). Natural mortality was probably greatest for young S. fuscus and $S$. floridae because of increased predation and cannibalism, but we cannot control for these situations in field studies (Campbell and Able 1998; Lourie et al. 1999). Overall, we believe our collections accurately represented the population structure of $S$. fuscus and S. floridae.

Growth rates for $S$. fuscus and S. floridae were comparable. Our 3 year average fell between reports for S. fuscus of $1.2 \mathrm{~mm} \mathrm{day}^{-1}$ and $0.8 \mathrm{~mm} \mathrm{day}^{-1}$ (Tatham et al. 1984; Campbell and Able 1998). Over the period of our study, the range of mean growth rates for 
S. fuscus approached the two previously reported values. Syngnathus floridae growth adhered to a narrower range of lower rates. Still, since fry of both species measure 10-12 mm at release (Dawson 1982; Ripley and Foran 2006), the similar growth rate for S. fuscus and $S$. floridae provided the potential for young born early in the season to grow to the size for sexual maturation and to even spawn in the same season. Growth rate significantly dropped from May through September for $S$. fuscus. A general decline in growth rate over the spawning period was recently documented for field-collected $S$. biaculeatus (Takahashi et al. 2003). Growth slowed as temperature peaked and began to fall and the majority of YOY reached adult size. Accelerated growth early in the summer explains the midseason size difference between brooding and non-brooding males described earlier. As growth slowed later in the season, the number of males undergoing pouch development and sexual maturation decreased.

The monthly field collections provided estimates of the longevity of $S$. fuscus and $S$. floridae. Two size classes representing two year classes were identified for both species. Large individuals in May most likely represented fish that spawned the previous year. Following growth rate approximations and the knowledge that growth is suspended over the winter, some of the larger individuals may have even been born the year before (Wicklund et al. 1968; Ryer and Boehlert 1983; Able and Fahay 1998; Campbell and Able 1998). Thus, in May, this cohort was between 12 and 20 months old. The observation that the frequency of fish in these size classes did not increase over the summer indicated most died or stopped growing during the season. Overall, S. fuscus and S. floridae probably partake in at least part of 2 spawning seasons to a maximum age of 2 years. This longevity estimate corresponds with other approximations for S. fuscus (Mercer 1973; Dawson 1982; Tatham et al. 1984). Otolith studies or another aging measure is needed to verify these estimates of longevity. 
Evolutionary theory predicts in species where one sex exhibits extensive parental care, the opposite sex will compete for access to the caring sex as this latter group will be more discriminating in their choice of mates (Trivers 1972). Sexual selection through mate competition and/or mate choice can result in sexual dimorphism (Trivers 1972; Searcy 1982; Berglund et al. 1986). Large body size, and traits correlated with it, often confers an advantage in mate competition (Dugatkin and FitzGerald 1997). For instance, male Syngnathus typhle prefer larger females for the greater egg size and average number of eggs transferred per spawning (Berglund et al. 1986; Jones et al. 2000). In S. fuscus, males provide extensive parental care by allocating nutrients through the brood pouch to offspring (Ripley and Foran 2006). Our observation of larger females follows records of a femalebiased sex ratio, overall indicating high competition for males (Teixeira and Musick 1995; Ripley and Foran 2006). Size sexual dimorphism fits with other secondary sexual characteristics evolved by S. fuscus females including dimorphic banding coloration and large roaming areas and the absence of these traits in S. floridae (Roelke and Sogard 1993; Berglund et al. 1997). Relative to $S$. fuscus, paternal nutrient allocation is limited in $S$. floridae and this species is characterized by an equal sex ratio (Teixeira and Musick 1995; Ripley and Foran 2006). Accordingly, no size difference between sexes was observed. These observations support the hypothesis that the strength of sexual selection, and potentially the extent of sex role reversal, is greater in S. fuscus when compared to S. floridae (Emlen and Oring 1977; Gwynne 1991; Vincent et al. 1992).

Syngnathus fuscus and S. floridae are sympatric for almost half of their home ranges, but few studies present comparative data and moreover, very little is known about $S$. floridae. In the Chesapeake Bay, SAV currently occupies only $10 \%$ of the area covered pre-1950 and with the watershed's population predicted to increase at least $20 \%$ by 2020 , degradation increases despite significant remedial efforts (McConnell 1995; Harwell and Orth 2002; 
Kiddon et al. 2003). This study provided baseline information from a neighboring, relatively pristine bay that can be immediately applied to the Chesapeake Bay for ecosystem assessment. The growth rates, catches, and seasonal movements recorded here also provide comparisons for investigations of these widely distributed pipefishes in other areas of their range. 


\section{References}

Able, K. W., and M. P. Fahay. 1998. The First Year in the Life of Estuarine Fishes in the Middle Atlantic Bight. Rutgers University Press, New Jersey.

Ashley-Ross, M. A. 2002. Mechanical properties of the dorsal fin muscle of seahorse (Hippocampus) and pipefish (Syngnathus). Journal of Experimental Zoology 293:561577.

Azzarello, M. Y. 1991. Some questions concerning the Syngnathidae brood pouch. Bulletin of Marine Science 49:741-747.

Berglund, A., G. Rosenqvist, and I. Svensson. 1986. Mate choice, fecundity and sexual dimorphism in two pipefish species (Syngnathidae). Behavioral Ecology and Sociobiology 19:301-307.

Berglund, A., G. Rosenqvist, and P. Bernet. 1997. Ornamentation predicts reproductive success in female pipefish. Behavioral Ecology and Sociobiology 40:145-150.

Blake, R. W. 1980. Undulatory median fin propulsion of two teleosts with different modes of life. Canadian Journal of Zoology 58:2116-2119.

Bolland, J., and A. Boettcher. 2005. Population structure and reproductive characteristics of the Gulf pipefish, Syngnathus scovelli, in Mobile Bay, Alabama. Estuaries 28:957965.

Breder, C. M. 1929. Field Book of Marine Fishes of the Atlantic Coast. G. P. Putnam's Sons, New York.

Breitburg, D. L. 1992. Episodic hypoxia in Chesapeake Bay: Interacting effects of recruitment, behavior, and physical disturbance. Ecological Monographs 62:525-546.

Campbell, B. C., and K. W. Able. 1998. Life history characteristics of the Northern pipefish, Syngnathus fuscus, in Southern New Jersey. Estuaries 21:470-745. 
Carcupino, M., A. Baldacci, M. Mazzini, and P. Franzoi. 1997. Morphological organization of the male brood pouch epithelium of Syngnathus abaster Risso (Teleostea, Syngnathidae) before, during, and after egg incubation. Tissue \& Cell 29:21-30.

Carcupino, M., A. Baldacci, M. Mazzini, and P. Franzoi. 2002. Functional significance of the male brood pouch in the reproductive strategies of pipefishes and seahorses: A morphological and ultrastructural comparative study on three anatomically different pouches. Journal of Fish Biology 61:1465-1480.

Dawson, C. E. 1982. Family Syngnathidae, p. 1-172. In J. E. Bölke (ed.), Fishes of the Western North Atlantic, Part Eight, Order Gasterosteiformes, Suborder Syngnathoidei. Yale University, New Haven, Connecticut.

Diaz, R. J., and R. Rosenberg. 1995. Marine benthic hypoxia: A review of its ecological effects and the behavioral responses of benthic macrofauna. Oceanography and Marine Biology Annual Review 33:245-303.

Diaz-Ruiz, S., A. Aguirre-Leon, and O. Perez-Solis. 2000. Distribution and abundance of Syngnathus louisianae and Syngnathus scovelli (Syngnathidae) in Tamiahua Lagoon, Gulf of Mexico. Ciencias Marinas 26:125-143.

Drozdov, A. L., E. S. Kornienko, and A. V. Krasnolutsky. 1997. Reproduction and development of Syngnathus acusimilis. Russian Journal of Marine Biology 23:265268.

Dugatkin, L. A., and G. J. FitzGerald. 1997. Sexual selection, p. 266-291. In J. J. Godin (ed.), Behavioural Ecology of Teleost Fishes. Oxford University Press, Oxford, United Kingdom.

Emlen, S. T., and L. W. Oring. 1977. Ecology, sexual selection, and the evolution of mating systems. Science 197:215-313. 
Gwynne, D. T. 1991. Sexual competition among females: What causes courtship role reversal? Trends in Ecology and Evolution 6:118-121.

Harwell, M. C., and R. J. Orth. 2002. Seed bank patterns in Chesapeake Bay eelgrass (Zostera marina L.): A Bay-wide perspective. Estuaries 25:1196-1204.

Herald, E. S. 1942. Three new pipefishes from the Atlantic coast of North and South America, with a key to the Atlantic American species. Stanford Ichthyological Bulletin 2:125-134.

Herald, E. S. 1965. Studies on the Atlantic American pipefishes with descriptions of new species. Proceedings of the California Academy of Sciences 32:363-375.

Jones, A. G., G. Rosenqvist, A. Berglund, and J. C. Avise. 2000. Mate quality influences multiple maternity in the sex-role-reversed pipefish Syngnathus typhle. OIKOS 90:321-326.

Kiddon, J. A., J. F. Paul, H. W. Buffum, C. S. Strobel, S. S. Hale, D. Cobb, and B. S. Brown. 2003. Ecological condition of US Mid-Atlantic estuaries, 1997-1998. Marine Pollution Bulletin 46:1224-1244.

Lazzari, M. A., and K. W. Able. 1990. Northern pipefish, Syngnathus fuscus, occurrences over the Mid-Atlantic Bight continental shelf: Evidence of seasonal migration. Environmental Biology of Fishes 27:177-185.

Lockwood, S. 1867. The seahorse (Hippocampus hudsonius) and its young. The American Naturalist 1:225-234.

Lourie, S. A., A. C. J. Vincent, and H. J. Hall. 1999. Seahorses: An Identification Guide to the World's Species. Project Seahorse, London, United Kingdom.

McConnell, R. L. 1995. The human population carrying capacity of the Chesapeake Bay watershed: A preliminary analysis. Population and Environment 16:339-352. 
Mercer, L. P. 1973. The Comparative Ecology of Two Species of Pipefish (Syngnathidae) in the York River, Virginia. M. S. Thesis, Virginia Institute of Marine Science, The College of William and Mary, Gloucester Point, Virginia.

Monteiro, N., V. C. Almada, A. M. Santos, and M. N. Vieira. 2001. The breeding ecology of the pipefish Nerophis lumbriciformis and its relation to latitude and water temperature. Journal of the Marine Biological Association of the United Kingdom 81:1031-1033.

Murdy, E. O., R. S. Birdsong, and J. A. Musick. 2002. Fishes of the Chesapeake Bay. Smithsonian Institution Press, Washington D.C.

Officer, C. B., R. B. Biggs, J. L. Taft, L. E. Cronin, M. A. Tyler, and W. R. Boynton. 1984. Chesapeake Bay anoxia: Origin, development and significance. Science 233:22-27.

Orth, R. J. 1973. Benthic infauna of eelgrass, Zostera marina, beds. Chesapeake Science 14:258-269.

Orth, R. J. 1976. The demise and recovery of eelgrass, Zostera marina, in the Chesapeake Bay, Virginia. Aquatic Botany 2:141-159.

Orth, R. J., and K. L. Heck. 1980. Structural components of eelgrass (Zostera marina) meadows in the lower Chesapeake Bay - fishes. Estuaries 3:278-288.

Orth, R. J., and K. A. Moore. 1984. Distribution and abundance of submerged aquatic vegetation in Chesapeake Bay: An historical perspective. Estuaries 7:531-540.

Power, M., and M. J. Attrill. 2003. Long-term trends in the estuarine abundance of Nilsson's pipefish (Syngnathus rostellatus Nilsson). Estuarine, Coastal and Shelf Science 57:325-333.

Ripley, J. L., and C. M. Foran. 2006. Differential parental nutrient allocation in two congeneric pipefish species (Syngnathidae: Syngnathus spp.). Journal of Experimental Biology 209:1112-1121. 
Roelke, D. L., and S. M. Sogard. 1993. Gender-based differences in habitat selection and activity level in the Northern pipefish (Syngnathus fuscus). Copeia 1993:528-532.

Ryer, C. H., and G. W. Boehlert. 1983. Feeding chronology, daily ration, and the effects of temperature upon gastric evacuation in the pipefish, Syngnathus fuscus. Environmental Biology of Fishes 6:301-306.

Ryer, C. H., and R. J. Orth. 1987. Feeding ecology of the Northern pipefish, Syngnathus fuscus, in a seagrass community of the lower Chesapeake Bay. Estuaries 10:330-336.

Searcy, W. A. 1982. The evolutionary effects of mate selection. Annual Review of Ecology and Systematics 13:57-85.

Sellner, K. G. 1987. Phytoplankton in Chesapeake Bay: Role in carbon, oxygen and nutrient dynamics, p. 134-157. In S. K. Majumdar, L. W. Hall, and H. M. Austin (eds.), Contaminant Problems and Management of Living Chesapeake Bay Resources. The Pennsylvania Academy of Science.

Takahashi, K., R. M. Connolly, and S. Y. Lee. 2003. Growth and reproduction of doubleended pipefish, Syngnathoides biaculeatus, in Moreton Bay, Queensland, Australia. Environmental Biology of Fishes 67:23-33.

Targett, T. E. 1984. A breeding population of Gulf pipefish (Syngnathus scovelli) in a Georgia estuary, with discussion on the ecology of the species. Contributions in Marine Science 27:169-174.

Tatham, T. R., D. L. Thomas, and D. J. Danila. 1984. Fishes of Barnegat Bay, New Jersey, p. 241-280. In M. J. Kennish, and R. A. Lutz (eds.), Ecology of Barnegat Bay, New Jersey. Springer-Verlag, New York.

Teixeira, R. L., and J. A. Musick. 1995. Trophic ecology of two congeneric pipefishes (Syngnathidae) of the lower York River, Virginia. Environmental Biology of Fishes 43:295-309. 
Thayer, G. W., D. A. Wolfe, and R. B. Williams. 1975. The impact of man on seagrass systems. American Scientist 63:288-296.

Tong, S. T. Y. 2001. An integrated exploratory approach to examining the relationships of environmental stressors and fish responses. Journal of Aquatic Ecosystem Stress and Recovery 9:1-19.

Trivers, R. L. 1972. Parental Investment and Sexual Selection, p. 136-179. In B. Campbell (ed.), Sexual Selection and the Descent of Man. Aldine-Atherton, Chicago.

Vincent, A. C. J. 1996. The International Trade in Seahorses. TRAFFIC International, Cambridge, United Kingdom.

Vincent, A., I. Ahnesjö, A. Berglund, and G. Rosenqvist. 1992. Pipefishes and seahorses: Are they all sex role reversed? Trends in Ecology and Evolution 7:237-241.

Vincent, A. C. J., K. L. Evans, and A. D. Marsden. 2005. Home range behaviour of the monogamous Australian seahorse, Hippocampus whitei. Environmental Biology of Fishes 72:1-12.

Wood, R. J., D. F. Boesch, and V. S. Kennedy. 2002. Future consequences of climate change for the Chesapeake Bay ecosystem and its fisheries. American Fisheries Society Symposium 32:171-184.

Wicklund, R. I., S. J. Wilk, and J. Ogren. 1968. Observations on wintering locations of the northern pipefish and spotted seahorse. Underwater Naturalist 5:26-28. 
Chapter III: Differential Parental Nutrient Allocation in Two Congeneric Pipefish Species (Syngnathidae: Syngnathus spp.) 


\begin{abstract}
Male seahorses and pipefishes of the family Syngnathidae are heralded for their unique brood pouch structures for incubating embryos. There are three general types of brood pouch with increasing complexity: simple ventral gluing, two pouch flaps and a completely sealed sac. The diversity of functional roles within a type in providing nutrition, aeration and protection to offspring is unknown. Here we reveal significant differences in parental nutrient allocation to embryos for two closely related, sympatric pipefishes described with similar brood pouch structure. We document differences in embryo attachment, depletion of pouch fluid nutrients over development and egg nutrient partitioning between Syngnathus floridae and Syngnathus fuscus. In S. fuscus, females produce nutritionally poor eggs, while males implant developing embryos in the brood pouch adjacent to blood vessels. A female-biased breeding population was observed supporting the hypothesis that the cost of male parental care is high in this species. The loose connection between eggs and brood pouch tissues and the appearance of undeveloped eggs and lipid droplets in the pouch of $S$. floridae males suggest this species utilizes nutrient-rich eggs produced by females as nurse eggs to supplement embryonic development. A balanced sex-ratio for $S$. floridae further supports more equal parental contribution. This comparison provides evidence of a decline in female gametic investment and reveals the rapid diversification of Syngnathid brood pouch function. Our results indicate gross classification of brooding structures into one of the three general pouch types does not predict the energetic investment of males in parental care. But rather, physiological characterization of the relative investment by each sex to offspring is essential to understanding the functional significance of the brood pouch.
\end{abstract}




\section{Introduction}

Females tend to provide substantial parental care in mammals and other vertebrate taxa. Part of the explanation for this role lies in the gamete dimorphism that defines the sexes. Females invest in large, nutritious eggs while males produce small, mobile sperm (Parker et al., 1972; Alexander and Borgia, 1979). Anisogamy, gametes of two different sizes from the male and female, underlies the evolution of sex differences in morphology and behavior including parental care (Maynard-Smith, 1978). Evolutionary theory predicts that in species with female parental care, males will compete for access to females (Trivers, 1972). When males exhibit paternal care, they incur a loss of fitness due to increased predation, decreased foraging time and territory and limited mating opportunities relative to males of other species (Williams, 1966, 1975; Gross and Shine, 1981; Vincent et al., 1992; Svennsson, 1998). Caring males are accordingly expected to be more discriminating in their choice of mates, and females will compete for access to receptive males. Sex roles are therefore historically defined by mating competition (Emlen and Oring, 1977). Species exhibiting greater competition by females than males for mates are said to be sex-role reversed (Gwynne, 1991). The occurrence of sex-role reversal offers an opportunity to explore the evolution of sex differences. For example, an extreme case of sex-role reversal has been suggested to result in complete sex reversal where anisogamy is inverted as indicated by a loss of nutritional investment from female gametes (Pagel, 2003).

Pipefishes and seahorses of the family Syngnathidae are characterized by a unique mode of ovoviviparous reproduction in which the male carries the developing embryos in a special organ referred to as the brood pouch (Lockwood, 1867). The degree of brood pouch closure varies considerably and has classically been grouped into three types: ventral gluing, two pouch flaps that meet midline and a completely sealed sac (Duncker, 1915; Herald, 1959). A female oviposits her eggs directly onto the brooding skin where they are fertilized. 
"Internal" fertilization in males assures paternity and is likely one of the selective pressures behind the evolution of this structure (Helfman et al., 1997; Jones and Avise, 1997; Jones et al., 1998, 1999). The developing embryos remain in the brood pouch for a lengthy incubation period before being released as independent young without a yolk sac.

The brood pouch is believed to protect, aerate, osmotically buffer and nourish the embryos (for review see Azzarello, 1991; Carcupino et al., 1997; Drozdov et al., 1997; Carcupino et al., 2002). An investigation on the pipefish Syngnathus acusimilis demonstrated that the dorsal epithelial lining of the brood pouch is well vascularized and composed of thick cuboidal cells similar to those known to have a secretory function (Drozdov et al., 1997). The Syngnathid brood pouch is expected to be an epithelochordal placenta, because eggs are deposited with a large amount of yolk and a yolk sac is still visible once the fry hatch in the pouch. Therefore, the Syngnathid brood pouch resembles that of squamate lizards, conferring inorganic ion exchange (Stewart, 1992). Several authors have suggested an ionic exchange function that regulates the osmolality of the brood pouch fluid to that of paternal blood, facilitating embryonic development (Linton and Soloff, 1964; Quast and Howe, 1980; Watanabe et al., 1999). A nourishment function for the brood pouch has been suggested in Syngnathus scovelli, because smaller eggs are absorbed by the pouch epithelium and thought to serve as "nurse eggs" (Ahnesjö, 1996). The pouch has also been suggested to transfer steroid or growth hormones to the embryos, but this function has yet to be fully investigated (Haresign and Shumway, 1981; Azzarello, 1991; Mayer et al., 1993).

The extent to which the various pouch types perform these physiological roles is unknown. For instance, in two related pipefish species where fry measure 11-13 mm total length (TL) at release, removal of $S$. scovelli embryos at least $4 \mathrm{~mm}$ TL resulted in normal development (Azzarello, 1991). Conversely, S. acusimilis young could not survive outside the brood pouch until 11-12 mm TL (Drozdov et al., 1997). Molecular phylogenetic analyses 
indicate the Syngnathid brood pouch underwent rapid diversification evidenced by repeated evolution of a number of pouch types (Wilson et al., 2001). Rapid diversification of placental function in females has been documented in another teleost system (Morrell, 2002; Resnick et al., 2002). These studies suggest the function of the paternal brood pouch is a fairly plastic trait and that Syngnathid groups may differ in brood pouch physiology.

Regardless of the degree of closure, all Syngnathid brood pouches were once assumed to provide developing embryos with protection, osmoregulation and nutrients (Vincent et al., 1992; Jones and Avise, 1997). However, sex-role reversal as predicted by extensive male investment was not consistently reported within these taxa (Vincent et al., 1992). Recent ultrastructural comparisons of three Syngnathid species representing each of the brood pouch types refuted the hypothesis of uniform functionality by suggesting the epithelium has different functions in each type of enclosure. Specifically, more enclosed pouches were observed to contain greater anatomical complexity and secretory function (Carcupino et al., 2002). Based on this positive correlation between the degree of pouch closure and male parental care (Berglund et al., 1986; Masonjones, 2001; Carcupino et al., 2002), the frequency of sex-role reversal across Syngnathidae was examined as a measure of female competition. The predicted relationship of frequent sex-role reversal in taxa with more enclosed brood pouches was not observed (Carcupino et al., 2002; Wilson et al., 2003).

Our comparison of two closely related, sympatric species, the northern pipefish Syngnathus fuscus and the dusky pipefish Syngnathus floridae, supports the rejection of brood pouch functional uniformity in Syngnathids, as well as provides a hypothesis for the lack of relationship between sex-role reversal and pouch structure. We propose pouch closure is not indicative of the degree of physiological allocation of nutrients by brooding males to embryos, but rather, brood pouch physiology varies between related species with similar brood pouch appearance. Brood enclosure for S. fuscus and S. floridae is intermediate 
within Syngnathids with two pouch folds sealing along the midline but not permanently fusing. Our species comparison of nutrient concentrations in mature, unfertilized eggs and newly released fry, brood pouch morphology and nutrient levels of fluid from inside the brood pouch and blood plasma were used to evaluate this hypothesis. Further, characterization of parental nutrient allocation to offspring examines the proposition of the progression of some species of Syngnathids toward complete sex reversal (Pagel, 2003).

\section{Materials and methods}

\section{Fish collection and population sex ratios}

We conducted Syngnathus fuscus (Storer, 1839) and Syngnathus floridae (Jordan and Gilbert, 1882) collections by seining in the seasonally abundant shallow eelgrass (Zostera marina) beds of the Chincoteague Bay, VA, USA from May-September 2003-2004. Seining events covered a distance of $25 \mathrm{~m}$ in approximately one minute using a $3.7 \mathrm{~m}$ by $1.2 \mathrm{~m}$ net with a $1.5 \mathrm{~m}^{2}$ bag and $0.4 \mathrm{~cm}^{2}$ mesh (Fish Net Company, Jonesville, LA, USA). Collected organisms were immediately sorted on a submerged platform and sex and species of pipefish

were noted. We calculated sex ratios for monthly collections yielding over 50 individuals by dividing the total number of males caught by the number of females for each species. All males with brood pouches and females larger than the recorded size for sexual maturation were included in this calculation (Teixeira and Musick, 1995). Initially, all adult males and females were retained for laboratory dissections while juveniles were held briefly in aerated tanks onboard the boat and returned before leaving the site. Once the data set neared completion, the developmental state of the brood was estimated by examining the embryos through the translucent pouch flap and only animals filling gaps in the data were collected from catches. Pipefish were held for a maximum of three days at the field station in aerated 
tanks with daily water changes. Adults were transported in Kordon ${ }^{\circledR}$ breathing bags

(Novalek Inc., Hayward, CA, USA) chilled with ice to the laboratory for tissue collection.

\section{Tissue collection and nutrient analysis}

In the laboratory, pipefishes were held in same sex groups of 10-12 fish in filtered 37.81 tanks maintained at $24 \pm 1^{0} \mathrm{C}$ on a $14 \mathrm{~h}: 10 \mathrm{~h}$ light:dark cycle (on 06:00: off 20:00).

Pipefish were given a recovery period of at least $16 \mathrm{~h}$ in the laboratory with food withheld for a minimum of $36 \mathrm{~h}$ during travel and acclimation. Fish were not fed prior to tissue collection to avoid influences on nutrient levels from food intake, or the lack thereof. All tissues were collected within 2 days of laboratory arrival. We anaesthsized pipefish with 3 -aminobenzoic acid ethyl ester (MS222; Sigma Aldrich, St. Louis, MO, USA) in saltwater until opercle movement ceased and the fish failed to respond to pinching the caudal peduncle. Pouch fluid from brooding and non-brooding males was collected with microcapillary tubes (Drummond Scientific Co., Broomall, PA, USA) by inserting the tube along the junction of the pouch flaps at the anterior of the brood pouch by the anus. The capillary tube could then be used to separate the pouch flaps and collect fluid from all areas of the brood pouch. In non-brooding males the pouch flaps are not fused and saltwater could mix with any secretions produced by the male. Pouch fluid was collected from these animals to determine how different this fluid is from the surrounding saltwater. Pouch fluid was immediately stored at $-80^{\circ} \mathrm{C}$ until analysis. Blood was collected from the heart of brooding and non-brooding males and females with heparinized microcapillary tubes. We transferred blood samples to microcentrifuge tubes containing $2 \mu \mathrm{l}$ of a $6.5 \mathrm{mg} \mathrm{mL}^{-1}$ solution of sodium heparin salt in water, and centrifuged at $21,000 \mathrm{~g}$ for 10 minutes at $4^{\circ} \mathrm{C}$. The plasma fraction was removed and stored in a microcentrifuge tube containing phenylmethylsulfonyl fluoride (PMSF, 99\% purity; Sigma Aldrich) at $-80^{\circ} \mathrm{C}$ until analysis. Brooding embryos and eggs were collected 
directly from the brood pouch or ovary, respectively, with fine point forceps. Developing embryos were anaesthsized with MS222 in saltwater. Before fry release, brooding males were isolated so that newly released fry could be collected with nets. They were then anaesthsized in MS222 in saltwater. For each brooding male in the study, 20 embryos or newly released fry (within $12 \mathrm{~h}$ ) were pooled and homogenized with $40 \mu \mathrm{l}$ of homogenization

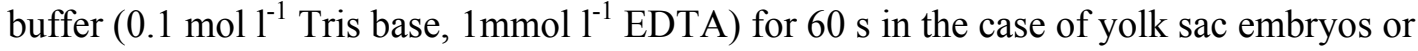
$120 \mathrm{~s}$ for late stage fry. Females with immature follicles that could not be removed intact from the ovary were termed immature females to distinguish them from gravid females with mature eggs that could be separated. From gravid females, 20 eggs were removed from the posterior section of the ovary. The pipefish ovary has been classified as an asynchronous type with follicles in all stages of development (Wallace and Selman, 1981; Begovac and Wallace, 1987). By collecting those closest to the ovipositor, the sample contained mature eggs ready for fertilization. Eggs were homogenized in buffer for $60 \mathrm{~s}$ and the homogenate centrifuged at $21,000 \mathrm{~g}$ for $30 \mathrm{~min}$ at $4^{\circ} \mathrm{C}$. The supernatant was removed and stored at $-80^{\circ} \mathrm{C}$ until analysis.

An additional sample of 5 eggs, embryos or fry from each fish were viewed with an Olympus SZ40 dissecting microscope (Melville, NY, USA) and photographed with a Spot Insight color camera (Diagnostic Instruments Inc., Sterling Heights, MI, USA; model 3.2.0). These samples were used to classify the stage of development of fertilized embryos. Mature, unfertilized eggs were considered stage 0. Embryonic development was divided into seven stages based on the presence of the embryo stripe (stage 1), development of eye spots and cups (stage 2), detachment of the tail from the yolk sac (i.e. hatched; stage 3), heart development (stage 4), presence of fins (stage 5), development of striped pigmentation (stage 6) and complete absorption of the yolk sac (stage 7). Newly released fry were classified as stage 8. Both S. fuscus and S. floridae embryos fitted these developmental stages with the 
distinction of S. floridae fry exhibiting longer snout lengths in states 6-8. In this study, these embryonic development classifications were considered distinct stages in place of specific time periods from the date of fertilization because observations indicated factors such as the number of embryos in the pouch, water temperature and male size influenced brooding periods (Berglund et al., 1989; Ahnesjö, 1992). Individuals of both species at every stage were included in our analysis. Egg diameter and standard length of newly released fry were measured with the software Image Pro Plus (Media Cybernetics, Silver Spring, MD, USA). We averaged the five measures for a single data point for each individual. Any excess eggs, embryos or fry collected were frozen or fixed in formalin for analysis in concurrent studies.

Nutrients, specifically proteins, lipids and carbohydrates, were measured in tissue samples as follows. Protein content was measured from dilutions of blood plasma (1:99), pouch fluid (1:99) and the supernatants from homogenized eggs (1:199) and fry (1:99). Total protein concentrations were determined using a Bio-Rad protein dye reagent and a standard curve of bovine serum albumin. The samples were transferred to a 96-well plate and read at 490nm by a Tecan GENios (Durham, NC, USA). Lipid content was determined by acidifying methanol/chloroform extracts, adding a vanillin reagent and comparing the sample to known amounts of soybean oil (Wheeler and Buck, 1992; Lotufo et al., 2000). Samples were analyzed at $595 \mathrm{~nm}$. Carbohydrate dilutions of 1:3 for all samples were quantified at 490nm using an anthrone assay and standards of sucrose (Van Handel, 1985; Wheeler and Buck, 1992). For each nutrient analysis, the sample was measured in triplicate and averaged for a single data point. Normality and homogeneity of data sets were assessed prior to the use of parametric statistics. All statistical analyses were performed with JMP 5.1. Variability measures calculated from these data can be used in power analyses to determine required sample sizes for future experiments. 


\section{Results}

Seines conducted in the Chincoteague Bay, VA, USA produced abundant catches of S. fuscus and S. floridae pipefishes. Sex ratio data indicate a heavily female-biased population for $S$. fuscus. The ratio of females to males differed significantly from 1:1 for $S$. fuscus $\left(\chi^{2}=147.717, \mathrm{P}<0.001\right.$; Fig. 1) but not for S. floridae $\left(\chi^{2}=0.949, \mathrm{P}=0.917\right.$; Fig. 1).

Analyses reveal comparable nutrient levels in S. floridae $(\mathrm{N}=6)$ and $S$. fuscus $(\mathrm{N}=7)$ fry at release (Table 1). However, protein (Fig. 2A, Table 1), lipid (Fig. 2B, Table 1) and carbohydrate (Fig. 2C, Table 1) reserves in unfertilized eggs of $S$. floridae $(\mathrm{N}=26)$ are significantly higher than in $S$. fuscus $(\mathrm{N}=16)$. Even though $S$. floridae females partitioned elevated levels of nutrients in eggs over $S$. fuscus, egg size ( $S$. fuscus, $0.87 \pm 0.27 \mathrm{~mm}, \mathrm{~N}=8$; S. floridae, $1.18 \pm 0.10 \mathrm{~mm}, \mathrm{~N}=12$ ) was comparable between species while the standard length of fry at release (S. fuscus, $10.18 \pm 0.28 \mathrm{~mm}, \mathrm{~N}=11 ;$ S. floridae, $11.74 \pm 0.20 \mathrm{~mm}$, $\mathrm{N}=10$ ) diverged with $S$. floridae producing significantly larger fry (2-way ANOVA, $\mathrm{F}=1482.06, \mathrm{P}<0.0001$; post-hoc Tukey HSD, $\mathrm{Q}=2.6898, \mathrm{P}<0.05)$.

Morphological observations of developing embryos held within the brood pouch of $S$. fuscus and S. floridae show a previously undescribed close association between fry and the pouch lining. Unlike most fish species in which the outer membrane hardens following fertilization to protect the embryo from water loss and environmental adversities, these pipefish embryos lack a rigid chorion (Jobling, 1995). In S. fuscus, the two flaps of the male brood pouch seal independently to the ventral body surface forming two chambers (Fig. 3A). Embryos are embedded under a clear membrane on the vascularized flaps of the brood pouch until release (Fig. 3A,B). Although most embryos develop at the same rate, one row on either side of the midline seal frequently remains underdeveloped relative to the rest of the brood. Limited vascularization and epithelial tissue in this region are likely to decrease the connectivity between embryos and the brood pouch. For $S$. floridae, the two flaps forming 
the pouch seal at the midline resulting in a single large brooding chamber (Fig. 3C). One side of the fertilized egg becomes strongly attached to the ventral flap of the pouch (Fig. 3C,D). As the yolk sac is absorbed, this connection dissolves and embryos are contained within the pouch. Undeveloped eggs and lipid droplets are found interspersed with embryos all at the same stage of development (Fig. 3D). When fry are released, a clear matrix similar in appearance to a honey comb and approximately the size of the pouch is also released. Overall our observations reveal differences between $S$. floridae and S. fuscus in the arrangement of undeveloped eggs and the connectivity of embryos to paternal tissue.

Nutrients potentially available for uptake by developing embryos were measured by determining protein, lipid and carbohydrate content of fluid collected from the pouch of brooding ( $\mathrm{N}=21$ per species) and non-brooding males ( $\mathrm{N}=15$ per species). When the two species are grouped together, brooding males with embryos in various developmental stages harbor pouch fluid rich in proteins (Table 2, Fig. 4A), lipids (Table 2, Fig. 4B) and carbohydrates (Table 2, Fig. 4C) relative to non-brooding males. Nutrient concentrations in the pouch fluid do not differ between males of the two species. However, in S. floridae, protein concentrations of the pouch fluid begin high for newly fertilized broods and decline rapidly over development (Table 3, Fig. 4A). A significantly more gradual decline characterizes the depletion of lipid from $S$. floridae pouch fluid (Table 3, Fig. 4B). Whereas carbohydrate content of pouch fluid for S. floridae and S. fuscus significantly decreased over embryonic development, species differences in this rate of decline were not observed (Table 3, Fig. 4C). To examine control of pouch fluid content in non-brooding males, nutrient levels were compared to saltwater containing MS222. Pouch fluid from non-brooding males of both species contained significantly higher protein, lipid and carbohydrate concentrations than saltwater with MS222 (Table 2). 
Blood plasma concentrations of total protein, lipids and carbohydrates are similar between brooding males and gravid females in both species. Considering species and reproductive state, significant differences in protein content were not detected (2-way ANOVA, $\mathrm{F}=1.9132, \mathrm{P}=0.0983$; Table 4). Furthermore, when plasma protein concentration was examined over embryonic development in brooding males, trends did not emerge in either species (S. fuscus, $\mathrm{R}^{2}=0.1017, \mathrm{P}=0.1480$, Slope=-1.5663; S. floridae, $\mathrm{R}^{2}=0.0868$, $\mathrm{P}=0.1529$, Slope $=-1.7106)$. There was a significant difference in lipid content of blood plasma with gravid females circulating lower lipid levels than non-brooding males (2-way ANOVA, $\mathrm{F}=3.2819, \mathrm{P}=0.0087$; post-hoc Tukey HSD, $\mathrm{Q}=2.3791, \mathrm{P}<0.05$; Table 4). In addition, S. floridae overall contain higher concentrations of plasma lipids than $S$. fuscus (post-hoc Student's t, t=1.9840, $\mathrm{P}<0.05$ ). Significant changes in plasma lipid content over the brooding period were not evident $\left(S\right.$. fuscus, $\mathrm{R}^{2}=0.0493, \mathrm{P}=0.2970$, Slope=-0.0701; $S$. floridae, $\mathrm{R}^{2}=0.0475, \mathrm{P}=0.3300$, Slope $=-0.0710$ ). Examination of plasma carbohydrate concentrations revealed brooding $S$. floridae had higher levels compared with brooding $S$. fuscus (2-way ANOVA, $\mathrm{F}=3.1526, \mathrm{P}=0.0110$; post-hoc Tukey $\mathrm{HSD}, \mathrm{Q}=2.9057, \mathrm{P}<0.05$; Fig. 5, Table 4). Again, examining changes over embryonic development yields no trends in plasma carbohydrate levels ( $S$. fuscus, $\mathrm{R}^{2}=0.0188, \mathrm{P}=0.5324$, Slope=-1.2927; S. floridae, $\mathrm{R}^{2}=0.0108, \mathrm{P}=0.6533$, Slope $=0.7158$ ). 
Table 1. Species comparisons of nutrient content of unfertilized eggs and newly released fry

\begin{tabular}{lccc}
\hline Nutrient $\left(\mathrm{mg} \mathrm{embryo}^{-1}\right)$ & \multicolumn{1}{c}{ Eggs } & Fry & Two-way ANOVA \\
\hline Protein & S. fuscus $<$ S. floridae & S. fuscus $\approx$ S. floridae & $\mathrm{F}=78.8973, \mathrm{P}<0.0001$ \\
Lipid & S. fuscus $<$ S. floridae & S. fuscus $\approx$ S. floridae & $\mathrm{F}=24.8992, \mathrm{P}<0.0001$ \\
Carbohydrate & S. fuscus $<$ S. floridae & S. fuscus $\approx$ S. floridae & $\mathrm{F}=9.2084, \mathrm{P}<0.0001$ \\
$\quad$ For all nutrient comparisons, the post-hoc Tukey HSD test was utilized $(\mathrm{Q}=2.6559, \mathrm{P}<0.05)$. & \\
\hline
\end{tabular}


Table 2. Relative nutrient content of the pouch fluid of brooding and non-brooding males

\begin{tabular}{|c|c|c|c|}
\hline Comparison & [Protein] $\left(\mathrm{mg} \mathrm{ml}^{-1}\right)$ & [Lipid] $\left(\mathrm{mg} \mathrm{ml}^{-1}\right)$ & [Carbohydrate] $\left(\mathrm{mg} \mathrm{ml}^{-1}\right)$ \\
\hline Brooding vs. Non-Brooding & $\begin{array}{l}\text { Brooding }>\text { Non-Brooding } \\
\text { S. fuscus } \approx S \text {. floridae }\end{array}$ & $\begin{array}{l}\text { Brooding }>\text { Non-Brooding } \\
\text { S. fuscus } \approx S \text {. floridae }\end{array}$ & $\begin{array}{l}\text { Brooding }>\text { Non-Brooding } \\
\text { S. fuscus } \approx S . \text { floridae }\end{array}$ \\
\hline Two-way ANOVA & $\mathrm{F}=5.9721, \mathrm{P}=0.0011$ & $\mathrm{~F}=3.7717, \mathrm{P}=0.0143$ & $\mathrm{~F}=4.3950, \mathrm{P}=0.0069$ \\
\hline Post-hoc Student's t & $\mathrm{t}=1.9935, \mathrm{P}<0.05$ & $\mathrm{t}=1.9944, \mathrm{P}<0.05$ & $\mathrm{t}=1.9950, \mathrm{P}<0.05$ \\
\hline $\begin{array}{l}\text { Non-Brooding vs. Saltwater } \\
\text { Student's t }\end{array}$ & Non-Brooding $>$ Saltwater & Non-Brooding $>$ Saltwater & Non-Brooding $>$ Saltwater \\
\hline $\begin{array}{l}\text { S. fuscus } \\
\text { S. floridae }\end{array}$ & $\begin{array}{l}\mathrm{t}=10.7035, \mathrm{P}<0.0001 \\
\mathrm{t}=6.7976, \mathrm{P}<0.0001\end{array}$ & $\begin{array}{l}\mathrm{t}=3.8613, P=0.0026 \\
\mathrm{t}=7.4050, P<0.0001\end{array}$ & $\begin{array}{l}\mathrm{t}=8.4348, \mathrm{P}<0.0001 \\
\mathrm{t}=6.1250, \mathrm{P}<0.0001\end{array}$ \\
\hline
\end{tabular}


Table 3. Regressions of nutrient concentrations in brood pouch fluid over the stages of embryonic development

\begin{tabular}{|c|c|c|c|c|c|c|c|c|}
\hline Nutrient $\left(\mathrm{mg} \mathrm{ml}^{-1}\right)$ & \multicolumn{3}{|c|}{ Syngnathus fuscus } & \multicolumn{3}{|c|}{ Syngnathus floridae } & \multicolumn{2}{|c|}{ F-test* } \\
\hline Lipid & 0.8073 & $<0.0001$ & -10.8902 & 0.6679 & $<0.0001$ & -7.4870 & 4.3495 & 0.0430 \\
\hline${ }^{*}$ F-test for homoge & $\mathrm{y}$ of regr & n slopes. & & & & & & \\
\hline
\end{tabular}


Table 4. Blood plasma concentrations of nutrients from adults collected in the Chincoteague Bay, VA, USA

\begin{tabular}{|c|c|c|c|c|c|c|}
\hline \multirow[b]{2}{*}{ Group } & \multicolumn{6}{|c|}{ Concentration $\left(\mathrm{mg} \mathrm{ml}^{-1}\right)$} \\
\hline & Protein & $\mathrm{N}$ & Lipid* & $\mathrm{N}$ & Carbohydrate $^{\dagger}$ & $\mathrm{N}$ \\
\hline \multicolumn{7}{|l|}{ Syngnathus fuscus } \\
\hline Gravid females & $33.51 \pm 0.64$ & 16 & $10.75 \pm 0.60$ & 15 & $3.04 \pm 0.44$ & 16 \\
\hline Females w/o mature eggs & $28.48 \pm 0.83$ & 18 & $12.07 \pm 0.77$ & 16 & $3.72 \pm 0.29$ & 16 \\
\hline Brooding males & $34.53 \pm 0.66$ & 25 & $12.12 \pm 0.64$ & 24 & $2.06 \pm 0.21$ & 23 \\
\hline Non-brooding males & $31.65 \pm 0.70$ & 18 & $14.80 \pm 0.64$ & 15 & $2.31 \pm 0.32$ & 15 \\
\hline \multicolumn{7}{|l|}{ Syngnathus floridae } \\
\hline Gravid females & $24.96 \pm 0.85$ & 15 & $11.68 \pm 0.65$ & 15 & $2.81 \pm 0.28$ & 16 \\
\hline Females w/o mature eggs & $18.07 \pm 0.96$ & 14 & $11.24 \pm 0.63$ & 12 & $3.35 \pm 0.39$ & 11 \\
\hline Brooding males & $31.17 \pm 0.71$ & 22 & $16.61 \pm 0.62$ & 22 & $3.47 \pm 0.26$ & 21 \\
\hline Non-brooding males & $31.44 \pm 0.80$ & 15 & $19.08 \pm 0.84$ & 15 & $2.54 \pm 0.23$ & 15 \\
\hline \multicolumn{7}{|c|}{$\begin{array}{l}\text { Values are mean } \pm \mathrm{SE} \text {; N, sample number. } \\
\text { "Two-way ANOVA reveals gravid females have higher circulating lipid levels than non-brooding males. Overall, S. floridae } \\
\text { plasma lipid concentrations are greater than that for S. fuscus. } \\
\text { See Fig. } 5 \text {. }\end{array}$} \\
\hline
\end{tabular}




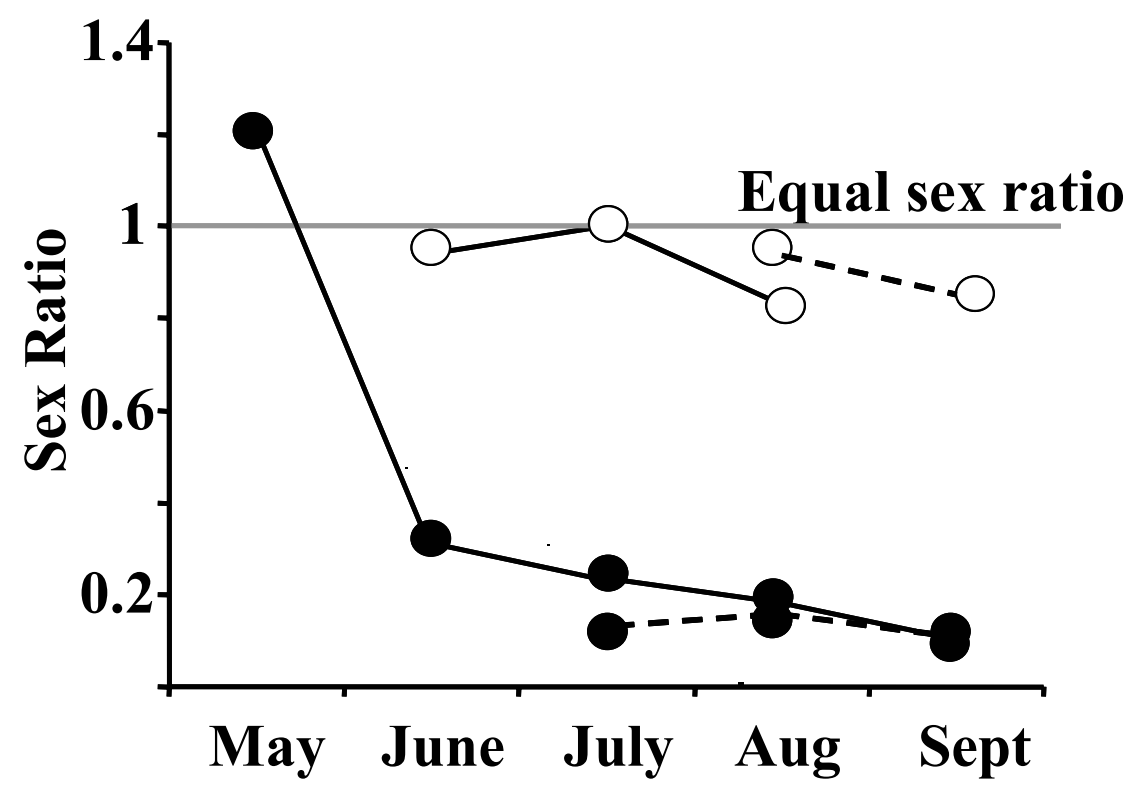

Fig. 1. Population sex ratios (number of males/number of females) for Syngnathus fuscus (black) and Syngnathus floridae (white) collected in the Chincoteague Bay, VA, USA during the 2003 (broken line) and 2004 (solid line) reproductive seasons. Sample sizes ranged from a minimum of 88 Syngnathus fuscus collected in September 2004 to 859 individuals of the same species counted in June 2004. 

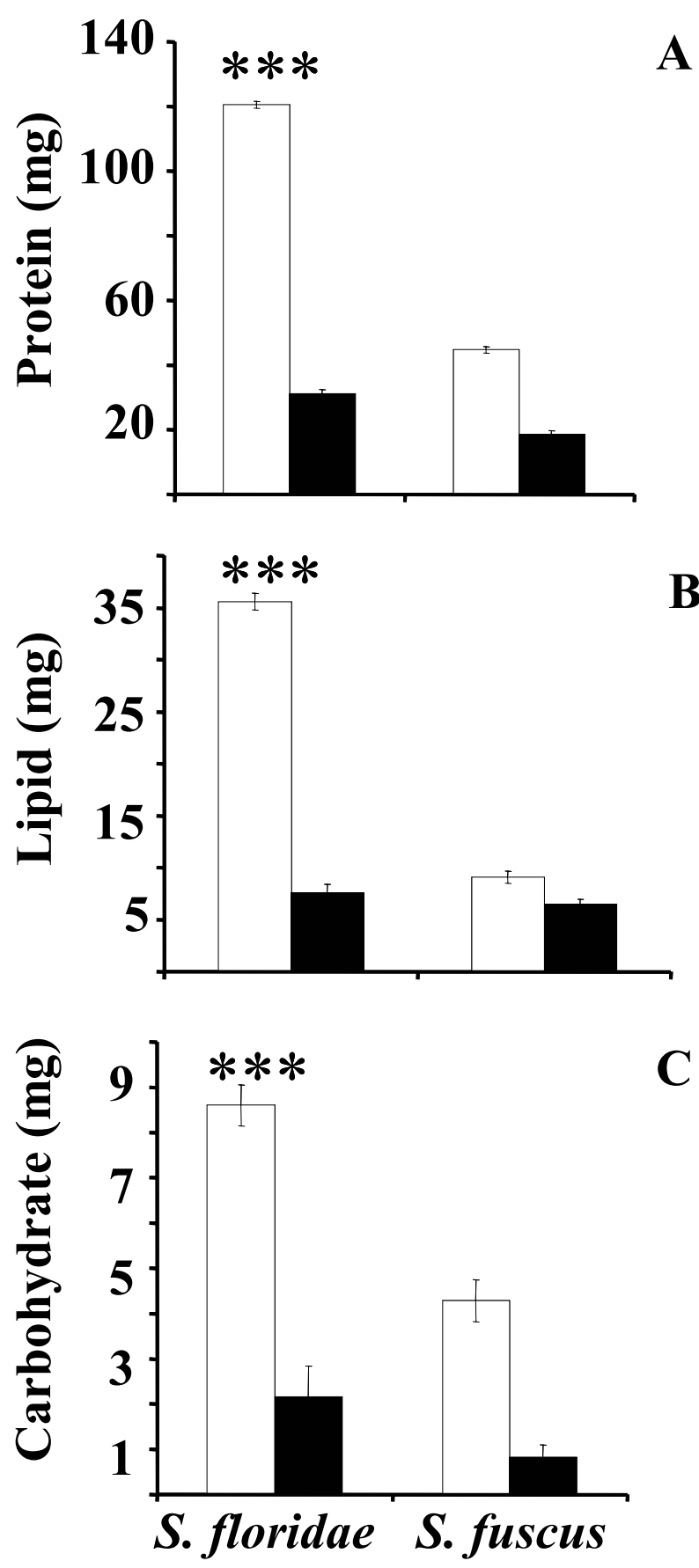

Fig. 2. (A) Protein, (B) lipid and (C) carbohydrate content of mature eggs (white) and released fry (black) from Syngnathus floridae (eggs, N=26; fry, N=6) and Syngnathus fuscus (eggs, N=16, fry, $\mathrm{N}=7$ ). Values are mean $\pm \mathrm{SE}$. For all comparisons, interspecific differences (asterisks) exist between eggs but not fry $(\mathrm{P}<0.0001)$. 


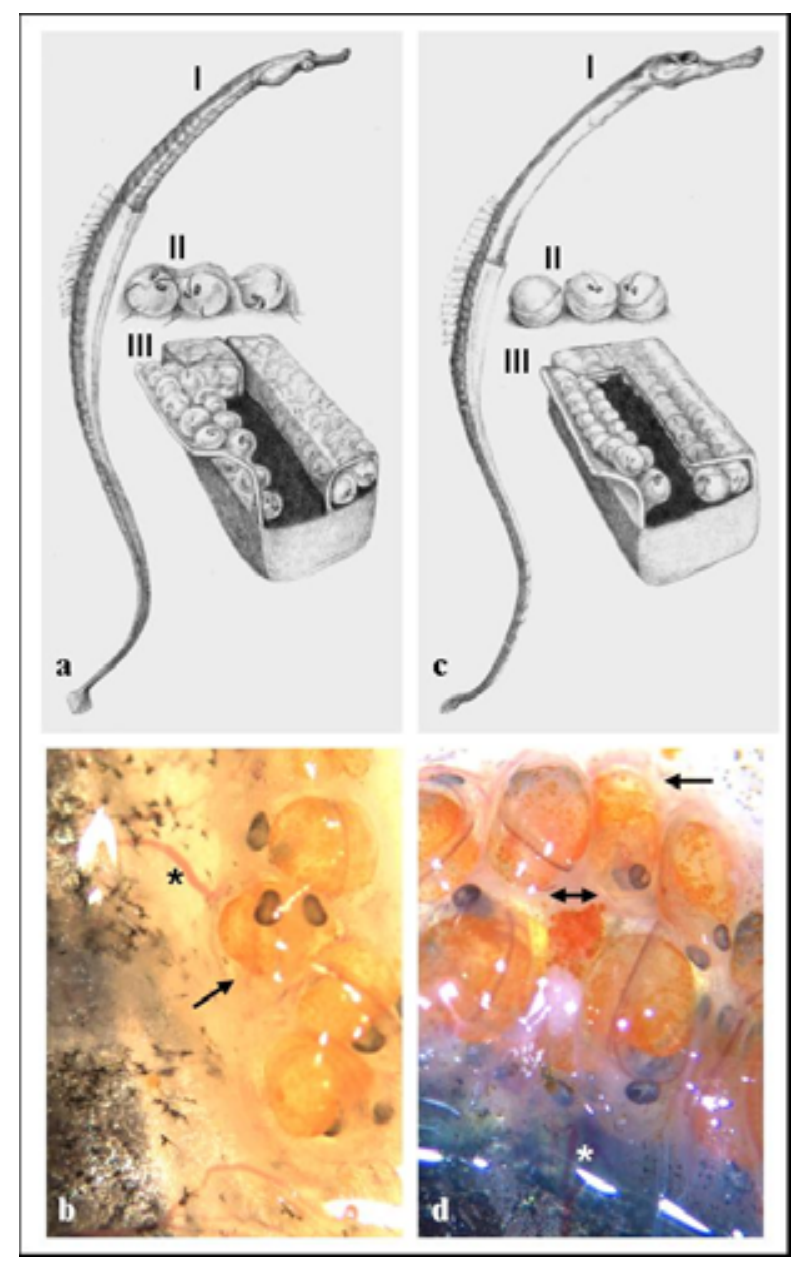

Fig. 3. Illustrations and photomicrographs depict morphological differences in the Syngnathus fuscus (A and B) and Syngnathus floridae (C and D) male brood pouch. (A) Syngnathus fuscus are distinguished by their shorter snout length (I) and enclosure of developing embryos underneath a pouch-derived epithelium (II). Males form an enclosed brood pouch by the attachment of each flap to the ventral surface of the animal (III). (B) Blood vessels (asterisk) transverse the pouch flaps in close proximity to embedded developing embryos (arrow). (C) Syngnathus floridae, with the longer snout (I), attach embryos on only one face (II) to the pouch flap. The two flaps that form the pouch seal at the midline (III). (D) Lipid droplets (doublesided arrow) are distinguishable in the pouch secretions, while blood vessels (asterisk) pass below the embryo connection to the pouch flap (arrow). 


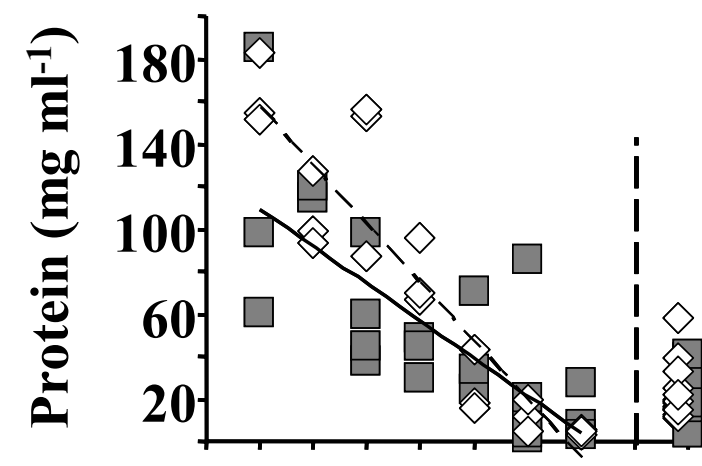

A

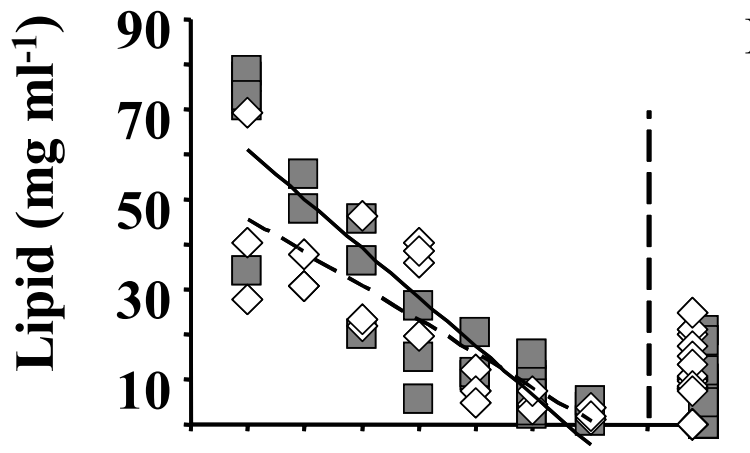

B

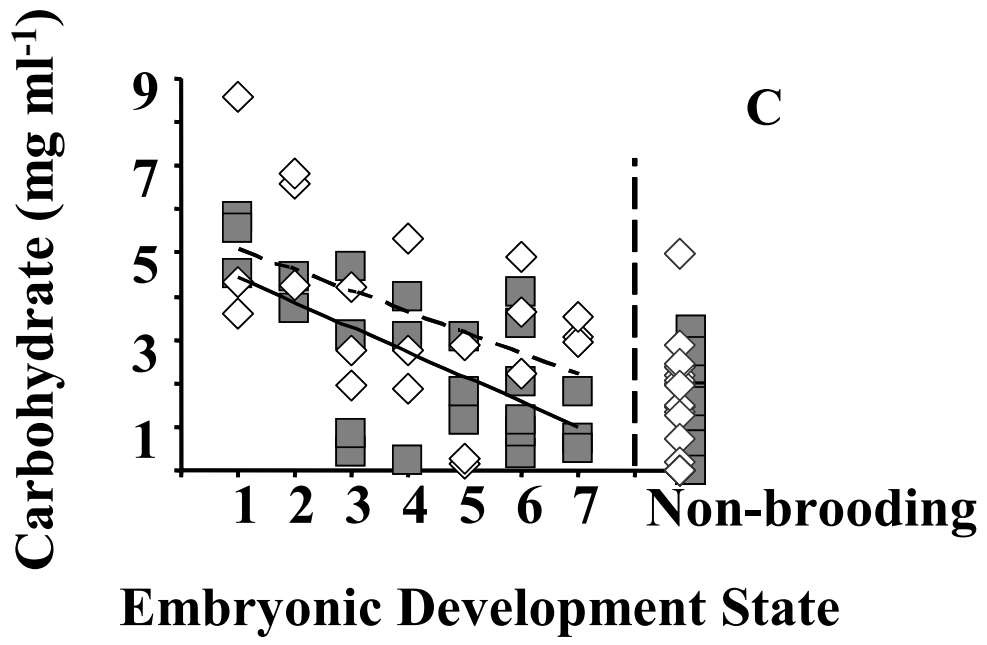

Fig. 4. Changes in (A) protein, (B) lipid, and (C) carbohydrate concentrations in the pouch fluid of Syngnathus fuscus (gray squares; solid line) and Syngnathus floridae (white diamonds; broken line) across the progression of embryonic development. For both species, nutrient levels significantly decline in pouch fluid over the seven stages of development $(\mathrm{P}<0.05)$. The decrease in protein occurs at a steeper rate for Syngnathus floridae, while lipid concentrations drop more quickly in Syngnathus fuscus (both $\mathrm{P}<0.05$ ). 


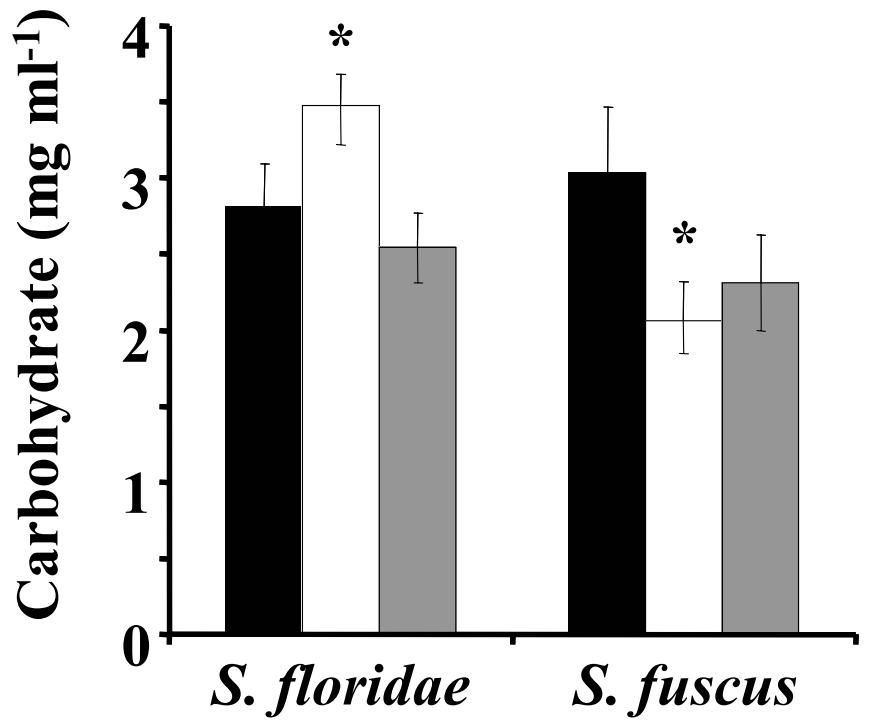

Fig. 5. Circulating carbohydrate levels in blood plasma of gravid females (black bars), brooding males (white bars) and non-brooding males (grey bars). Values are means \pm SE. An asterisk indicates a significant difference between groups $(\mathrm{P}<0.05)$. 


\section{Discussion}

Our comparison reveals $S$. fuscus and S. floridae possess different balances in the dependence on maternal and paternal resources for embryonic development. Nutrients are normally lost during development due to the incomplete conversion of proteins and lipids into body tissue as they are used as metabolic fuels (Jobling, 1995). Indeed, lower concentrations of proteins, lipids and carbohydrates were measured in fry than eggs of both species. Still, significant species differences in the nutrient reserves of eggs indicate $S$. floridae embryos are more adequately supplied by the egg. Female $S$. fuscus produce eggs with considerably less nutrients than $S$. floridae, which must be balanced by elevated paternal provisioning. These observations of S. fuscus follow predictions of evolutionary theory and the progression to complete sex reversal (Pagel, 2003).

The paternal brood pouch serves as a source of nutritional supplementation during development for both species by bathing embryos in a fluid rich in macronutrients. Since the chorion is absent, nutrients and hormones may be readily absorbed without this "egg shell." Differences between seawater and pouch fluid indicate concentrations of proteins, lipids and carbohydrates in the pouch can be regulated physiologically. Pouch fluid nutrients are nearly depleted over the brooding period. These decreases may reflect changes in the male's contribution, providing less to fry as they approach release, or a change in utilization of the pouch fluid by the embryos, increasing intake in relation to reduced yolk reserves. In placental sharks, embryos are initially reliant on yolk reserves sequestered in the egg until maternal supplementation is activated (Hamlett et al., 1987, 1993). A comparable series of events likely transpires in pipefish. Our study shows that species differ in the rate of decline of pouch fluid nutrients. The presence of yolk droplets floating in the pouch of $S$. floridae suggests utilization 
of "nurse eggs," or release from fertilized embryos, provides a nutrient source in pouch fluid. Conversely, paternal contribution is more pronounced in $S$. fuscus with males encompassing relatively nutrient-poor eggs in epithelia supplied by a well defined brood pouch vasculature. The steep nutrient drop in the pouch fluid over embryonic development corresponds with differential use of protein from nurse eggs in S. floridae and lipids provided by the brooding male in S. fuscus. A level supply of protein across $S$. fuscus development is consistent with males continually secreting nutrients into the brood pouch. However the steeper drop in lipids may reflect dependence of S. fuscus embryos on brood pouch secretions for metabolic fuel. For both species, fry are released once paternal resources are exhausted.

Undeveloped nurse eggs in the S. floridae brood pouch are believed to have originated from overripe oocytes (Teixeira and Vieira, 1995). Other Syngnathid species frequently possess undeveloped eggs as well. In Syngnathus typhle, these eggs and less developed embryos attach to the placenta-like structure in the pouch (Ahnesjö, 1992). The presence of lipid cells in the pouch epithelium of the seahorse Hippocampus brevirostris has led to the suggestion that egg yolk can be re-absorbed (Rauther, 1925). From these observations, the Syngnathid pouch fluid is believed to be at least partially derived from nurse eggs. Specifically, the protein hormone, prolactin, is released in the pouch causing enzymatic breakdown of the egg to form a placental fluid (Boisseau, 1967; Ahnesjö, 1996). In pipefish, the presence of undeveloped eggs in the brood pouch is more likely to indicate that a nurse egg system is being employed rather than eggs simply not being fertilized. Internal fertilization in these species involves sperm released into the pouch, and therefore, the rate of fertilization is high (Fielder, 1954). Employing a nurse egg system in S. floridae and thus decreasing paternal nutrient allocation may translate into a 
more equal sex ratio, as well as higher circulating nutrient concentrations for brooding $S$. floridae males over S. fuscus.

The matrix construct observed with fry release in $S$. floridae may be a structure produced by the male during brooding to support developing embryos. In two Stigmatopora pipefish, males incur an additional energetic cost in making membranous egg-holding compartments within the brood pouch. These specialized structures are not present in the non-brooding $S$. floridae males or Stigmatopora, implying this structure must be rebuilt every time a male broods (Berglund et al., 1986; Steffe et al., 1989). The functional significance of this matrix has yet to be explored.

A different embryonic supplementation mechanism revealed by our study involves a paternally-derived, nutrient-rich pouch fluid. S. fuscus brood pouch flaps show epithelial coverings and extensive vascularization that are only visible when males are brooding. Histological examinations show similar morphological changes in the pouch wall concurrent with brooding in several Syngnathids (Lockwood, 1867; Huot, 1902; Steffe et al., 1989; Carcupino et al., 1997, 2002; Drozdov et al., 1997). Most commonly noted is the development and growth of capillaries in the epithelium of the pouch walls (Gill, 1905; Thevenin, 1936; Carcupino et al., 1997; Drozdov et al., 1997). Carcupino et al. (2002) hypothesized that nutrients may be transferred from the paternal blood to the pouch by transcytosis or may be synthesized or modified in the epithelial cells. In S. abaster, large intercellular spaces form at the bases of epithelial cells functioning as a "freeway" to facilitate the passage of molecules from capillaries to the lumen of the pouch (Carcupino et al., 1997). Accordingly, we believe profusion of blood vessels in the pouch flaps and implantation of embryos adjacent to these vessels is evidence for paternal provisioning in S. fuscus. 
Blood plasma nutrient levels provide further evidence of greater paternal investment in $S$. fuscus. We document equivalent plasma nutrient levels between brooding males and conspecific gravid females, suggesting brooding males incur a cost for parental care in both species. A study on threespine sticklebacks measuring lipid, glycogen and protein found the concentrations of all these substances peaked at the beginning of the breeding season. At the end of the season, males that brooded had lower energy reserves and higher mortality rates than males that did not breed (Chellappa et al., 1989). Thus, low nutrient levels in spawning fish indicate allocation to gamete production and/or parental care. Our data reveal circulating carbohydrate concentrations are lower for brooding S. fuscus males when compared to S. floridae. Because the pipefish diet is nearly exclusively comprised of proteins and lipids, carbohydrate levels are a measure of the availability of metabolic fuel (Ryer and Boehlert, 1983; Huh, 1986; Jobling, 1995). Lower concentrations in S. fuscus are indicative of the higher metabolic cost of brooding.

Our data concerning egg and fry size support the hypothesized paternal provisioning mechanisms suggested by the adult nutrient analyses. If changes in weight from egg to fry state are considered for species with various modes of development, viviparous organisms commonly loose up to $50 \%$ in weight, oviparous $20-30 \%$ and matrotrophic oviparous gain $11-369 \%$ (Needham, 1942; Amoroso, 1960; Hamlett et al., 1993). Rather than note weight changes, we examined alterations in nutrient levels. The difference in nutrient stores between mature, unfertilized eggs and released fry was always greater for S. floridae. When compared to $S$. fuscus, the nutrient declines in S. floridae were greater in magnitude by 2.4 for protein, 9.6 for lipids and 0.9 for carbohydrates. Considering the brood period for both species overlap (personal observation; Bigelow and Schroeder, 1953), S. fuscus would necessarily acquire more nutrients from the pouch fluid. 
Brooding in Syngnathids has been described as carrying a cost of parental care which exceeds that of most vertebrates (Breder and Rosen, 1966; Clutton-Brock and Vincent, 1991). Within this family, it has been stated that species with less complex brood pouches spend less energy brooding young than do males with more enclosed pouches (Berglund et al., 1986; Masonjones, 2001; Carcupino et al., 2002). Although the physiological cost of parental care is not equivalent to parental investment in offspring, energy expenditures may be positively correlated with parental care in many cases (Wilson et al., 2003). Higher costs of parental care are likely to be reflected in a lower frequency of potential mates, and therefore a skewed operational sex ratio in breeding populations (Trivers, 1975; Clutton-Brock and Vincent, 1991; Gwynne, 1991). Defined as the ratio of fertilizable females to sexually active males, the operational sex ratio is dependent upon several factors in addition to differences in parental care, including spatial and temporal clumping of the limited sex and life history differences between the sexes (Emlen, 1976; Emlen and Oring, 1977; Berglund and Rosenqvist, 1993; Andersson, 1994). Hence, if other factors are constant or very similar, paternal nutrient provisioning and the cost of reproduction for male Syngnathids should be reflected in sex ratios. Breeding populations of the two species in this study overlap spatially and temporally. Although we cannot completely rule out other factors, a significant difference in the proportion of wild-caught adult males between $S$. fuscus and S. floridae breeding populations suggests higher relative paternal energy expenditure in S. fuscus. The costs of parental care and parental investment to brooding offspring in these species need to be tested through an examination of lifetime reproductive success.

If, as we have suggested from our data, $S$. fuscus males contribute a greater proportion of parental care than S. floridae males, we predict a corresponding divergence in sex roles, mating 
competition and the evolution of secondary sexual characteristics between these species. Some of these predictions are supported by accounts in the literature. S. fuscus females are reported to roam a larger area and to develop dimorphic banding coloration to find and attract mates (Roelke and Sogard, 1993; Berglund et al., 1997; Bernet et al., 1998). More balanced investment in progeny between the sexes in S. floridae predicts comparable reproductive rates for males and females. The sexes would not be expected to evolve strongly dimorphic behaviors and traits in this species, and descriptions of S. floridae report no obvious secondary sexual characters (Jones and Avise, 2001). Regardless of these accounts, the behavioral ecology of these species needs to be studied to support the above hypothesis.

Our results highlight the importance of basic reproductive physiology in understanding the functional significance of the brood pouch. The location and enclosure of the male brood pouch defines primary taxonomic groupings (Dunker, 1915; Herald, 1959). In general, Syngnathid phylogeny is largely based on the three paternal brood pouch types (Herald, 1959; Wilson et al., 2001). Our comparison reveals physiology differs considerably within a pouch type. Perhaps both phylogeny and taxonomy should be reinvestigated with more detailed reproductive physiological data. Syngnathids offer a plethora of opportunities to explore the evolution of placental-like structures and their role in development (Milius, 2000). Connectivity of embryos to the brood pouch of S. floridae and S. fuscus differs considerably, and the physiological mechanism for this distinction may provide a greater understanding of selective pressures for parental investment. The comparison of the eggs from these two species provides evidence of female restriction in gametic provisioning. Our results imply that female allocation to offspring in oviviparous animals can be altered with relative selective pressure. Since females are defined through the production of large, nutrient-laden gametes, a decrease in egg nutrient 
content represents the logical progression from a sex-role reversed to a fully sex-reversed species (Pagel, 2003). The comparison of S. fuscus and S. floridae offers unique insight into the evolution of mechanisms of parental care, and provides an interesting mechanism to explore the distinction between the sexes based on gamete production. 


\section{References}

Ahnesjö, I. (1992). Consequences of male brood care: weight and number of newborn in a sex-role reversed pipefish. Funct. Ecol. 6, 274-281.

Ahnesjö, I. (1996). Apparent resource competition among embryos in the brood pouch of a male pipefish. Behav. Ecol. Sociobiol. 38, 167-172.

Alexander, R. D. and Borgia, G. (1979). On the origin and basis of the male-female phenomenon. In Sexual Selection and Reproductive Competition in Insects (ed. M. F. Blum and N. Blum), pp. 417-440. New York: Academic Press.

Amoroso, E. C. (1960). Viviparity in fishes. Symp. Zool. Soc. (Lond) 1, 153-181.

Andersson, M. (1994). Sexual Selection. Princeton, NJ, USA: Princeton University Press.

Azzarello, M. Y. (1991). Some questions concerning the Syngnathidae brood pouch. Bull. Mar. Sci. 49, 741-747.

Begovac, P. C. and Wallace, R. A. (1987). Ovary of the pipefish, Syngnathus scovelli. J. Morph. 193, 117-133.

Berglund, A. and Rosenqvist, G. (1993). Selective males and ardent females in pipefishes. Behav. Ecol. Socio. 32, 331-336.

Berglund, A., Rosenqvist, G. and Svensson, I. (1986). Reversed sex roles and parental energy investment in zygotes of two pipefish (Syngnathidae) species. Mar. Ecol. Prog. Ser. 29, 209-215.

Berglund, A., Rosenqvist, G. and Svensson, I. (1989). Reproductive success of females limited by males in two pipefish species. Amer. Nat. 133, 506-516.

Berglund, A., Rosenqvist, G. and Bernet, P. (1997). Ornamentation predicts reproductive success in female pipefish. Behav. Ecol. Socio. 40, 145. 
Bernet, P., Rosenqvist, G. and Berglund, A. (1998). Female-female competition affects female ornamentation in the sex-role reversed pipefish Syngnathus typhle. Behaviour 135,535 .

Bigelow, H. B. and Schroeder, W. C. (1953). Fishes of the Gulf of Maine. US Fish. Bull. 53, $1-597$.

Boisseau, J. (1967). Les Regulations Hormonales de l'Incubations Chez un Vertebre Male: Recherches Sur la Reproduction de l'Hippocampe. DSc thesis, University of Bordeaux.

Breder, C. M. and Rosen, D. E. (1966). Modes of Reproduction in Fishes. New York: Natural History Press.

Carcupino, M., Baldacci, A., Mazzini, M. and Franzoi, P. (1997). Morphological organization of the male brood pouch epithelium of Syngnathus abaster Risso (Teleostea, Syngnathidae) before, during, and after egg incubation. Tissue Cell 29, 21-30.

Carcupino, M., Baldacci, A., Mazzini, M. and Franzoi, P. (2002). Functional significance of the male brood pouch in the reproductive strategies of pipefishes and seahorses: a morphological and ultrastructural comparative study on three anatomically different pouches. J. Fish Biol. 61, 1465-1480.

Chellappa, S., Huntingford, F. A., Strang, R. H. C. and Thomson, R. Y. (1989). Annual variation in energy reserves in male three-spined stickleback, Gasterosteus aculeatus L. (Pisces, Gasterostidae). J. Fish Biol. 35, 275-286.

Clutton-Brock, T. H. and Vincent, A. C. (1991). Sexual selection and the potential reproductive rates of males and females. Nature 351, 58-60.

Drozdov, A. L., Kornienko, E. S. and Krasnolutsky, A. V. (1997). Reproduction and development of Syngnathus acusimils. Rus. J. Mar. Biol. 23, 265-268. 
Duncker, G. (1915). Revision der Syngnathidae. Jahrbuch der Hamburgischen Wissenschaftlichen Antalten 32, 9-120.

Emlen, S. T. (1976). Lek organization and mating strategies in the bullfrog. Behav. Ecol. Socio. 1, 283-313.

Emlen, S. T. and Oring, L. W. (1977). Ecology, sexual selection, and the evolution of mating systems. Science 197, 215-223.

Fiedler, K. (1954). Vergleichende Verhaltensstudien an Seenadeln, Schangennadeln und Seepferdchen (Syngnathidae). Z. Tierpsychol. 11, 358-416.

Gill, T. (1905). The life history of the sea-horses (Hippocampids). Proc. US Natl. Mus. 28, 805-814.

Gross, M. R. and Shine, R. (1981). Parental care and mode of fertilization in ectothermic vertebrates. Evolution 35, 775-793.

Gwynne, D. T. (1991). Sexual competition among females: what causes courtship role reversal? Trends Ecol. Evol. 6, 118-121.

Hamlett, W. C., Schwartz, F. J. and DiDio, L. J. A. (1987). Subcellular organization of the yolk syncytial-endoderm complex in the preimplantation yolk sac of the shark, Rhizoprionodon terraenovae. Cell Tissue Res. 247, 275-285.

Hamlett, W. C., Eulitt, A. M., Jarrell, R. L. and Kelly, M. A. (1993). Uterogestation and placentation in elasmobranches. J. Exp. Zool. 266, 347-367.

Haresign, T. W. and Schumway, S. E. (1981). Permeability of the marsupium of the pipefish Syngnathus fuscus to [14C]-alpha animo isobutyric acid. Comp. Biochem. Physiol. 69A, 603-604. 
Helfman, G. S., Collette, B. B. and Facey, D. E. (1997). The Diversity of Fishes. Malden, MA, USA: Blackwell Science.

Herald, E. S. (1959). From pipefish to seahorse - a study of phylogenetic relationships. Proc. Calif. Acad. Sci. 29, 465-473.

Huh, S. H. (1986). Ontogenetic food habits of four common fish species in seagrass meadows. J. Ocean. Soc. Korea 21, 25-33.

Huot, A. (1902). Recherches sur les poisons lophobranches. Ann. Sci. Nat. (Zool) 8, $197-$ 288.

Jobling, M. (1995). Environmental Biology of Fishes. New York, NY, USA: Chapman and Hall.

Jones, A. G. and Avise, J. C. (1997). Microsatellite analysis of maternity and the mating system in the Gulf pipefish Syngnathus scovelli, a species with male pregnancy and sexrole reversal. Mol. Ecol. 6, 203-213.

Jones, A. G. and Avise, J. C. (2001). Mating systems and sexual selection in male-pregnant pipefishes and seahorses: insights from microsatellite-based studies of maternity. $J$. Hered. 92, 150-158.

Jones, A. G., Kvarnemo, C., Moore, G. I., Simmons, L.W. and Avise, J. C. (1998). Microsatellite evidence for monogamy and sex-biased recombination in the Western Australian seahorse Hippocampus angustus. Mol. Ecol. 7, 1497-1505.

Jones, A. G., Rosenqvist, G., Berglund, A. and Avise, J. C. (1999). The genetic mating system of a sex-role-reversed pipefish (Syngnthus typhle): a molecular inquiry. Behav. Ecol. Socio. 46, 357-365. 
Jordan, D. S. and Gilbert, C. H. (1882). Notes on fishes observed about Pensacola, Florida, and Galveston, Texas with descriptions of new species. Proc. US Natl. Mus. 241-272.

Linton, J. R. and Soloff, B. L. (1964) The physiology of the brood pouch of the male seahorse, Hippocampus erectus. Bull. Mar. Sci. Gulf Caribb. 14, 45-61.

Lockwood, S. (1867). The seahorse (Hippocampous hudsonius) and its young. Amer. Nat. 1, 225-234.

Lotufo, G. R., Farrar, J. D. and Bridges, T. S. (2000). Effects of exposure source, worm density, and sex on DDT bioaccumulation and toxicity in the marine polychaete Neanthes arenaceodentata. Environ. Toxicol. Chem. 19, 472-484.

Masonjones, H. D. (2001). The effect of social context and reproductive status on the metabolic rates of dwarf seahorses (Hippocampus zosterae). Comp. Biochem. Physiol. 129A, 541-555.

Mayer, I., Rosenqvist, G., Borg, B., Ahnesjö, I., Berglund, A. and Schulz, R. W. (1993). Plasma levels of sex steroids in three species of pipefish (Syngnathidae). Can. J. Zool. 71, 1903-1907.

Maynard-Smith, J. (1978). The Evolution of Sex. Cambridge: Cambridge University Press. Milius, S. (2000). Pregnant and still macho. Sci. News 157, 168.

Morrell, V. (2002). Placentas may nourish complexity studies. Science 298, 945.

Needham, J. (1942). Biochemistry and Morphogenesis. Cambridge: Cambridge University Press.

Pagel, M. (2003). Evolutionary biology: polygamy and parenting. Nature 424, 23-24.

Parker, G. A., Baker, R. R. and Smith, V. G. F. (1972). The origin and evolution of gamete dimorphism and the male-female phenomenon. J. Theor. Biol. 36, 181-198. 
Quast, W. D. and Howe, N. R. (1980). The osmotic role of the brood pouch in the pipefish Syngnathus scovelli. Comp. Biochem. Physiol. 67A, 675-678.

Rauther, M. (1925). Die Syngnathiden des Golfes von Neapel. Fauna Flora Golfo Napoli Monograph., 36.

Resnick, D. N., Mateos, M. and Springer, M. S. (2002). Independent origins and rapid evolution of the placenta in the fish genus Poeciliopsis. Science 298, 1018-1020.

Roelke, D. L. and Sogard, S. M. (1993). Gender-based differences in the habitat selection and activity level in the northern pipefish (Syngnathus fuscus). Copeia 1993, 528.

Ryer, C. H. and Boehlert, G. W. (1983). Feeding chronology, daily ration, and the effects of temperature upon gastric evacuation in the pipefish, Syngnathus fuscus. Environ. Biol. Fishes 6, 301-306.

Steffe, A. S., Westoby, M. and Bell, J. D. (1989). Habitat selection and diet in two species of pipefish from seagrass: sex difference. Mar. Ecol. Prog. Ser. 55, 23-30.

Stewart, J. R. (1992). Placental structure and nutritional provision to embryos in predominantly lecithotrophic vivparous reptiles. Amer. Zool. 32, 303-312.

Storer, D.H. (1839). A report on the fishes of Massachusetts. Boston J. Nat. Hist. 289-558.

Svensson, I. (1988). Reproductive costs in two sex-role reversed pipefish species (Syngnathidae). J. Anim. Ecol. 57, 929-942.

Teixeira, R. L. and Musick, J. A. (1995). Trophic ecology of two congeneric pipefishes (Syngnathidae) of the lower York River, Virginia. Envir. Biol. Fishes 43, 295-309.

Teixeira, R. L. and Vieira, J. P. (1995). The breeding population of the pipefish, Syngnathus folletti (Pisces: Syngnathidae) from Southern Brazil. Atlantica 17, 123-134.

Thevenin, R. (1936). The curious life habits of the sea horse. Nat. His. 1936, 211-222. 
Trivers, R. L. (1972). Parental Investment and Sexual Selection. In Sexual Selection and the Descent of Man, 1871-1971 (ed. B. Campbell), pp. 136-179. Chicago, IL, USA: AldineAtherton.

Trivers, R. L. (1975). Social Evolution. Menlo Park, CA, USA: Benjamin Cummings.

Van Handel, E. (1985). Rapid-determination of glycogen and sugars in mosquitoes. J. Amer. Mos. Cont. Assoc. 1, 299-301.

Vincent, A., Ahnesjö, I., Berglund, A. and Rosenqvist, G. (1992). Pipefishes and seahorses: are they all sex role reversed? Trends Ecol. Evol. 7, 237-241.

Wallace, R. A. and Selman, K. (1981). Cellular and dynamic aspects of oocyte growth in teleosts. Amer. Zool. 21, 325-343.

Watanabe, S., Kaneko, T. and Watanabe, Y. (1999). Immunocytochemical detection of mitochondria-rich cells in the brood pouch epithelium of the pipefish, Syngnathus schlegeli: structural comparison with mitochondria-rich cells in the gills and larval epidermis. Cell Tissue Res. 295, 141-149.

Wheeler, D. E. and Buck, N. A. (1992). Protein, lipid and carbohydrate use during metamorphosis in the fire ant, Solenopsis xyloni. Physiol. Entomol. 17, 397-403.

Williams, G. C. (1966). Adaptation and Natural Selection. Princeton, NJ, USA: Princeton University Press.

Williams, G. C. (1975). Sex and Evolution. Princeton, NJ, USA: Princeton University Press.

Wilson, A. B., Vincent, A., Ahnesjö, I. and Meyer, A. (2001). Male pregnancy in seahorses and pipefishes (family Syngnathidae): rapid diversification of paternal brood pouch morphology inferred from a molecular phylogeny. J. Hered. 92, 159-166. 
Wilson, A. B., Ahensjö, I., Vincent, A. C. J. and Meyer, A. (2003). The dynamics of male brooding, mating patterns, and sex roles in pipefishes and seahorses (family Syngnathidae). Evolution 57, 1374-1386. 
Chapter IV: Comparison of Parental PCB Exposure on Nutrient Allocation to Egg Production and Developing Embryos in the Placenta-like Paternal Brood Pouch of Two Pipefishes 


\begin{abstract}
Male pipefishes and seahorses of the family Syngnathidae carry developing embryos from fertilization until the fry are free-swimming in a specialized organ commonly referred to as the brood pouch. Because of the potential for lipophilic contaminants to be transferred to developing pipefish through the paternal brood pouch, pipefish are likely to be exposed to contaminants during critical stages of development analogous to human in utero exposure. In an earlier study, we uncovered differences in the relative parental nutrient contribution between two related pipefish species. Syngnathus fuscus males compensate for the production of nutrientpoor eggs by implanting embryos adjacent to pouch blood vessels. In Syngnathus floridae females produce nutrient-laden eggs some of which males utilize as nurse eggs. Based on these differences, we hypothesized that PCB exposure during brooding would exhibit a greater effect on the development of S. fuscus while exposure during egg production would have a greater impact on S. floridae females. We exposed laboratory-mated brooding males and field-collected females to mid-range environmental concentrations of the PCB mixture Aroclor 1254. Protein, lipid, and carbohydrate concentrations in adult blood plasma, paternal pouch fluid, and fry and eggs were quantified to assess the influence of PCB treatment. We found increased plasma protein and lipid levels in gravid females of both species and S. fuscus males, suggesting altered metabolic demands. Pouch fluid protein and lipid concentrations also declined with Aroclor 1254 treatment in S. fuscus. Regardless of changes in parental measures, PCB exposure did not alter the nutrient reserves of $S$. fuscus eggs or fry. Yet, fry standard length decreased. The first samples from S. fuscus indicate this species is more sensitive than S. floridae to Aroclor 1254. Pipefish, in particular S. fuscus, provide a unique model to investigate developmental impairment from placental exposure.
\end{abstract}




\section{Introduction}

Polychlorinated biphenyls (PCBs) are among the most prevalent classes of environmental pollutants worldwide (Damstra et al., 2002). This group of 209 congeners were used in large quantities as capacitor dielectrics, transformer coolants, lubricants, hydraulic fluids, plasticizers, and flame retardants (Schwarzenbach et al., 1993; Kime, 2001). Widespread industrial manufacture from 1929 until 1980 in the United States and Europe produced 1.2 million metric tons (Schwarzenbach et al., 1993; Kime, 2001). PCBs are lipophilic and highly resistant to degradation. These compounds persist in animal and environmental reservoirs and bioamplify through the food chain, ultimately depositing in lipid-rich human tissues (Schwarzenbach et al., 1993; Kime, 2001). Despite the ban on production, sale, and import of PCBs into North America since 1978, they are still ubiquitous in the environment (Wassermann et al., 1979; Laden et al., 1999; Dekoning and Karmaus, 2000).

Human PCB exposure occurs through environmental accidents, dietary intake, and in utero (Polishuk et al., 1977; Brown et al., 1994; Guo et al., 1994; Stewart et al., 1999). Long term exposure has been associated with an increased incidence of cancers (Brouwer et al., 1999), developmental changes (Sher et al., 1998), and endocrine disruption (Colborn et al., 1993). Due to heightened developmental sensitivity and concentrated placental transfer, PCB exposure has been demonstrated to be a greater health threat to fetuses than adults (Guo and Lambert, 1995; Dekoning and Karmaus, 2000). Reported effects in infants include reduced birth weight and postnatal growth (Fein et al., 1984; Rylander et al., 1996; Patandin et al., 1998; Kimbrough and Krouskas, 2001), impaired neural development (Colborn et al., 1996; Jacobson and Jacobson, 1997, 2002; Longnecker et al., 2003), weakened immune response (Weisglas-Kuperus et al., 
1995; Weisglas-Kuperus, 1998), and lower thyroid hormone levels (Weisglas-Kuperus, 1998; Brouwer et al., 1999; Wang et al., 2005).

Pipefishes and seahorses of the family Syngnathidae are characterized by a unique mode of ovoviviparous reproduction in which the male carries developing embryos in a special organ referred to as the brood pouch (Lockwood, 1867). The degree of brood pouch closure varies considerably and has been classically grouped into three types: ventral gluing, two pouch flaps that meet midline, and a completely sealed sac (Duncker, 1915; Herald, 1959). A female oviposits her eggs directly onto the brooding skin where they are fertilized. The developing embryos remain in the brood pouch for a lengthy incubation period before being released as independent young without a yolk sac. The brood pouch is believed to protect, aerate, osmotically buffer, and nourish the embryos (for review see Azzarello, 1991; Carcupino et al., 1997, 2002; Drozdov et al., 1997). However, the extent to which the various pouch types perform these physiological roles is not well understood.

The unique mode of reproduction in Syngnathids makes these species accessible models for investigations of how parental physiology and environmental factors impact reproduction and development. This study compares two sympatric species, the Northern, Syngnathus fuscus, and the Dusky pipefish, Syngnathus floridae, both common residents of Atlantic grass beds of the Chincoteague and Chesapeake Bays, USA (Orth and Heck, 1980). Recently we described the interspecific divergence in parental investment in these fishes possessing similar pouch enclosure (Ripley and Foran, 2006). The pouch type is intermediate with two flaps meeting at the midline without fusing. Both species bathe developing embryos in a nutrient-rich pouch fluid, but the origin of this supplementation differs. S. fuscus females produce nutritionally poor eggs. Males provision developing embryos by implanting them under highly vascularized epithelial tissue. In 
S. floridae, nutritional dependence falls to the female who supplies protein and lipid-rich eggs. Syngnathus floridae males employ a nurse egg system to produce the nutrient-rich pouch fluid in which the loosely attached embryos are bathed (Ripley and Foran, 2006).

Due to the potential for contaminants to be transferred to developing pipefish through blood vessels and secretions in the paternal brood pouch, pipefish are likely to be exposed during critical stages of development analogous to human in utero exposure. We believe differential dependence on parental contributions during development will alter the susceptibility of these species to environmental insult. Specifically, S. floridae fry will be less impacted than S. fuscus fry from paternal exposure to PCBs, because $S$. floridae development is less dependent on paternal contributions. Conversely, greater alterations on S. floridae egg production are expected due to maternal PCB treatment. We measured total protein, lipid, and carbohydrate levels in adult blood plasma, pouch fluid, newly released fry, and unfertilized eggs to investigate differences related to PCB exposure in parental nutrient allocation. Changes in brood period and fry and egg size were also explored. The results of this experiment provide a valuable tool in predicting changes in reproduction and development in pipefish populations impacted by organic contaminants.

\section{Materials and methods}

\section{Fish collection and environmental PCB concentrations}

We collected pipefish by seining in the seasonally abundant shallow eelgrass (Zostera marina) beds of the Chincoteague Bay, VA, USA from May through September 2004 and 2005. Seining events covered a distance of $\sim 25 \mathrm{~m}$ in approximately one minute using a $3.7 \mathrm{~m}$ by $1.2 \mathrm{~m}$ net with a $1.5 \mathrm{~m}^{2}$ bag and $0.4 \mathrm{~cm}^{2}$ mesh (Fish Net Company, Jonesville, LA, USA). Collected 
organisms were immediately sorted on a submerged platform. All adult pipefish were retained for laboratory exposures while juveniles were held momentarily in aerated tanks onboard the boat and returned before leaving the site. Males were morphologically distinguished by the presence of a ventral brood pouch, while gravid females were identified by the distension of the anterior portion of the trunk (Herald, 1942). Juveniles were classified based on their small size and absence of the abovementioned sexual characteristics. Pipefish were held for a maximum of three days at the field station in aerated tanks with daily water changes. Adults were transported to the laboratory in Kordon ${ }^{\circledR}$ breathing bags (Novalek Inc., Hayward, CA, USA) chilled with ice. Water and sediment samples were collected in August 2004 to characterize ambient PCB concentrations in the Bay. Five sites were sampled prior to pipefish seining. Two sites were visited for two consecutive days and only one collection was conducted on the third day. Sample areas were separated by at least $100 \mathrm{~m}$. We employed glass Pyrex ${ }^{\circledR}$ media bottles (1 l) and I$\mathrm{Chem}^{\circledR}$ wide mouth jars (250 mL; VWR International, Bristol, CT, USA) for water and sediment collection respectively. Jars were washed with Micro- $90^{\circledR}$ concentrated cleaning solution (International Products Corporation, Burlington, NJ, USA) and thoroughly rinsed with acetone. In the field, we collected water samples first. One bottle was submerged approximately $0.5 \mathrm{~m}$ below the surface and rinsed three times before being filled. Sediment was collected by utilizing the lip of the jar to scrape the top $5 \mathrm{~cm}$ of the grass bed floor until the jar was packed. We wrapped both containers in aluminum foil to prevent photodegradation and placed them on ice in a cooler. On shore, samples were stored at $4{ }^{\circ} \mathrm{C}$ until analysis. PCB levels were characterized by gas chromatography/mass spectrometry by the National Research Center for Coal and Energy at West Virginia University (WVU NRCCE; Morgantown, WV, USA). 
In the laboratory, pipefishes were held in conspecific, same sex groups of 10-12 fish in

filtered 37.81 tanks maintained at $24 \pm 1^{0} \mathrm{C}$ and on a $14 \mathrm{~h}: 10 \mathrm{~h}$ light:dark cycle (on 06:00: off 20:00). Photoperiod mimicked the average seasonal trend for the collection location, while temperature was maintained on the low end of the seasonal range to ward off disease and parasite infections. We used artificial seawater (Instant Ocean, Mentor, OH, USA) and reduced salinity from Bay averages of 30 to 20 parts per thousand (ppt) to prevent parasite transfer between animals. Pieces of non-living coral and artificial eelgrass fashioned from nylon rope provided shelter. Two 2081 tanks were established under identical conditions. These tanks, one for each species, provided ample space for courtship and mating. Approximately 5 non-brooding males and 8-10 conspecific females were added. Every morning we checked the mating tanks for brooding males which were readily distinguished by the distension and orange color of the brood pouch due to the presence of eggs. Brooding males were immediately removed and replaced by non-brooding males. Females were exchanged with those in small same sex tanks weekly.

The exposure study was conducted in an Enconair ecological chamber (Winnipeg, Canada; model GC-16). Photoperiod and air temperature were programmed to follow the abovementioned laboratory conditions. Three treatment groups were established: true control, acetone control, and PCB exposure. In this study, we selected the congener mixture Aroclor 1254 due to widespread prevalence in the Chesapeake Bay waters, sediment, and organisms and its listing among toxics of concern for this region (Ashley and Baker, 1999; Toschik et al., 2005; Smith, 2006). Sixteen 5.21 glass rectangular tanks $(25 \times 16 \times 18 \mathrm{~cm})$ and eight 7.61 drum aquaria (Aquarium Guys, Malvern, PA, USA; 27 x 17 x $26 \mathrm{~cm}$ ) were outfitted with $10.2 \mathrm{~cm}$ bubble wands (Marineland, Rahway, NJ, USA) and filled with 41 of artificial saltwater. 
Plexiglass lids covered tanks to limit evaporation and cross contamination, and prohibit startled pipefish from jumping. Ten tanks were positioned on either side of the chamber with one half designated for the acetone control and the other for the Aroclor 1254 treatment. Four aquaria aligned in the center held the true control group.

A $2 \mu \mathrm{g} / \mu \mathrm{l}$ PCB stock solution was created by diluting Aroclor 1254 (Ultra Scientific, North Kingstown, RI, USA) in acetone. The concentration of this solution was confirmed by the WVU NRCCE. Our aim was to examine a concentration of 100 parts per billion (ppb), representing environmental concentrations at the high range in the Chesapeake Bay (Ashley and Baker, 1999; Foster et al., 2000; Pinkney et al., 2001). To achieve this exposure, each tank (4 1 of saltwater) in the PCB treatment group received $200 \mu \mathrm{l}$ of Aroclor 1254 stock solution. Likewise, $200 \mu$ of acetone was added to the acetone control tanks. We collected water samples immediately after PCB spiking from three tanks at three different times during the study for analysis of nominal concentrations by the WVU NRCCE. Aged water ( $48 \mathrm{~h})$ from three tanks was also analyzed for nominal concentrations at three different times over the course of the study to determine chemical stability.

Males were introduced to the exposure study immediately following spawning and identification of brooding. Females subjected to the chemical exposures and not involved in mating began treatment 16-24 $\mathrm{h}$ after arrival to the laboratory. Pipefish were housed individually in tanks and designated to alternating treatment groups. Prior to adding fish, tanks assigned to the PCB treatment were filled and spiked with the Aroclor 1254 stock solution. Water was changed in this static system after $48 \mathrm{~h}$ and the steps repeated. Brooding males remained in assigned treatments for the duration of the brooding period. We assumed egg maturation follows a periodicity similar to the paternal brooding period to allow spawning synchronization 
(Ahnesjö, 1996; Drozdov et al., 1997; Watanabe and Watanabe, 2001). Accordingly, the chosen time frame approximated the brood period (Hildebrand and Schroeder, 1928). That is, exposure of gravid females spanned 14 days. Fish were fed mysid shrimp and Artemia to satiation three times daily. Tanks were rinsed with freshwater between individuals, always remaining in the same treatment group.

\section{Tissue collection and nutrient analysis}

Tissues were collected following fry release or the conclusion of the treatment period for females. Details of tissue collection and nutrient analyses are described in Ripley and Foran (2006). Procedures are briefly summarized here. We anaesthsized pipefish with 3-aminobenzoic acid ethyl ester (MS222; Sigma Aldrich, St. Louis, MO, USA) in saltwater. Standard length (SL) and weight were recorded. Blood was collected from the heart of adults with heparinized microcapillary tubes (Drummond Scientific Co., Broomall, PA, USA). We also used microcapillary tubes to separate the pouch flaps and collect paternal pouch fluid. The pouch fluid and plasma fraction of the blood samples were stored at $-80^{\circ} \mathrm{C}$ until analysis. For each adult, 20 newly released fry or eggs from the posterior portion of the ovary were pooled and homogenized. The supernatant from centrifuging was removed and stored at $-80^{\circ} \mathrm{C}$.

An additional sample of 5 eggs or fry from each adult were viewed with an Olympus SZ40 dissecting microscope (Melville, NY, USA) and photographed with a Spot Insight color camera (Diagnostic Instruments Inc., Sterling Heights, MI, USA; model 3.2.0). Egg diameter and standard length of newly released fry were measured with the software Image Pro Plus (Media Cybernetics, Silver Spring, MD, USA). We utilized the average of the five measures as a single data point for each individual. 
Nutrients, specifically proteins, lipids, and carbohydrates, were measured in tissue samples as follows. Total protein concentrations were determined using a Bio-Rad protein dye reagent (Hercules, CA, USA) and a standard curve of bovine serum albumin. Lipid content was determined by acidifying methanol/chloroform extracts, adding a vanillin reagent, and comparing the sample to known amounts of soybean oil (Wheeler and Buck, 1992; Lotufo et al., 2000). Carbohydrate levels were quantified using an anthrone assay and standards of sucrose (Van Handel, 1985; Wheeler and Buck, 1992). The samples were transferred to 96-well plates and read by a Tecan GENios (Durham, NC, USA). For each nutrient analyzed, the sample was measured in triplicate and averaged as a single data point.

\section{Statistical analyses}

Normality and homogeneity of data sets were assessed prior to the use of parametric statistics. An alpha value of 0.05 denoted significance. When non-parametric Wilcoxon rank sum tests were performed, normal approximations were applied to sample sizes exceeding 8 . Analyses of male and fry data did not include true control values due to the absence of data for $S$. fuscus. All statistical analyses were performed with JMP 5.1.

\section{Results \\ Environmental PCB concentrations}

The Chincoteague Bay is considered a relatively pristine site based on trace detection of PCBs. Water samples measured a mean PCB concentration of $1.6 \pm 0.51 \mathrm{ppb}(\mathrm{n}=5$, range $=\mathrm{ND}$ $-3 \mathrm{ppb}$ ) with Aroclor 1260 as the dominant congener mixture. Four out of the 5 sediment 
samples revealed non-detectable concentrations. The prevailing PCB mixture in the one area with measurable sediment concentrations was Aroclor $1260(\mathrm{n}=5$, range $=\mathrm{ND}-131 \mathrm{ppb})$.

\section{Exposure concentrations of Aroclor 1254}

Analysis of the prepared stock solution confirmed a concentration of $1.95 \pm 0.05 \mu \mathrm{g} / \mu \mathrm{l}(\mathrm{n}=$

2). Immediately following the addition of Aroclor 1254, exposure levels measured $52.89 \pm 2.12$ $\mathrm{ppb}(\mathrm{n}=9$, range $=44-62 \mathrm{ppb})$. At the time of water changes approximately 48 hours after Aroclor 1254 spiking, concentrations dropped to $2.22 \pm 0.36 \mathrm{ppb}(\mathrm{n}=9$, range $=1-4 \mathrm{ppb})$.

\section{Nutrient measurements}

Blood plasma concentrations of total protein and lipids tended to increase with Aroclor 1254 exposure in S. floridae and S. fuscus gravid females and S. fuscus males following brood release. Comparisons of gravid females suggest protein concentrations are higher in Aroclor 1254 exposed females compared to control females but these differences are not significant at an alpha level of 0.05 (2-way ANOVA, F = 2.2275, p = 0.0714; Fig. 1, Table 1). Plasma lipid content displayed significant differences with Aroclor 1254 treated females circulating greater levels than controls (2-way ANOVA, F = 6.2159, $\mathrm{p}=0.0003$; post-hoc Tukey HSD, $\mathrm{Q}=2.4388$, $\alpha=0.05$; Fig. 1, Table 1). Assessment of plasma carbohydrate concentrations revealed no significant treatment differences (S. floridae, Kruskal-Wallis, $\mathrm{K}=2.1897, \mathrm{p}=0.1262 ;$ S. fuscus, $\mathrm{K}=3.5641, \mathrm{p}=0.1683 ;$ Fig. 1, Table 1). Examining $S$. floridae males, plasma protein levels do not change with Aroclor 1254 exposure (Kruskal-Wallis, $\mathrm{K}=4.3700, \mathrm{p}=0.1125$; Fig. 1, Table 1). Conversely, protein tended to increase in Aroclor 1254 treated S. fuscus males over acetone controls (Wilcoxon rank sum, $\mathrm{W}=21, \mathrm{p}=0.0527$; Fig. 1A, Table 1). The increase in plasma 
protein between acetone and PCB exposed S. fuscus males was 8.1 times greater than the change in S. floridae. Plasma lipid levels also indicated increases following Aroclor 1254 exposure in $S$. fuscus (Wilcoxon rank sum, $\mathrm{W}=20, \mathrm{p}=0.1332$; Fig. 1, Table 1). Circulating lipid $(\mathrm{K}=3.2989$, $\mathrm{p}=0.1922$; Fig. 1, Table 1) and carbohydrate concentrations $(\mathrm{K}=3.5641, \mathrm{p}=0.1683$; Fig. 1 , Table 1) for S. floridae males which just released fry showed no significant difference with treatment. The increase between lipid levels in acetone controls and Aroclor 1254 treated $S$. fuscus males was 14.3 fold greater than the same change for S. floridae. Overall under identical treatment conditions, blood plasma concentrations of total protein and lipids were comparable between males which just released a brood and gravid females. That is, circulating protein levels did not vary based on species, sex, or treatment (3-way ANOVA, $F=1.5492, \mathrm{p}=0.1621$; Fig. 1, Table 1). Interspecific and sex distinctions were not revealed in plasma lipid concentrations, but Aroclor 1254 exposure did significantly increase lipid levels from control values (3-way ANOVA, $F=4.3789, p=0.0003$; post-hoc Student's $t, t=1.9883, \alpha=0.05$; Fig. 1, Table 1). Nutrients potentially available for uptake by developing embryos were measured by determining protein, lipid, and carbohydrate content of fluid collected from the pouch of males following brood release. Exposure to Aroclor 1254 over the brood period did not alter protein (Kruskal-Wallis, $\mathrm{K}=0.5257, \mathrm{p}=0.7689)$, lipid $(\mathrm{K}=0.6949, \mathrm{p}=0.7065)$, or carbohydrate levels $(\mathrm{K}=2.2471, \mathrm{p}=0.1876$; Fig. 2, Table 2) of S. floridae pouch fluid. However, in S. fuscus, Aroclor 1254 treatment tended to lower pouch fluid protein (Wilcoxon rank sum, $\mathrm{W}=30, \mathrm{p}=$ 0.0645 ) and lipid content $(\mathrm{W}=20, \mathrm{p}=0.1967 ;$ Fig. 2, Table 2). Differences in S. fuscus pouch fluid nutrients with PCB exposure were 6.4 and 28.1 times greater for protein and lipids respectively than the same change in S. floridae. Interspecific comparisons of the acetone control males did not reveal significant differences in pouch fluid concentrations of either protein 
(Wilcoxon, $\mathrm{W}=43, \mathrm{p}=0.5228$ ) or lipid $(\mathrm{W}=28, \mathrm{p}=0.5340)$. Yet when exposed to Aroclor 1254 for the entire brood period, lower pouch fluid protein (Wilcoxon rank sum, $Z=-1.9403, p$ $=0.0523)$ and lipid concentrations $(\mathrm{W}=42, \mathrm{p}=0.0389$; Fig. 2, Table 2) characterized S. fuscus compared to S. floridae.

Analyses revealed greater protein and lipid reserves in $S$. floridae eggs over $S$. fuscus regardless of treatment (Fig. 3, Table 3). In other words, Aroclor 1254 exposure did not alter protein concentrations, but on the whole, $S$. floridae egg protein levels were significantly higher than S. fuscus (2-way ANOVA, $\mathrm{F}=14.041, \mathrm{p}<0.0001$; post-hoc Student's $\mathrm{t}, \mathrm{t}=2.0244, \alpha=$ 0.05; Fig. 3, Table 3). No significant difference in lipid concentrations was observed following Aroclor 1254 treatment (2-way ANOVA, $\mathrm{F}=3.3335, \mathrm{p}=0.0136)$. Yet, lipid content of $S$. floridae eggs was greater than S. fuscus (post-hoc Student's t, $\mathrm{t}=2.0244, \alpha=0.05$, Fig. 3, Table 3). Carbohydrate concentrations did not vary based on species or treatment (2-way ANOVA, F $=1.9926, \mathrm{p}=0.1019$; Fig. 3, Table 3). Analogous to unfertilized eggs, newly released $S$. floridae fry contained higher concentrations of protein (2-way ANOVA, $\mathrm{F}=6.9841, \mathrm{p}=0.0006$; post-hoc Student's $t, t=2.0129, \alpha=0.05)$, lipids $(F=4.9663, p=0.0045 ; t=2.0129, \alpha=0.05)$, and carbohydrates $(\mathrm{F}=4.8896, \mathrm{p}=0.0052 ; \mathrm{t}=2.0167, \alpha=0.05)$ compared to $S$. fuscus. Nutrient levels did not change with Aroclor 1254 treatment in either species (Fig. 3, Table 3).

\section{Egg diameter and fry standard length}

Egg size was not comparable between species. Syngnathus floridae females produced larger eggs (2-way ANOVA, $\mathrm{F}=9.2326, \mathrm{p}<0.0001$; post-hoc Student's $\mathrm{t}, \mathrm{t}=2.0244, \alpha=0.05$; Table 3). Aroclor 1254 exposure did not alter egg diameter in either species (Table 3). Neither female SL (S. floridae, $\mathrm{r}^{2}=0.0362, \mathrm{p}=0.2967 ;$. fuscus, $\left.\mathrm{r}^{2}=0.0143, \mathrm{p}=0.7112\right)$ nor weight $(S$. 
floridae, $\mathrm{r}^{2}=0.0012, \mathrm{p}=0.8512 ;$ S. fuscus, $\left.\mathrm{r}^{2}=0.0153, \mathrm{p}=0.7014\right)$ corresponded to egg diameter when the treatment data were combined or considered separately (all $\mathrm{p}>0.05$ ).

Interspecific differences in fry SL were observed. For both species, Aroclor 1254 exposed fry were smaller than conspecific acetone controls (2-way ANOVA, $F=3.4926, p=0.0231$; post-hoc Student's t, t $=2.0141, \alpha=0.05$; Table 3). Moreover, S. floridae fry tended to be longer than S. fuscus (F-test, $\mathrm{F}=3.5031, \mathrm{p}=0.0678$; Table 3). Paternal SL (S. floridae, $\mathrm{r}^{2}=$ $0.0309, \mathrm{p}=0.2426 ;$ S. fuscus, $\left.\mathrm{r}^{2}=0.0392, \mathrm{p}=0.5598\right)$ and weight $\left(\right.$ S. floridae, $\mathrm{r}^{2}=0.0560, \mathrm{p}=$ $0.1133 ;$ S. fuscus, $\mathrm{r}^{2}=0.03558, \mathrm{p}=0.5786$ ) did not influence fry size when the treatments were considered together and individually (all $\mathrm{p}>0.05$ ).

\section{Brooding period}

Brooding period was not affected by Aroclor 1254 exposure; however, interspecific differences were evident with $S$. floridae males incubating embryos longer than S. fuscus (2-way ANOVA, F $=8.1294, \mathrm{p}=0.0002$; post-hoc Student's $\mathrm{t}, \mathrm{t}=2.0076, \alpha=0.05$ ). Syngnathus floridae males grouped into true controls held developing embryos for $12.50 \pm 0.50$ days $(\mathrm{n}=4)$, while acetone and Aroclor 1254 treated males brooded for $13.16 \pm 0.24$ days $(\mathrm{n}=25)$ and 12.58 \pm 0.32 days $(\mathrm{n}=19)$ respectively. The brooding period spanned $8.50 \pm 1.57$ days $(\mathrm{n}=2)$ for $S$. fuscus acetone controls and $10.44 \pm 0.42$ days $(\mathrm{n}=9)$ for S. fuscus males exposed to Aroclor 1254. 
Table 1. Interspecific comparisons of blood plasma nutrient concentrations from controls and adult pipefish exposed to Aroclor 1254 over the brooding period

\begin{tabular}{|c|c|c|c|c|c|c|}
\hline \multirow[b]{2}{*}{ Treatment Group } & \multirow[b]{2}{*}{ Protein } & \multicolumn{3}{|c|}{ Concentration $(\mathrm{mg} / \mathrm{ml})$} & \multirow[b]{2}{*}{ Carbohydrate } & \multirow[b]{2}{*}{$\mathrm{N}$} \\
\hline & & $\mathrm{N}$ & Lipid $^{\dagger}$ & $\mathrm{N}$ & & \\
\hline \multicolumn{7}{|l|}{ Gravid females } \\
\hline \multicolumn{7}{|l|}{ Syngnathus fuscus } \\
\hline True control & $26.47 \pm 1.25$ & 6 & $7.93 \pm 0.66^{\mathrm{a}}$ & 6 & $1.30 \pm 0.28$ & 6 \\
\hline Acetone control & $22.39 \pm 0.89$ & 3 & $8.06 \pm 0.92^{\mathrm{a}}$ & 3 & $1.69 \pm 0.54$ & 3 \\
\hline Aroclor 1254 & $37.54 \pm 1.67$ & 3 & $12.67 \pm 0.79^{b}$ & 3 & $1.80 \pm 0.55$ & 3 \\
\hline \multicolumn{7}{|l|}{ Syngnathus floridae } \\
\hline True control & $28.28 \pm 1.29$ & 5 & $9.46 \pm 0.70^{\mathrm{a}}$ & 5 & $1.96 \pm 0.30$ & 5 \\
\hline Acetone control & $27.42 \pm 0.80$ & 13 & $8.91 \pm 0.40^{\mathrm{a}}$ & 13 & $1.29 \pm 0.22$ & 13 \\
\hline Aroclor 1254 & $38.25 \pm 1.15$ & 14 & $15.51 \pm 0.63^{b}$ & 14 & $2.59 \pm 0.29$ & 13 \\
\hline \multicolumn{7}{|l|}{ Released fry males } \\
\hline \multicolumn{7}{|l|}{ Syngnathus fuscus } \\
\hline \multicolumn{7}{|l|}{ True control* } \\
\hline Acetone control* & $18.13 \pm 1.37$ & 4 & $8.82 \pm 0.74$ & 4 & & \\
\hline Aroclor 1254 & $34.45 \pm 1.42$ & 11 & $19.68 \pm 1.00$ & 11 & $1.80 \pm 0.37$ & 7 \\
\hline \multicolumn{7}{|l|}{ Syngnathus floridae } \\
\hline True control & $16.22 \pm 1.46$ & 4 & $9.99 \pm 0.78$ & 4 & $1.17 \pm 0.33$ & 4 \\
\hline Acetone control & $28.73 \pm 0.71$ & 25 & $12.76 \pm 0.44$ & 26 & $1.65 \pm 0.19$ & 22 \\
\hline Aroclor 1254 & $30.74 \pm 0.95$ & 19 & $13.52 \pm 0.45$ & 19 & $2.04 \pm 0.25$ & 17 \\
\hline
\end{tabular}

Values are mean $\pm \mathrm{SE}$; N, sample number.

*Empty cells indicate data has not yet been collected for this treatment or nutrient measure.

$\uparrow$ Groups not connected by the same letter are significantly different (two-way ANOVA, $\mathrm{p}<0.05$ ). 
Table 2. Effect of Aroclor 1254 exposure on nutrient levels in paternal pouch fluid following fry release

\begin{tabular}{|c|c|c|c|c|c|c|}
\hline \multirow[b]{2}{*}{ Treatment Group } & \multicolumn{6}{|c|}{ Concentration (mg/ml) } \\
\hline & Protein & $\mathrm{N}$ & Lipid & $\mathrm{N}$ & Carbohydrate & $\mathrm{N}$ \\
\hline \multicolumn{7}{|l|}{ Syngnathus fuscus } \\
\hline \multicolumn{7}{|l|}{ True control* } \\
\hline Acetone control* & $24.64 \pm 1.86$ & 3 & $6.90 \pm 0.88$ & 3 & & \\
\hline Aroclor 1254 & $11.66 \pm 0.81$ & 9 & $4.65 \pm 0.64$ & 6 & $0.41 \pm 0.33$ & 3 \\
\hline \multicolumn{7}{|l|}{ Syngnathus floridae } \\
\hline True control & $19.85 \pm 0.89$ & 2 & $6.45 \pm 1.20$ & 2 & $3.42 \pm 0.65$ & 2 \\
\hline Acetone control & $21.02 \pm 0.70$ & 20 & $8.47 \pm 0.60$ & 19 & $1.67 \pm 0.34$ & 11 \\
\hline Aroclor 1254 & $18.99 \pm 0.80$ & 17 & $8.39 \pm 0.49$ & 17 & $2.07 \pm 0.48$ & 7 \\
\hline
\end{tabular}

Values are mean $\pm \mathrm{SE} ; \mathrm{N}$, sample number.

*Empty cells indicate data has not yet been collected for this treatment or nutrient measure. 
Table 3. Species comparisons of nutrient content and length of mature, unfertilized eggs and newly released fry from control and Aroclor 1254 exposed parents

\begin{tabular}{|c|c|c|c|c|c|}
\hline \multirow[b]{2}{*}{ Group } & \multicolumn{5}{|c|}{ Concentration $(\mathrm{mg})^{\dagger}$} \\
\hline & $\mathrm{N}$ & Protein & Lipid & Carbohydrate & Length $(\mathrm{mm})$ \\
\hline \multicolumn{6}{|l|}{ Unfertilized eggs } \\
\hline \multicolumn{6}{|l|}{ Syngnathus fuscus } \\
\hline True control & 6 & $47.78 \pm 1.48^{\mathrm{b}}$ & $16.10 \pm 0.89^{b}$ & $2.14 \pm 0.38$ & $0.75 \pm 0.10^{\mathrm{b}}$ \\
\hline Acetone control & 3 & $51.01 \pm 1.40^{\mathrm{b}}$ & $15.12 \pm 1.14^{\mathrm{b}}$ & $0.73 \pm 0.26$ & $0.84 \pm 0.07^{\mathrm{b}}$ \\
\hline Aroclor 1254 & 3 & $71.95 \pm 1.69^{b}$ & $15.88 \pm 0.52^{b}$ & $1.11 \pm 0.54$ & $0.76 \pm 0.13^{b}$ \\
\hline \multicolumn{6}{|l|}{ Syngnathus floridae } \\
\hline True control & 5 & $153.92 \pm 3.25^{\mathrm{a}}$ & $26.02 \pm 1.52^{\mathrm{a}}$ & $1.98 \pm 0.50$ & $0.99 \pm 0.14^{\mathrm{a}}$ \\
\hline Acetone control & 13 & $144.18 \pm 1.44^{\mathrm{a}}$ & $27.84 \pm 0.84^{\mathrm{a}}$ & $2.81 \pm 0.36$ & $1.03 \pm 0.10^{\mathrm{a}}$ \\
\hline Aroclor 1254 & 14 & $148.66 \pm 1.69^{\mathrm{a}}$ & $25.89 \pm 0.73^{\mathrm{a}}$ & $2.64 \pm 0.31$ & $1.04 \pm 0.10^{\mathrm{a}}$ \\
\hline \multicolumn{6}{|l|}{ Newly released fry } \\
\hline \multicolumn{6}{|l|}{ Syngnathus fuscus } \\
\hline \multicolumn{6}{|l|}{ True control* } \\
\hline Acetone control & 4 & $18.13 \pm 1.37^{\mathrm{y}}$ & $6.14 \pm 0.72^{\mathrm{y}}$ & $0.73 \pm 0.16^{\mathrm{y}}$ & $11.35 \pm 0.64^{x}$ \\
\hline Aroclor 1254 & 7 & $12.01 \pm 1.10^{\mathrm{y}}$ & $6.05 \pm 0.52^{\mathrm{y}}$ & $0.61 \pm 0.26^{\mathrm{y}}$ & $10.36 \pm 0.43^{\mathrm{y}}$ \\
\hline \multicolumn{6}{|l|}{ Syngnathus floridae } \\
\hline True control & 4 & $40.48 \pm 2.14$ & $10.21 \pm 0.93$ & $1.42 \pm 0.45$ & $11.32 \pm 0.39$ \\
\hline Acetone control & 22 & $32.22 \pm 0.66^{\mathrm{x}}$ & $10.97 \pm 0.44^{\mathrm{x}}$ & $1.90 \pm 0.24^{\mathrm{x}}$ & $11.74 \pm 0.20^{\mathrm{x}}$ \\
\hline Aroclor 1254 & 17 & $35.63 \pm 1.02^{x}$ & $9.27 \pm 0.42^{\mathrm{x}}$ & $0.97 \pm 0.22^{\mathrm{x}}$ & $11.28 \pm 0.22^{\mathrm{y}}$ \\
\hline
\end{tabular}

Values are mean $\pm \mathrm{SE}$; N, sample number.

*Categories missing values denote data has not yet been collected for this treatment.

$\dagger$ Groups not connected by the same letter are significantly different (two-way ANOVA, $\mathrm{p}<0.05$ ). True controls were not considered in the analysis of newly released fry due to the absence of data for S. fuscus. 


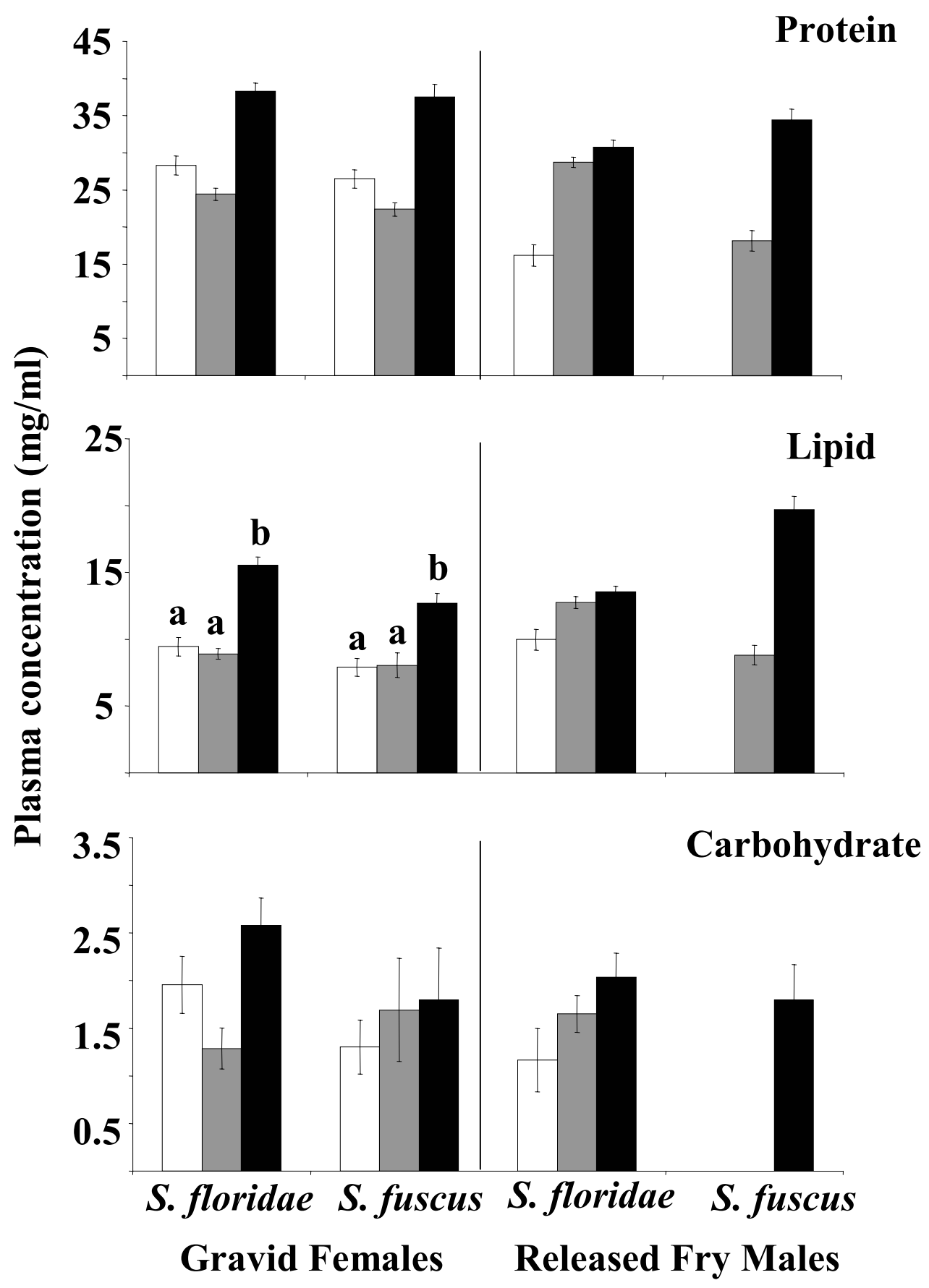

Fig. 1. Circulating protein, lipid, and carbohydrate concentrations in the blood plasma of Syngnathus fuscus and Syngnathus floridae gravid females and males which released fry from true control (white bars), acetone control (gray bars), and Aroclor 1254 treatments (53 ppb; black bars). Bars are mean \pm SE. Bars not connected by the same letter are significantly different (two-way ANOVA, $\mathrm{p}<0.05$ ). 


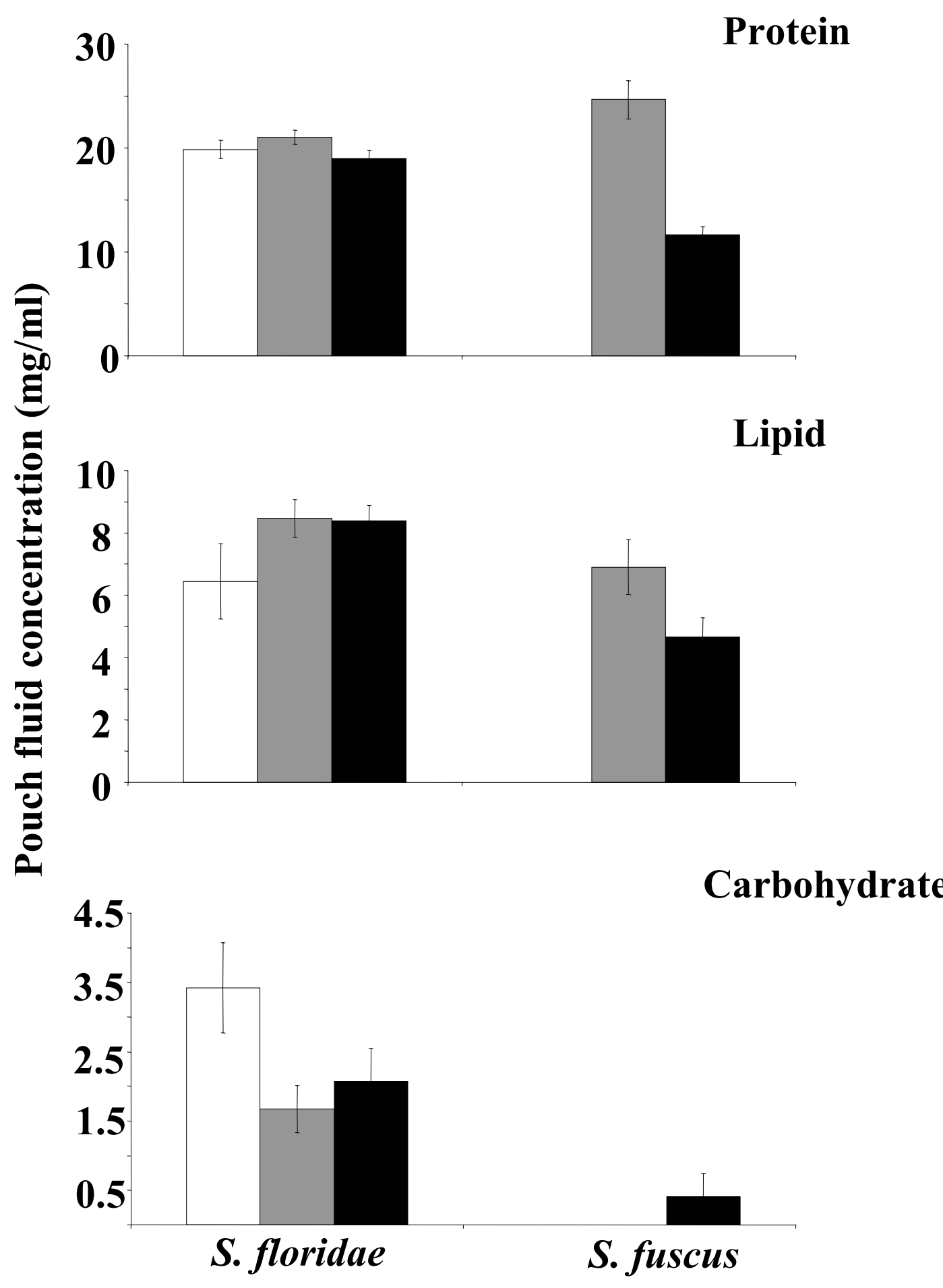

Fig. 2. Pouch fluid protein, lipid, and carbohydrate concentrations in true control (white bars), acetone control (gray bars), and Aroclor 1254 exposed (53 ppb; black bars) Syngnathus fuscus and Syngnathus floridae released fry males. Bars are mean \pm SE. 


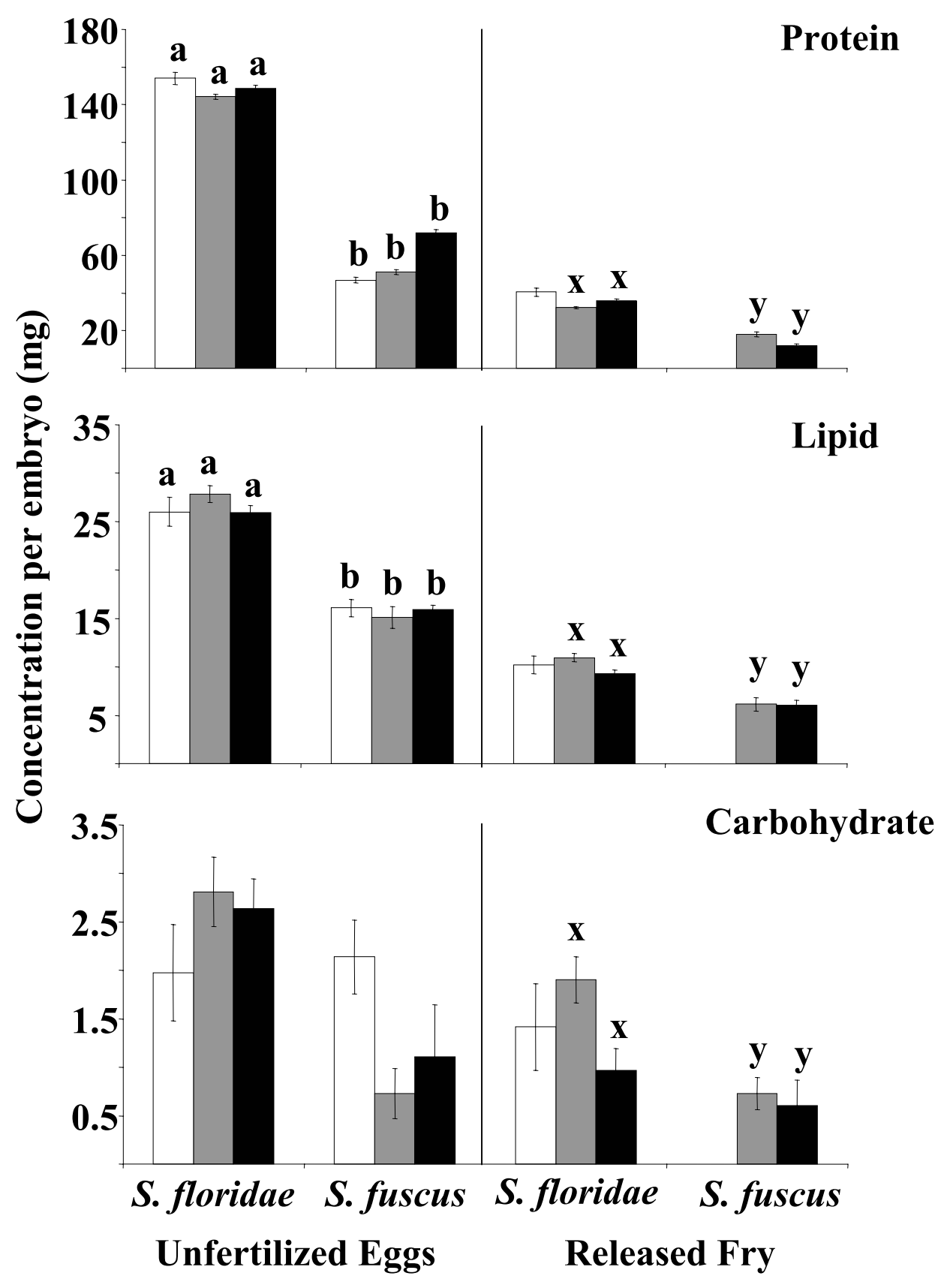

Fig. 3. Protein, lipid, and carbohydrate content of Syngnathus fuscus and Syngnathus floridae mature, unfertilized eggs and released fry from true control (white bars), acetone control (gray bars), and Aroclor 1254 (53 ppb; black bars) treated adults. Bars are mean \pm SE. Bars not connected by the same letter are significantly different (two-way ANOVA, $\mathrm{p}<0.05$ ). True control fry were not considered in the statistical analyses due to the absence of data for S. fuscus. 


\section{Discussion}

The first samples from $S$. fuscus indicate this species is more sensitive than S. floridae to Aroclor 1254 exposure during embryonic development and egg production. Circulating nutrient levels provide a measure of allocation to gamete production and/or parental care (Chellappa et al., 1989). In the viviparous teleost family Goodeidae, low plasma concentrations result from the transport of nutrients from the maternal circulatory system across the ovarian epithelium to create a nutrient-rich ovarian fluid which bathes the embryos during gestation (Hollenberg and Wourms, 1995). We documented equivalent, low plasma nutrient levels in both brooding males and gravid females in an earlier investigation, leading us to suggest that brooding males incur a cost for parental care in both species (Ripley and Foran, 2006). The same relationship holds in this study. Reduced S. floridae paternal allocation compared to S. fuscus was also previously indicated (Ripley and Foran, 2006). Interspecific differences in paternal nutrient contribution are revealed among acetone-treated males in this study evidenced by higher circulating protein and lipid levels in S. floridae. Only those groups providing substantial contributions to offspring should show impacts from Aroclor 1254 exposure. Accordingly, elevated protein and lipid plasma concentrations in gravid females of both species and S. fuscus males suggest these individuals now allocate less to gametes and developing embryos. On the contrary, no significant change in circulating nutrient content was observed for $S$. floridae males. Since $S$. floridae paternal allocation is generally limited, the treatment effect is minimal. These changes should not only be considered in light of nutrient provisioning, but also in the transfer of PCBs to gametes and developing embryos. Lipids and proteins function as transporters of PCBs in the plasma (Borlakoglu et al., 1990). Increased plasma concentrations of lipids are well established

responses to PCBs in humans and animals. Lipid droplets sequestrating PCBs accumulate in the 
liver to diminish adverse effects (Jonsson et al., 1981; Baumann et al., 1983; Stehr-Green et al., 1986; Borlakoglu et al., 1990). Reductions in parental nutrient allocation, specifically lipids, would limit PCB transfer to offspring. Future investigations need to quantify PCB levels in these tissues.

The greater sensitivity of S. fuscus to paternal Aroclor 1254 exposure is further evidenced by decreases in protein and lipid pouch fluid levels. These decreases may be correlated to the higher circulating concentrations of these nutrients described above or developing embryos may be utilizing more of the available nutrients. No changes observed in the protein and lipid content of $S$. floridae pouch fluid suggests $S$. floridae males may not be major contributors to the nutrient-rich pouch fluid. The decline in S. fuscus pouch fluid nutrient content is a response to Aroclor 1254 treatment and not the result of general sensitivity to experimental conditions. Field-collected males of both species contained comparable pouch fluid nutrient levels following fry release (Ripley and Foran, 2006). In this study, the interspecific comparison on acetonetreated males did not reveal differences in protein or lipid levels. Rather, species differences and decreases in S. fuscus pouch fluid protein and lipid concentrations were observed following Aroclor 1254 exposure. These interspecific differences in Aroclor 1254 sensitivity support the hypothesis that $S$. fuscus males contribute significant nutritional resources to developing young.

Decreases in potential S. fuscus paternal nutrient allocation with PCB treatment were not substantiated with lower fry nutrient content. However, protein, lipid, and carbohydrate reserves were lower in S. fuscus fry across treatments contrary to the characterization of field-collected individuals that showed comparable nutrient levels between fry of both species (Ripley and Foran, 2006). These species may represent two variations of parental provisioning described in the Poeciliidae family of fishes with maternal care. Lecithotrophic species rely on stores in the 
egg, receiving limited supplementation from the female (Wourms, 1981; Reznick et al., 1996).

Matrotrophic species present less yolk to the eggs and instead, transfer nutrients during development (Wourms, 1981; Reznick et al., 1996). Instances of low food availability do not lead to changes in offspring size or nutrient reserves at release in lecithotrophic species (Reznick et al., 1996). Matrotrophic species, on the other hand, employ an "interchangeable" mode of embryonic nutrition contribution in which smaller offspring with reduced reserves are produced (Reznick et al., 1996; Marsh-Matthews et al., 2001). Accordingly, with access to increased food supply, additional energy and nutrients are directed to the developing offspring of matrotrophic species (Reznick et al., 1996; Marsh-Matthews et al., 2001). S. floridae display similarities with the lecithotrophic Poeciliid species. Paternal allocation by S. fuscus may be regulated similar to matrotrophic fishes. Perhaps food quality, housing conditions, individual separation, water changes, or a combination of these factors contributed to depressed nutrient reserves in S. fuscus fry.

Decreased maternal allocation with Aroclor 1254 exposure suggested by plasma nutrient levels was not observed in egg nutrient reserves. Only species differences were apparent with $S$. floridae females producing more nutrient-rich eggs. These egg data indicate lower pouch fluid protein and lipid concentrations in S. fuscus is attributed to decreased paternal allocation and not increased embryonic utilization because PCB treatment does not alter eggs nutrient content. The trend of lower protein levels in PCB exposed S. fuscus fry further supports this hypothesis. If exposed embryos more efficiently incorporated pouch fluid nutrients, identical egg reserves would transform into greater fry concentrations. Even though alterations in nutrient provisioning to eggs was not observed following maternal Aroclor 1254 treatment, PCB transfer to eggs warrants investigation. For many species, the difficulty in penetrating the chorion prevents 
extensive PCB uptake by eggs (Solbakken et al., 1984; Kime, 2001). The absence of the chorion in Syngnathids is necessary to allow nutrients to be readily absorbed (Ripley and Foran, 2006). Yet, this mechanism may also permit enhanced uptake of PCBs. For egg production, S. floridae may exhibit a greater impact from PCB exposure. The elevated protein and lipid concentrations of S. floridae eggs increase the potential for PCB transport from the mother (Borlakoglu et al., 1990; Gundersen and Pearson, 1992; Kime, 2001). For embryonic development in S. fuscus, decreased pouch fluid nutrients may serve as a mechanism to minimize transfer.

Egg diameter measures suggest $S$. fuscus females exhibit heightened sensitivity to environmental conditions. Whereas eggs from field-collected females were similarly sized between species, S. fuscus produced smaller eggs in the laboratory. Hydration is the primary cause for the volume increases observed during oocyte maturation (Jobling, 1995). Accordingly, these size differences are most likely explained by variations in water uptake, especially considering nutrient levels were comparable to field-collected eggs (Ripley and Foran, 2006). Reduced water uptake may be attributed to a defect in the hydration mechanism or by reduced ovarian development and egg immaturity. The primary means of egg hydration for freshwater and euryhaline teleosts involves the influx of inorganic ions which leads to the osmotic influx of water (Jobling, 1995). Blocked transport, impeded movement, or reduced concentrations of ions and/or water could cause the observed small size. A range of pollutants and environmental factors have been shown to delay ovarian development to the point where oocytes remain small and immature and thus do not approach the stage of hydration (Thomas, 1988, 1990; Kime, 2001). Regardless of the explanation for the decrease in egg diameter, the implications of diminished S. fuscus egg size are significant. Syngnathus fuscus eggs and embryos intimately associate with the paternal brood pouch. Epithelia cover developing embryos bringing them into 
close proximity of paternal blood vessels (Ripley and Foran, 2006). Size changes could gravely impact this intimate association ultimately interfering with paternal nutrient allocation and/or embryonic uptake.

Length measures of S. fuscus and S. floridae fry decreased with Aroclor 1254 treatment. Lower birth weights as well as postnatal growth have been associated with prenatal PCB exposure in humans (Fein et al., 1984; Guo and Lambert, 1995; Weisglas-Kuperus, 1998; Kimbrough and Krouskas, 2001). This decreased growth in humans is attributed to developmental disruption of thyroid function. Animal studies show PCBs affect thyroid hormone secretion, transport, and action (Kime, 2001). In humans, PCB exposure is specifically associated with a decrease in thyroid hormones (Weisglas-Kuperus, 1998; Persky et al., 2001; Wang et al., 2005). The effects of hypothyroidism on fetal growth and development are irreversible and can last for several years (Jacobson and Jacobson, 1996; Patandin et al., 1999; Persky et al., 2001; Wang et al., 2005). Offspring size influences fitness (Hutchings, 1991; Parichy and Kaplan, 1992). Accordingly, decreased pipefish size at fry release carries the potential to gravely affect survival. Limited swimming speed and mobility characterizes Syngnathids (Roelke and Sogard, 1992; Ashley-Ross, 2002). Young S. fuscus and S. floridae already incur increased predation due to movement limitations (Campbell and Able, 1998; Lourie et al., 1999). Smaller size at release only elevates these predation risks. Snout size greatly restricts diet composition of both species. Syngnathus floridae prefer to prey upon various sized grass shrimp, Palaemonetes pugio, while S. fuscus appear to be more gape-limited, only feeding on small crustaceans (Ryer and Boehlert, 1983; Ryer and Orth, 1987; Teixeira and Musick, 1995). Choice of prey items becomes substantially more limited with smaller body size and snout lengths. Combining the lower nutrient reserves at fry release, smaller SL with PCB 
exposure, and the interspecific trend of smaller fry size, S. fuscus sensitivity compared to $S$. floridae to Aroclor 1254 is apparent. The data from this single exposure investigating a midrange PCB concentration highlight population level impacts can quickly materialize in S. fuscus.

Human infants exposed in utero to PCBs tend to be born prematurely (Fein et al., 1984; Taylor et al., 1989; Weisglas-Kuperus, 1998; Brouwer et al., 1999). The first data on S. fuscus does not indicate a shortened brood period with Aroclor 1254 exposure. Laboratory conditions also do not affect brooding as the time span we documented follows the 10 day incubation period previously noted for this species (Bigelow and Schroeder, 1953).

In investigating the allocation of nutrients to gametes and developing embryos, protein and lipids, and not carbohydrates, show a reliable response. Because the pipefish diet is almost exclusively comprised of proteins and lipids, carbohydrate levels are a measure of the availability of metabolic fuel (Ryer and Boehlert, 1983; Huh, 1986; Jobling, 1995). In the maternal provisioning Goodeid fishes, embryos bathed in nutrient-rich ovarian fluid possess protein and/or lipid absorbing organs (Hollenberg and Wourms, 1995). That is, only protein and lipids are supplemented during gestation. Protein and lipids also play an important role in plasma transport of PCBs (Borlakoglu et al., 1990). Future studies may omit examination of carbohydrate concentrations.

Exposure concentrations differed considerably from target Aroclor 1254 levels. Persistence of PCBs in the environment increases with the degree of chlorination of the congener. Those mixtures with a high degree of chlorination such as Aroclor 1254 biodegrade slowly (Boyle et al., 1992; Alder et al., 1993; Fish and Principe, 1994). Considering the abbreviated exposure period between water changes and absence of extensive biotransforming microbial colonies, as well as the instantaneous difference in desired verses actual levels, 
biodegradation is most likely not the cause for lower exposure concentrations. Rather, volatization and adsorption most likely explain the observed concentration differences. The halflife of Aroclor 1254 at $25^{\circ} \mathrm{C}$ from a saturated water solution $1 \mathrm{~m}$ deep is 1.2 minutes (Kopp, 1976). The half-life for Aroclor 1260 is almost 30 times that of Aroclor 1254 at 28.8 minutes (Kopp, 1976). These properties may explain the deviation from the target study concentration and the characterization of Aroclor 1260 as the dominant mixture in the Bay. Moreover, Aroclor 1254 is less soluble, readily adsorbing to glass and biological tissue (Kopp, 1976;

Schwarzenbach et al., 1993). Water concentrations would therefore reflect this characteristic.

Understanding the placental-like function of the Syngnathid brood pouch offers a unique perspective into mammalian placental physiology. Mammalian studies on the effects of fetal exposure are time consuming and produce small numbers of offspring. For these studies, newlymated female rats or mice are fed or injected with different concentrations of suspected developmental toxicants and the offspring reared for $2-2.5$ months before testing (Brouwer et al., 1999; Palanza et al., 2002). Litter sizes limit data collection for only up to 12 pups per exposed female are generally available for testing. Screening potential developmental toxicants and defining their effective concentrations would benefit from a model with rapid development and large brood size, especially if the in vivo factors of maternal metabolism and placental function can be incorporated. Syngnathus fuscus employs a unique reproductive strategy in which developing embryos may be exposed to lipophilic contaminants transferred through the highly vascularized paternal brood pouch. Therefore, these animals are exposed to contaminants during critical stages of development, analogous to human in utero. Because of the accessibility of embryos within the pouch, the large number of young per brood, the short brood period, and multiple mating events per season much information can be gained quickly on the impact of 
embryonic contaminant exposure including examination at various points in development. This study assessed the effects of developmental exposure to a well-characterized endocrine disrupting contaminant to validate the animal model in comparison to mammalian systems. We hope future studies will utilize this unique model system to rapidly screen environmental chemicals and characterize potential developmental damage. Ultimately, our goal is to predict developmental impacts before they are witnessed in the human population. 


\section{References}

Alder, A.C., Haggblom, M.M., Oppenheimer, S.R., Young, L.Y., 1993. Reductive dechlorination of polychlorinated biphenyls in anaerobic sediments. Environ. Sci. Technol. 27, 530-538.

Ahnesjö, I., 1996. Apparent resource competition among embryos in the brood pouch of a male pipefish. Behav. Ecol. Sociobiol. 38, 167-172.

Ashley, J.T.F., Baker, J.E., 1999. Hydrophobic organic contaminants in surficial sediments of Baltimore harbor: inventories and sources. Environ. Toxicol. Chem. 18, 838-849.

Ashley-Ross, M.A., 2002. Mechanical properties of the dorsal fin muscle of seahorse (Hippocampus) and pipefish (Syngnathus). J. Exper. Zool. 293, 561-577.

Azzarello, M.Y., 1991. Some questions concerning the Syngnathidae brood pouch. Bull. Mar. Sci. 49, 741-747.

Baumann, M., Deml, E., Schaffer, E., Greim, H., 1983. Effects of polychlorinated biphenyls at low dose levels in rats. Arch. Environ. Contam. Toxicol. 12, 509-515.

Bigelow, H.B., Schroeder, W.C., 1953. Fishes of the Gulf of Maine. U.S. Fish. Bull. 53, 1-597. Borlakoglu, J.T., Welch, V.A., Edwards-Webb, J.D., Dils, R.R., 1990. Transport and cellular uptake of polychlorinated biphenyls (PCBs) - II: changes in vivo in plasma lipoproteins and proteins of pigeons in response to PCBs, and a proposed model for the transport and cellular uptake of PCBs. Biochem. Pharmacol. 40, 273-281.

Brouwer, A., Longnecker, M.P., Birnbaum, L.S., Cogliano, J., Kostyniak, P., Moore, J., Schantz, S., Winneke, G., 1999. Characterization of potential endocrine-related health effects at low-dose levels of exposure to PCBs. Environ. Health Perspect. 107, 639-649. 
Brown, J.F., Lawton, R.W., Morgan, C.B., 1994. PCB metabolism, persistence, and health effects after occupational exposure: implications for risk assessment. Chemosphere 29, 2287-2294.

Boyle, A.W., Silvin, C.J., Hassett, J.P., Nakas, J.P., Tanenbaum, S.W., 1992. Bacterial PCB biodegradation. Biodegradation 3, 285-298.

Campbell, B.C., Able, K.W., 1998. Life history characteristics of the Northern pipefish, Syngnathus fuscus, in Southern New Jersey. Estuaries 21, 470-745.

Carcupino, M., Baldacci, A., Mazzini, M. and Franzoi, P., 1997. Morphological organization of the male brood pouch epithelium of Syngnathus abaster Risso (Teleostea, Syngnathidae) before, during, and after egg incubation. Tissue Cell 29, 21-30.

Carcupino, M., Baldacci, A., Mazzini, M. and Franzoi, P., 2002. Functional significance of the male brood pouch in the reproductive strategies of pipefishes and seahorses: a morphological and ultrastructural comparative study on three anatomically different pouches. J. Fish Biol. 61, 1465-1480.

Chellappa, S., Huntingford, F.A., Strang, R.H.C., Thomson, R.Y., 1989. Annual variation in energy reserves in male three-spined stickleback, Gasterosteus aculeatus L. (Pisces, Gasterostidae). J. Fish Biol. 35, 275-286.

Colborn, T., vom Saal, F.S., Soto, A.M., 1993. Developmental effects of endocrine-disrupting chemicals in wildlife and humans. Environ. Health Perspect. 101, 378-384.

Colborn, T., Dumanoski, D., Myers, J.P., 1996. Our Stolen Future. Penguin Book, New York, NY.

Damstra, T., Barlow, S., Bergman, A., Kavlock, R., van der Kraak, G., 2002. Global assessment of the state-of-the-science of endocrine disruptors. WHO/PCS/EDC/02.2. 
Dekoning, E.P., Karmaus, W., 2000. PCB exposure in utero and via breast milk. A review. J. Expo. Anal. Environ. Epidemiol. 10, 285-293.

Drozdov, A.L., Kornienko, E.S., Krasnolutsky, A.V., 1997. Reproduction and development of Syngnathus acusimils. Rus. J. Mar. Biol. 23, 265-268.

Duncker, G., 1915. Revision der Syngnathidae. Jahrbuch der Hamburgischen Wissenschaftlichen Antalten 32, 9-120.

Fein, G.G., Jacobson, J.L., Jacobson, S.W., Schwartz, P.M., Dowler, J.K., 1984. Prenatal exposure to polychlorinated biphenyls: effects on birth size and gestational age. J. Pediatr. 105, 315-320.

Fish, K.M., Principe, J.M., 1994. Biotransformations of Aroclor 1242 in Hudson River test tube microcosms. App. Environ. Microbiol. 60, 4289-4296.

Foster, G.D., Lippa, K.A., Miller, C.V., 2000. Seasonal concentrations of organic contaminants at the fall line of the Susquehanna river basin and estimated fluxes to Northern Chesapeake Bay, USA. Environ. Toxicol. Chem. 19, 992-1001.

Gundersen, D.T., Pearson, W.D., 1992. Paritioning of PCBs in the muscle and reproductive tissues of paddlefish, Polyodon spathula, at the falls of the Ohio River. Bull. Environ. Contam. Toxicol. 49, 455-462.

Guo, Y.L., Chen, Y.-C., Yu, M.-L., Hsu, C.-C., 1994. Early development of Yu-Cheng children born seven to twelve years after the Taiwan PCB outbreak. Chemosphere 29, 2395-2404.

Guo, Y.L., Lambert, G.H., 1995. Growth abnormalities in the population exposed in utero and early postnatally to polychlorinated biphenyls and dibenzofurans. Environ. Health Perspect. Suppl. 103, 117-122. 
Hollenberg, F., Wourms, J.P., 1995. Embryonic growth and maternal nutrient sources in Goodeid fishes (Teleostei: Cyprinodontiformes). J. Exp. Zool. 271, 379-394.

Herald, E. S., 1942. Three new pipefishes from the Atlantic coast of North and South America, with a key to the Atlantic American species. Stanford Ichthyol. Bull. 2, 125-134.

Herald, E. S., 1959. From pipefish to seahorse - a study of phylogenetic relationships. Proc. Calif. Acad. Sci. 29, 465-473.

Hildebrand, S.F., Schroeder, W.C., 1928. Fishes of the Chesapeake Bay. Bull. U.S. Bur. Fish., $182-185$.

Hollenberg, F., Wourms, J.P., 1995. Embryonic growth and maternal nutrient sources in Goodeid fishes (Teleostei: Cyprinodontiformes). J. Exper. Zool. 271, 379-394.

Huh, S.H., 1986. Ontogenetic food habits of four common fish species in seagrass meadows. J. Ocean. Soc. Korea 21, 25-33.

Hutchings, J.A., 1991. Fitness consequences of variation in egg size and food abundance in brook trout Salvelinus fontinalis. Evolution 45, 1162-1168.

Jacobson, J.L., Jacobson, S.W., 1996. Intellectual impairment in children exposed to polychlorinated biphenyls in utero. N. Engl. J. Med. 335, 783-789.

Jacobson, J.L., Jacobson, S.W., 1997. Evidence for PCBs as neurodevelopmental toxicants in humans. Neurotoxicol. 18, 415-424.

Jacobson, J.L., Jacobson, S.W., 2002. Breast-feeding and gender as moderators of teratogenic effects on cognitive development. Neurotoxicol. Teratol. 24, 249-358.

Jobling, M., 1995. Environmental Biology of Fishes. Chapman and Hall, New York, NY. 
Jonsson, H.T., Walker, E.M., Greene, W.B., Hughson, M.D., Hennigar, G.R., 1981. Effects of prolonged exposure to dietary DDT and PCB on rat liver morphology. Arch. Environ. Contam. Toxicol. 10, 171-183.

Kimbrough, R.D., Krouskas, C.A., 2001. Polychlorinated biphenyls, dibenzo-p-dioxins, and dibenzofurans and birth weight and immune and thyroid function in children. Reg. Toxicol. Pharmcol. 34, 42-52.

Kime, D.E., 2001. Endocrine Disruption in Fish. Kluwer Academic Pubishers, Boston, MA.

Kopp, T., 1976. PCBs in the United States Industrial Use and Environmental Distribution. Environmental Protection Agency, Washington, D.C.

Laden, F., Neas, L.M., Speigelman, D., Hankinson, S.E., Willett, W.C., Ireland, K., Wolff, M.S., Hunter, D.J., 1999. Predictors of plasma concentrations of DDE and PCBs in a group of U.S. women. Environ. Health Prespect. 107, 75-81.

Lockwood, S., 1867. The seahorse (Hippocampous hudsonius) and its young. Amer. Nat. 1, 225-234.

Longnecker, M.P., Wolff, M.S., Gladen, B.C., Brock, J.W., Grandjean, P., Jacobson, J.L., Korrick, S.A., Rogan, W.J., Weisglas-Kuperus, N., Picciotto-Hertz, I., Ayotte, P., Stewart, P., Winneke, G., Charles, M.J., Jacobson, S.W., Dewailly, E., Boersma, E.R., Altshul, L.M., Heinzow, B., Pagano, J.J., Jensen, A.A., 2003. Comparison of polychlorinated biphenyl levels across studies of human neurodevelopment. Environ. Health Perspect. 111, 65-70.

Lotufo, G.R., Farrar, J.D., Bridges, T.S., 2000. Effects of exposure source, worm density, and sex on DDT bioaccumulation and toxicity in the marine polychaete Neanthes arenaceodentata. Envir. Tox. Chem. 19, 472-484. 
Lourie, S.A., Vincent, A.J.C., Hall, H.J., 1999. Seahorses: An Identification Guide to the World's Species. Project Seahorse, London, UK.

Marsh-Matthews, E., Skierkowski, P., DeMarais, A., 2001. Direct evidence for mother-toembryo transfer of nutrients in the livebearing fish Gambusia geiseri. Copeia 2001, 1-6.

Orth, R. J., Heck, K.L., 1980. Structural components of eelgrass (Zostera marina) meadows in the lower Chesapeake Bay - fishes. Estuaries 3, 278-288.

Palanza, P.L., Howdeshell, K.L., Parmigiani, S., vom Saal, F.S., 2002. Exposure to a low dose of bisphenol A during fetal life or in adulthood alters maternal behavior in mice. Environ. Health Perspect. 110, 415-422.

Parichy, D.M., Kaplan, R.H., 1992. Maternal effects on offspring growth and development depend on environmental quality in the frog Bombina orientalis. Oecologia 91, 579-586.

Patandin, S., Koopman-Esseboom, C., de Ridder, M.A., Weisglas-Kuperus, N., Sauer, P.J., 1998. Effects of environmental exposure to polychlorinated biphenyls and dioxins on birth size and growth in Dutch children. Pediatr. Res. 44, 538-545.

Patandin, S., Lanting, C.I., Mulder, P.G., Boersma, E.R., Sauer, P.J., Weisglas-Kuperus, N., 1999. Effects of environmental exposure to polychlorinated biphenyls and dioxins on cognitive abilities in Dutch children at 42 months of age. J. Pediatr. 134, 33-41.

Persky, V., Turyk, M., Anderson, H.A., Hanrahan, L.P., Falk, C., Steenport, D.N., Chatterton, R., Freels, S., 2001. The effects of PCB exposure and fish consumption on endogenous hormones. Environ. Health Perspect. 109, 1275-1283.

Pinkney, A.E., Harshbarger, J.C., May, E.B., Melancon, M.J., 2001. Tumor prevalence and biomarkers of exposure in brown bullheads (Ameiurus nebulosus) from the tidal Potomac river, USA, watershed. Environ. Toxicol. Chem. 20, 1196-1205. 
Polishuk, Z.W., Wasserman, D., Wasserman, M., Cucos, S., Ron, M., 1977. Organochlorine compounds in mother and fetus during labor. Environ. Res. 13, 278-284.

Reznick, D., Callahan, H., Llauredo, R., 1996. Maternal effects on offspring quality in Poeciliid fishes. Amer. Zool. 36, 147-156.

Ripley, J.L., Foran, C.M., 2006. Differential parental nutrient allocation in two congeneric pipefish species (Syngnathidae: Syngnathus spp.). J. Exp. Biol. 209, 1112-1121.

Roelke, D.L., Sogard, S.M., 1993. Gender-based differences in habitat selection and activity level in the Northern pipefish (Syngnathus fuscus). Copeia 1993, 528-532.

Ryer, C.H., Boehlert, G.W., 1983. Feeding chronology, daily ration, and the effects of temperature upon gastric evacuation in the pipefish, Syngnathus fuscus. Environ. Biol. Fishes 6, 301-306.

Ryer, C.H., Orth, R.J., 1987. Feeding ecology of the Northern pipefish, Syngnathus fuscus, in a seagrass community of the lower Chesapeake Bay. Estuaries 10, 330-336.

Rylander, L., Stroemberg, U., Hagmar, L., 1996. Dietary intake of fish contaminated with persistent organochlorine compounds in relation to low birth weight. Scand. J. Work Environ. Health 22, 260-266.

Schwarzenbach, R.P., Gschwend, P.M., Imboden, D.M., 1993. Environmental Organic Chemistry. John Wiley \& Sons, Inc., New York, NY.

Sher, E.S., Xu, X.M., Adams, P.M., Craft, C.M., Stein, S.A., 1998. The effects of thyroid hormone level and action in developing brain: are these targets for the actions of polychlorinated biphenyls and dioxins? Toxicol. Ind. Health 14, 121-158.

Smith, D.H, 2006. The Reduction of Toxics in State Waters: Monitoring Year 2005. Department of Environmental Quality, Commonwealth of Virginia, Richmond, VA. 
Solbakken, J.E., Tilseth, S., Palmork, K.H., 1984. Uptake and elimination of aromatic hydrocarbons and chlorinated biphenyl in eggs and larvae of cod Gadus morhua. Mar. Ecol. 16, 297-301.

Stehr-Green, P.A., Welty, E., Steele, G., Steinberg, K., 1986. Evaluation of potential health effects associated with serum polychlorinated biphenyl levels. Environ. Health Perspect. $70,255-259$.

Stewart, P., Darvill, T., Lonky, E., Reihman, J., Pagano, J., Bish, B., 1999. Assessment of prenatal exposure to PCBs from maternal consumption of Great Lakes fish: an analysis of PCB pattern and concentration. Environ. Res A80, S87-S96.

Taylor, P.R., Stelma, J.M, Lawrence, C.E., 1989. The relation of polychlorinated biphenyls to birth weight and gestational age in the offspring of occupationally exposed mothers. Am. J. Epidemiol. 129, 395-406.

Teixeira, R.L., Musick, J.A., 1995. Trophic ecology of two congeneric pipefishes (Syngnathidae) of the lower York River, Virginia. Environ. Biol. Fishes 43, 295-309.

Thomas, P., 1988. Reproductive endocrine function in female Atlantic croaker exposed to pollutants. Mar. Environ. Res. 24, 179-183.

Thomas, P., 1990. Teleost model for studying the effects of chemicals on female reproductive endocrine function. J. Exp. Zool. Suppl. 4, 126-128.

Toschik, P.C., Rattner, B.A., McGowan, P.C., Christman, M.C., Carter, D.B., Hale, R.C., Matson, C.W., Ottinger, M.A., 2005. Effects of contaminant exposure on reproductive success of ospreys (Pandion haliaetus) nesting in Delaware River and Bay, USA. Environ. Toxicol. Chem. 24, 617-628. 
Van Handel, E., 1985. Rapid-determination of glycogen and sugars in mosquitoes. J. Amer. Mos. Cont. Assoc. 1, 299-301.

Wang, S.-L., Su, P.-H., Jong, S.-B., Guo, Y.L., Chou, W.-L., Papke, O., 2005. In utero exposure to dioxins and polychlorinated biphenyls and its relations to thyroid function and growth hormone in newborns. Environ. Health Perspect. 113, 1645-1650.

Wassermann, M., Wassermann, D., Cucos, S., Miller, H.J., 1979. World PCBs map: storage and effects in man and his biologic environment in the 1970s. Ann. N.Y. Acad. Sci. 320, 69124.

Watanabe, S., Watanabe, Y., 2001. Brooding season, sex ratio, and brood pouch development in the seaweed pipefish, Syngnathus schlegeli, in Otsuchi Bay, Japan. Ichthyol. Res. 48, 155-160.

Weiglas-Kuperus, N., 1998. Neurodevelopmental, immunological and endocrinological indices of perinatal human exposure to PCBs and dioxins. Chemosphere 37, 1845-1853.

Weiglass-Kuperus, N., Sas, T.C., Koopman-Esseboom, C., van der Zwan, C.W., de Ridder, M.A., Beishuizen, A., Hooijkass, H., Sauer, P.J., 1995. Immunologic effects of background prenatal and postnatal exposure to dioxins and polychlorinated biphenyls in Dutch infants. Pediatr. Res. 38, 404-410.

Wheeler, D.E., Buck, N.A., 1992. Protein, lipid and carbohydrate use during metamorphosis in the fire ant, Solenopsis xyloni. Physiol. Entomol. 17, 397-403.

Wourms, J., 1981. Viviparity: The maternal-fetal relationship in fishes. Amer. Zool. 21, 473-515. 
Chapter V: Influence of Estuarine Hypoxia on Feeding and Sound Production by Two Sympatric Pipefish Species (Syngnathidae) 


\begin{abstract}
This research utilizes the acoustic behavior of two sympatric pipefish species to assess the impact of hypoxia on feeding behavior. We collected northern, Syngnathus fuscus, and dusky pipefishes, Syngnathus floridae, from the relatively pristine Chincoteague Bay, Virginia, USA and audiovisually recorded behavior in the laboratory of fish held in normoxic $(>5 \mathrm{mg} / \mathrm{L}$ $\left.\mathrm{O}_{2}\right)$ and hypoxic $\left(2\right.$ and $\left.1 \mathrm{mg} / \mathrm{L} \mathrm{O}_{2}\right)$ conditions. Both species produced high frequency $(\sim 0.9$ $1.4 \mathrm{kHz}$ ), short duration ( 3 - $22 \mathrm{msec}$ ) clicks. Positive correlations were revealed between feeding strikes and wet weight of ingested food with the number of clicks produced. Thus, sound production serves as an accurate measure of feeding activity. Under hypoxia, reduced food intake corresponded with decreased sound production. Significant drops in both behaviors were evident after 1 day and continued as long as hypoxic conditions were maintained. Interspecific differences in sensitivity revealed a breakdown in the coupling of sound production with food intake in $S$. fuscus at $2 \mathrm{mg} / \mathrm{L} \mathrm{O}_{2}$ with clicks being produced in other contexts, specifically choking and food expulsion. Behavior and sound production by $S$. floridae, as well as $S$. fuscus, were impacted by $1 \mathrm{mg} / \mathrm{L} \mathrm{O}_{2}$ conditions. Reductions in feeding will ultimately impact growth, health, and eventually reproductive output as resources are devoted to survival instead of gamete production. This work suggests a novel technique to acoustically monitor field sites to assess pipefish populations and feeding changes associated with nutrient runoff.
\end{abstract}




\section{Introduction}

One of the most detrimental consequences of high nutrient loading from urbanization and expanded agricultural activities to coastal and estuarine waters is reduced dissolved oxygen (DO) levels (Diaz, 2001; Goldberg, 1995). Excess nutrients add organic matter by increasing primary production. Much of this organic matter settles to the bottom of shallow estuaries and bays as the nutrients entering the system exceed the capacity of the food chain to assimilate them. Coupled with physcial stratification, DO levels plummet (Miller, Poucher, \& Coiro, 2002; Diaz, 2001). The condition of low DO is known as hypoxia and is commonly defined as oxygen concentrations below 2 mg/L (Diaz, 2001; Diaz \& Rosenberg, 1995; Nixon, 1995). Waters impacted by hypoxia have severely stressed, and in some instances eliminated, populations by decreasing growth rate, altering behavior, disrupting endocrine hormones, and interfering with other physiological activities (Wu, Zhou, Randall, Woo, \& Lam, 2003; Taylor \& Miller, 2001).

The Chesapeake Bay is the largest estuary in the United States and yields more than $70 \%$ of the nation's blue crab production (Wang, Batiuk, Linker, \& Shenk, 2001). Extensive oxygen depletion dominates the summer months and in fact, conditions seasonally decline to anoxic levels ( $\geq 0.2$ mg/L O 2 ; Diaz, 2001; Breitburg, 1990; Holland, Shaughnessey, \& Hiegel, 1987; Officer, Biggs, Taft, Cronin, Tyler, \& Boynton, 1984). Accordingly, low DO is thought to be one of the central factors decreasing the capacity of the Chesapeake Bay to support economically important fisheries. Research points to early European settlement of the Bay's watershed, as long as 300 years ago, as the key event that set the stage for current hypoxia problems (Cooper \& Brush, 1991). However, the catalyst for today's troubles dates to the 1930 s, coinciding to the period during which the human population in the Bay watershed nearly doubled and the use of inorganic fertilizers tripled (Boesch, Brinsfield, \& Magnien, 2001; Zimmerman \& Canuel, 2000; 
Davidson, Merwin, Capper, Power, \& Shivers, 1997; Cornwell, Conley, Owens, \& Stevenson, 1996; Newcombe \& Horne, 1938).

Hypoxia induces a variety of physiological, biochemical, and behavioral reactions in aquatic organisms. One of the first responses involves the conservation of energy expenditure by depressing feeding activity. Research demonstrated that for Atlantic cod (Gadus morhua) and rainbow trout (Oncorhynchus mykiss) held at 60\% water oxygen saturation, food consumption decreased significantly (Chabot \& Dutil, 1999; Neji, Naimi, Lallier, \& De La Noüe, 1991). Reduced food intake is likely the main cause for growth impairment under hypoxic conditions. Both juvenile turbot (Scopthalmus maximus) and European sea bass (Dicentrarchus labrax) show decreased growth and food intake under hypoxia less than $3.5 \mathrm{mg} / \mathrm{L} \mathrm{O}_{2}$ (Pichavant, PersonLe-Ruyet, Le Bayon, Sévère, Le Roux, \& Boeuf, 2001; Pichavant, Person-Le-Ruyet, Le Bayon, Sévère, Le Roux, Quéméner et al., 2000). Further, hypoxia induces significant reductions in energy allocated to somatic growth and reproduction in carp (Cyprinus carpio; Zhou, Wu, Randall, \& Lam, 2001). Thus, while the direct effects of low DO are readily visible in fish kills, the sublethal effects of reduced feeding activity leading to decreases in growth and ultimately reproductive output are potentially as harmful to populations.

Acoustic signals play a key role in intraspecific and interspecific communication in many organisms. Anecdotal reports of sound production by Hippocampus seahorses have existed for more than a century (Dufossé, 1874). Seahorse sounds have been described as loud clicks resembling the snapping of a finger against the thumb (Fish \& Mowbray, 1970; Fish, 1954; Gill, 1905). Overall acoustic studies on the family Syngnathidae, comprising both the seahorses and pipefishes, have focused on only a handful of Hippocampus species. These investigations recorded sound production during the introduction to new surroundings, courtship and spawning, 
and feeding (Colson, Patek, Brainerd, \& Lewis, 1998; Bergert \& Wainwright, 1997; Fish \& Mowbray, 1970; Tarasov, 1963; Fish, 1953; Gill, 1905). Among these contexts, feeding clicks are the most widely documented. Behavioral observations revealed a positive correlation between sound production and feeding strikes in two seahorse species (Colson et al., 1998). The mechanism of sound production has long been hypothesized to be stridulatory in origin involving the articulation of bony edges of the skull (Fish \& Mowbray, 1970; Fish, 1953; Fish, Kelsey, \& Mowbray, 1952). Colson et al. (1998) recently confirmed this mechanism and pinpointed the supraoccipital-coronet articulation. Reports on sound production by the closely related pipefishes are considerably rare. Studies have noted clicking by Syngnathus louisanae (Burkenroad, 1931) and S. fuscus (Fish et al., 1952), but the context, mechanism, and measurement details of sounds produced by pipefishes have not been extensively documented.

This study recorded sounds produced during feeding by northern, Syngnathus fuscus, and dusky pipefishes, Syngnathus floridae, of the Chesapeake Bay region. Our first aim focused on exploring the relationship between sound production and feeding. Next, we wished to investigate the utility of sound production as a marker of behavioral changes by documenting the impact of low DO on feeding. Under hypoxic conditions, we predicted food intake and accordingly, temporal frequency of sound production would decrease. Finally, by studying two sympatric species, we wanted to examine potential interspecific differences in hypoxia sensitivity which might translate into severe impacts for the more susceptible species and impending alterations in community dynamics. The ultimate purpose of this investigation is to explore the utilization of pipefish acoustic behavior as an indicator of population changes in feeding due to environmental stressors, thereby providing a direct assessment of impacts on activities central to health and reproductive success. 


\section{Materials and methods}

Study animals

We collected pipefish by seining in the seasonally abundant shallow eelgrass beds (Zostera marina) of the Chincoteague Bay, VA, USA from May through September 2003-2005. Dissolved oxygen levels were recorded for each site with a YSI 85 handheld meter (YSI Incorporated, Yellow Springs, OH, USA). Pipefish were housed for a maximum of three days at the field station in aerated tanks with daily water changes before being transported to the laboratory in Kordon ${ }^{\circledR}$ breathing bags (Novalek Inc., Hayward, CA, USA) chilled with ice.

\section{Baseline feeding behavior}

Acclimation to laboratory conditions and diet spanned at least four weeks during which pipefish were housed in aerated, filtered 381 tanks at $24 \pm 1^{\circ} \mathrm{C}$ on a $14 \mathrm{~h}: 10 \mathrm{~h}$ photoperiod (06:00 on; 20:00 off). Photoperiod mimicked the average seasonal trend for the collection location, while temperature was maintained on the low end of the seasonal range to minimize disease and parasite infections. We used artificial seawater (Instant Ocean, Mentor, OH, USA) in the laboratory and decreased salinity from Bay averages of 30 to $20-25$ parts per thousand (ppt) to prevent parasite transfer between animals. Fish were separated by species and sex and maintained at a density of less than ten per tank. During acclimation, pipefish were fed frozen mysid shrimp and Artemia to satiation three times daily.

For the baseline feeding observations, pipefish were moved to acoustically buffered 381 tanks maintained as described above. Acoustic buffering was achieved by standing tanks on a 4 $\mathrm{cm}$ thick platform of rubber. Tanks held a single, large chunk of non-living coral in the center to buffer $\mathrm{pH}$, thereby circumventing any $\mathrm{pH}$ changes from the build-up of carbon dioxide (Sagasti, 
Schaffner, \& Duffy, 2001; Burnett, 1997). Artificial eelgrass fashioned from nylon rope filled the right side of the tank while the left contained the filter but was otherwise bare. Pairs of conspecific, same sex fish were moved one at a time with 5 minutes separating the introduction of each fish. We recorded acoustic and visual behavior during this introduction event beginning 1 minute before the first fish was added to 10 minutes after the second addition for a total taping of approximately 16 minutes. Food was not introduced during this period. Synchronous audiovisual data was recorded by an omnidirectional hydrophone (Aquarian Audio Products, Anacortes, WA, USA; model AQ-6; frequency range $20 \mathrm{~Hz}-100 \mathrm{kHz}$ ) connected to both a Sony Hi8 video camera recorder (model no. CCD-TRV43) and a Hewlett Packard Pavilion zv5000 laptop computer. The video camera stood on a tripod approximately $1.5 \mathrm{~m}$ in front of the tank. We directly digitized acoustic data by the connection to the laptop with use of CoolEdit 2000 (Syntrillium Software Corporation, Phoenix, AZ, USA) and Raven 1.2 sound analysis software (Cornell Laboratory of Ornithology, Ithaca, NY, USA). Sounds were digitized at a 16-bit resolution and a sampling rate of $44.1 \mathrm{kHz}$. All pumps, filters, and heaters were turned off for recording sessions.

Pipefish pairs were acclimated to the acoustic tanks for three to five days during which food was always introduced on the right, barren side of the tank. On the morning of the audiovisual recording, DO levels were documented. Next we videotaped and acoustically digitized the feeding event for 15 minutes starting with the introduction of food as previously described. Food was added to the right section of the tank in $0.33 \mathrm{~mL}$ increments every 5 minutes with a graduated, disposable pipette to ensure constant movement of an abundance of food. To quantify food consumption, we anaesthsized both fish immediately following the feeding session with 3-aminobenzoic acid ethyl ester (MS222; Sigma Aldrich, St. Louis, MO, 
USA) in saltwater. Standard length and weight were recorded. Ryer and Boehlert (1983)

showed that the time required to completely evacuate a meal in $S$. fuscus was 14.1 hours at $23^{\circ} \mathrm{C}$ with time decreasing at higher temperatures. Since the recording session was always the morning episode, the last feeding event was at least 16 hours earlier. Thus, the entire content of the gut was consumed during the feeding event of interest. Syngnathus fuscus and S. floridae possess relatively undifferentiated gastrointestinal tracts (Teixeira \& Musick, 1995; Ryer \& Orth, 1987). Therefore, the contents of the whole gastrointestinal tract were extracted and wet weight noted. We repeated these procedures on 10 males and females of each species for a grand total of 40 individuals examined.

\section{Behavior and sound analysis}

Videotapes were reviewed noting sound production and behavioral accompaniment, context, position in the water column and tank, individual identity, and counter time associated with sound production. The frequency of behavioral pairing with sound production was calculated for each individual and averaged for the species. Non-parametric Spearman correlations compared sound production with food intake, or the number of Artemia consumed, and wet weight of gut content to investigate the accuracy of sound production as a measure of feeding behavior for S. fuscus and S. floridae.

Five sounds produced by each pipefish were randomly selected for analysis. Background noise and artifacts characteristic of small tanks can complicate acoustic recordings (Okumura, Akamatsu, \& Yan, 2002; Yager, 1992; Parvulescu, 1967). Reflections and reverberations off the tank walls may interfere with parameter measurements when fish are resting on the bottom or against the side. Thus, only sounds produced when the fish was positioned in the water column 
were included in this analysis. Counter times and behavioral observations permitted straightforward identification of the appropriate sounds to analyze. We measured two acoustic variables: sound duration and peak frequency. Sound duration quantifies the temporal length of the sound and is calculated from the waveform. Peak frequency is the frequency at peak amplitude read from the spectrogram. Peak frequency is less affected by tank characteristics than other frequency assessments, making it the preferred measure in this study employing tanks of rather small size (de Amorim, 1996). We used Raven 1.2 exclusively to analyze the sounds.

\section{Feeding and acoustic behavior in hypoxic waters}

Syngnathus fuscus and S. floridae pipefish were moved to acoustic tanks and videotaped as described for the baseline study. After a 3-5 day acclimation, DO levels were noted and fish in normoxic conditions videotaped for a 15 -minute morning feeding session. This recording was designated day 0 . Immediately following the video and acoustic taping, DO levels were decreased over a four hour period by bubbling nitrogen gas into the tanks. Similar abrupt oxygen changes take place in the Chesapeake Bay (Sagasti et al., 2001; Kuo \& Neilson, 1987). Two hypoxic levels were tested: 2 and $1 \mathrm{mg} / \mathrm{L} \mathrm{O}_{2}$. The definition of hypoxia, the level at which many animals suffocate, encompasses DO levels below $2 \mathrm{mg} / \mathrm{L}$ and hence, this concentration was selected (Diaz, 2001; Diaz \& Rosenberg, 1995; Nixon, 1995). We chose $1 \mathrm{mg} / \mathrm{L}$ as a second treatment because DO concentrations below this level are lethal to Bay grasses (Holmer \& Bondgaard, 2001; Smith, Pregnall, \& Alberte, 1988). Dissolved oxygen levels were maintained within $\pm 0.2 \mathrm{mg} / \mathrm{L}$ of the target concentration. The YSI 85 meter was calibrated daily and DO levels checked five times a day. As the typical duration of hypoxic episodes in the Chesapeake Bay lasts 5 days (Sagasti et al., 2001; Kuo, Neilson, Brubaker, \& Ruzecki, 1993), maintenance of 
hypoxic conditions spanned 5 days in this study. We recorded morning feeding sessions on days 1,3 , and 5 . On the even days, $50 \%$ water changes were performed to maintain water quality and prevent the build-up of metabolic byproducts as the filters did not run during exposures. We established reservoirs of water of the appropriate DO level to be utilized during water changes to avoid large fluctuations in oxygen concentrations. Water quality was tested on odd days and measures were kept within an optimum range (ammonia $<0.50$ parts per million $(\mathrm{ppm})$, nitrate $<$ $10 \mathrm{ppm}$, nitrite $<0.50 \mathrm{ppm}, \mathrm{pH}=8.2-8.6$ ). Immediately following the feeding event on day 5 , we anaesthsized fish and recorded standard length and weight. Ten males and females of both species were tested at each hypoxia level for a total of 80 experimental pipefish.

Videotapes were reviewed noting the same measurements listed for the baseline study. Again, frequencies of sound production and food intake pairings were calculated for individuals and averaged for the species. Changes in food intake and sound production between species with duration of hypoxia exposure were investigated at both dissolved oxygen levels. Differences in sound production between oxygen concentrations with exposure period were also examined for each species. We randomly selected 5 sounds produced on day 0 and $3-5$ sounds from each hypoxia recording for sound duration and peak frequency analysis. Individuals that did not produce sound on one or more days or produced sound that did not meet the position requirements were not included in the analysis. Changes in sound variables between day 0 and hypoxic conditions on days 1, 3 and 5 were investigated for each pipefish. All statistical analyses were performed with JMP 5.1. 


\section{Results}

Dissolved oxygen levels in the Chincoteague Bay, VA, USA peaked at $9.62 \mathrm{mg} / \mathrm{L}$ in early May 2005 and dipped to a low reading of $3.76 \mathrm{mg} / \mathrm{L}$ in late July 2005. Monthly mean dissolved oxygen concentrations for June through August 2003-05 spanned 4.33-6.48 mg/L which were above hypoxic levels. Thus, we assumed this site did not experience extended periods of low dissolved oxygen and the fish had not been previously exposed to chronic hypoxia.

This study recorded 53.85 hours of feeding activity, 19.05 hours of introduction to new surroundings, and 1.72 hours of spawning behavior by $S$. fuscus and S. floridae with observation time divided equally between the two species.

\section{Feeding behavior}

Food intake in S. fuscus and S. floridae pipefishes is accompanied by a rapid head snap behavior in which head and snout elevation is immediately followed by a quick return to the resting position. That is, pipefish employ feeding strikes to capture and engulf food. Behavioral observations from this study indicate each feeding strike results in the ingestion of one Artemia. Tallying feeding strikes therefore estimates food consumption. In both species, food intake is always accompanied by sound production and a head snap (Table 1). However, pipefish can produce sound without ingesting food (Table 1). When a sound is produced, a head snap is also performed. However, S. fuscus and S. floridae can perform head snaps without sound accompaniment (Table 1).

Sound production is positively correlated with feeding strikes in $S$. fuscus $(\mathrm{r}=0.8528, \mathrm{p}<$ 0.0001; Fig. 1(a)) and S. floridae $(\mathrm{r}=0.9666, \mathrm{p}<0.0001$; Fig. 1(a)). The number of sounds 
produced also shows a significant positive correlation with the wet weight of food in the gut of $S$. fuscus $(\mathrm{r}=0.5968, \mathrm{p}=0.0055$; Fig. 1(b)) and S. floridae $(\mathrm{r}=0.5053, \mathrm{p}<0.0019$; Fig. 1(b)).

Sex differences in feeding behavior were not detected for S. floridae, but in S. fuscus, females ingested more food (2-way ANOVA, $\mathrm{F}=12.6148, \mathrm{p}<0.0001$; post-hoc Tukey HSD, Q $=2.6932, \alpha=0.05$ (post-hoc test identical for subsequent comparisons)), performed more head snaps $(\mathrm{F}=21.0858, \mathrm{p}<0.0001)$, and produced more sounds than males $(\mathrm{F}=22.9633, \mathrm{p}<$ 0.0001). Syngnathus fuscus females were also heavier $(\mathrm{F}=18.6249, \mathrm{p}<0.0001)$ and longer $(\mathrm{F}=$ 17.9056, $\mathrm{p}<0.0001$ ) and accordingly contained a greater wet weight of food in the gut than conspecific males $(\mathrm{F}=6.7583, \mathrm{p}=0.0010)$. Following that weight is positively correlated with both food intake $(r=0.6764, p=0.0011)$ and wet weight of ingested food $(r=0.7181, p=$ 0.0004), the sex differences in behavior can be attributed to larger $S$. fuscus females eating more. Since size distinctions account for the behavioral disparities, only interspecific differences are examined for the remaining data analyses.

\section{Feeding click characterization}

Syngnathus fuscus and S. floridae produce high frequency, short duration clicks while feeding (Table 2; Fig. 2). Body weight and peak frequency were not significantly related in either species (S. fuscus; $\mathrm{r}=0.0168, \mathrm{p}=0.8124 ;$ S. floridae $; \mathrm{r}=0.0477, \mathrm{p}=0.4345$ ). Interspecific differences were detected in sound duration (Nested 2-way ANOVA, F $=2.5047, \mathrm{p}$ $=0.0155 ;$ post-hoc Student's $\mathrm{t}, \mathrm{t}=1.9651, \alpha=0.05)$ and peak frequency (Nested 2-way ANOVA, $\mathrm{F}=6.6705, \mathrm{p}<0.0001 ;$ post-hoc Student's $\mathrm{t}, \mathrm{t}=1.9651, \alpha=0.05)$ with $S$. fuscus producing longer sounds of higher frequency. 
Click production by S. fuscus and S. floridae was largely limited to feeding activity and related events. Neither S. fuscus nor S. floridae clicked when moved individually or in same sex pairs to a new aquarium. Males aligned parallel to each other and quivered to one another while courting females, but clicks were not produced. Courting pairs also exchanged quivers. Although low frequency sound production most likely accompanied aggressive and courtship quiver behavior, it was not quantified in this study. Both S. fuscus and S. floridae clicked when held out of water during field collections and in the laboratory.

\section{Feeding behavior under $2 \mathrm{mg} / \mathrm{L}$ hypoxic conditions}

Syngnathus fuscus and S. floridae exhibited significant drops in food intake after one day of housing in dissolved oxygen concentrations of $2 \mathrm{mg} / \mathrm{L}$ (2-way ANOVA, $\mathrm{F}=9.3560, \mathrm{p}<$ 0.0001; post-hoc Tukey HSD, Q $=2.5983, \alpha=0.05$; Fig. 3(a)). Over the five day period of hypoxia, the number of feeding strikes did not change in either species (Fig. 3(a)). Both species responded to $2 \mathrm{mg} / \mathrm{L}$ dissolved oxygen levels with similar decreases in feeding activity (Fig. 3(a)). Likewise, sound production by S. fuscus and S. floridae decreased significantly following one day of housing in dissolved oxygen concentrations of $2 \mathrm{mg} / \mathrm{L}$ and the number of clicks did not recover or wane over the length of the hypoxia period (2-way ANOVA, $F=6.7955, p<$ 0.0001; post-hoc Tukey HSD, Q $=2.5983, \alpha=0.05$; Fig. 3(b)). Species differed in the number of sounds produced with S. floridae clicking significantly less often than S. fuscus (post-hoc Student's t, $t=1.9760, \alpha=0.05$; Fig. 3(b)). For this hypoxia level, pipefishes did not significantly differ in standard length (2-way ANOVA, $\mathrm{F}=2.0821, \mathrm{p}=0.1188$; Table 2) or weight (2-way ANOVA, $\mathrm{F}=1.3813, \mathrm{p}=0.2632$; Table 2) based on species or sex. 
The strong association of click production with food intake was no longer evident when oxygen concentration was held at $2 \mathrm{mg} / \mathrm{L}$. While every feeding strike was still accompanied by sound production for both species, many more clicks were produced without food intake under hypoxic conditions. The disassociation between feeding and clicks was more extreme for $S$. fuscus (2-way ANOVA, $\mathrm{F}=4.9723, \mathrm{p}<0.0001$; post-hoc Student's t, $\mathrm{t}=1.9772, \alpha=0.05$; Fig. 4(a-b)). That is, more of the clicks $S$. fuscus produced coincided with other behaviors besides food intake. This significant interruption in the correlation of sound and food intake for S. fuscus appeared one day after housing in $2 \mathrm{mg} / \mathrm{L}$ hypoxic conditions and showed the greatest disruption at day 5 (post-hoc Tukey HSD, Q = 2.6004, $\alpha=0.05$; Fig. 4(a)).

When food intake does not accompany sound production, one of four other behaviors corresponded with clicks in this study. Behaviors included a series of head snaps with a piece of food moving back and forth in the snout that eventually led to food expulsion, head snaps directly coupled with food expulsion, and head snaps at the water surface. The fourth situation involved head snaps unrelated to any context. Pipefish would simply perform a solo head snap at various locations in the tank and times during the behavioral recordings. When food intake did not coincide with sound production, a series of head snaps leading to food expulsion was the most performed behavioral accompaniment for both species (S. fuscus; 1-way ANOVA, F = 498.1768, $\mathrm{p}<0.0001$; post-hoc Tukey-Kramer HSD, $\mathrm{Q}=2.5839, \alpha=0.05$; Fig. 4(a); S. floridae; 1-way ANOVA, $\mathrm{F}=179.9342, \mathrm{p}<0.0001$; post-hoc Tukey-Kramer HSD, $\mathrm{Q}=2.5881, \alpha=0.05$; Fig. 4(b)). Syngnathus floridae coupled clicks with head snaps at the surface more often than $S$. fuscus during both the baseline and hypoxia periods (2-way ANOVA, $\mathrm{F}=2.7733, \mathrm{p}=0.0103$; post-hoc Student's t, $\mathrm{t}=1.9793, \alpha=0.05$; Fig. 4(a-b)). Interspecific distinctions and hypoxiainduced changes were not observed in the performance of food expulsion $(F=0.6079, p=$ 
0.7485), repetitive head snaps $(F=0.9603, p=0.4633)$, or solo head snaps $(F=0.3514, p=$ 0.9283; Fig. 4(a-b)).

\section{Feeding behavior under $1 \mathrm{mg} / \mathrm{L}$ hypoxic conditions}

Food intake declined significantly for S. fuscus and S. floridae when housed in dissolved oxygen conditions of $1 \mathrm{mg} / \mathrm{L}$ ( 2 -way ANOVA, $\mathrm{F}=25.5577, \mathrm{p}<0.0001$; Fig. 5(a)). For both species, the decrease in feeding strikes occurred after one day in hypoxic waters and did not recover or wane over the duration of exposure (post-hoc Tukey HSD, Q $=2.5981, \alpha=0.05$; Fig. 5(a)). Interspecific differences in food intake existed with $S$. fuscus performing more feeding strikes in $1 \mathrm{mg} / \mathrm{L}$ hypoxia (post-hoc Student's $\mathrm{t}, \mathrm{t}=1.9759, \alpha=0.05$; Fig. 5(a)). Click production by $S$. fuscus and $S$. floridae also decreased significantly under $1 \mathrm{mg} / \mathrm{L}$ hypoxic conditions (2-way ANOVA, F = 11.2447, $\mathrm{p}<0.0001$; Fig. 5(b)). Sound production dropped following one day of housing in a dissolved oxygen concentration of $1 \mathrm{mg} / \mathrm{L}$ and did not change over the duration of treatment (post-hoc Tukey HSD, Q = 2.5981, $\alpha=0.05$; Fig. 5(b)). Syngnathus fuscus pipefish produced significantly more clicks than S. floridae at each day over the five day hypoxia period (post-hoc Student's $t, t=1.9759, \alpha=0.05$; Fig. 5(b)). Similar to the baseline study, S. fuscus females were longer (2-way ANOVA, $\mathrm{F}=6.1806, \mathrm{p}=0.0016$; post-hoc Tukey HSD, $\mathrm{Q}=2.6898, \alpha=0.05$; Table 2) and heavier (2-way ANOVA, $\mathrm{F}=9.1189, \mathrm{p}=$ 0.0001; post-hoc Tukey HSD, Q $=2.6898, \alpha=0.05$; Table 2) than S. fuscus males.

Both species showed a similar breakdown in the correlation of sound production with food intake. All feeding strikes were accompanied by clicks, but after one day of $1 \mathrm{mg} / \mathrm{L}$ hypoxic conditions, S. fuscus and S. floridae coupled sound production with food intake less often (2-way ANOVA, F = 9.1747, p < 0.0001; Fig. 4(c-d)). Rather, clicks coincided more 
frequently with behaviors other than food ingestion. This disruption of the pairing of sound production with feeding strikes did not change over the course of hypoxia treatment for either species (post-hoc Tukey HSD, Q = 2.6023, $\alpha=0.05$; Fig. 4(c-d)).

When sound production was not associated with food intake, head snaps in a series ultimately leading to food expulsion were again the most commonly performed behavioral accompaniment to click production for S. fuscus (1-way ANOVA, $\mathrm{F}=112.3430, \mathrm{p}<0.0001$; Fig. 4(c)) and S. floridae (1-way ANOVA, F = 41.6517, $\mathrm{p}<0.0001$; Fig. 4(d)). Syngnathus floridae exhibited a significant decline in the frequency of expelling food with $1 \mathrm{mg} / \mathrm{L}$ hypoxia treatment (2-way ANOVA, $\mathrm{F}=3.7125, \mathrm{p}=0.0012$; post-hoc Tukey HSD, $\mathrm{Q}=3.0865, \alpha=0.05$; Fig. 4(d)). The decrease in this behavioral pairing appeared after one day and did not change over the duration of the hypoxia period. Although both species clicked at the surface more frequently under $1 \mathrm{mg} / \mathrm{L}$ dissolved oxygen conditions $(\mathrm{F}=3.4523, \mathrm{p}=0.0021$; post-hoc Tukey HSD, Q $=2.6064, \alpha=0.05)$, S. floridae exhibited a greater frequency of this behavior than $S$. fuscus (post-hoc Student's t, t =1.9805, $\alpha=0.05$; Fig. 4(c-d)). Differences in behavior performance due to species distinctions and hypoxia treatment were not observed for repetitive $(\mathrm{F}=1.1417, \mathrm{p}=0.3420)$ or solo head snaps $(\mathrm{F}=0.6668, \mathrm{p}=0.6997$; Fig. $4(\mathrm{c}-\mathrm{d}))$.

\section{Characterization of clicks produced under hypoxic conditions}

Analysis of sound parameters over the course of the five day $2 \mathrm{mg} / \mathrm{L}$ hypoxia treatment for both species did not reveal any significant individual differences in sound duration or peak frequency (Tables 2 and 3). Likewise, duration and peak frequency were not altered with a 5 day exposure to $1 \mathrm{mg} / \mathrm{L}$ dissolved oxygen levels (Tables 2 and 3 ). 
Comparisons between clicks produced during feeding strikes and those accompanying head snaps before food expulsion did not uncover significant differences in sound parameters. Specifically, sound duration and peak frequency were not different between feeding strikes and non-feeding behavior for either species (Table 3).

\section{Comparison of sound production temporal frequency at 2 and $1 \mathrm{mg} / \mathrm{L}$ hypoxia}

As stated previously, sound production decreased significantly for both species after one day of $2 \mathrm{mg} / \mathrm{L}$ and $1 \mathrm{mg} / \mathrm{L}$ hypoxia and did not fluctuate with the duration of exposure (S. fuscus; 2-way ANOVA, F = 6.5096, $\mathrm{p}<0.0001$; post-hoc Tukey HSD, $\mathrm{Q}=2.5968, \alpha=0.05$; Fig. 6(a); S. floridae; 2-way ANOVA, F = 11.8464, $\mathrm{p}<0.001$; post-hoc Tukey HSD, $\mathrm{Q}=2.5997, \alpha=0.05$; Fig. 6(b)). More clicks were produced by fish held at $2 \mathrm{mg} / \mathrm{L}$ hypoxic conditions compared to 1 $\mathrm{mg} / \mathrm{L}$ dissolved oxygen (S. fuscus; post-hoc Student's t, t =1.9752, $\alpha=0.05$; Fig. 6(a); $S$. floridae; post-hoc Student's t, t $=1.9768, \alpha=0.05$; Fig. 6(b)). Both species responded to the more severe hypoxic conditions with a reduction in sound production. 
Table 1. Behavioral pairings for Syngnathus fuscus (bold text) and Syngnathus floridae

\begin{tabular}{lccc}
\hline & Sound Production & Food Intake* & Head Snap \\
\hline \multirow{2}{*}{ Sound Production } & & $\mathbf{6 8 . 6}$ & $\mathbf{1 0 0}$ \\
\hline \multirow{2}{*}{ Food Intake } & $\mathbf{1 0 0}$ & 82.8 & 100 \\
\hline \multirow{2}{*}{ Head Snap } & 100 & & $\mathbf{1 0 0}$ \\
\hline
\end{tabular}

*The frequency (\%) of coupling the actions listed down the left column with the actions listed along the top are reported. For example, $68.6 \%$ of the sounds produced and $66.0 \%$ of the head snaps performed by $S$. fuscus accompany food intake. 
Table 2. Ranges of individual sizes and sound parameters of feeding clicks for the baseline and hypoxia studies

\begin{tabular}{cccccc}
\hline & $\begin{array}{c}\text { Weight } \\
(\mathrm{mg})\end{array}$ & $\begin{array}{c}\text { Standard } \\
\text { Length } \\
(\mathrm{mm})\end{array}$ & $\begin{array}{c}\text { Number } \\
\text { of Sounds } \\
(\mathrm{n})\end{array}$ & $\begin{array}{c}\text { Sound } \\
\text { Duration } \\
(\mathrm{ms})\end{array}$ & $\begin{array}{c}\text { Peak } \\
\text { Frequency } \\
(\mathrm{Hz})\end{array}$ \\
\hline Baseline Study & & & & & \\
S. fuscus Males & $978-3312$ & $131-185$ & 50 & $7-17$ & $1310-1440$ \\
Females & $2371-3848$ & $171-230$ & 50 & $8-16$ & $1298-1456$ \\
S. floridae Males & $930-2272$ & $138-167$ & 50 & $5-16$ & $996-1378$ \\
Females & $861-2153$ & $129-164$ & 50 & $5-22$ & $988-1446$ \\
\hline Hypoxia 2 mg/L & & & & & \\
S. fuscus Males & $524-1238$ & $116-157$ & 158 & $3-15$ & $985-1449$ \\
Females & $1157-1857$ & $146-176$ & 164 & $4-13$ & $1039-1397$ \\
S. floridae Males & $718-2104$ & $128-157$ & 152 & $3-16$ & $1019-1308$ \\
Females & $750-2472$ & $127-176$ & 182 & $5-15$ & $1071-1405$ \\
\hline Hypoxia 1 mg/L & & & & & \\
S. fuscus Males & $673-2625$ & $131-181$ & 113 & $4-15$ & $1087-1416$ \\
Females & $593-4008$ & $124-220$ & 111 & $3-11$ & $921-1405$ \\
S. floridae Males & $717-1880$ & $128-157$ & 88 & $4-15$ & $980-1395$ \\
Females & $751-2597$ & $127-186$ & 107 & $4-16$ & $942-1373$ \\
\hline
\end{tabular}


Table 3. Summary of p-values investigating individual differences in sound parameters over the course of hypoxia exposure and between clicks produced during food intake versus a series leading to food expulsion

\begin{tabular}{|c|c|c|c|c|c|c|c|c|}
\hline Parameter & $\begin{array}{l}\text { S. fuscus } \\
\mathrm{n}\end{array}$ & $\begin{array}{l}\text { p-values } \\
\text { Median }\end{array}$ & Min & Max & $\begin{array}{l}\text { S. floridae } \\
\mathrm{n}\end{array}$ & $\begin{array}{l}\text { p-values } \\
\text { Median }\end{array}$ & Min & Max \\
\hline \multicolumn{9}{|c|}{$\begin{array}{l}\text { Changes with exposure duration } \\
2 \mathrm{mg} / \mathrm{L}\end{array}$} \\
\hline Duration & 14 & 0.4006 & 0.2112 & 0.9834 & 20 & 0.4377 & 0.1371 & 0.9947 \\
\hline $\begin{array}{l}\text { Peak Frequency } \\
\mathbf{1 ~} \mathbf{~ m g} / \mathbf{L}\end{array}$ & 14 & 0.3452 & 0.1527 & 0.7147 & 20 & 0.4186 & 0.2279 & 0.7807 \\
\hline Duration & 13 & 0.3777 & 0.1980 & 0.5993 & 12 & 0.4686 & 0.2082 & 0.6931 \\
\hline Peak Frequency & 13 & 0.3774 & 0.1708 & 0.7386 & 12 & 0.4288 & 0.2119 & 0.9863 \\
\hline \multicolumn{9}{|c|}{$\begin{array}{l}\text { Comparison between feeding strikes and series leading to food expulsion } \\
2 \mathrm{mg} / \mathrm{L}\end{array}$} \\
\hline Duration & 11 & 0.3776 & 0.1984 & 0.7352 & 8 & 0.5540 & 0.1434 & 0.9109 \\
\hline $\begin{array}{l}\text { Peak Frequency } \\
1 \mathbf{~ m g / L}\end{array}$ & 11 & 0.4797 & 0.1155 & 0.9211 & 8 & 0.4870 & 0.1076 & 0.8703 \\
\hline Duration & 8 & 0.2837 & 0.1511 & 0.4868 & 13 & 0.3913 & 0.1646 & 0.4501 \\
\hline Peak Frequency & 8 & 0.6512 & 0.4367 & 0.9484 & 13 & 0.4040 & 0.1977 & 0.8954 \\
\hline
\end{tabular}



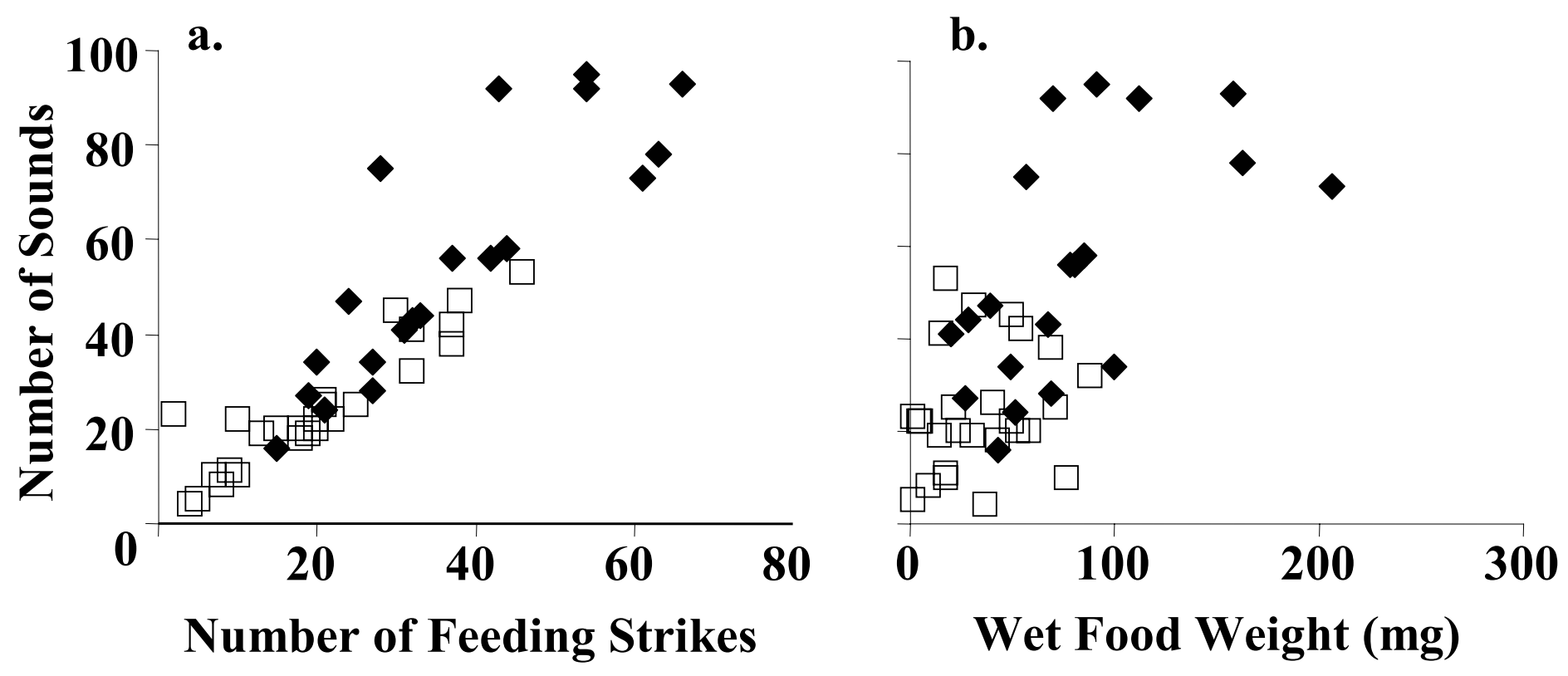

Fig. 1. Correlation of sound production with (a) feeding strikes and (b) wet weight (mg) of food in the gut of Syngnathus fuscus (black diamonds) and Syngnathus floridae (white squares). 


\section{Syngnathus fuscus}

\section{Syngnathus floridae}
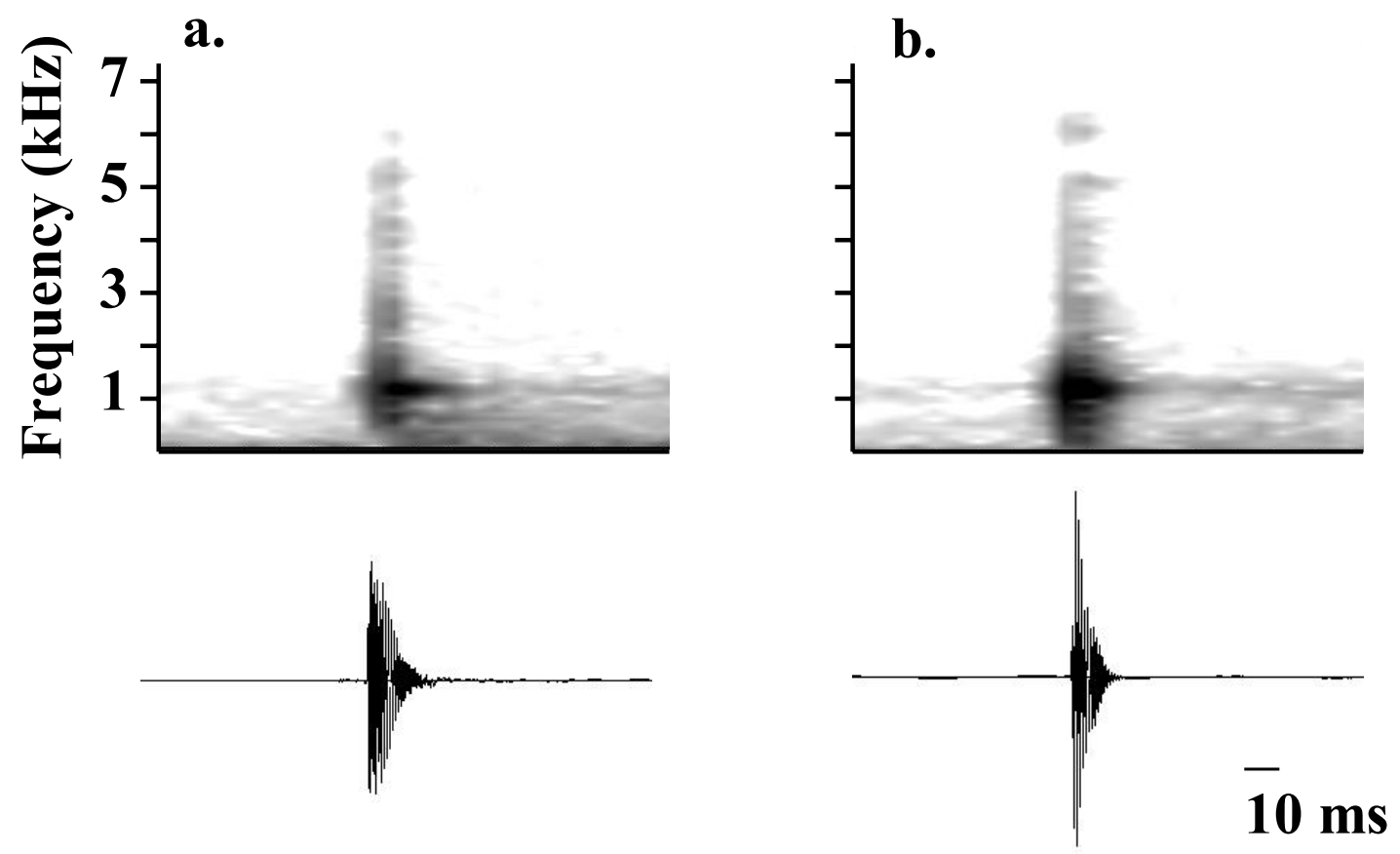

Fig. 2. Spectrograms (top) and waveforms (bottom) of clicks produced during food intake by (a) Syngnathus fuscus and (b) Syngnathus floridae. Peak frequency is denoted by the darker shading in the spectrogram. 


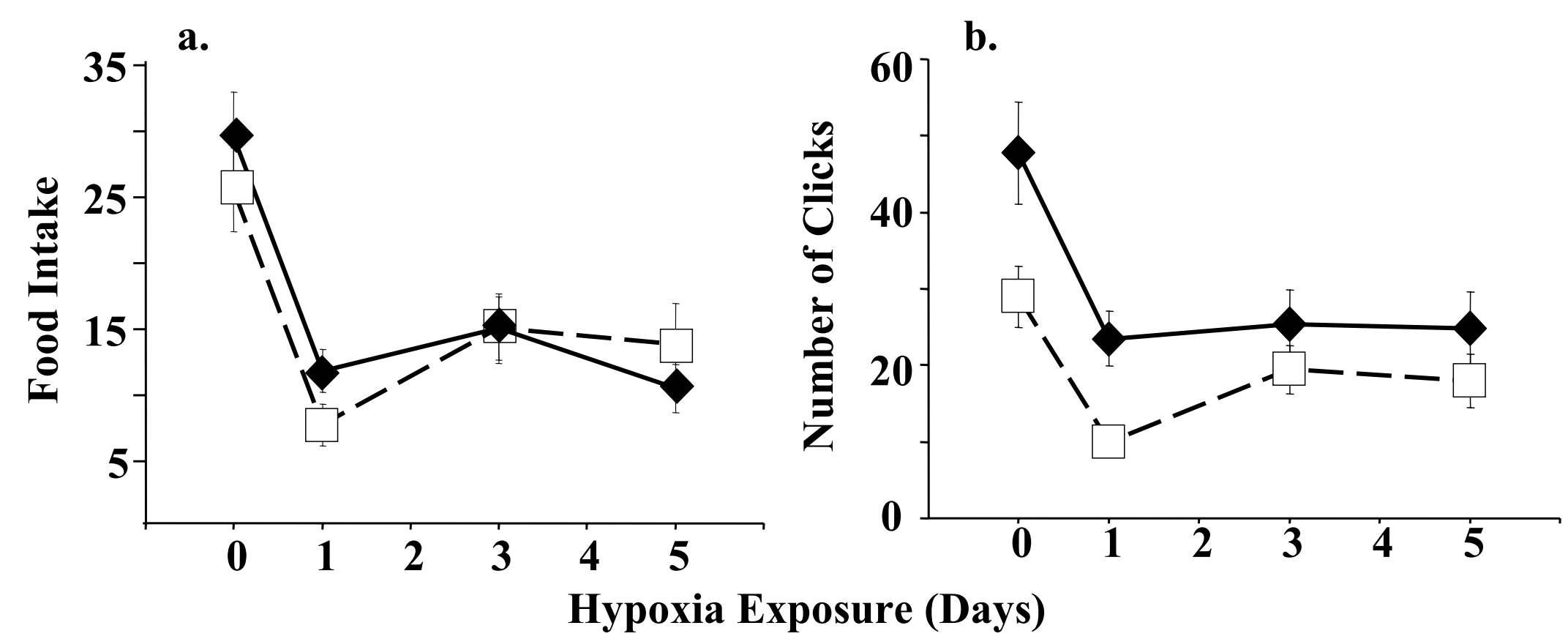

Fig. 3. Effects of five days of $2 \mathrm{mg} / \mathrm{L}$ hypoxia on (a) food intake and (b) sound production by Syngnathus fuscus (black diamonds) and Syngnathus floridae (white squares). Means \pm SE are plotted. 
Dissolved Oxygen $2 \mathrm{mg} / \mathrm{L}$

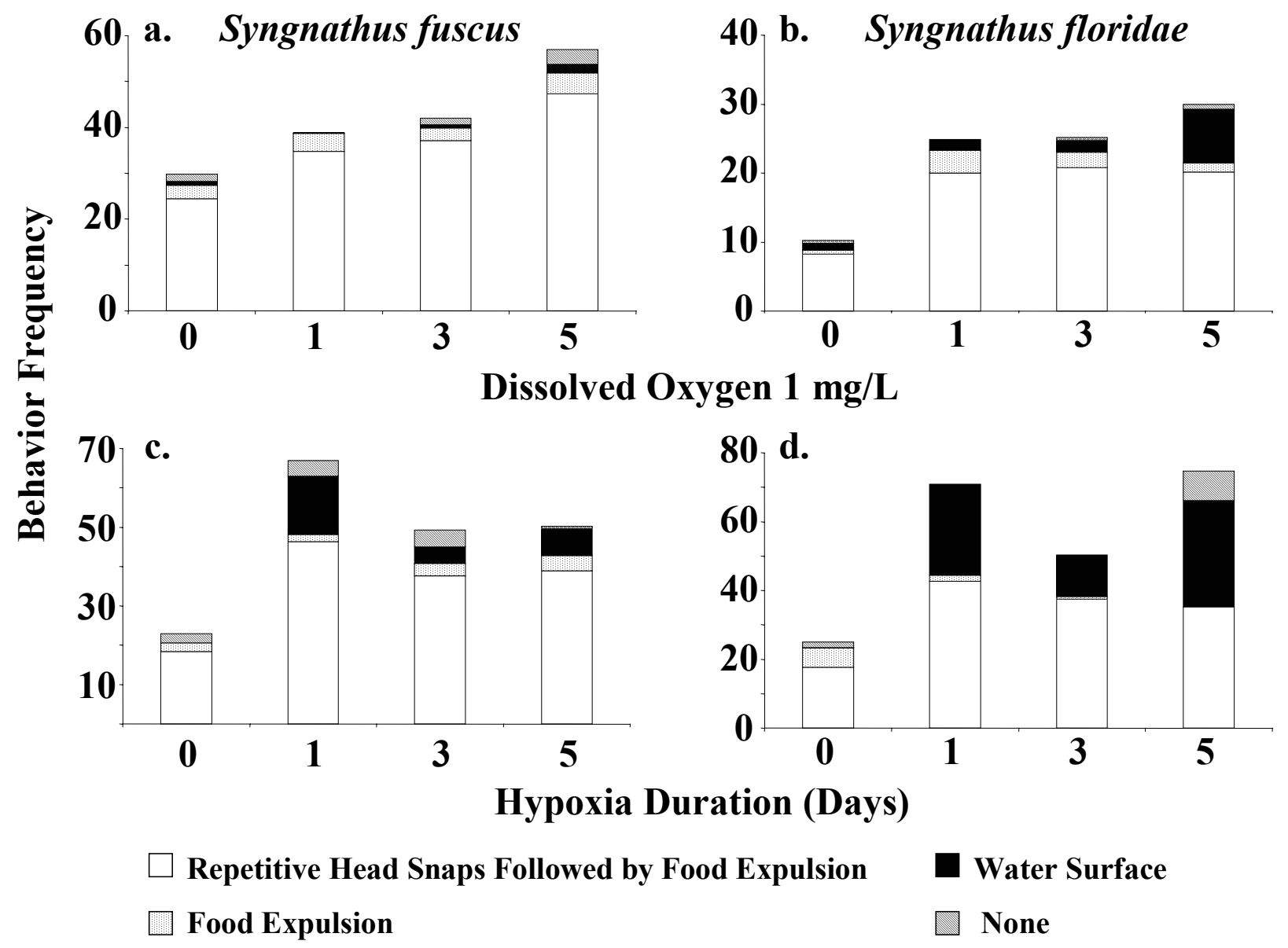

Fig. 4. Behaviors associated with click production when food is not ingested by (a, c) Syngnathus fuscus and (b, d) Syngnathus floridae at (a, b) $2 \mathrm{mg} / \mathrm{L}$ and (c, d) $1 \mathrm{mg} / \mathrm{L}$ hypoxia. The accompaniment of sound production by food intake comprises the remaining behavioral coupling. Note the differences in the ranges of the behavior frequencies (y-axis). 
a.

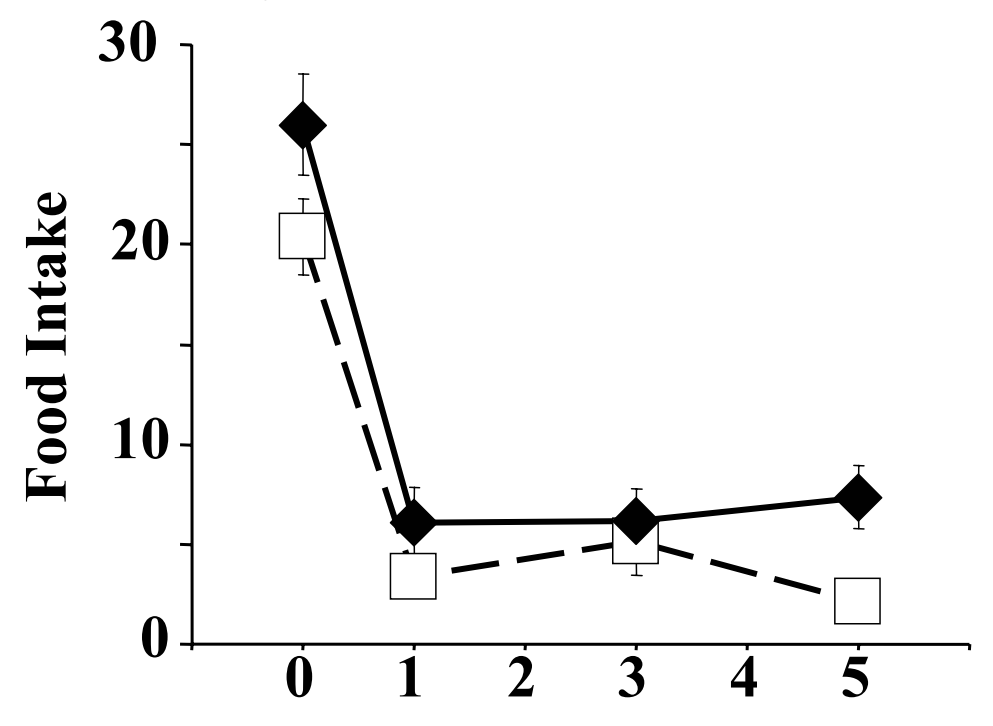

b.

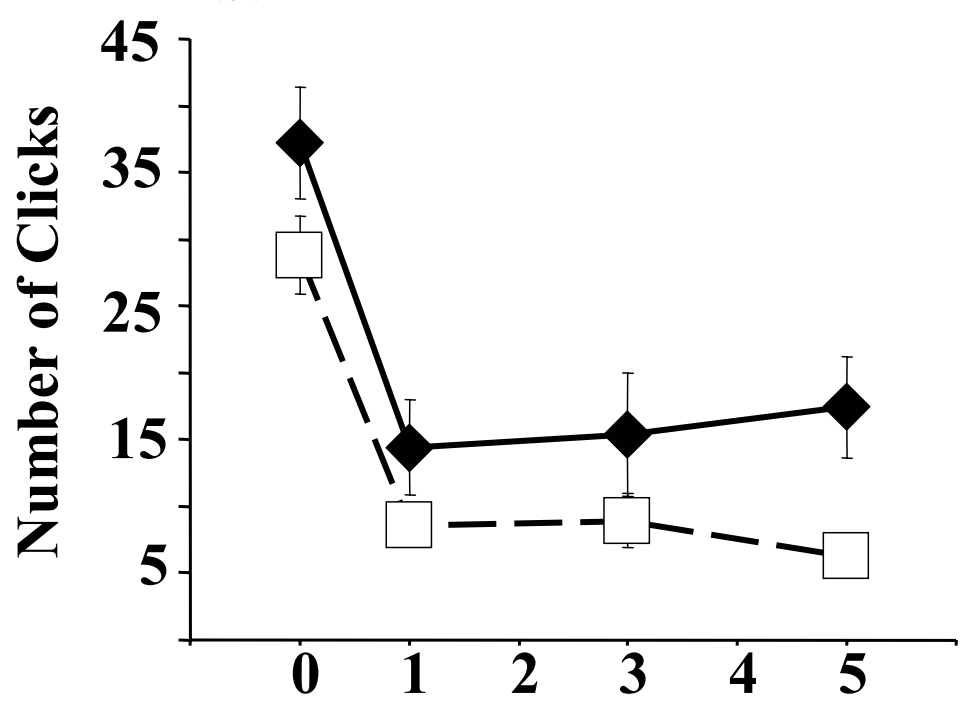

\section{Hypoxia Exposure (Days)}

Fig. 5. Effects of five days of $1 \mathrm{mg} / \mathrm{L}$ hypoxia on (a) food intake and (b) sound production by Syngnathus fuscus (black diamonds) and Syngnathus floridae (white squares). Means $\pm \mathrm{SE}$ are plotted. 

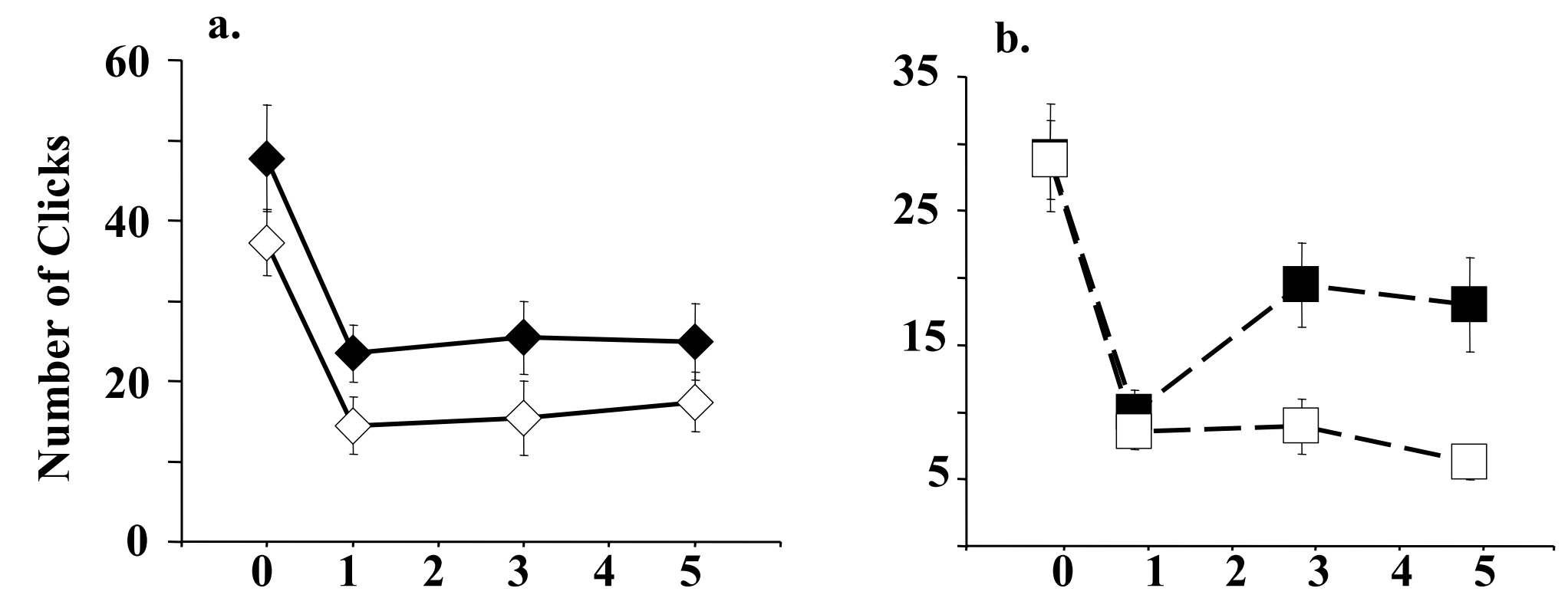

\section{Hypoxia Exposure (Days)}

Fig. 6. Effects of $2 \mathrm{mg} / \mathrm{L}$ (black) and $1 \mathrm{mg} / \mathrm{L}$ (white) hypoxia exposure on sound production by Syngnathus fuscus (diamonds) and Syngnathus floridae (squares). Means $\pm \mathrm{SE}$ are plotted. 


\section{Discussion}

This study demonstrates that sound production serves as an accurate measure of food intake in S. fuscus and S. floridae. Similar observations of seahorses have noted that over $93 \%$ of the feeding strikes were accompanied by clicks for Hippocampus zosterae and $100 \%$ for $H$. erectus (Colson et al., 1998). Both S. fuscus and S. floridae always produced sound concurrently with food intake. Regardless of posture differences, pipefish feeding strikes also resembled behavioral descriptions of seahorses. The prey capture sequence for $H$. erectus begins with a nearly synchronous, extremely rapid head elevation and mouth opening which brings the mouth into a position close to the prey (Bergert \& Wainwright, 1997). Within $2 \mathrm{msec}$ of head elevation, clicks are produced (Colson et al., 1998). Feeding strikes by H. zosterae that failed to produce detectable clicks showed reduced relative angular movements of specific skull components (Colson et al., 1998). Perhaps this restricted movement explains the performance of head snaps unaccompanied by sound in $S$. fuscus and $S$. floridae as just the presentation of the behavior was noted. Comparisons with Hippocampus species further support our data, indicating acoustic monitoring of pipefish feeding clicks accurately estimates food intake.

Based on the behavioral similarities with seahorses and the defining characters of stridulation sound production, we believe $S$. fuscus and $S$. floridae feeding clicks to be stridulatory in origin. Identifying traits of stridulatory sound include a non-harmonic structure (i.e. the spectrogram does not resolve into a series of horizontal, parallel bars at harmonic intervals) and a wide frequency spread with the maximum energy located in the higher end of the spectrum (Tavolga, 1964; Fish, 1954; Fish et al., 1952). Spectrograms of all of the clicks produced by S. fuscus and S. floridae either during food intake or the performance of other behaviors never revealed harmonics. Further, pipefish peak frequency measurements were 
moderately high, matching the ranges of H. zosterae $(2650-3430 \mathrm{~Hz})$ and H. erectus $(1960-$ $2370 \mathrm{~Hz}$; Colson et al., 1998). The lack of correlations between sound duration and frequency with fish size found for S. fuscus and S. floridae has also been documented for other species producing stridulatory sounds (Ladich, 1997). The wide frequency range of these sounds may be the reason for the absence of any relationship (Ladich, 1997). Analogous head movements and sound parameters point to a potential skull articulation mechanism comparable to what has been described for seahorses (Colson et al., 1998; Bergert \& Wainwright, 1997). An identical soundproducing structure cannot be assumed, however, due to differences in head morphology and posture.

The functional significance, if there is one, of Syngnathid feeding clicks is not known. This study did not investigate the ecological and behavioral implications of pipefish sound production. From casual observations, patterns did not emerge indicating a role for feeding clicks in communicating the presence of food or serving as a warning to deter conspecifics as has been suggested in other systems (Amorim, Stratoudakis, \& Hawkins, 2004; Amorim \& Hawkins, 2000). Many reports have documented the same feeding click being produced during courtship and spawning in seahorses (Colson et al., 1998; Fish \& Mowbray, 1970; Fish, 1954). We did not observe such clicks during reproduction in S. fuscus and S. floridae. Syngnathids are generally classified into polygamous pipefish and monogamous seahorses with a few pipefish species also exhibiting monogamy (Carcupino, Baldacci, Mazzini, \& Franzoi, 2002; Vincent, Ahnesjö, Berglund, \& Rosenqvist, 1992). Perhaps these differences in reproductive strategies translate into distinctions in click production. Reproductive divergence may explain the presence of a positive correlation between frequency and individual size in $H$. zosterae and the absence of such relationship in S. fuscus and S. floridae (Colson et al., 1998). Since most seahorse species 
maintain strong pair bonds, this correlation may aid in the identification of a partner. Syngnathid feeding clicks may not play a communicative role at all, as is the case for the feeding sounds of rainbow trout (Phillips, 1989). Future studies should investigate these hypothesized functions.

Shallow estuaries and bays are among the most intensively fertilized environments on earth (Nixon, 1990). The dramatic growth of human populations and agriculture along the coasts along with the difficulty and expense of removing nutrients, especially nitrogen, from wastewater further spurs hypoxic conditions in our estuaries (Wu, 1999; Goldberg, 1995). The Chesapeake Bay perhaps has suffered the greatest and as a result, monitoring programs continuously assess environmental conditions (Kiddon, Paul, Buffum, Strobel, Hale, Cobb et al., 2003; Dauer \& Alden, 1995). Our study site in the Chincoteague Bay, however, mirrors the habitats and community structure of the Chesapeake without the significant water quality problems. DO measurements never approached hypoxic conditions in our three years of monitoring and likewise, published data from 1997-98 presented only one recording below 5 $\mathrm{mg} / \mathrm{L}$. Overall, the Chincoteague Bay received an index of environmental integrity rating of "good" with less than $20 \%$ of the area exhibiting impairment (Kiddon et al., 2003). The pipefish used in this study, accordingly, were collected from a relatively pristine site and the behaviors observed are assumed to be unaltered by prior exposure to extreme environmental factors.

Pipefish are ideal model organisms for studying disturbances to estuarine habitats due to their seasonal abundance and behavioral responses. Syngnathids fall among the most abundant fish families occupying subaquatic vegetated environments worldwide, including the AtlanticMediterranean and Indo-Pacific regions (Howard \& Koehn, 1985; Pollard, 1984). In the Chesapeake Bay, S. fuscus ranks second in abundance among fishes followed by S. floridae in the sixth position (Orth \& Heck, 1980). Accordingly, the acoustic monitoring introduced in this 
study may be broadly applied to grass beds worldwide. The migration of $S$. fuscus and $S$. floridae from deeper waters to shallow Chesapeake Bay eelgrass beds overlaps summer hypoxic events (Wang et al., 2001; Lazzari \& Able, 1990; Holland et al., 1987; Officer et al., 1984). Thus, hypoxic conditions and pipefish populations are abundant concurrently. As swimming speed and elevated predation risk to brooding males limits movement, pipefish do not react to low DO by fleeing to oxygenated areas which is common for more mobile species (Ashley-Ross, 2002; Wannamaker \& Rice, 2000; Breitburg, 1992; Roelke \& Sogard, 1993). Instead these species remain a prevalent component of the macrobenthos. Adult S. fuscus and S. floridae survived and, in some cases, continued to feed at DO levels down to $1 \mathrm{mg} / \mathrm{L}$. The lethal 1-day concentration for juvenile $S$. fuscus approaches anoxia at $0.9 \mathrm{mg} / \mathrm{L} \mathrm{O}_{2}$ (Miller et al., 2002). Pipefish are tolerant to DO levels below lethal levels characterized for most commercially important species of the Bay and so, pipefish will survive while other fish are affected (Miller et al., 2002; Diaz \& Rosenberg, 1995; Davis, 1975). Acoustic monitoring of pipefish is a rather conservative estimate of impact because by the time these changes are noted, the consequences to commercial species are probably more severe.

Numerous studies have been carried out on the physiological and biochemical responses of aquatic animals, especially fishes, to hypoxia even though behavior may be more directly associated with individual and population survival and reproductive success. Behavior is very sensitive to contaminants, demonstrating links between effects at different levels of organization since changes are often associated with alterations at the biochemical level and may be readily translated into population level effects (Shumway, 1999; Weis, Smith, \& Zhou, 1999). Specifically, feeding is a consistent and highly sensitive endpoint (Weis et al., 1999; Morgan \& Kiceniuk, 1990). Hypoxia significantly reduces feeding in S. fuscus and S. floridae. Similar to 
studies determining lethal thresholds for low DO, depressed feeding in this study appeared immediately and did not change greatly beyond day 1 of treatment (Miller et al., 2002). For $S$. fuscus, energy assimilation depends on temperature with increases speeding gastric evacuation and increasing the number of prey items processed (Ryer \& Boehlert, 1983). With hypoxic events correlating to periods of high prey availability and energy intake, growth of S. fuscus during the summer can be greatly limited by the severe drops in food intake following one day of hypoxia. While the pipefish lifespan covers 1-2 years, most Chesapeake Bay epifaunal species live only one season (Able \& Fahay, 1998; Campbell \& Able, 1998; Abbe, 1987). Accordingly, short disruptions in feeding behavior could impact a considerable portion of an animal's lifetime. Even brief reductions in feeding carry the potential to profoundly impact growth and health and eventually reproductive output as resources are devoted to survival instead of gamete production. Hypoxia may also disrupt ecosystems by prompting alternations in predator/prey interactions. The two sympatric pipefish species in this study show significant differences in diet composition. Syngnathus floridae prefer to prey upon various sized grass shrimp, Palaemonetes pugio, while S. fuscus appear to be more gape-limited, only feeding on small crustaceans (Teixeira \& Musick, 1995; Ryer \& Orth, 1987; Ryer \& Boehlert, 1983). Amphipods, particularly Gammarus mucronatus, comprise the majority of the diet of S. fuscus and in fact, predation by S. fuscus is believed to largely control populations of this amphipod (Ryer \& Orth, 1987). Reduced predation could readily result in altered size structure and/or population density of prey species. Pipefish serve as an agent in the transfer of carbon from planktonic to benthic food webs (Ryer \& Boehlert, 1983). Hence, changes in feeding activity could greatly impact estuarine food webs and community dynamics. 
We documented changes in behaviors other than food intake. Decreased locomotion is commonly employed to conserve energy under hypoxia and a reduction in swimming may be the cause for the drop in feeding as searching for and capturing prey requires too much energy in these conditions (Wu, 2002). Our observations revealed the incidences of a choking-like behavior and food expulsion prevailed in hypoxic conditions when sound coincided with activities besides food consumption. The cause of this choking behavior was not investigated but one possibility may be related to respiration. If respiration in hypoxic conditions is rapid and shallow, the potential exists that the proper force may not be generated for normal section feeding and thus the food may become trapped in the snout or upper alimentary canal (Bergert \& Wainwright, 1997; Branch, 1966). For S. fuscus and S. floridae, energy wasted choking on and expelling food may exceed energy acquisition and thus, these pipefishes may simply forgo feeding. Further, the danger of having food caught in the snout may deter food intake. Changes in swimming activity with hypoxia and behavior following a choking event should be investigated to determine if locomotion is depressed or if choking-like behavior deters feeding in pipefish. Both species, but more so for S. floridae, gulped at the surface for air under hypoxic conditions. Naked gobies effectively use aquatic surface respiration (ASR) to escape low oxygen in the field (Breitburg, 1992). By swimming to the surface, fish can irrigate their gills with more highly oxygenated surface water (Gee \& Gee, 1991; Kramer, 1987). Due to inherent and hypoxia-induced swimming constraints, pipefish appear to employ the same behavior.

Interspecific differences in hypoxia sensitivity exist between $S$. fuscus and S. floridae. Syngnathus fuscus not only demonstrated a greater drop in food intake under $2 \mathrm{mg} / \mathrm{L} \mathrm{O}_{2}$, but also showed a more pronounced breakdown between food intake and sound production with clicks accompanying choking, food expulsion, and other behaviors more often. The increased 
performance of ASR by S. floridae also points to the greater sensitivity of S. fuscus. The ability to partake in ASR may serve as an adaptation to combat low DO levels. Further studies are needed to elucidate the reasons for sensitivity differences between these closely related, sympatric pipefishes. However, we hypothesize differences in their home ranges may offer an explanation. A more northerly distribution from Halifax to North Carolina characterizes $S$. fuscus, while S. floridae are common from the Chesapeake Bay to Panama (Dawson, 1982). These ranges are translated into differences in the time of appearance and disappearance from the Chesapeake Bay with $S$. fuscus migrating to the eelgrass beds earlier in the spring and reaching peak abundance in June and $S$. floridae hitting peak numbers in July and August and remaining in the estuary until October (Mercer, 1973). Hypoxia problems dominate the later summer months and more southerly bodies of water where human populations congregate, corresponding to when and where S. floridae are abundant (Diaz, 2001). Hence, prevalence in areas plagued with low DO is consistent with lower sensitivity. Regardless of an explanation for the species sensitivity differences, this distinction may serve as an additional indicator of ecosystem disturbance. Comparisons of the growth rate and population structure for S. fuscus and $S$. floridae may reveal different impacts on these species related to poor but not severe hypoxic conditions. Acoustic monitoring of populations with DO measurements could allow population assessment of these species separately during those periods when one species dominates the residency of eelgrass beds.

The practicality of acoustically monitoring pipefish feeding clicks is confounded by the variety of sound producing organisms inhabiting the same locales. Snapping shrimp (Crangonidae), mussels (Mytilidae), sea urchins (Echinometridae), and various crabs produce stridulatory sounds in estuarine and coastal ecosystems (Fish, 1964). Still, acoustic monitoring is 
feasible and a valuable tool to employ (Shumway, 1999). Passive acoustic detection of the damselfish, Dascyllus albisella, in the field allowed reproductive activity to be monitored over long periods and wide spatial scales (Mann \& Lobel, 1995). Confusion of sounds produced by other organisms should be readily separated by matching parameters within the ranges documented in this study. For our research, field recordings need to be conducted before acoustic screening is suggested as a monitoring technique. Syngnathus fuscus and S. floridae feed almost continuously over the daylight hours and as such, the counts of food intake reported in this study are not applicable to the field (Teixeira \& Musick, 1995; Ryer \& Orth, 1987; Ryer $\&$ Boehlert, 1983). Once a baseline feeding rate is established, acoustic monitoring techniques should be easy to apply. 


\section{References}

Abbe, G. R. (1987). Epifauna. In K. L. Heck (Ed.), Ecological studies in the middle reach Chesapeake Bay: Calvert Cliffs, lecture notes on coastal and estuarine studies No. 23 (pp. 82-96). New York: Springer-Verlang.

Able, K. W., \& Fahay, M. P. (1998). The first year in the life of estuarine fishes in the middle Atlantic Bight. New Jersey: Rutgers University Press.

Amorim, M. C., \& Hawkins, A. D. (2000). Growling for food: acoustic emissions during competitive feeding of the streaked gurnard. Journal of Fish Biology, 57, 895-907.

Amorim, M. C. P., Stratoudakis, Y., \& Hawkins, A. D. (2004). Sound production during competitive feeding in the grey gurnard. Journal of Fish Biology, 65, 182-194.

Ashley-Ross, M. A. (2002). Mechanical properties of the dorsal fin muscle of seahorse (Hippocampus) and pipefish (Syngnathus). Journal of Experimental Zoology, 293, 561577.

Bergert, B. A., \& Wainwright, P. C. (1997). Morphology and kinematics of prey capture in the Syngnathid fishes Hippocampus erectus and Syngnathus floridae. Marine Biology, 127, 563-570.

Boesch, D. F., Brinsfield, R. B., \& Magnien, R. E. (2001). Chesapeake Bay eutrophication: scientific understanding, ecosystem restoration, and challenges for agriculture. Journal of Environmental Quality, 30, 303-320.

Branch, G. M. (1966). Contribution to the function morphology of fishes. Part III. The feeding mechanism of Syngnathus acus Linnaeus. Zoologica Africana, 2, 69-89.

Breitburg, D. L. (1990). Near-shore hypoxia in the Chesapeake Bay: patterns and relationships among physical factors. Estuarine, Coastal and Shelf Science, 30, 593-609. 
Breitburg, D. L. (1992). Episodic hypoxia in Chesapeake Bay: interacting effects of recruitment, behavior, and physical disturbance. Ecological Monographs, 62, 525-546.

Burkenroad, M. D. (1931). Notes on the sound-producing marine fishes of Louisiana. Copeia, 1931, 20-29.

Burnett, L. E. (1997). The challenges of living in hypoxic and hypercapnic aquatic environments. American Zoology, 37, 633-640.

Campbell, B. C., \& Able, K. W. (1998). Life history characteristics of the Northern pipefish, Syngnathus fuscus, in Southern New Jersey. Estuaries, 3, 470-745.

Carcupino, M., Baldacci, A., Mazzini, M., \& Franzoi, P. (2002). Functional significance of the male brood pouch in the reproductive strategies of pipefishes and seahorses: a morphological and ultrastructural comparative study on three anatomically different pouches. Journal of Fish Biology, 61, 1465-1480.

Chabot, D., \& Dutil, J. D. (1999). Reduced growth of Atlantic cod in non-lethal hypoxic conditions. Journal of Fish Biology, 55, 472-491.

Colson, D. J., Patek, S. N., Brainerd, E. L., \& Lewis, S. M. (1998). Sound production during feeding in Hippocampus seahorses (Syngnathidae). Environmental Biology of Fishes, 51, 221-229.

Cooper, S. R., \& Brush, G. S. (1991). Long-term history of Chesapeake Bay anoxia. Science, 992-996.

Cornwell, J. C., Conley, D. J., Owens, M., \& Stevenson, J. C. (1996). A sediment chronology of the eutrophication of the Chesapeake Bay. Estuaries, 19, 488-499.

Dauer, D. M., \& Alden, R. W. (1995). Long-term trends in the macrobenthos and water quality of the lower Chesapeake Bay (1985-1991). Marine Pollution Bulletin, 2, 840-850. 
Diaz, R. J. (2001). Overview of hypoxia around the world. Journal of Environmental Quality, 2, 275-281.

Daiz, R. J., \& Rosenberg, R. (1995). Marine benthic hypoxia: a review of its ecological effects and the behavioural responses of benthic macrofauna. Oceanography and Marine Biology Annual Review, 22, 245-303.

Davidson, S. G., Merwin, J. G., Capper, J., Power, G., \& Shivers, F. R. (1997). Chesapeake waters: four centuries of controversy, concern, and legislation. Centreville, Maryland: Tidewater Publications.

Davis, J. C. (1975). Minimal dissolved oxygen requirements of aquatic life with emphasis on Canadian species: a review. Journal of the Fisheries Research Board of Canada, 32, $2295-2232$

Dawson, C. E. (1982). Family Syngnathidae. In J. E. Bölke (Ed.), Fishes of the Western North Atlantic, Part Eight, Order Gasterosteiformes, Suborder Syngnathoidei (pp. 1-172). New Haven, Connecticut: Yale University.

de Amorim, M. C. P. (1996). Sound production in the blue-green damselfish, Chromis viridis (Cuvier, 1830) (Pomacentridae). Bioacoustics, 6, 265-272.

Dufossé, P. M. (1874). Recherches sur les bruits et les ons expressif que font entendre les poissons d'Europe et sur les organes producteurs de ces phenomenes acoustiques ainsi que sur les appareils de l'audition de plusieurs de ces animaux. Annales des Sciences Naturelle, 3, 1-134.

Fish, M. P. (1953). The production of underwater sound by the Northern seahorse, Hippocampus hudsonius. Copeia, 2, 93-94. 
Fish, M. P. (1954). The character and significance of sound production among fishes of the Western North Atlantic. Bulletin of the Bingham Oceanographic Collection, 14, 1-109.

Fish, M. P. (1964). Biological sources of sustained ambient sea noise. In W. H. Tavolga (Ed.), Marine Bioacoustics (pp. 175-194). New York: Pergamon Press.

Fish, M. P., \& Mowbray, W. H. (1970). Sounds of western North Atlantic fishes. Baltimore: Johns Hopkins Press.

Fish, M. P., Kelsey, J., \& Mowbray, W. H. (1952). Studies on the production of underwater sound by North Atlantic coastal fishes. Journal of Marine Research, 11, 180-193.

Gee, J. H. \& Gee, P. A. (1991). Reactions of gobioid fishes to hypoxia: buoyancy control and aquatic surface respiration. Copeia, 1991, 17-28.

Gill, T. (1905). The life history of the sea horses (Hippocampids). Proceedings of the United States National Museum, 1408, 805-814.

Goldberg, E. D. (1995). Emerging problems in the coastal zone for the twenty-first century. Marine Pollution Bulletin, 31, 152-158.

Holland, A. F., Shaughnessey, A. T., \& Hiegel, M. H. (1987). Long-term variation in a mesohaline Chesapeake Bay macrobenthos: spatial and temporal patterns. Estuaries, 10, $227-245$.

Holmer, M., \& Bondgaard, E. J. (2001). Photosynthetic and growth response of eelgrass to low oxygen and high sulfide concentrations during hypoxic events. Aquatic Botany, 70, 2938.

Howard, R. K., \& Koehn, J. D. (1985). Population dynamics and feeding ecology of pipefish (Syngnathidae) associated with eelgrass beds of Western Port, Victoria. Australian Journal of Marine and Freshwater Research, 36, 361-370. 
Kiddon, J. A., Paul, J. F., Buffum, H. W., Strobel, C. S., Hale, S. S., Cobb, D., et al. (2003). Ecological condition of US Mid-Atlantic estuaries, 1997-1998. Marine Pollution Bulletin, 46, 1224-1244.

Kramer, D. L. (1987). Dissolved oxygen and fish behavior. Environmental Biology of Fishes, 18, $81-92$.

Kuo, A. Y., \& Neilson, B. J. (1987). Hypoxia and salinity in Virginia estuaries. Estuaries, 10, 277-283.

Kuo, A. Y., Neilson, B. J., Brubaker, J. M., \& Ruzecki, E. P. (1993). Data report: hypoxia in the York River, 1991. Virginia Institute of Marine Science Data Report No. 47, Gloucester Point, Virginia.

Ladich, F. (1997). Comparative analysis of swimbladder (drumming) and pectoral (stridulation) sounds in three families of catfishes. Bioacoustics, 8, 185-208.

Lazzari, M. A., \& Able, K. W. (1990). Northern pipefish, Syngnathus fuscus, occurrences over the Mid-Atlantic Bight continental shelf: evidence of seasonal migration. Environmental Biology of Fishes, 27, 177-185.

Mann, D. A., \& Lobel, P. S. (1995). Passive acoustic detection of sounds produced by the damselfish Dascyllus albisella (Pomacentridae). Bioacoustics, 6, 199-213.

Mercer, L. P. (1973). The comparative ecology of two species of pipefish (Syngnathidae) in the York River, Virginia. (pp. 37). MS Thesis, Virginia Institute of Marine Science, The College of William and Mary, Gloucester Point, Virginia.

Miller, D. C., Poucher, S. L., \& Coiro, L. (2002). Determination of lethal dissolved oxygen levels for selected marine and estuarine fishes, crustaceans, and a bivalve. Marine Biology, 140, 287-296. 
Morgan, M. J., \& Kiceniuk, J. W. (1990). Effect of fenitrothion on the foraging behavior of juvenile Atlantic salmon. Environmental Toxicology and Chemistry, 9, 489-495.

Neji, H., Naimi, N., Lallier, R., \& De La Noüe, J. (1991). Relationships between feeding, hypoxia, digestibility and experimentally induced furnunculosis in rainbow trout. Fish Nutrition in Practice, 61, 187-197.

Newcombe, C. L., \& Horne, W. A. (1938). Oxygen poor waters in the Chesapeake Bay. Science, 88,80 .

Nixon, S. W. (1990). Marine eutrophication: a growing international problem. Ambio, 3, 101.

Nixon, S. W. (1995). Coastal marine eutrophication: a definition, social causes, and future concerns. Ophelia, 41, 199-219.

Officer, C. B., Biggs, R. B., Taft, J. L., Cronin, L. E., Tyler, M. A., \& Boynton, W. R. (1984). Chesapeake Bay anoxia: origin, development and significance. Science, 233, 22-27.

Okumura, T., Akamatsu, T., \& Yan, H.Y. (2002). Analyses of small tank acoustics: empirical and theoretical approaches. Bioacoustics, 12, 330-332.

Orth, R. J., \& Heck, K. L. (1980). Structural components of eelgrass (Zostera marina) meadows in the lower Chesapeake Bay - fishes. Estuaries, 4, 278-288.

Parvulescu, A. (1967). The acoustics of small tanks. In W.N. Tavolga (Ed.), Marine bioacoustics (pp. 7-13). Oxford: Pergamon Press.

Phillips, M. J. (1989). The feeding sounds of rainbow trout, Salmo gairdneri Richardson. Journal of Fish Biology, 35, 589-592.

Pichavant, K., Person-Le-Ruyet, J., Bayon, N. L., Sever, A., Roux, A. L., \& Boeuf, G. (2001). Comparative effects of long-term hypoxia on growth, feeding and oxygen consumption in juvenile turbot and European sea bass. Journal of Fish Biology, 59, 875-883. 
Pichavant, K., Person-Le-Ruyet, J., Bayon, N. L., Sévère, A., Le Roux, A., Quéméner., L., et al. (2000). Effects of hypoxia on growth and metabolism of juvenile turbot. Aquaculture, $188,103-114$.

Pollard, D. A. (1984). A review of ecological studies on seagrass-fish communities, with particular reference to recent studies in Australia. Aquatic Botany, 18, 3-42.

Roelke, D. L., \& Sogard, S. M. (1993). Gender-based differences in habitat selection and activity level in the Northern pipefish (Syngnathus fuscus). Copeia, 2, 528-532.

Ryer, C. H., \& Boehlert, G. W. (1983). Feeding chronology, daily ration, and the effects of temperature upon gastric evacuation in the pipefish, Syngnathus fuscus. Environmental Biology of Fishes, 3/4, 301-306.

Ryer, C. H., \& Orth, R. J. (1987). Feeding ecology of the Northern pipefish, Syngnathus fuscus, in a seagrass community of the lower Chesapeake Bay. Estuaries, 4, 330-336.

Sagasti, A., Schaffner, L. C., \& Duffy, J. E. (2001). Effects of periodic hypoxia on mortality, feeding and predation in an estuarine epifaunal community. Journal of Experimental Marine Biology and Ecology, 258, 257-283.

Shumway, C. A. (1999). A neglected science: applying behavior to aquatic conservation. Environmental Biology of Fishes, 55, 183-201.

Smith, R. D., Pregnall, A. M., \& Alberte, R. S. (1988). Effects of anaerobiosis on root metabolism of Zostera marina (eelgrass): implications for survival in reducing sediments. Marine Biology, 98, 131-141.

Tarasov, N. I. (1963). Zhivyye zvuki morya (The live sounds of the sea). Washington, D.C.: U.S. Naval Oceanographic Office. 
Tavolga, W. N. (1964). Sonic characteristics and mechanisms in marine fishes. In W.N. Tavolga (Ed.), Marine bioacoustics (pp. 195-211). Oxford: Pergamon Press.

Taylor, J. C., \& Miller, J. M. (2001). Physiological performance of juvenile southern flounder, Paralichthys lethostigma (Jordan and Gilbert, 1884), in chronic and episodic hypoxia. Journal of Experimental Marine Biology and Ecology, 258, 195-214.

Teixeira, R. L., \& Musick, J. A. (1995). Trophic ecology of two congeneric pipefishes (Syngnathidae) of the lower York River, Virginia. Environmental Biology of Fishes, 43, 295-309.

Vincent, A., Ahnesjö, I., Berglund, A., \& Rosenqvist, G. (1992). Pipefishes and seahorses: are they all sex role reversed? Trends in Ecology and Evolution, 237-241.

Wang, P., Batiuk, R., Linker, L., \& Shenk, G. (2001). Assessment of best management practices for improvement of dissolved oxygen in Chesapeake Bay estuary. Water Science and Technology, 7, 173-180.

Wannamaker, C. M., \& Rice, J. A. (2000). Effects of hypoxia on movements and behavior of selected estuarine organisms from the southeastern United States. Journal of Experimental Marine Biology and Ecology, 249, 145-163.

Weis, J. S., Smith, G. M., \& Zhou, T. (1999). Altered predator/prey behavior in polluted environments: implications for fish conservation. Environmental Biology of Fishes, 55, 43-51.

Wu, R. S. S. (1999). Eutrophication, trace organics and water-borne pathogens: pressing problems and challenges. Marine Pollution Bulletin, 39, 11-22.

Wu, R. S. S. (2002). Hypoxia: from molecular responses to ecosystem responses. Marine Pollution Bulletin, 45, 35-45. 
Wu, R. S. S., Zhou, B. S., Randall, D. J., Woo, N. Y. S., \& Lam, P. K. S. (2003). Aquatic hypoxia is an endocrine disruptor and impairs fish reproduction. Environmental Science and Technology, 37, 1137-1141.

Yager, D. D. (1992). Underwater acoustic communication in the African pipid frog Xenopus borealis. Bioacoustics, 4, 1-24.

Zhou, B. S., Wu, R. S., Randall, D. J., \& Lam, P. K. (2001). Bioenergetics and RNA/DNA ratios in the common carp (Cyprinus carpio) under hypoxia. Journal of Comparative Physiology B, 171, 49-57.

Zimmerman, A. R., \& Canuel, E. A. (2000). A geochemical record of eutrophication and anoxia in Chesapeake Bay sediments: anthropogenic influence on organic matter composition. Marine Chemistry, 69, 117-137. 
Chapter VI: Discussion and Future Studies 
These studies establish an expansive knowledgebase on two members of the family Syngnathidae furthering our understanding of population dynamics, reproductive physiology, and behavioral ecology. As few baseline data exist for seahorses and pipefishes, the state of many populations is uncertain. For instance, collections by traders indicate seahorse populations from Southeast Asia have perhaps declined by $15-50 \%$ in 5 years and Philippine species may have suffered population declines of $30-70 \%$ over 10 years (Vincent, 1996). However, these decreases are only vague estimates as historic population densities are unknown. Collections from the Chesapeake Bay at this point would not provide a reliable baseline of Syngnathid populations. The 2005 State of the Bay report released annually by the Chesapeake Bay Foundation indicated a state dangerously out of balance with a failing score of 27 out of a possible 100 (Chesapeake Bay Foundation, 2005). Fish consumption advisories traversed the watershed, Virginia issued new advisories for PCBs and mercury, and hypoxic dead zones spanned more than $40 \%$ of the Bay's main stem (Chesapeake Bay Foundation, 2005). In May, scientists predicted one of the worst summer anoxic events on record based on the amounts of nitrogen and phosphorus pollution that washed into the Bay over the spring. Accordingly, reports documented the volume of the Bay that was anoxic was among the largest in 21 years of monitoring (Chesapeake Bay Foundation, 2005). Given the grave state of the Chesapeake Bay, quantification of pipefish catches and categorization of size frequencies would only depict remaining populations. Our characterization of a neighboring, pristine site (Chapter 1) provides an appropriate comparison to assess the state of Syngnathid populations in the Chesapeake Bay. The landmark Chesapeake 2000 Agreement signed in June 2000 called for the restoration of the Bay by 2010. Implemented efforts have been unsuccessful; today's rating falls below the 2000 score of 28 (Chesapeake Bay Foundation, 2005). Evaluation of Chesapeake Bay collections 
against our data may spur remediation efforts. Moreover, a comparison may predict the future of pipefish populations in the Chesapeake Bay.

The results of the paternal brood pouch investigations (Chapter 2 and 3) provide an understanding of the divergence of reproductive physiology in related species and how functional diversity relates to the potential of environmental conditions to impact development. The preliminary brood pouch study (Chapter 2) examining the divergence in reproductive physiology among Syngnathus fuscus and Syngnathus floridae presents a comparative understanding of parental influence on development in Syngnathidae. These studies are among the first to explore the physiological basis for parental care in these species, and describe physiological differences between male brood pouches within this group of pipefishes. Ultimately our results call for revision of Syngnathid taxonomy and phylogeny. Syngnathid phylogeny is largely based on the three paternal brood pouch types (Herald, 1959; Wilson et al., 2001). Accordingly, the location and enclosure of the male brood pouch defines primary taxonomic groupings (Duncker, 1915; Herald, 1959). This classification centers on more enclosed pouches displaying greater anatomical complexity and thus providing greater paternal care (Berglund et al., 1986; Masonjones, 2001; Carcupino et al., 2002). Considering the extensive paternal care provided by S. fuscus, some pipefish species with an intermediate enclosure may parallel nutrient allocation roles fulfilled by some seahorses. Additional species, both pipefish and seahorse, should be investigated in the future to further elucidate the diversity of physiological functions performed by the paternal brood pouch.

Understanding the importance of parental care in S. fuscus and S. floridae has a direct application to conservation of rare and threatened seahorse species while studying related, abundant populations. Unlike seahorses, pipefish are not popular in the medicinal, aquaria, and 
souvenir trades. Yet, our results highlight the potential physiological similarities between some pipefish and seahorse species. The second portion of this research (Chapter 3) begins to define the role environmental factors play in reproductive disruption and species sustainability, and development as an indicator of population stress. Future studies could pinpoint specific developmental stages that exhibit heighten sensitivity. Efforts focused on laboratory rearing of pipefish fry may even result in captive rearing protocols for seahorses, establishing a supply to satisfy medicinal and aquaria demands.

Understanding the placental-like function of the brood pouch offers a unique perspective into mammalian placental physiology. Parallels may be drawn to cases of maternal limitation of fetal growth. These comparisons may suggest physiological mechanisms for the development of placental connectivity as well as insights into the developmental effects of limited parental investment. Moreover with the emerging realization of the detrimental physiological consequences of persistent toxicants, the unknown developmental impacts on exposed fetuses to the plethora of currently used chemicals demand examination. An animal model with placental provisioning, a large brood size, rapid development, and multiple mating events would be ideal to address this issue at a rate comparable to the introduction of potential developmental contaminants. Pipefish provide a unique animal system to investigate developmental impairment from placental exposure. Our preliminary studies suggest $S$. fuscus may be used to rapidly screen environmental chemicals and characterize potential developmental damage, ultimately before they are witnessed in the human population. Before implementation of a pipefish model, the impacts of well characterized environmental contaminants should be verified. Following equivalent outcomes in multiple developmental endpoints, a screening use would be validated. 
We have already initiated several studies to examine additional points of comparison between mammalian and pipefish placenta provisioning. First, we are attempting to trace the movement of lipids and proteins from brooding males to developing embryos by following the transfer of heavy-labeled nutrients (Appendix I). In addition to nutrients, the Syngnathid brood pouch has also been hypothesized to transfer steroids to developing embryos. Considering PCB exposure commonly manifests into changes in endogenous steroid hormone concentrations (Colborn et al., 1993; Nisbet et al., 1996), we are interested in not only exploring the role of the brood pouch in supplying steroids, but also potential alterations in steroid levels due to estrogenic contaminant exposure. A capillary electrophoresis (CE) technique capable of separating 7 steroids in 4 minutes is currently being developed to investigate this mechanism (Appendix II).

We have attempted to quantify the extent of vascularization in the $S$. fuscus and $S$. floridae brood pouches. In mammalian systems, the extent of placental vascularization has been related to vascular endothelial growth factor (VEGF; Regnault et al., 2002), as have changes in zebrafish angiogenesis (Childs et al., 2002). We hypothesized that comparisons of VEGF release and VEGF target tissues across S. fuscus and S. floridae might explain morphological and physiological differences in the male brood pouch. Studies of zebrafish have shown that VEGF and angiogenesis inhibitors injected into either the yolk sac or the perivitelline space increase and decrease angiogenesis in embryos respectively (Serbedzija et al., 1999). Along these lines, we attempted to determine the effectiveness of brood pouch VEGF treatment to change connectivity by injecting flourescein dye into the circulation of the male parent. The extent of blood vasculature has been quantified using a similar technique in the liver of rainbow trout (Hinton et al., 1989) and in zebrafish embryos (Childs et al., 2002). Preliminary observations 
from this experiment were unclear and time consuming to quantify. The next proposed approach involves in vivo microscopy and chemiluminescence procedures repeatedly utilized to view microcirculation of the spinotrapezius muscle of rats (Boegehold, 2002; Nurkiewicz and Boegehold, 2004; Nurkiewicz et al., 2004).

Among the human health concerns raised by PCB studies is the potential impact on fetal neural development. Preliminary histological analyses have begun to look for fry deformities and anatomical measures of the development of the central nervous system (Appendix III). Ongoing investigations will compare the size and cell number of neurons in the brain following parental PCB exposure (Foran and Bass, 1998). Cytochrome P450 1A (CYP1A) activity is another measure that has been frequently performed in humans and wildlife and thus could be readily analyzed in pipefish (Kennedy et al., 1993; Nacci et al., 1998; Willett et al., 2001; Meyer et al., 2002). CYP1A activity, which is induced by PCBs, indicates changes in transcriptional activity in response to halogenated aromatic hydrocarbons including PCBs. Determining CYP1A activity following developmental exposure is important because it will indicate exposure (Pereg et al., 2002), the level of activation of the aryl hydrocarbon receptor (Hahn, 1998), changes in the metabolic capacity for xenobiotics, and their potential transformation to more potent carcinogens (Hankinson, 1995). We attempted to assess CYP1A activity in microsomal samples from pooled fry (Appendix IV). Future studies will employ techniques to examine activity in individual fry (Appendix IV; Nacci et al., 1998; Meyer et al., 2002; Schewerte and Fritsche, 2003).

The bioacoustics work (Chapter 4) is vital in understanding aspects of the behavioral ecology of Syngnathids and developing novel monitoring tools for assessing the impacts of ecosystem changes on pipefish populations. Numerous studies have been carried out on the 
physiological and biochemical responses of aquatic animals, especially fishes, to environmental toxicants and disturbances, even though behavior ultimately determines survival and reproductive success. These biochemical and enzymatic tests regularly require blood and/or tissue samples where animals must often be sacrificed. Behavior is very sensitive to contaminants, demonstrating links between effects at different levels of organization since changes are frequently associated with alterations at the biochemical level and may be readily translated into population level effects (Shumway, 1999; Weis et al., 1999). Correspondingly, one of our aims in conducting this research was to develop a simple, inexpensive monitoring technique that may be tested directly in the field without disturbing the populations we wish to protect. Bioacoustics is generally a rich communication modality and as such, sound production is dominant among inhabitants of eelgrass beds where visual range is limited by turbidity and dense vegetation. Known sound producers in the Chincoteague and Chesapeake Bays include toadfish, pufferfish, pipefish, striped bass, croakers, snapping shrimp, mussels, sea urchins, crabs, and various other species (Fish et al., 1952; Fish, 1964; Winn, 1967). The results of this bioacoustics study introduce a protocol that parallels, and even surpasses, many biochemical assays in ease and time requirements. Simply counting the number of sounds evades experimental mistakes due to poor technique and reagents. Our findings should now be practiced in the field. Once feeding rates are characterized for pipefish populations occupying the relatively pristine Chincoteague Bay, the state of Chesapeake Bay populations may be explored. Further, with the plethora of sound producers in these Bays, similar monitoring protocols could be developed to assess these more commercially important species.

Observations of quiver exchange during courtship and spawning warrant the investigation of low frequency sound production in $S$. fuscus and $S$. floridae. The lowest tone audible to 
people of normal hearing is about $20 \mathrm{~Hz}$ (Tavolga, 1971; Payne, 1995). At $20 \mathrm{~Hz}$, sound is "felt" rather than heard. In water, when the receiver is within close range to the sound source, the propagation of sound involves particle displacement. This displacement has been termed the near field effect (Harris and van Bergeijk, 1962; Harris, 1964; van Bergeijk, 1964, 1967; Tavolga, 1971). Sounds exchanged by fishes in the near field are often low frequency and detected by the lateral line as well as the auditory system (Webb, 2002). While the accompaniment of courtship and spawning with quiver behavior has been documented in other teleost species, audible sounds correspond with these behaviors as the pair is often separated by sizeable distance of at least three body lengths (Lobel, 1998; Ripley and Lobel, 2004). Observations of S. fuscus and S. floridae are novel in noting the exchange of close proximity quiver behavior potentially concurrent with very low frequency sound production. These low frequency sounds may signal the readiness and orientation of mates to coordinate spawning activities. Understanding what role, if any, low frequency sounds play in reproduction may have implications for conservation. Motor boat wake and breaking waves generate low frequency sounds that could interfere with pair formation and courtship (Means and Heitmeyer, 2001; Ohta et al., 2005; Vagle and Burch, 2005).

In summary, these distinct projects share a common focus to directly investigate changes in nutrient uptake with individual health and population success ultimately impacted by these environmental factors. These studies could be readily repeated with the environmental factors switched. In fact, hypoxia has recently been classified as an endocrine disruptor. Blood plasma levels of sex steroids significantly decrease in carp held in hypoxic conditions (Wu et al., 2003). Disturbances in the balance of testosterone and estradiol during embryonic stages have also been documented aside delayed development and malformations (Shang and $\mathrm{Wu}, 2004$ ). Reduced egg 
production at low dissolved oxygen is common for many invertebrate species (Grove and Breitburg, 2005; Sedlacek and Marcus, 2005). Accordingly, parental nutrient allocation under hypoxic conditions would prove an interesting study. Overall, these projects present a foundation for numerous, valuable future investigations. 


\section{References}

Berglund, A., Rosenqvist, G., Svensson, I., 1986. Reversed sex roles and parental energy investment in zygotes of two pipefish (Syngnathidae) species. Mar. Ecol. Prog. Ser. 29, 209-215.

Boegehold, M.A., 2002. Microvascular structure and function in salt-sensitive hypertension. Microcirculation 9, 225-241.

Carcupino, M., Baldacci, A., Mazzini, M., Franzoi, P., 2002. Functional significance of the male brood pouch in the reproductive strategies of pipefishes and seahorses: a morphological and ultrastructural comparative study on three anatomically different pouches. J. Fish Biol. 61, 1465-1480.

Chesapeake Bay Foundation, 2005. State of the Bay 2005. Chesapeake Bay Foundation, Annapolis, Maryland.

Childs, S., Chen, J.-N., Garrity, D.M., Fishman, M.C., 2002. Patterning of angiogenesis in the zebrafish embryo. Development 129, 973-982.

Colborn, T., vom Saal, F.S., Soto, A.M., 1993. Developmental effects of endocrine-disrupting chemicals in wildlife and humans. Environ. Health Perspect. 101, 378-384.

Duncker, G., 1915. Revision der Syngnathidae. Jahrbuch der Hamburgischen Wissenschaftlichen Antalten 32, 9-120.

Fish, M.P., 1964. Biological sources of sustained ambient sea noise. In: Tavolga, W.H. (Ed.), Marine Bio-Acoustics. Pergamon Press, Oxford, UK, pp. 175-194.

Fish, M.P., Kelsey, A.S., Mowbray, W.H., 1952. Studies on the production of underwater sound by North Atlantic coastal fishes. J. Mar. Res. 11, 180-193. 
Foran, C.M., Bass, A.H., 1998. Preoptic AVT immunoreactive neurons of a teleost fish with alternative reproductive tactics. Gen. Comp. Endocr. 111, 271-282.

Grove, M., Breitburg, D.L., 2005. Growth and reproduction of gelatinous zooplankton exposed to low dissolved oxygen. Mar. Ecol. Prog. Ser. 301, 185-198.

Hahn, M.E., 1998. The aryl hydrocarbon receptor: a comparative perspective. Comp. Biochem. Physiol. C 121, 23-53.

Hankinson, O., 1995. The aryl hydrocarbon receptor complex. Annu. Rev. Pharmacol. Toxicol. $35,307-340$.

Harris, G.G. 1964. Considerations on the physics of sound production by fishes. In: Tavolga, W.H (Ed.), Marine Bio-Acoustics. Pergamon Press, Oxford, UK, pp. 233-247.

Harris, G.G., van Bergeijk, W.A., 1962. Evidence that the lateral-line organ responds to nearfield displacements of sound sources in water. J. Acoust. Soc. Am. 34, 1831-1841.

Herald, E.S., 1959. From pipefish to seahorse - a study of phylogenetic relationships. Proc. Calif. Acad. Sci. 29, 465-473.

Hinton, D.E., Lauren, D.J., McCuskey, R.S., McCuskey, P.A., Lantz R.C., 1989. In vivo microscopy of liver microvasculature in rainbow trout (Oncorhynchus mykiss). Mar. Environ. Res. 28, 407-410.

Kennedy, S.W., Lorenzen, A., James, C.A., Collins, B.T., 1993. Ethoxyresorufin-O-deethylase and porphyrin analysis in chicken hepatocyte cultures with a fluorescence multiwell plate reader. Anal. Biochem. 211, 102-112.

Lobel, P.S., 1998. Possible species specific courtship sounds by two sympatric cichlid fishes in Lake Malawi, Africa. Environ. Biol. Fishes 52, 443-452. 
Masonjones, H.D., 2001. The effect of social context and reproductive status on the metabolic rates of dwarf seahorses (Hippocampus zosterae). Comp. Biochem. Physiol. 129A, 541555.

Means, S.L., Heitmeyer, R.M., 2001. Low-frequency sound generation by an individual openocean breaker. J. Acoust. Soc. Am. 110, 761-768.

Meyer, J.N., Nacci, D.E., Di Giulio, R.T., 2002. Cytochrome P4501A (CYP1A) in killifish (Fundulus heteroclitus): heritability of altered expression and relationship to survival in contaminated sediments. Toxicol. Sciences 68, 69-81.

Nacci, D., Coiro, L., Kuhn, A., Champlin, D., Munns, W., Specker, J., Cooper, K., 1998. Nondestructive indicator of ethoxyresorufin- $O$-deethylase activity in embryonic fish. Environ. Toxicol. Chem. 17, 2481-2486.

Nisbet, I.C.T., Fry, D.M., Hatch, J.J., Lynn, B., 1996. Feminization of common tern embryos is not correlated with exposure to specific PCB congeners. Bull. Environ. Contam. Toxicol. $57,895-901$.

Nurkiewicz, T.R., Boegehold, M.A., 2004. Calcium-independent release of endothelial nitric oxide in the arteriolar network: onset during rapid juvenile growth. Microcirculation 11, 453-462.

Nurkiewicz, T.R., Porter, D.W., Barger, M., Castranova, V., Boegehold, M.A., 2004. Particulate matter exposure impairs systemic microvascular endothelium-dependent dilation. Environ. Health Perspect. 112, 1299-1306.

Ohta, K., Okabe, K., Morishita, I., Ozaki, S., Frisk, G.V., 2005. Inversion for seabed geoacoustic properties in shallow water experiments. Acoust. Sci. Technol. 26, 326-337. 
Payne, R., 1995. Appendix: a primer of ocean acoustics. In: Payne, R., Among Whales. Scribner, New York, New York, USA, pp. 359-402.

Pereg, D., Dewally, E., Poirier, G.G., Ayotte, P., 2002. Environmental exposure to polychlorinated biphenyls and placental CYP1A1 activity in Inuit women from Northern Quebec. Environ. Health Perspect. 110, 607-612.

Regnault, T.R., Galan, H.L., Parker, T.A., Anthony, R.V., 2002. Placental development in normal and compromised pregnancies - a review. Placenta 23, S119-129.

Ripley, J.L., Lobel, P.S., 2004. Correlation of acoustic and visual signals in the cichlid fish, Tramitichromis intermedius. Environ. Biol. Fishes 71, 389-394.

Schwerte, T., Fritsche, R., 2003. Understanding cardiovascular physiology in zebrafish and Xenopus larvae: the use of microtechniques. Comp. Biochem. Physiol. A 135, 131-145.

Sedlacek, C., Marcus, N.H., 2005. Egg production of the copepod Acartia tonsa: the influence of hypoxia and food concentration. J. Exp. Mar. Biol. Ecol. 318, 183-190.

Serbedzija, G.N., Flynn, E., Willett, C.E., 1999. Zebrafish angiogenesis: a new model for drug screening. Angiogenesis 3, 353-359.

Shang, E.H.H., Wu, R.S.S., 2004. Aquatic hypoxia is a teratogen and affects fish embryonic development. Environ. Sci. Technol. 38, 4763-4767.

Shumway, C. A., 1999. A neglected science: applying behavior to aquatic conservation. Environ. Biol. Fishes 55, 183-201.

Tavolga, W.N., 1971. Sound production and detection. In: Hoar, W.S., Randall, D.J. (Eds.), Fish Physiology Volume V: Sensory Systems and Electric Organs. Academic Press, New York, New York, USA, pp. 135-205. 
Vagle, S., Burch, H., 2005. Acoustic measurements of the sound-speed profile in the bubbly wake formed by a small motor boat. J. Acoust. Soc. Am. 117, 153-163.

van Bergeijk, W.A., 1964. Directional and nondirectional hearing in fish. In: Tavolga, W.N. (Ed.), Marine Bio-Acoustics. Pergamon Press, Oxford, UK, pp. 281-299.

van Bergeijk, W.A., 1967. Discussion of critical bands in hearing of fishes. In: Tavolga, W.N. (Ed.), Marine Bio-Acoustics Volume 2. Pergamon Press, Oxford, UK, pp. 244-245.

Vincent, A.C.J., 1996. The International Trade in Seahorses. TRAFFIC Internation, Cambridge, UK.

Webb, J.F., 2002. Functional evolution of the lateral line system: Implications for fish bioacoustics. Bioacoustics 12, 145-147.

Weis, J.S., Smith, G.M., Zhou, T., 1999. Altered predator/prey behavior in polluted environments: implications for fish conservation. Environ. Biol. Fishes 55, 43-51.

Willett, K.L., Wassenberg, D., Lienesch, L., Reichert, W., Di Giulio, R.T., 2001. In vivo and in vitro inhibition of CYP1A-dependent activity in Fundulus heteroclitus by the polynuclear aromatic hydrocarbon fluoranthene. Toxicol. Applied Parmacol. 177, 264-271.

Wilson, A.B., Vincent, A., Ahnesjö, I., Meyer, A., 2001. Male pregnancy in seahorses and pipefishes (family Syngnathidae): rapid diversification of paternal brood pouch morphology inferred from a molecular phylogeny. J. Hered. 92, 159-166.

Winn, H.E., 1967. Vocal facilitation and the biological significance of toadfish sounds. In: Tavolga, W.N. (Ed.). Marine Bio-Acoustics Volume II. Pergamon Press, Oxford, UK, pp. 283-304.

Wu, R.S.S., Zhou, B.S., Randall, D.J., Woo, N.Y.S., Lam, P.K.S., 2003. Aquatic hypoxia is an endocrine disruptor and impairs fish reproduction. Environ. Sci. Technol. 37, 1137-1141. 
Appendix I: Paternal-Fetal Transfer of ${ }^{13}$ C-Palmitic Acid and ${ }^{15} \mathrm{~N}-\mathrm{L}$-Lysine in Two Congeneric Pipefish Species 


\section{Background}

The movement of lipids and proteins from brooding males to developing embryos were assessed by following the transfer of heavy-labeled nutrients. Carbohydrates were not included in this study because previous research indicated they serve as a source of metabolic fuel rather than building blocks essential to embryonic development. Similar methods have been used to document the transfer of lipids across the placenta (Hummel et al., 1976; Larqué et al., 2003), and the movement of amino acids in livebearing fish and lizards (Swain and Jones, 1997; MarshMatthews et al., 2001). Development of our method is based on the work of Haresign and Shumway (1981), which used a radioactively-labeled amino acid to determine the transfer rate in S. fuscus. We used stable isotopes instead to limit exposure to radioactive seawater and animal tissues.

For this study, we decided to examine the transfer of palmitic acid and lysine. Long chain polyunsaturated fatty acids, such as palmitic acid, are critical for the early development of the brain and visual system in humans (Neuringer et al., 1998; Larqué et al., 2002). Lysine was chosen because it is one of the ten essential amino acids in fishes and humans (Jobling, 1995). We reasoned that essential nutrients were most likely to be transferred if only limited paternal allocation occurs. Even though the essential amino acid leucine has been utilized in previous studies (Swain and Jones, 1997; Marsh-Matthews et al., 2001), we decided not to trace leucine because it has the potential to stimulate protein synthesis through activation of the mTOR pathway (Norton and Layman, 2006; per K. Blemmings). In order to limit the number of experimental animals, we decided to select one compound with a heavy isotope of carbon and the other nitrogen. Accordingly, the transfer of both nutrients could be examined in one male. 


\section{Objectives}

1. Determine whether the concentration of the paternal injections are sufficient to detect both isotopes in adult tissue and embryos.

2. Document the transfer of ${ }^{13} \mathrm{C}$-palmitic acid and ${ }^{15} \mathrm{~N}$-L-lysine from the brooding father to developing young.

\section{Procedures}

Brooding males collected from the field received two subsequent intraperitoneal injections. First, developmental stage of the brood was estimated by examining the embryos through the translucent pouch flaps. The early developmental stages $1-3$ were indicated by a vivid orange tint. A lighter orange color and the appearance of eyes suggested embryos had progressed to stage 4 or 5 . When the pouch flaps possessed a tan to black tint, fry fell between developmental stages 6 and 7 and were approaching release. We examined broods at various stages to assess transfer at these different developmental time points. The injections were derived from a $20 \mu \mathrm{g} / \mu 1$ stock solution of 16:0-Palmitic Acid-1- ${ }^{13} \mathrm{C}$ (Medical Isotopes, Inc., Pelham, NH) prepared in warmed corn oil and a $20 \mu \mathrm{g} / \mu$ l stock solution of L-Lysine- ${ }^{15} \mathrm{~N}_{2}$ (Medical Isotopes, Inc., Pelham, NH) in marine teleost Ringers solution.

Male standard length and weight were recorded. To determine the amount of stock solution required to match the target concentration of $100 \mu \mathrm{g} / \mathrm{g}$ of fish, weight was multiplied by 5 and the resultant number was the injection volume in $\mu 1$. Two $10 \mu 1$ Hamilton syringes were

filled with the calculated amount of the stable isotope mixture, one for each solution. Fish were briefly anesthetized with MS222 in saltwater until body movement slowed but opercle motion was still observed. The sedated male was positioned on its back on a sponge, soaked in 
saltwater, modified with a center trough. A hypodermic needle was used to create a small, shallow hole in the belly by the anus directly above the anterior end of the brood pouch. The lysine mixture was injected slowly. Injection of the palmitic acid solution immediately followed. A brief period passed before removing this second needle to allow the solution to fill the body cavity. A drop of Vetbond ${ }^{\mathrm{TM}}(3 \mathrm{M}$, St. Paul, MN) was applied to the injection site to seal the area and prevent loss of the stable isotope solutions. Fish were held in aerated tanks for 48 hours. Food was withheld during this period. Through this experimental design, transfer can be measured, while the loss of heavy labeled nutrients through metabolism is expected to be constant.

Brooding males were sacrificed with an overdose of MS222 48 hours after injection, and the entire brood removed from the pouch. Untreated brooding males were also sacrificed to determine background levels of heavy isotopes in pipefish tissue. Broods were examined and photographed to verify developmental stage estimates. Adult tissue and embryos were frozen at $-80^{\circ} \mathrm{C}$, and then freeze-dried for 24 hours. Dried tissue was thoroughly ground into powder. Commercial analysis requested concentrations of carbon less than $200 \mu \mathrm{M}$ and greater than $2 \mu \mathrm{M}$ for nitrogen. We assumed pipefish tissue is composed of approximately $45 \%$ carbon and $5 \%$ nitrogen. From these calculations, we weighed the ground tissue with a microbalance into $2.0 \pm$ $0.2 \mathrm{mg}$ samples (2 replicates for each animal or brood). Samples were shipped to the Idaho Stable Isotopes Laboratory at the University of Idaho for analysis of ${ }^{13} \mathrm{C}$ and ${ }^{15} \mathrm{~N}$ content.

\section{Preliminary Results}

Analysis of the first S. fuscus samples indicates L-lysine- ${ }^{15} \mathrm{~N}_{2}$ is transferred to brooding fry as the $\delta^{15} \mathrm{~N}$ value was higher in stable isotope injected males and fry compared to controls 
(Table 1). Conversely the similar $\delta^{13} \mathrm{C}$ values for both stable isotope and control S. fuscus suggest greater ${ }^{13} \mathrm{C}$-palmitic acid injections may be necessary to account for metabolism or other mechanisms of lipid loss (Table 1). The nitrogen composition (i.e. percent nitrogen) of fry tissue is considerably less than that of adult tissue (Table 1 and 2). Lower percent carbon content is also apparent for fry but the magnitude of difference with that of adult tissue is not as great as that seen for nitrogen (Table 1 and 2).

\section{Procedure Modifications and Future Studies}

We are currently consulting scientists knowledgeable in the field of stable isotopes to determine ways in which to analyze the preliminary data. Particularly, we are investigating if, and how, we need to account for the differences in percent nitrogen and carbon between samples.

To reduce the total injected amount, the concentration of the stock solutions will be doubled. We also propose to standardize the injection amount across fish to $10 \mu$ l. Corn oil or marine teleost Ringers solution appropriately will supplement the measured stock solution to achieve a total injection of $5 \mu \mathrm{l}$ for each stable isotope mixture. Overall, this procedure will be repeated on brooding males carrying embryos at various developmental stages to increase sample sizes for analysis. 
Table 1. Transfer of L-lysine- ${ }^{15} \mathrm{~N}_{2}$ and ${ }^{13} \mathrm{C}$-palmitic acid across the Syngnathus fuscus paternal brood pouch to developing young

\begin{tabular}{|c|c|c|c|c|c|c|c|}
\hline Treatment & Weight $(\mathrm{g})$ & $\begin{array}{c}\text { Standard } \\
\text { Length }(\mathrm{mm})\end{array}$ & Brood State & $\delta^{15} \mathrm{~N}^{*}$ & $\% \mathrm{~N}^{*}$ & $\delta^{13} \mathrm{C}^{*}$ & $\% \mathrm{C}^{*}$ \\
\hline \multicolumn{8}{|c|}{ Control - No Injection } \\
\hline & 0.969 & 121 & 5 & 13.31 & 11.882 & -16.99 & 38.52 \\
\hline & & & & 12.68 & 5.505 & -18.25 & 24.41 \\
\hline & 0.989 & 127 & 5 & 13.07 & 12.045 & -17.43 & 40.22 \\
\hline & & & & 12.32 & 4.744 & -18.28 & 21.92 \\
\hline \multicolumn{8}{|c|}{ Double Injection } \\
\hline & 1.1292 & 135 & 2 & 67.84 & 11.075 & -14.83 & 38.76 \\
\hline & & & & 43.80 & 8.577 & -17.07 & 40.63 \\
\hline & 0.7668 & 123 & 2 & 124.67 & 11.022 & -13.26 & 38.74 \\
\hline & & & & 20.79 & 4.355 & -18.73 & 19.86 \\
\hline & 1.804 & 157 & 3 & 55.04 & 11.040 & -13.25 & 36.94 \\
\hline & & & & 36.73 & 5.593 & -18.47 & 24.65 \\
\hline & 0.8504 & 117 & 5 & 99.09 & 10.863 & -15.48 & 38.53 \\
\hline & & & & 38.59 & 3.190 & -18.72 & 14.40 \\
\hline & 0.7773 & 115 & 5 & 68.19 & 11.049 & -13.65 & 37.71 \\
\hline & & & & 44.88 & 7.088 & -17.28 & 32.02 \\
\hline & 0.8981 & 125 & 5 & 54.20 & 11.046 & -13.65 & 38.91 \\
\hline & & & & 22.62 & 8.919 & -17.28 & 40.03 \\
\hline & 1.64 & 151 & 5 & 68.17 & 11.991 & -13.99 & 41.01 \\
\hline & & & & 21.82 & 6.268 & -17.76 & 28.75 \\
\hline & 1.288 & 134 & 6 & 65.03 & 11.480 & -15.90 & 38.84 \\
\hline & & & & 24.55 & 5.682 & -18.12 & 25.61 \\
\hline
\end{tabular}

Values are the mean of two replicate samples from the same individual.

Corresponding fry data are listed below the parental data (in bold). 
Table 2. Transfer of L-lysine- ${ }^{15} \mathrm{~N}_{2}$ and ${ }^{13} \mathrm{C}$-palmitic acid across the Syngnathus floridae paternal brood pouch to developing young

\begin{tabular}{|c|c|c|c|c|c|c|c|}
\hline Treatment & Weight (g) & $\begin{array}{c}\text { Standard } \\
\text { Length }(\mathrm{mm})\end{array}$ & Brood State & $\delta^{15} \mathrm{~N}^{*}$ & $\% \mathrm{~N}^{*}$ & $\delta^{13} \mathrm{C}^{*}$ & $\% \mathrm{C}^{*}$ \\
\hline \multicolumn{8}{|l|}{ Double Injection } \\
\hline & 0.7328 & 117 & 1 & 80.80 & 10.623 & -16.04 & 37.88 \\
\hline & & & & 36.83 & 3.835 & -19.42 & 17.44 \\
\hline & 0.5604 & 101 & 3 & 103.19 & 10.675 & -17.54 & 36.79 \\
\hline & & & & 40.19 & 5.327 & -19.86 & 24.30 \\
\hline & 1.328 & 139 & 8 & 96.95 & 10.350 & -13.85 & 37.19 \\
\hline & & & & 37.37 & 2.453 & -19.70 & $\mathbf{1 1 . 4 5}$ \\
\hline
\end{tabular}

Values are the mean of two replicate samples from the same individual.

Corresponding fry data are listed below the parental data (in bold). 


\section{References}

Haresign, T.W., Shumway, S.E., 1981. Permeability of the marsupium of the pipefish Syngnathus fuscus to $\left[{ }^{14} \mathrm{C}\right]$-alpha amino isobutyric acid. Comp. Biochem. Physiol. A 69, 603-604.

Hummel, L., Zimmermann, T., Schirrmeister, W., Wagner, H., 1976. Synthesis, turnover and compartment analysis of free fatty acids in the placenta of rats. Acta. Biol. Med. Ger. 35, 1311-1316.

Jobling, M., 1995. Environmental Biology of Fishes. Chapman \& Hall, New York, New York, USA.

Larqué, E., Demmelmair, H., Berger, B., Hasbargen, U., Koletzko, B., 2003. In vivo investigation of the placental transfer of ${ }^{13} \mathrm{C}$-labeled fatty acids in humans. J. Lipid Res. $44,49-55$.

Marsh-Matthews, E., Skierkowski, P., DeMarais, A., 2001. Direct evidence for mother-toembryo transfer of nutrients in the livebearing fish Gambusia geiseri. Copeia 2001, 1-6.

Neuringer, M., Anderson, G.J., Connor, W.E., 1988. The essentiality of n-3 fatty acids for the development and function of the retina and brain. Annu. Rev. Nutr. 8, 517-541.

Norton, L.W., Layman, D.K., 2006. Leucine regulates translation initiation of protein synthesis in skeletal muscle after exercise. J. Nutr. 136, 533S-537S.

Swain, R., Jones, S.M., 1997. Maternal-fetal transfer of ${ }^{3} \mathrm{H}$-labelled leucine in the viviparous lizard Niveoscincus metallicus (Scincidae: Lygosominae). J. Exp. Zool. 277, 139-145. 
Appendix II: Capillary Electrophoresis Method for Characterization of Steroid Hormone Profiles 


\section{Background}

The endocrine system is the chemical communication system of the body, regulating such activities as body fluid homeostasis, stress management, and perhaps most importantly, reproduction and fertility (Jobling, 1995). In most male teleosts, 11-ketotestosterone is the dominant circulating androgen responsible for secondary sexual characteristics, gonadal development, and behavior (Kime, 1993, 2001). Generally, the levels of 11-ketotestosterone are high in males and low in females, whereas $17 \beta$-estradiol displays the opposite pattern (Kime, 1993, 2001). Testosterone, the "male" hormone in mammals, is often secreted by both sexes of fish although its function is not well understood (Fostier et al., 1983; Kime, 1993, 2001). Even though progesterone is not common in fishes, $17 \alpha, 20 \beta$-dihydroxyprogesterone plays an important part in final gamete maturation leading to spawning (Kime, 1993, 2001).

Because of the role of steroids in sexual differentiation, it is necessary to determine whether developing fry are exposed to parental hormones during critical periods of development (Crews, 1994). Early neonatal steroid exposure in mammals can change the regulation of transcription, yielding long term and even epigenetic changes in response to excess hormonal signaling (McLachlan et al., 2001). These changes in gene regulation, termed imprinting, have been implicated in the susceptibility to environmentally related diseases, including cancer (Jirtle et al., 2000). The embryos of egg-laying vertebrates are exposed to maternally-derived steroids that are deposited in the egg yolk (Schwabl, 1993; Conley et al., 1997; Jansen et al., 1998; Lipar et al., 1999). The concentrations of steroids transferred to the eggs seem to reflect maternal plasma concentrations of these hormones (Schwabl, 1996b). The pipefishes and seahorses of the family Syngnathidae possess a second opportunity for embryonic exposure to parentally-derived steroids. A hypothesized role of the Syngnathid paternal brood pouch involves the transfer of 
steroid and growth hormones to developing embryos, but this function has yet to be fully investigated (Haresign and Shumway, 1981; Azzarello, 1991; Mayer et al., 1993). Hormonal changes associated with male parental behavior have been documented in the related group of sticklebacks (Páll et al., 2002). Considering the potential for both Syngnathid parents to contribute to embryonic steroid loads, we expect deviations in the characteristic sex hormones of males and females and their levels.

The possible effects of environmental estrogens have drawn attention to the sensitivity of the vertebrate reproductive system to disruption by environmental pollutants (Kime, 2001). Specifically, the estrogenic actions of polychlorinated biphenyls (PCBs) have been well documented in mammals and wildlife (Colborn et al., 1993, 1996). Exposure commonly manifests into changes in endogenous steroid hormone concentrations, but profound disturbance of organ differentiation resulting in the formation of ovotestis in males has also been observed (Colborn et al., 1993; Nisbet et al., 1996). In mammals, maternal steroid hormones readily impact fetal development by crossing the placenta, signifying the grave potential for maternal PCB-exposure to alter embryonic development (Colborn et al., 1993). Likewise, egg-producing females exposed to endocrine active contaminants, including PCBs, transfer altered concentrations of steroids to eggs (Schwabl, 1996a; Willingham et al., 2000; French et al., 2001). Pipefish present a unique situation to investigate the cumulative impact of two sources of parental disruption.

The first aim of this study is to determine parental contributions of steroid hormones known to be important regulators of development. A comparison between Syngnathus fuscus and Syngnathus floridae in the transfer of parental steroids will investigate how yolk deposition and brood pouch vascularization contribute to an embryo's steroid load. The results of this 
experiment will quantify the contributions of both parents as sources of the steroid hormones important for regulating development. The second focus of this project is to investigate potential changes in parental steroids and the resulting alterations in egg and fry hormone levels following Aroclor 1254 exposure. In order to complete all of these comparisons, steroid hormone concentrations will be quantified in adult blood plasma, paternal pouch fluid, eggs, developing embryos, and released fry.

Initially we proposed to quantify $17-\beta$-estradiol and the testosterones (11ketotestosterone and testosterone) using enzyme immunosorbant assays (EIA; Foran et al., 2002). The limitations of this method were quickly realized as concentrations fell below the detection limit of the assay. Further, the inability to distinguish the different testosterones, as well as measure other important steroid hormones, was not ideal. This research details the development of a capillary electrophoresis (CE) method to quantify seven steroid hormones including estriol, 17 $\beta$-estradiol, estrone, testosterone, 11-ketotestosterone, 17 $\alpha, 20 \beta$ dihydroxyprogesterone, and progesterone. These seven steroids were selected based on their importance in fish reproduction and their quantification in related studies (Estay et al., 2003; Onuma et al., 2003; Noaksson et al., 2003, 2004). The defining characters that suggested the utilization of CE for our purposes included the high efficiency separation of both large and small molecules, small sample volumes, and short separation time (Kuhn and Hoffstetter-Kuhn, 1993; Baker, 1995; Weinberger, 2000).

\section{Objectives}

1. Construct a custom built capillary electrophoresis (CE) system under the advice of the Holland laboratory (West Virginia University, Chemistry Department). 
2. Detect and distinguish two neutral markers by flow injection analysis (FIA) and CE.

3. Separate seven steroid standards by CE.

4. Compare concentrations of $17 \beta$-estradiol and the testosterones (both testosterone and 11ketotestosterone) in catfish blood samples determined by CE and enzyme immunosorbant assays (EIA).

5. Quantify steroid hormones in maternal and paternal blood plasma, pouch fluid, eggs, developing embryos, and fry from field-collected Syngnathus fuscus and Syngnathus floridae.

6. Quantify steroid hormones in maternal and paternal blood plasma, pouch fluid, eggs, and fry from Aroclor 1254 exposed S. fuscus and S. floridae.

\section{Procedure}

Fabrication of a Custom Built Capillary Electrophoresis Instrument

A capillary electrophoresis (CE) system was constructed under the guidance of the Holland laboratory (West Virginia University, Chemistry Department, Morgantown, WV). A schematic of the system is presented in Fig. 1 and detailed fabrication instructions can be found on their website at http://www.as.wvu.edu/ /holland/.

\section{Cutting a Capillary and Creating a Detection Window}

A ceramic cutter (VWR Scientific, West Chester, PA) held at a $45^{\circ}$ angle was used to score a $24 \mu \mathrm{m}$ inner diameter fused silica capillary (Polymicro Technologies, Phoenix, AZ) to a total length of $30 \mathrm{~cm}$. Capillaries of longer lengths required extended time periods for samples to pass, while shorter capillaries could not span the distance from the injection to the waste vial. Further, this capillary diameter was chosen because it dissipated heat very well and thus 
permitted the use of high voltages. High voltages give shorter separation times and high efficiencies (Kuhn and Hoffstetter-Kuhn, 1993; Baker, 1995; Weinberger, 2000). The choice of a fused silica over a glass capillary was based on the trait that the first is transparent at shorter wavelengths, corresponding to the detector incorporated in our system (Baker, 1995). The target location of the detection window, approximately 7 to $8 \mathrm{~cm}$ from one end of the capillary, was marked with a permanent pen. Next, the capillary was gently bent into a loop and orientated to position this window mark at the peak of the loop. Using a lighter, a flame was quickly passed across the area to remove the polyimide coating. We used a dampened Kimwipe (KimberlyClark, Neenah, WI) to wipe away the soot, thus revealing a 1 to $2 \mathrm{~mm}$ detection window.

\section{Solution Preparation}

All solutions and buffers were microfiltered and vacuum degassed daily. After mixing, the solution was passed through a Acrodisc $25 \mathrm{~mm}$ syringe filter outfitted with a $0.45 \mu \mathrm{m}$ polytetrafluoroethylene membrane (PTFE; PALL Life Sciences, East Hills, NY) into an $4 \mathrm{~mL}$ amber glass vial (National Scientific Co., Duluth, GA). Uncapped vials were positioned in a desiccator under vacuum for exactly two minutes. After degassing, the vials were carefully capped to avoid aerating the solution by shaking, dropping, or stirring. Solutions were acclimated to room temperature before use.

\section{Capillary Conditioning}

Two $0.4 \mathrm{~mm}$ graphite ferrules (Alltech, Deerfield, IL) secured the capillary in the LabAlliance ultraviolet detector (UV; model 500; ChromTech, Apple Valley, MN). The capillary was threaded through the detector window screw and graphite ferrule with the cone- 
shaped end pointed down. Then the capillary was passed across the detector window and through the second ferrule with the cone-shaped end pointed up and the other screw. We employed on-column detection. That is, the section of the capillary with the polyimide coating removed was placed in the light path of the detector so the solutes were detected while in the capillary. Therefore, before tightening the screws, the capillary window was aligned with the detector window. The capillary was considered secure when tugging did not misalign the windows. Lastly, we replaced the cover over the detector and capillary windows.

Capillary conditioning was required prior to the first sample run to charge the inside of the capillary for separation. The surface charge of the capillary affects the electroosmotic flow, or bulk flow (Kuhn and Hoffstetter-Kuhn, 1993; Baker, 1995; Weinberger, 2000). In our configuration, the electroosmotic flow moves from the injection (anode) to detection (cathode) end of the capillary. To accomplish this movement, we negatively charged the capillary wall to allow the attraction of positively-charged ions from the sample, thus creating an electrical double layer. When a voltage is applied across the capillary, cations in the double layer migrate in the direction of the cathode, carrying buffer with them. The result is a net flow of buffer solution in the direction of the negative electrode (Kuhn and Hoffstetter-Kuhn, 1993; Baker, 1995; Weinberger, 2000). Once the capillary was conditioned, these steps were not repeated until a new capillary was cut.

The injection vial contained $3.5 \mathrm{~mL}$ of $1 \mathrm{~N}$ sodium hydroxide $(\mathrm{NaOH})$. Three holes - one for the air tubing, capillary, and electrode - were punctured in a Teflon/silicone septum (National Scientific Company, Duluth, GA). The injection vial and septum were screwed into the threaded anode platform housed inside the Plexiglas interlock box (Chemistry Department, West Virginia University, Morgantown, WV) and the three tubes and wires were pushed through the septum. 
The capillary and anode electrode were submerged in the injection solution, while the air tubing was positioned just below the septum to avoid the creation of air bubbles. If the septum leaked air at any time, it was replaced. The waste vial was filled with $3 \mathrm{~mL}$ of deionized (DI) water to allow for the collection of $\mathrm{NaOH}$. Multiple holes were punctured in the septum for the waste vial. Two were used to position the capillary and cathode electrode in the solution while the remaining provided vents. The cathode vial was situated on a stainless steel platform of a support jack (VWR Scientific, West Chester, PA) beside the UV detector.

The anode and cathode vials were adjusted to identical heights by moving the respective platform or support jack. These positions were critical components of proper sample movement across the capillary and thus were checked with a level hand tool. The capillary and electrodes were similarly adjusted to ensure both ends were equally immersed in the anode and cathode vials. We charged the capillary with $1 \mathrm{~N} \mathrm{NaOH}$ for at least 2 hours at an air pressure of 20 pounds per square inch (psi). To flush the capillary with $\mathrm{NaOH}$, the main valve for the helium gas cylinder was opened. The system pressure was controlled by turning the valve on the regulator. Air pressure was monitored on the auxiliary pressure gauge connected to the system and not the gauge on the regulator itself for more accurate measures. The capillary was pressurized by turning the black control switch on the two-way valve towards the gas cylinder. After a few minutes, the capillary at the detection end was removed from the cathode vial. A drop of fluid visible at the tip of the capillary indicated the system was flushing properly. To depressurize the system and change the anode vial, the two-way valve was turned away from the helium tank. 


\section{Daily Capillary Flushing}

This flushing protocol was only necessary at the beginning of the day. Because the UV detector required a warm-up period of at least 30 minutes prior to use, it was turned on at the start of this routine. The wavelength setting on the UV detector was set to $225 \mathrm{~nm}$, the range to 0.001 , and the rise time to 0.3 seconds. Daily flushing followed a time ratio of 3:1:3. That is, the first solution was flushed across the capillary for 30 minutes, the second for 10, and the third for 30 minutes. The first flushing solution was $3.5 \mathrm{~mL}$ of $0.1 \mathrm{~N} \mathrm{NaOH}$. The waste vial at the detection end of the capillary contained $3.5 \mathrm{~mL}$ of DI water. The anode and waste vials, as well as the ends of the capillary and electrodes, were adjusted to identical heights. The three-way valve was switched and we flushed the capillary for 30 minutes at 20 psi with $0.1 \mathrm{~N} \mathrm{NaOH}$. The cathode end of the capillary was examined after a few minutes to note the presence of a drop of solution, indicating proper flow.

After 30 minutes, the system was depressurized by flipping the two-way valve and the injection vial containing $0.1 \mathrm{~N} \mathrm{NaOH}$ was replaced with a vial containing $3.5 \mathrm{~mL}$ of DI water. DI water flushed the capillary for 10 minutes at 20 psi. The system was depressurized again and the pressure dropped to $10 \mathrm{psi}$. The final flush involved the electrolyte buffer $50 \mathrm{mM}$ sodium dodecyl sulfate (SDS) and $30 \mathrm{mM}$ cyclodextrin in $50 \mathrm{mM}$ 2-[N-cyclohexylamino]ethanesulfonic acid) (CHES) buffer at $\mathrm{pH} 10$. The electrolyte buffer ran for 30 minutes at $10 \mathrm{psi}$.

\section{Sample Injection}

The steroid separation procedure employed two neutral standards as benchmarks to denote the beginning and end of the run. That is, all the steroids appeared between these two benchmarks of known concentration and separation time. The beginning benchmark, or neutral 
marker, was N,N-Dimethyl-formamide (DMF) and the ending, or micelle marker, was nDecanophenone (DEC).

In a vial containing $3 \mathrm{~mL}$ of the microfiltered electrolyte buffer, we added $2 \mu \mathrm{L}$ of DMF. This solution was vortexed, degassed, and placed at the anode end of the capillary. A vial with 3 $\mathrm{mL}$ of the electrolyte buffer was utilized as a waste vial and positioned on the cathode side. The black control switch located on the two-way valve was pointed away from the helium tank while the reading on the pressure gauge was adjusted to 5 psi. Next the timer box was turned on. The injection time was programmed using the gears located underneath the injection time display window to 2 seconds (reading on timer $=0020$ sec- 1 ). The sample was injected at 5 psi for 2 seconds by hitting the red button located on top of the timer box. During the injection, we monitored the pressure gauge to make sure the injection pressure remained steady. The timer box was turned off and the sample vial replaced with $3 \mathrm{~mL}$ of the electrolyte run buffer.

Generally, only a small volume of sample is required since just a few nanoliters are injected into the capillary. However, electrode lengths and available vials required the use of larger samples in this study.

\section{Flow Injection Analysis (FIA)}

Data was collected by the computer program IGORPro (WaveMetrics, Inc., Portland, OR). A data acquisition box and card (National Instruments, Austin, TX) relayed the absorbance values from the UV detector to the laptop computer (Hewlett Packard Pavilion zv5000, Palo Alto, CA) for real-time visualization of the electropherogram, or plot of absorbance against time.

Pressure was increased to $10 \mathrm{psi}$. The two-way switch was flipped to point toward the gas cylinder while we simultaneously clicked [Start] on the Scan Control window of IGORPro. 
The baseline was immediately zeroed by hitting the [Zero] button located on the UV detector. The pressure gauge required regular monitoring to ensure constant pressure and was adjusted as necessary. Real-time data was observed by viewing the graph screen on IGORPro. After the DMF peak was observed, we allowed the FIA to continue for 60 seconds to flush the sample entirely through the capillary. The black control valve was switched to the off position or away from the gas cylinder and we clicked [Stop] on the Scan Control window of IGORPro.

The absorbance peak always fell between 0 and 1 . Readings larger than 1 were not accurate and the range was adjusted until absorbance peaked below 1. The baseline drifted slightly in a straight-line fashion, but never went outside of -0.15 to 0.15 . Disturbing the lab jack, anode reservoir box, anode vial holder, capillary, or UV detector while conducting a run resulted in sudden shifts of the baseline. This was due to vibration interference which changed the orientation of the capillary. If this occurred, the baseline was reestablished and the run repeated.

\section{Capillary Electrophoresis}

The parameters on the high voltage power supply (Spellman, Hauppause, NY) were established prior to separation. The anode reservoir box lid was closed to complete the circuit and the power to the power supply was turned on. The current control knob was turned as far as it could go to make sure current was not limited. The voltage knob was turned until the voltage scale on the power supply read $16 \mathrm{kV}$.

We injected the electrolyte buffer with DMF as described above and replaced the sample vial with electrolyte run buffer. The power source was turned on while we simultaneously clicked [Start] on the Scan Control window of IGORPro. After approximately 3 seconds, we 
zeroed the UV detector. The baseline was monitored and once the DMF peak was observed, the sample was run for an additional minute to flush the sample out of the capillary.

Similar to FIA, if the absorbance peaked outside of 1, range adjustments were required. Disturbance of the system resulting in a shifted baseline also necessitated repeating the run. For $\mathrm{CE}$, as the electricity warmed the solution, the baseline often drifted downwards. We zeroed the detector as necessary to reestablish the baseline.

\section{DEC and DMF Separation}

We added $200 \mu \mathrm{L}$ of $10 \mathrm{mM}$ DEC to the sample vial containing the DMF in electrolyte solution. The mixture was vortexed and degassed. A 2 second sample was injected at 5 psi and separated by both the FIA and CE methods. Using CE, DMF peaked between 120 and 150 seconds and DEC appeared in the range of 450 to 500 seconds.

\section{Data Collection on IGORPro}

Peak analysis was completed from the graph window. First, we selected "Graph" from the toolbar and then "Show Info." For a second time, we selected "Graph" followed by "Show Tools." Two icons appeared in the upper left corner of the graph window. By pressing the [T] icon and clicking on the graph itself, we entered the run parameters including run type, buffer name, injection time, sample solutions, and pressure. After parameter entry, we clicked on the [Graph] button located in the graph window. Two lines appeared at the bottom of the graph window. To denote the start and end of the analyte peak, the circle icon located under the graph was dragged and positioned on the baseline as close to the beginning of the peak as possible. This step was repeated for the square icon, but with the square placed on the baseline at the end 
of the peak. "Analysis" was selected from the toolbar and "Curve Fitting" from the menu. These steps opened a new window. From the [Function and Data] tab, we confirmed "Gauss" was selected from the Function list, "Input 2" from the Y-Data list, and "_Calculated_" from the X-Data list. By pressing [Data Options] and the [Cursors] button in the Range box, the analysis was set to the square and circle icons denoting the boundaries of the analyte peak. Finally, we clicked [Do It] and a fitted line appeared on the graph. A data box opened that provided measures on height, width, migration time, and y-initial.

\section{Subsequent Trial Runs}

After several runs, the baseline began to deviate. We always flushed the capillary after 3 subsequent trials rather than wait for baseline fluctuations. The flushing protocol followed the time ratio described for daily flushing or 3:1:3. That is, $0.1 \mathrm{~N} \mathrm{NaOH}$ ran for 3 minutes at 20 psi, DI for 1 minute, and electrolyte buffer for 3 minutes. Sample runs immediately followed this cleaning without further conditioning.

\section{Steroid Standards Separation by Micellar Electrokinetic Chromatography (MEKC)}

Seven steroids (Steraloids, Inc., Newport, RI) were dissolved in methanol and added one at a time to the electrolyte buffer containing DMF and DEC. After the addition of a steroid, the mixture was vortexed, degassed, and separated by CE. The order of steroid addition follows: $200 \mu \mathrm{L}$ of $1 \mathrm{mM}$ estriol, $60 \mu \mathrm{L}$ of $10 \mathrm{mM} 17 \beta$-estradiol, $60 \mu \mathrm{L}$ of $10 \mathrm{mM}$ estrone, $60 \mu \mathrm{L}$ of 10 $\mathrm{mM}$ testosterone, $150 \mu \mathrm{L}$ of $1 \mathrm{mM} 11$-ketotestosterone, $50 \mu \mathrm{L}$ of $10 \mathrm{mM} 17 \alpha, 20 \beta$ dihydroxyprogesterone, and $60 \mu \mathrm{L}$ of $10 \mathrm{mM}$ progesterone. 
These steroids were resolved by micellar electrokinetic chromatography (MEKC). MEKC allows the resolution of uncharged molecules. Briefly, this mode of CE is based on the partitioning of solutes between micelles and the run buffer. Detergents such as SDS have a hydrophilic group on one end and a hydrophobic moiety on the other. When SDS is present in solution at a concentration higher than its critical micelle concentration, it forms micelles which are aggregations of individual detergent molecules. Micelles are generally spherical in shape and form such that the hydrophilic groups are on the outside toward the aqueous buffer and the hydrophobic hydrocarbons are in the center. When a hydrophobic compound is added to an aqueous solution that contains micelles, it partitions into the hydrophobic portions of the micelles. Conversely, hydrophilic molecules spend all of the time in the buffer since they do not partition into the micelles. These hydrophilic compounds are carried through the capillary at the rate of the electroosmotic flow and are the first to elute. Very hydrophobic molecules that are totally solubilized by the micelles spend all of the time in the micelles and so are carried through the capillary at the same rate as the micelles. Molecules that are partially soluble in the micelles partition between the micelles and the buffer and elute between these two times (Kuhn and Hoffstetter-Kuhn, 1993; Baker, 1995; Weinberger, 2000). We utilized DMF as a neutral marker which will elute first. Conversely, DEC served as a micelle marker in this study and thus will run through the capillary slowly.

This separation of steroid standards was an essential step for quantitative analysis. By adding one steroid at a time to the mixture, we recorded migration times for the seven steroids. When we run future samples, we can make peak assignments by comparing migration times of these standards to the sample unknowns. Our separation technique employs two internal standards: DMF and DEC. Considering both peak height and peak area are proportional to 
concentration, a calibration plot can be constructed for each solute to be quantified (Baker, 1995). The area ratios of solute to internal standard plotted against concentration ratios of solute to internal standard will be essential for concentration calculations of solutes in samples.

\section{Preliminary Results}

We successfully separated seven steroid standards between DMF and DEC on a custom built CE system on three separate occasions (Fig. 2). Migration times of the seven steroids relative to the neutral marker DMF were consistent over the three runs (Table 1). Preliminary quantification calculations of the micelle marker DEC relative to the neutral marker DMF indicate relative peak height, and not area, is correlated to concentration (Fig. 3).

\section{Procedure Modifications and Future Studies}

The preliminary quantification work is not reliable and must be repeated. Samples cannot be considered replicates if they are separated by more than two runs, and especially cannot be compared if performed on different days, because equipment heating significantly alters the separation. A three point standard curve must be performed after every three sample runs.

The Holland research team is currently modifying methods to clean and concentrate steroid samples extracted by methyl acetate from fish blood. Future research goals involve simultaneously running extracted steroids from catfish blood samples by EIA and CE to compare measured concentrations to verify $\mathrm{CE}$ quantification. The application of $\mathrm{CE}$ to pipefish samples will follow this verification of the technique. 
Table 1. Migration times for elution of seven steroids relative to the neutral marker DMF

\begin{tabular}{lcc}
\hline & \multicolumn{2}{c}{ Migration time $(\mathrm{s})$} \\
Steroid & Mean $\pm \mathrm{SE}$ & Range \\
\hline Estriol & $64.92 \pm 0.68$ & $63.41-66.08$ \\
$17 \beta$-Estradiol & $149.06 \pm 1.09$ & $145.22-152.20$ \\
Estrone & $205.14 \pm 1.14$ & $200.66-207.10$ \\
Testosterone & $226.01 \pm 1.44$ & $219.35-231.55$ \\
$11-$ Ketotestosterone & $238.49 \pm 1.41$ & $231.67-242.71$ \\
$17 \alpha, 20 \beta$-Dihydroxyprogesterone & $348.89 \pm 1.66$ & $339.59-355.18$ \\
Progesterone & $372.22 \pm 1.70$ & $362.24-378.22$ \\
\hline
\end{tabular}




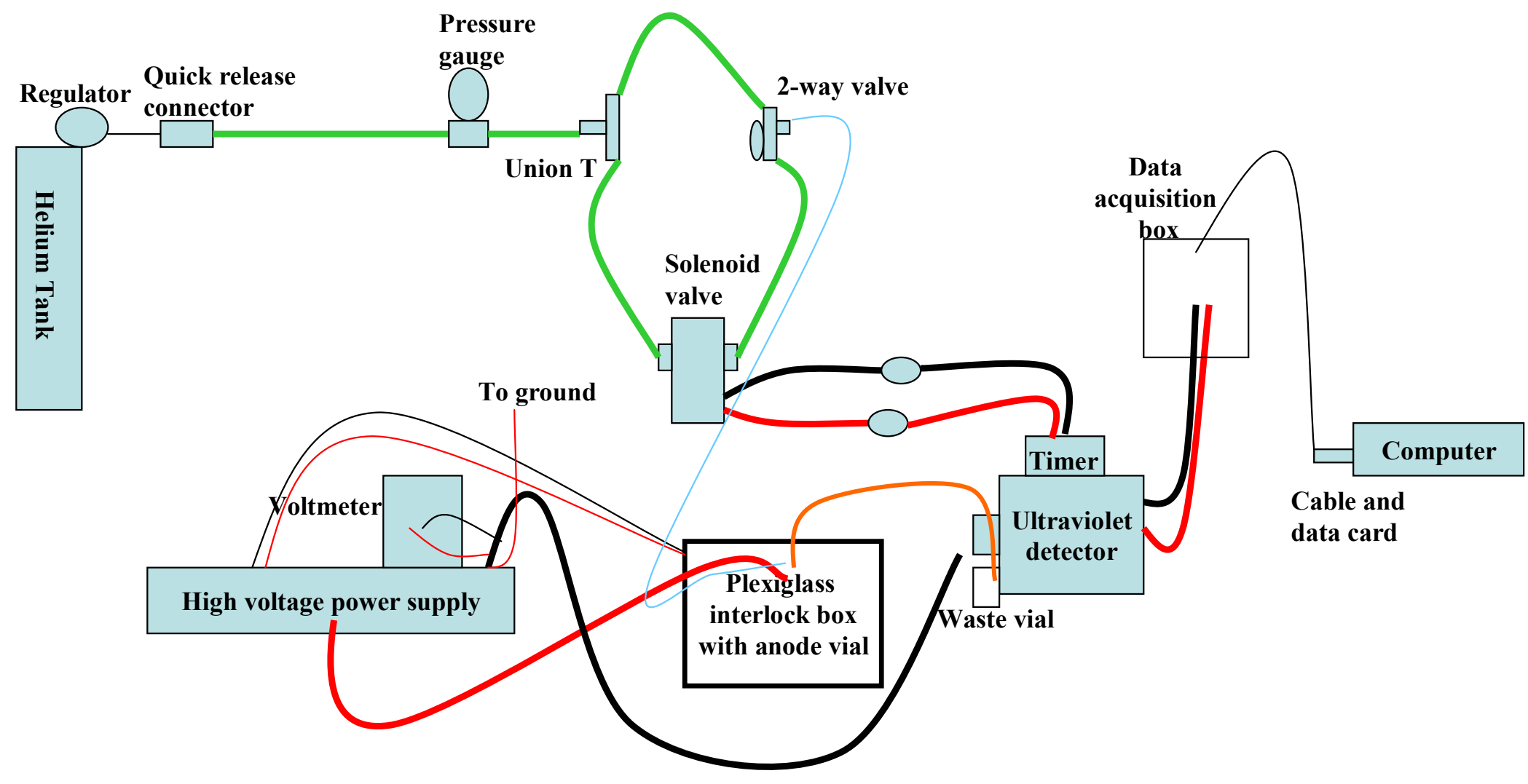

Fig. 1. Schematic of custom built capillary electrophoresis instrument. Directions for fabrication can be found at

http://www.as.wvu.edu/ lholland/. The colored lines represent plastic pressure tubing (blue), copper pressure tubing (green), positive and negative wires (red and black), and the capillary (orange). 


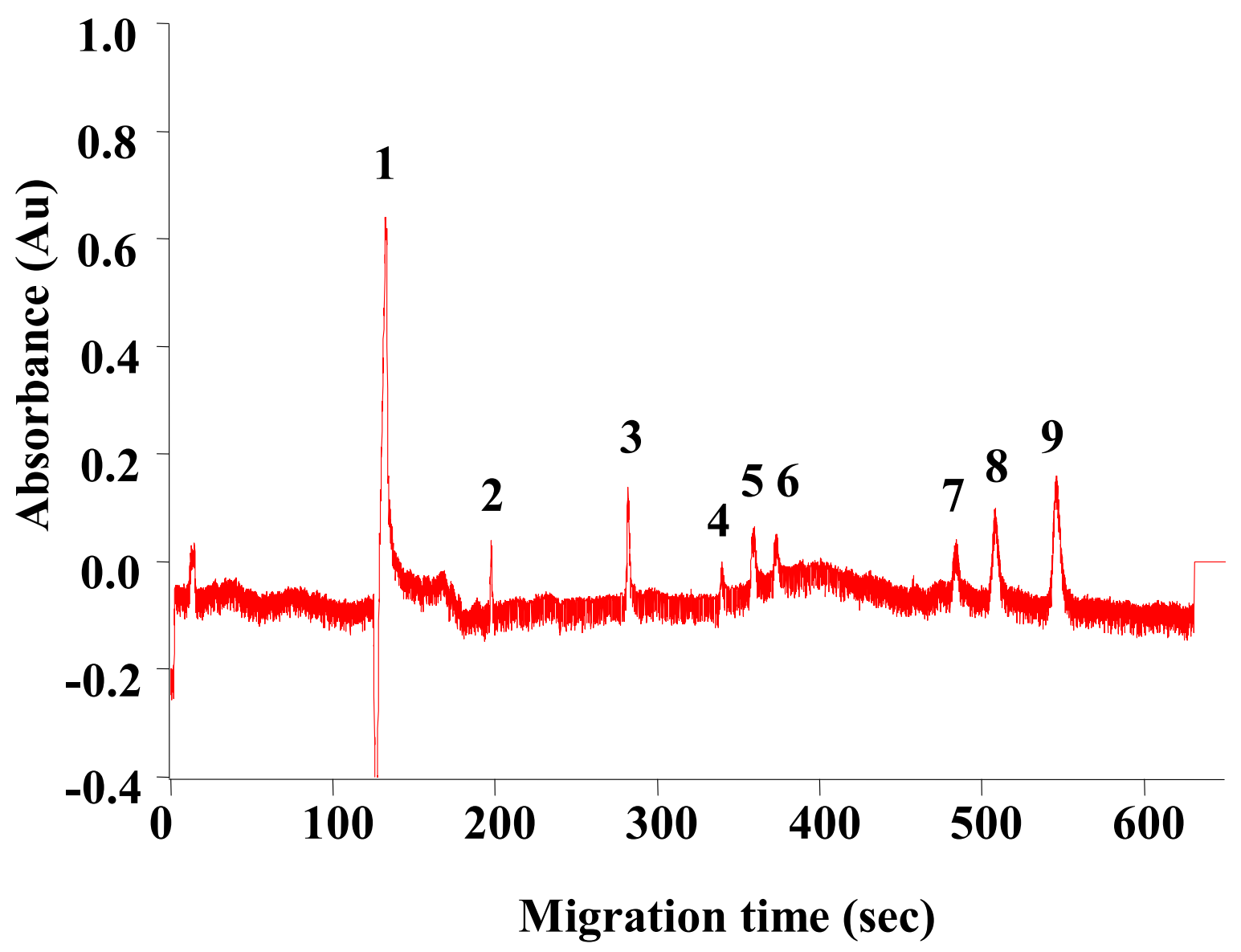

Fig. 2. Capillary electrophoresis separation of seven steroids on the lab built instrument: (1) DMF (i.e. neutral marker), (2) estriol, (3) 17ß-estradiol, (4) estrone, (5) testosterone, (6) 11ketotestosterone, (7) 17 $\alpha, 20 \beta$-dihydroxyprogresterone, (8) progesterone, and (9) ndecanophenone (i.e. micelle marker). 

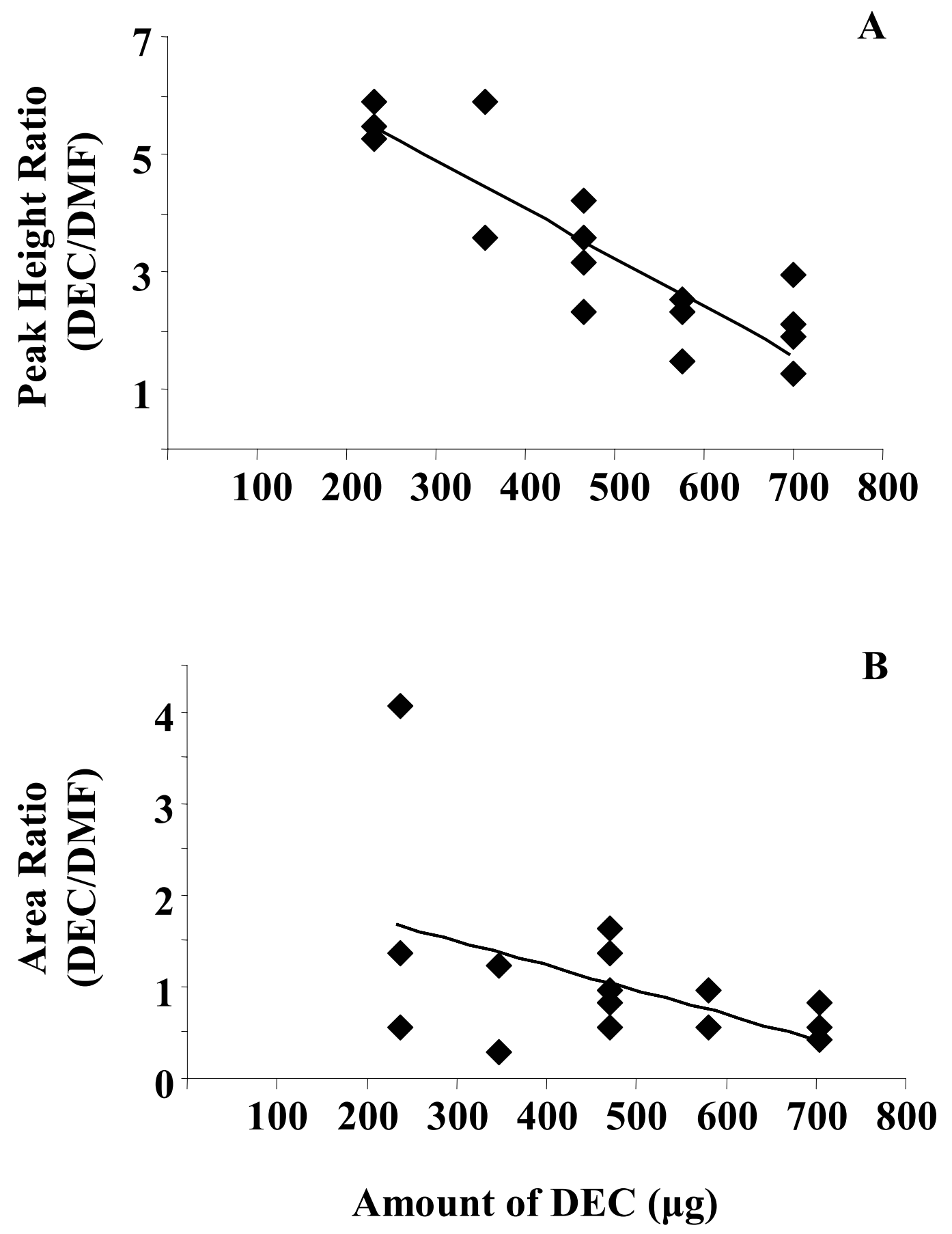

Fig. 3. Linear response ranges of the micelle marker n-decanophenone. (A) Relative peak height is significantly correlated with concentration $\left(r^{2}=0.8047, p<0.0001\right)$. (B) Conversely, relative area does not show a correlation $\left(r^{2}=0.2214, p=0.0767\right)$. 


\section{References}

Azzarello, M.Y., 1991. Some questions concerning the Syngnathidae brood pouch. Bull. Mar. Science 49, 741-747.

Baker, D.R., 1995. Capillary Electrophoresis. John Wiley \& Sons, Inc., New York, New York, USA.

Colborn, T., vom Saal, F.S., Soto, A.M., 1993. Developmental effects of endocrine-disrupting chemicals in wildlife and humans. Environ. Health Perspect. 101, 378-384.

Colborn, T., Dumanoski, D., Myers, J.P., 1996. Our Stolen Future. Penguin Books, New York, New York, USA.

Conley, A.J., Elf, P., Corbin, C.J., Dubowsky, S., Fivizzani, A., Lang, J.W., 1997. Yolk steroids decline during sexual differentiation in the alligator. Gen. Comp. Endocrinol. 107, 191200.

Crews, D., 1994. Temperature, steroids and sex determination. J. Endocrinol. 142, 1-8.

Estay, F., Diaz, A., Pedrazza, R., Colihueque, N., 2003. Oogenesis and plasma levels of sex steroids in cultured females of brown trout (Salmo trutta Linnaeus, 1758) in Chile. J. Exp. Zool. A 298, 60-66.

Foran, C.M., Peterson, B.N., Benson, W.H., 2002. Influences of parental and developmental cadmium exposure on endocrine and reproductive function in Japanese Medaka (Oryzias latipes). Comp. Biochem. Physiol. C 133: 345-354.

Fostier, A., Jalabert, B., Billard, R., Breton, B., Zohar, Y., 1983. The gonadal steroids. In: Hoar, W.D., Randall, D.J., Donaldson, E.M. (Eds.). Fish Physiology. Academic Press, New York, New York, USA, pp. 277-372. 
French, J.B., Nisbet, I.C.T., Schwabl, H., 2001. Maternal steroids and contaminants in common tern eggs: a mechanism of endocrine disruption? Comp. Biochem. Physiol. C. 128, 9198.

Haresign, T.W., Shumway, S.E., 1981. Permeability of the marsupium of the pipefish Syngnathus fuscus to $\left[{ }^{14} \mathrm{C}\right]$-alpha amino isobutyric acid. Comp. Biochem. Physiol. A 69, 603-604.

Jansen, F.J., Wilson, M.E., Tucker, J.K., Ford, S.P., 1998. Endogenous yolk steroid hormones in turtles with different sex-determining mechanisms. Gen. Comp. Endocrinol. 111, 306317.

Jirtle, R.L., Sander, M., Barrett, J.C., 2000. Genomic imprinting and environmental disease susceptibility. Environ. Health Perspect. 108, 271-278.

Jobling, M., 1995. Environmental Biology of Fishes. Chapman \& Hall, New York, New York, USA.

Kime, D.E., 1993. "Classical” and "non-classical” steroids in teleost fish. Rev. Fish. Biol. Fisheries 3, 160-180.

Kime, D.E., 2001. Endocrine Disruption in Fish. Kluwer Acadmeic Publishers, Boston, Massachusetts, USA.

Kuhn, R., Hoffstetter-Kuhn, S., 1993. Capillary Electrophoresis: Principles and Practice. Springer-Verlag, New York, New York, USA.

Lipar, J.L., Ketterson, E.D., Nolan, V., 1999. Intraclutch variation in testosterone content of redwinged blackbird eggs. Auk 116, 231-235. 
Mayer, I., Rosenqvist, G., Borg, B., Ahnesjo, I., Berglund, A., Schulz, R.W., 1993. Plasma levels of sex steroids in three species of pipefish (Syngnathidae). Can. J. Zool. 71, 19031907.

McLachlan, J.A., Newbold, R.R., Burow, M.E., Li, S.F., 2001. From malformations to molecular mechanisms in the male: three decades of research on endocrine disruptors. APMIS 109, 263-272.

Nisbet, I.C.T., Fry, D.M., Hatch, J.J., Lynn, B., 1996. Feminization of common tern embryos is not correlated with exposure to specific PCB congeners. Bull. Environ. Contam. Toxicol. $57,895-901$.

Noaksson, E., Gustavsson, B., Linderoth, M., Zebuhr, Y., Broman, D., Balk, L., 2004. Gonad development and plasma steroid profiles by HRGC/HRMS during one reproductive cycle in reference and leachate-exposed female perch (Perca fluviatilis). Toxicol. Appl. Pharmacol. 195, 247-261.

Noaksson, E., Linderoth, M., Bosveld, A.T., Balk, L., 2003. Altered steroid metabolism in several teleost species exposed to endocrine disrupting substances in refuse dump leachate. Gen. Comp. Endocrinol. 134, 273-284.

Onuma, T., Higashi, Y., Ando, H., Ban, M., Ueda, H., Urano, A., 2003. Year-to-year differences in plasma levels of steroid hormones in pre-spawning chum salmon. Gen. Comp. Endocrinol. 133, 199-215.

Páll, M.K., Mayer, I., Borg, B., 2002. Androgen and behavior in the male three-spined stickleback, Gasterosteus aculeatus I. - changes in 11-ketotestosterone levels during the nesting cycle. Horm. Behav. 41, 377-383. 
Schwabl, H., 1993. Yolk is a source of maternal testosterone for developing birds. Proc. Natl. Acad. Sci. 90, 11446-11450.

Schwabl, H., 1996a. Environment modifies the testosterone levels of a female bird and its eggs. J. Exp. Zool. 276, 157-163.

Schwabl, H., 1996b. Maternal testosterone in the avian egg enhances postnatal growth. Comp. Biochem. Physiol. A 114, 271-276.

Weinberger, R., 2000. Practical Capillary Electrophoresis. $2^{\text {nd }}$ ed. Academic Press, New York, New York, USA.

Willingham, E., Rhen, T., Sakata, J.T., Crews, D., 2000. Embryonic treatment with xenobiotics disrupts steroid hormone profiles in hatchling red-eared slider turtles (Trachemys scripta elegans). Environ. Health Perspect. 108, 329-332. 
Appendix III: Histological Examination of the Paternal Brood Pouch and Central Nervous System of Aroclor 1254 Developmentally Exposed Pipefish Fry 


\section{Background}

The next logical step to understanding the functional significance of the Syngnathus fuscus and Syngnathus floridae brood pouch involves a histological examination of this unique structure. Carcupino et al. (2002) conducted a comparative ultrastructural study on three different species of Syngnathids representing the three various pouch types. In Nerophis ophidion with simple ventral gluing, the bilayered epidermis of the pouch consists of pavement cells typical of fish skin (Carcupino et al., 2002). The intermediate Syngnathus abaster contains pavement cells interspersed with mitochondria-rich cells and numerous capillaries (Carcupino et al., 2002). These mitochondria-rich cells are thought to have an osmoregulatory role as they become abundant during incubation and degenerate following fry release (Carcupino et al., 1996, 1997, 2002). Large superficial capillaries and modified secretory flame cone cells characterize the completely closed brood pouch of Hippocampus hippocampus (Carcupino et al., 2002). Even though the morphological organization of the male brood pouch suggests greater paternal contribution with more enclosed pouch type, confirmation by physiological evidence has yet to be provided.

Among the human health concerns raised by PCB studies is the potential impact on fetal neural development (Tilson et al., 1990; Fritsche et al., 2005; Nguon et al., 2005). In rodent and primate studies, perinatal PCB exposure is associated with learning and cognition impairment (Levin et al., 1988; Schantz et al., 1995; Bushnell et al., 2002). Likewise, early life exposure has been associated with cognitive deficits among children (Weisglas-Kuperus, 1998; Schantz et al., 2003; Nakai et al., 2004; Gray et al., 2005). Exposure to PCB in utero has been implicated as neurotoxic more often than subsequent exposure (Rogan and Gladen, 1991; Jacobson and Jacobson, 1996; Patandin et al., 1999). 


\section{Objectives}

1. Compare brood pouch morphology before, during, and after brooding in Syngnathus fuscus and Syngnathus floridae.

2. Look for fry deformities and compare the size and number of neurons in the brain following paternal Aroclor 1254 exposure in Syngnathus fuscus and Syngnathus floridae.

\section{Procedure}

\section{Tissue fixation and preparation}

Syngnathus fuscus and S. floridae brooding males and fry were anesthetized with MS-222 in saltwater. Specimens were initially preserved in neutrally-buffered formalin and transferred to $4 \%$ paraformaldehyde and $1 \%$ gluteraldehyde in $0.2 \mathrm{M}$ phosphate buffer for 24 hours. Next, samples were held in $0.2 \mathrm{M}$ phosphate buffer for 24 hours. Following this rinse, newly released fry proceeded to sucrose sinking. Adult pipefish were placed in 1:1 Cal-Ex:phosphate buffer (Cal-Ex decalcifier, Fisher Scientific) for at least 48 hours or until the trunk region was bendable and then transferred to a second 24 hour wash in $0.2 \mathrm{M}$ phosphate buffer. Finally, tissues were soaked in $30 \%$ sucrose for at least 24 hours until the specimen physically sunk to the bottom of the container.

\section{Pipefish sectioning}

Tissues were embedded in cryo-medium and cut frozen on a cryostat at thickness of 10 microns. Cryostat sectioning allows rapid collection of small tissue sections in a similar orientation, resulting in accurate comparisons of anatomical structures. The paternal brood pouch was divided into sections approximately $70-80 \mathrm{~mm}$ in length. These pouch segments were 
numbered sequentially from the anterior and sectioned in turn. A small drop of water was placed on the chuck and allowed to freeze. Next, a drop of frozen tissue embedding media (HistoPrep, Fisher Scientific) covered the ice sheet and without delay a pouch segment was positioned vertically to section the anterior aspect first. In the case of newly released fry, the tail was removed posterior from the anus. The remaining fry tissue was laid horizontally on the chuck. Both specimen types were covered with subsequent layers of embedding media until the tissue was no longer visible.

Subsequent sections were placed on alternating slides (VWR superfrost plus micro slide, VWR International). That is, the first section adhered to "slide A" and the second was placed on "slide B." The third slice was laid on "slide A," the forth on "slide B" and so on. This method prevented data loss from slide damage or staining problems.

\section{Histological staining}

The following procedure was utilized for both brood pouch and fry sections (Drozdov et al., 1997). First, tissues were stained with hematoxylin for a maximum of 30 seconds and rinsed in tap water to remove excess dye. This rinsing consisted of dunking the slides in and out of the tap water several times until the only hematoxylin that remained was that that stained the tissue. The second staining event was comprised of a 10 second dip in Eosin B followed by another rinse in tap water. Next, slides were held in Nanopure water for precisely 2 minutes. The succeeding steps involved an ethanol series of $50 \%, 70 \%, 95 \%$ and $100 \%$ with the tissue held in each bath for exactly 2 minutes. Finally, the tissue sections proceeded through 2 xylene baths of 10 minutes each. Any remaining xylene was allowed to evaporate in the hood for 5 minutes, 
Parmount $^{\circledR}$ (Fisher Scientific) was added, and a cover slip laid over the Parmount ${ }^{\circledR}$. The adhesive was allowed to dry for at least 2 days before viewing the slide.

\section{Preliminary Results, Procedure Modifications and Future Studies}

Initial fixative methods and cryostat sectioning techniques readily permitted tissue tearing and did not preserve morphology for clear structure identification (Fig.1 and 2). Accordingly, the protocol has been modified to include fixation in $4 \%$ paraformaldehyde and $1 \%$ gluteraldehyde in $0.2 \mathrm{M}$ phosphate buffer. Furthermore, we decided to orientate the fry on a horizontal plane to ease identification. With experience and additional modifications, technique will improve. A similar study fixed the brood pouch in $2.5 \%$ glutaraldehyde and embedded in paraffin (Drozdov et al., 1997). We will try this technique next. Future work should increase sample sizes, including an investigation of brooding males at various developmental states.

Prospective future plans include a collaboration with Marcella Carcupino of Università di Sassari in Sassari, Italy. In June 2005, we discussed an investigation on the morphological organization of the S. fuscus and S. floridae brood pouch using electron microscopy and we are eagerly awaiting funding to act upon this opportunity. 


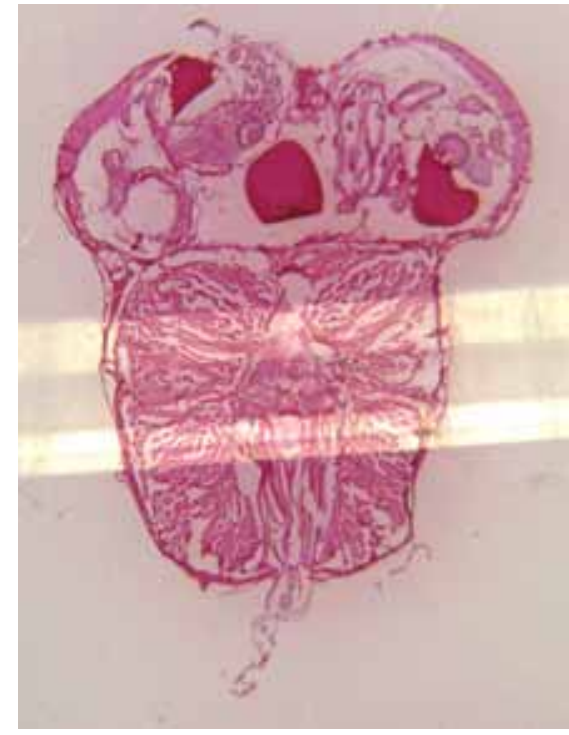

Syngnathus floridae

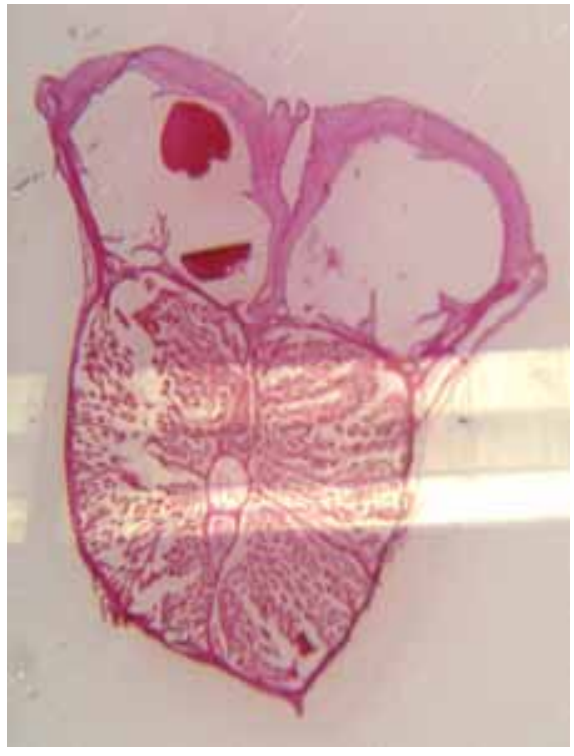

Syngnathus fuscus

Fig. 1. Preliminary histological sections of the paternal brood pouch with developing embryos. Note the interspecific differences in the connection of the two pouch flaps. Syngnathus floridae pouch folds meet midline while those of Syngnathus fuscus join at the ventral body surface. Magnification 40x. 


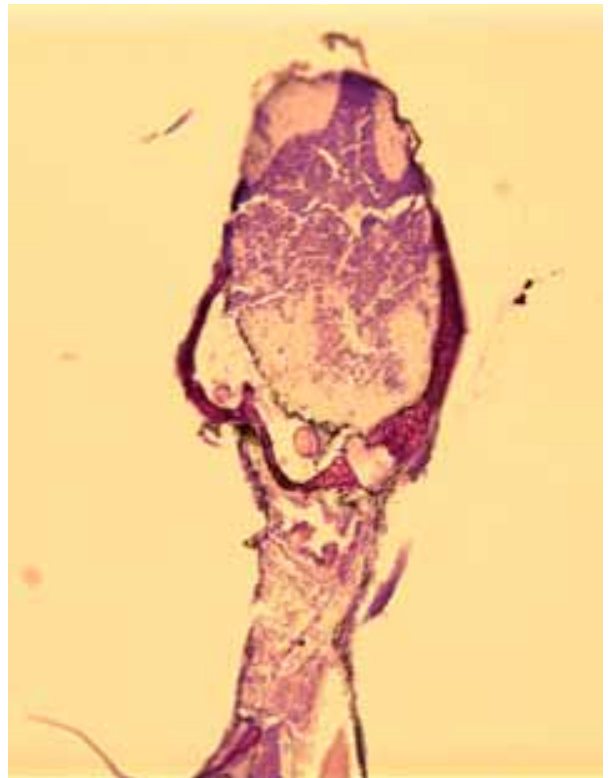

Syngnathus floridae

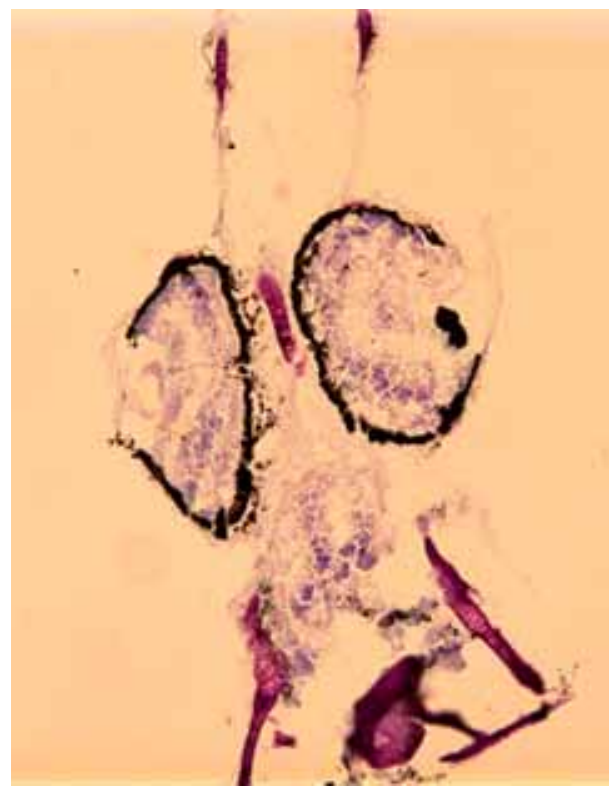

Syngnathus fuscus

Fig. 2. Preliminary histological sections of the anterior portion of newly released fry. These fry were developmentally exposed to acetone over the brooding period as a control for the Aroclor 1254 exposure. Magnification 40x. 


\section{References}

Bushnell, P.J., Moser, V.C., MacPhail, R.C., Oshiro, W.M., Derr-Yellin, E.C., Phillips, P.M., Kodavanti, P.R., 2002. Neurobehavioral assessments of rats perinatally exposed to a commercial mixture of polychlorinated biphenyls. Toxicol. Sci. 68, 109-120.

Carcupino, M., Baldacci, A., Franzoi, P., Mazzini, M., 1996. Morphological characterization of the male brood pouch in Syngnathus abaster Risso (Teleostea: Syngnathidae). Biol. Mar. Medit. 3, 529-530.

Carcupino, M., Baldacci, A., Mazzini, M., Franzoi, P., 1997. Morphological organization of the male brood pouch epithelium of Syngnathus abaster Risso (Teleostea, Syngnathidae) before, during, and after egg incubation. Tissue Cell 29, 21-30.

Carcupino, M., Baldacci, A., Mazzini, M., Franzoi, P., 2002. Functional significance of the male brood pouch in the reproductive strategies of pipefishes and seahorses: a morphological and ultrastructural comparative study on three anatomically different pouches. J. Fish Biol. 61, 1465-1480.

Drozdov, A.L., Kornienko, E.S., Krasnolutsky, A.V., 1997. Reproduction and development of Syngnathus acusimilis. Russ. J. Mar. Biol. 23, 265-268.

Fritsche, E., Cline, J.E., Nguyen, N.H., Scanlan, T.S., Abel, J., 2005. Polychlorinated biphenyls disturb differentiation of normal human neural progenitor cells: clue for involvement of thyroid hormone receptors. Environ. Health Perspect. 113, 871-876.

Gray, K.A., Klebanoff, M.A., Brock, J.W., Zhou, H., Darden, R., Needham, L., Longnecker, M.P., 2005. In utero exposure to background levels of polychlorinated biphenyls and cognitive functioning among school-age children. Am. J. Epidemiol. 162, 17-26. 
Jacobson, J.L., Jacobson, S.W., 1996. Intellectual impairment in children exposed to polychlorinated biphenyls in utero. N. Engl. J. Med. 335, 783-789.

Levin, E.D., Schantz, S.L., Bowman, R.E., 1988. Delayed spatial alternation deficits resulting from perinatal PCB exposure in monkeys. Arch. Toxicol. 62, 267-273.

Nakai, K., Suzuki, K., Oka, T., Murata, K., Sakamoto, M., Okamura, K., Hosokawa, T., Sakai, T., Nakamura, T., Saito, Y., Kurokawa, N., Kameo, S.., Satoh, H., 2004. The Tohoku study of child development: a cohort study of effects of perinatal exposures to methylmercury and environmentally persistent organic pollutants on neurobehavioral development in Japanese children. Tohoku J. Exp. Med. 202, 227-237.

Nguon, K., Baxter, M.G., Sajdel-Sulkowska, E.M., 2005. Perinatal exposure to polychlorinated biphenyls differentially affects cerebellar development and motor functions in male and female rat neonates. Cerebellum 4, 112-122.

Patandin, S., Lanting, C.I., Mulder, P.G., Boersma, E.R., Sauer, P.J., Weisglas-Kuperus, N., 1999. Effects of environmental exposure to polychlorinated biphenyls and dioxins on cognitive abilities in Dutch children at 42 months of age. J. Pediatr. 134, 33-41.

Rogan, W.J., Gladen, B.C., 1991. PCBs, DDE, and child development at 18 and 24 months. Ann. Epidemiol. 1, 407-413.

Schantz, S.L., Moshtaghian, J., Ness, D.K., 1995. Spatial learning deficits in adult rats exposed to ortho-substituted PCB congeners during gestation and lactation. Fundam. Appl. Toxicol. 26, 117-126.

Schantz, S.L., Widholm, J.J., Rice, D.C., 2003. Effects of PCB exposure on neuropsychological function in children. Environ. Health Perspect. 111, 357-376. 
Weisglas-Kuperus, N., 1998. Neurodevelopmental, immunological and endocrinological indices of perinatal human exposure to PCBs and dioxins. Chemosphere 27, 9-12. 
Appendix IV: Ethoxyresorufin-O-Deethylase (EROD) Activity in Pipefish Fry Developmentally Exposed to Aroclor 1254 


\section{Background}

The ability of environmental contaminants, including PCBs, to induce Cytochrome P450 1A (CYP1A) mediated ethoxyresorufin-O-deethylase (EROD) activity or gene expression has been well established in both humans and wildlife (Kennedy et al., 1993; Clemons et al., 1998; Nacci et al., 1998; Willett et al., 2001; Meyer et al., 2002). In fact, in vitro and in vivo bioassays using CYP1A-mediated endpoints are being proposed as a widespread biomarker to assess environmental exposure (Willett et al., 1997; Whyte et al., 2000; Arenal et al., 2004; Binelli et al., 2006). Standard methods for quantifying EROD activity employ destructive sampling. However, modified techniques now allow for the noninvasive and nondestructive assessment of environmental contaminants on the early development of fishes (Nacci et al., 1998; Meyer et al., 2002; Schewerte and Fritsche, 2003). Thus, we are able to link molecular indicators with organism level responses without harming the organisms we are attempting to protect.

\section{Objective}

1. Quantify EROD activity in Syngnathus fuscus and Syngnathus floridae fry developmentally exposed to the PCB mixture Aroclor 1254.

\section{Procedure}

\section{Microsome Preparation}

The entire brood of newly released fry was homogenized in 4 volumes of ice-cold buffer (0.1M Tris-HCl, 0.25M sucrose, 1mM EDTA, 1mM PMSF, $\mathrm{pH}$ 7.4). The homogenate was centrifuged at $4^{\circ} \mathrm{C}$ at $21,000 \mathrm{~g}$ for 20 minutes. The resulting supernatant was removed and centrifuged at $103,000 \mathrm{~g}$ for 1 hour. The pellet was resuspended in $40 \mu \mathrm{l}$ of buffer identical to 
that used for homogenization with the addition of $20 \%$ glycerol. We analyzed protein before storing samples at $-80^{\circ} \mathrm{C}$. Total protein concentrations were determined using a Bio-Rad protein dye reagent and a standard curve of bovine serum albumin (BSA).

\section{Microsomal EROD measurements}

Microsomal EROD activities were determined with a Tecan GENios plate reader outfitted with $535 \mathrm{~nm}$ excitation and $595 \mathrm{~nm}$ emission filters (Durham, NC). Each well contained $200 \mu \mathrm{l}$ including $50 \mu \mathrm{g}$ of microsomal protein incubated with cofactor-containing buffer $\left(110 \mu \mathrm{M}\right.$ NADH, $115 \mu \mathrm{M}$ NADPH, $5 \mathrm{mM} \mathrm{MgSO}_{4}, 0.1 \mathrm{M}$ HEPES). Reactions were initiated by the addition of $100 \mu 11.25 \mu \mathrm{M}$ ethoxyresorufin (ER) in cofactor solution which was converted to resorufin by CYP1A (Pohl and Fouts, 1980). The amount of resorufin produced by samples was measured kinetically every 2 minutes over a 20 minute period and compared to a standard curve. The resorufin standard curve (50 to $1 \mathrm{pmol}$ ) contained 50 $\mathrm{g}$ BSA protein instead of microsomes.

\section{Preliminary Results, Procedure Modifications and Future Studies}

We have repeatedly created an accurate resorufin standard curve $\left(r^{2} \geq 0.99, n \geq 6\right)$; however, microsomal EROD activity has not been detected in samples of 50 $\mathrm{\mu g}$ (acetone control, $\mathrm{n}=6$; Aroclor 1254, $\mathrm{n}=6$ ) and even $100 \mu \mathrm{g}$ (Aroclor 1254, $\mathrm{n}=3$ ) microsomal protein. Only $S$. floridae fry have been examined in these preliminary studies because the number of S. fuscus samples is limited.

An alternate method for detection of CYP1A activity has been described in individual fish embryos (Nacci et al., 1998; Meyer et al., 2002). Using this method, fry released by males following PCB, or solvent, exposure can be incubated with aqueous ER for 48 hours. An image 
of the fry can then be captured using a fluorescent microscope and camera, and the level of resorufin produced can be quantified optically. The benefit of this method is CYP1A activity can be determined for individual fry. We have considered modifying this technique by immobilizing the fry in low melting-point agarose. The fry can be held momentarily in the agarose at the time of data collection and then freed without any harm or they may be immobilized for the entire experiment (24-48 h) without compromising normal development (Schewerte and Fritsche, 2003). Future studies will explore these nondestructive techniques to quantify EROD activity in pipefish fry. 


\section{References}

Arenal, C.A., Halbrook, R.S., Woodruff, M., 2004. European starling (Sturnus vulgaris): avian model and monitor of polychlorinated biphenyl contamination at a Superfund site in southern Illinois, USA. Environ. Toxicol. Chem. 23, 93-104.

Binelli, A., Ricciardi, F., Riva, C., Provini, A., 2006. New evidences for old biomarkers: effects of several xenobiotics on EROD and AChE activities in Zebra mussel (Dreissena polymorpha). Chemosphere 62, 510-519.

Clemons, J.H., Allan, L.M., Marvin, C.H., Wu, Z., McCarry, B.E., Bryan, D.W., Zacharewski, T.R., 1998. Evidence of estrogen- and TCDD-like activities in crude and fractional extracts of PM10 air particulate material using in vitro gene expression assays. Environ. Sci. Technol. 32, 1853-1860.

Kennedy, S.W., Lorenzen, A., James, C.A., Collins, B.T., 1993. Ethoxyresorufin-O-deethylase and porphyrin analysis in chicken hepatocyte cultures with a fluorescence multiwell plate reader. Anal. Biochem. 211, 102-112.

Meyer, J.N., Nacci, D.E., Di Giulio, R.T., 2002. Cytochrome P4501A (CYP1A) in killifish (Fundulus heteroclitus): heritability of altered expression and relationship to survival in contaminated sediments. Toxicol. Sciences 68, 69-81.

Nacci, D., Coiro, L., Kuhn, A., Champlin, D., Munns, W., Specker, J., Cooper, K., 1998. Nondestructive indicator of ethoxyresorufin- $O$-deethylase activity in embryonic fish. Environ. Toxicol. Chem. 17, 2481-2486.

Pohl, R.J., Fouts, J.R., 1980. A rapid method for assaying the metabolism of 7-ethoxyresorufin by microsomal subcellular fractions. Anal. Biochem. 107, 150-155. 
Schwerte, T., Fritsche, R., 2003. Understanding cardiovascular physiology in zebrafish and Xenopus larvae: the use of microtechniques. Comp. Biochem. Physiol. A 135, 131-145.

Whyte, J., Jung, R.E., Schmitt, C.J., Tillitt, D.E., 2000. Ethoxyresorufin-O-deethylase (EROD) activity in fish as a biomarker of chemical exposure. Crit. Rev. Toxicol. 30, 347-570.

Willett, K.L., McDonald, S.J., Steinberg, M.A., Beatty, K.B., Kennicutt, M.C., Safe, S.H., 1997. Biomarker sensitivity for polynuclear aromatic hydrocarbon contamination in two marine fish species collected in Galveston Bay, Texas. Environ. Toxicol. Chem. 16, 1472-1479.

Willett, K.L., Wassenberg, D., Lienesch, L., Reichert, W., Di Giulio, R.T., 2001. In vivo and in vitro inhibition of CYP1A-dependent activity in Fundulus heteroclitus by the polynuclear aromatic hydrocarbon fluoranthene. Toxicol. Applied Parmacol. 177, 264-271. 


\title{
Curriculum Vitae
}

\author{
JENNIFER LAURA RIPLEY \\ 221 Roberts Street \\ Fairmont, WV 26554 \\ (304) 363-4351 \\ jenniferripley@hotmail.com
}

\section{EDUCATION}

Ph.D. Biology

West Virginia University, 2006.

Dissertation: Effects of environmental factors on the paternal brood pouch and sound production in two sympatric pipefish species from the Chincoteague Bay, Virginia

M.A. Biology/Marine Biology

Boston University Marine Program, 2001.

Thesis: Ontogenetic differences in reproductive behavior, sound production and hearing sensitivity in the Lake Malawi cichlid, Tramitichromis intermedius

B.S. Biology

West Virginia University, 1999.

\section{POSITIONS HELD}

2006-present Research Associate, Department of Biology, West Virginia University

2005 Graduate Research Assistant, Department of Biology, West Virginia University

2002-2005 Graduate Teaching Assistant, Department of Biology, West Virginia University

2002 Research Technician, Woods Hole Oceanographic Institution

2002 Visiting Instructor, Boston University Marine Program, Boston University

2001-2002 Senior Staff Coordinator, Course and Financial Coordinator, Boston University Marine Program, Boston University

2000 Graduate Research Assistant, Boston University Marine Program, Boston University

1999-2000 Senior Aquarist, Boston University Marine Program, Boston University

1998-1999 Teaching Assistant, Department of Biology, West Virginia University

\section{RESEARCH EXPERIENCE}

2006-present Investigation of environmental factors responsible for intersex smallmouth bass in the South Branch of the Potomac River in Hardy County, West Virginia. (Research Associate to C.M. Foran) 
2002-present

2004-present

2002

1999-2001

2000
Effects of environmental factors on the paternal brood pouch and sound production in two sympatric pipefish species from the Chincoteague Bay, Virginia. (Dissertation Research)

Identification of endocrine-modulating chemicals using systematic chemical analysis. (Research Assistant to C.M. Foran and L. Holland, WVU)

Nearshore/offshore hydrodynamics and population ecology (NO-HYPE). (Research Technician for J. Pineda, WHOI)

Ontogenetic differences in reproductive behavior, sound production and hearing sensitivity in the Lake Malawi cichlid, Tramitichromis intermedius. (Thesis Research)

Johnston Atoll Project (ARO DAAG55-98-1-0304). (Research Assistant to P.S. Lobel)

\section{TEACHING EXPERIENCE}

2002-2005 Spring Semester - "Functional Diversity of Organisms" Laboratory (BIOL 117, Teaching Assistant at WVU)

2002-2005 Fall Semester - "Principles of Biology" Laboratory (BIOL 115, Teaching Assistant at WVU)

2002 "Graduate Seminar" (Fall - BI 589; Spring - BI 590, Visiting Instructor at BUMP)

1999-2000 “General Biology” Laboratory (BIOL 103, Teaching Assistant at WVU)

\section{ACADEMIC SERVICE}

2005-2006 Co-coordinator of WVU Department of Biology Seminar Series

2000 WHSTEP Program, Lawrence Elementary School Science Fair Preparation, Woods Hole, MA

2000 Pen-pal with a Scientist, Hickory Ridge Elementary School, Cincinnati, OH

\section{PUBLICATIONS}

Ripley, J.L. \& C.M. Foran. 2006. Differential parental nutrient allocation in two congeneric pipefish species (Syngnathidae: Syngnathus spp.). Journal of Experimental Biology 209: 1112-1121.

Ripley, J.L. \& P.S. Lobel. 2005. Reproductive behavior of the Lake Malawi cichlid, Tramitichromis intermedius. Environmental Biology of Fishes 73: 171-190. 
Ripley, J.L. \& P.S. Lobel. 2004. Correlation of acoustic and visual signals in the cichlid fish Tramitichromis intermedius. Environmental Biology of Fishes 71: 389-394.

Ripley, J.L., P.S. Lobel \& H.Y. Yan. 2002. Correlation of sound production with hearing sensitivity in the Lake Malawi cichlid, Tramitichromis intermedius. Bioacoustics 12: 238-240.

\section{SUBMITTED MANUSCRIPTS}

Ripley, J.L. \& C.M. Foran. Population structure, growth rates, and seasonal abundance of the northern, Syngnathus fuscus, and dusky pipefishes, Syngnathus floridae, in the Chincoteague Bay, Virginia.

Ripley, J.L. \& C.M. Foran. Influence of Estuarine Hypoxia on Feeding and Sound Production by Two Sympatric Pipefish Species (Syngnathidae).

\section{PRESENTATIONS}

Ripley, J.L. \& C.M. Foran. 2005. Developmental exposure to PCBs through the placenta-like paternal brood pouch of two pipefishes. Poster presentation. Society for Environmental Toxicology and Chemistry $26^{\text {th }}$ Annual Meeting, Baltimore, MD, November 13-17, 2005.

Holland, L.A., L. Bykova, C. White, J.L. Ripley \& C.M. Foran. 2005. Capillary electrophoresis method for characterization of steroid hormone profiles. Poster presentation. Society for Environmental Toxicology and Chemistry $26^{\text {th }}$ Annual Meeting, Baltimore, MD, November 13-17, 2005.

Ripley, J.L. \& C.M. Foran. 2005. Eavesdropping on pipefish dinner conversation - a novel measure to assess hypoxia. Platform presentation. Society for Environmental Toxicology and Chemistry $26^{\text {th }}$ Annual Meeting, Baltimore, MD, November 13-17, 2005.

Ripley, J.L. \& C.M. Foran. 2005. The all-clear call: utilization of sound production by two sympatric pipefish species as an indicator of feeding activity and ecosystem health. Poster presentation. $13^{\text {th }}$ International Symposium of Pollutant Responses in Marine Organisms, Alessandria, Italy, June 19-22, 2005.

Ripley, J.L. \& C.M. Foran. 2005. Placental transfer - it's not just for mammals anymore. Poster presentation. $13^{\text {th }}$ International Symposium of Pollutant Responses in Marine Organisms, Alessandria, Italy, June 19-22, 2005. 
Ripley, J.L. \& C.M. Foran. 2005. The all-clear call: utilization of sound production by two sympatric pipefish species as an indicator of feeding activity and ecosystem health. Poster presentation. Society of Environmental Toxicology and Chemistry Chesapeake and Potomac Regional Chapter Meeting, Annapolis, MD, April 20, 2005.

Ripley, J.L. \& C.M. Foran. 2004. Comparison of reproductive physiology of the placenta-like brood pouch in pipefish. Platform presentation. Society of Environmental Toxicology and Chemistry Chesapeake and Potomac Regional Chapter Meeting, Shepherdstown, WV, April 22, 2004.

Ripley, J.L. \& C.M. Foran. 2004. Comparison of reproductive physiology of the placenta-like brood pouch in pipefish. Poster presentation. Society of Environmental Toxicology and Chemistry Fourth SETAC World Congress, Portland, OR, November 14-18, 2004.

Ripley, J.L. \& C.M. Foran. 2003. Comparison of reproductive physiology of the placenta-like brood pouch in pipefish. Poster presentation. Society of Environmental Toxicology and Chemistry $24^{\text {th }}$ Annual Meeting, Austin, November 9-13, 2003.

Ripley, J.L. 2001. Correlation of sound production with hearing sensitivity and behavior in the Lake Malawi cichlid, Tramitichromis intermedius. Poster presentation. Fish Bioacoustics: Sensory Biology, Behavior and Practical Applications, Chicago, IL, May 30-June 2, 2001.

\section{GUEST LECTURES}

Ripley, J.L. 2003. Introduction to Crustacean. Guest lecturer for BIOL 340 "Invertebrate Zoology", West Virginia University, Department of Biology.

Ripley, J.L. 2002. Aquaculture raceway systems. Guest lecturer for BIOL 339 “Aquaculture", West Virginia University, Department of Biology.

Ripley, J.L. 2001. Lophoporates. Guest lecturer for BI 547 “Invertebrate Zoology”, Boston University, Marine Program.

\section{AWARDS AND GRANTS}

WVU Foundation Distinguished Doctoral Fellowship, WVU Eberly College of Arts and Sciences

2005 Chesapeake and Potomac Regional Chapter of the Society of Environmental Toxicology and Chemistry Best Student Poster Presentation

2005 Recipient of WVU Eberly College of Arts and Sciences Doctoral Travel Award

2004 Chesapeake and Potomac Regional Chapter of the Society of Environmental Toxicology and Chemistry Student Research Award 
2004 Chesapeake and Potomac Regional Chapter of the Society of Environmental Toxicology and Chemistry Student Travel Award

2004 Society of Environmental Toxicology and Chemistry Student Travel Award Chesapeake and Potomac Regional Chapter of the Society of Environmental Toxicology and Chemistry Best Student Platform Presentation Award Recipient of WVU Eberly College of Arts and Sciences Doctoral Travel Award Recipient of WVU Eberly College of Arts and Sciences Doctoral Travel Award Humes Alumni Scholarship, Boston University Marine Program

\section{PROFESSIONAL MEMBERSHIPS}

Acoustical Society of America

Society for Environmental Toxicology and Chemistry 